Universidad Nacional de La Plata

Facultad de Ciencias Naturales y Museo

Secretaría de Posgrado

\title{
Los pescadores de Necochea/Quequén durante la expansión de la industria pesquera en Argentina (1975-2001)
}

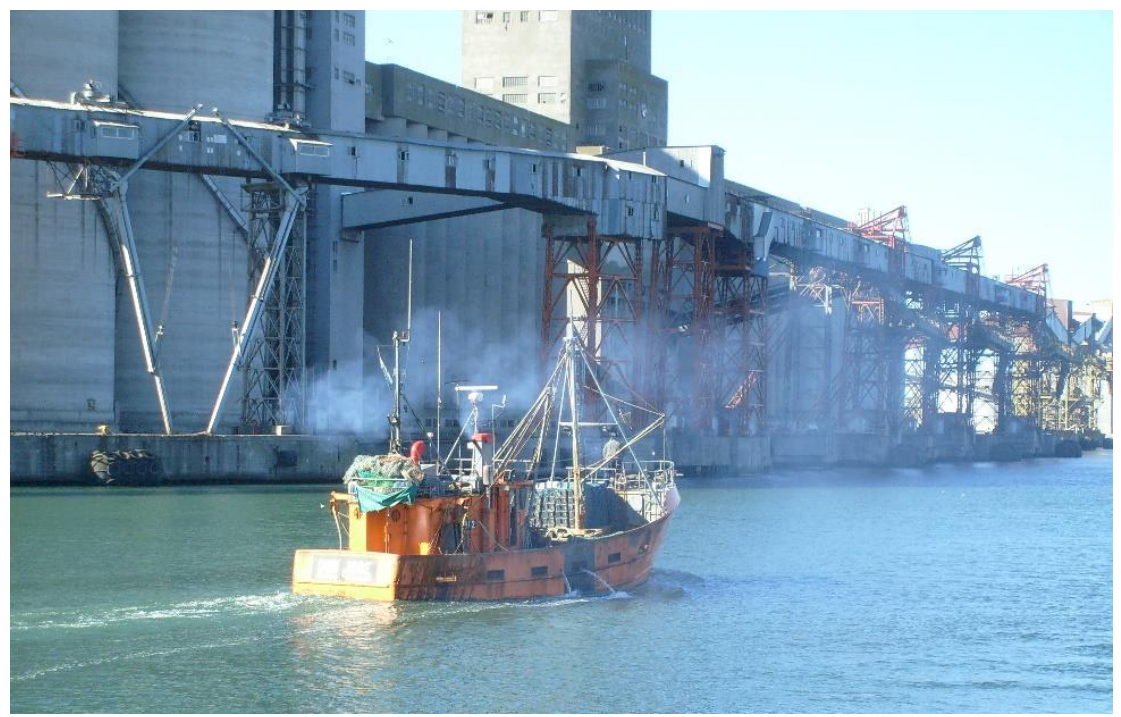

Lic. María Florencia Rispoli

Tesis para optar al grado de Doctora en Ciencias Naturales

Director: Dr. José Antonio Mateo

Co-directora: Dra. Alicia Castro 
A Mikel y Beltrán, simplemente gracias

A Miriam y Manuel, en su memoria 


\section{Agradecimientos}

"Quién no fue mujer ni trabajador piensa que el de ayer fue un tiempo mejor" María Elena Walsh

Estas palabras son para agradecer y reconocer a quienes me acompañaron en el proceso de elaboración y escritura de esta tesis.

En primer lugar, quiero reconocer a las y los trabajadores de todos los tiempos. A quienes invisibilizados laburan porque no queda otra que seguir tirando. A quienes en peores condiciones no tienen tiempo ni voz para pensarse o expresarse. A los y las que tienen posibilidad de organizarse y lucharon, y lucharán por sus (nuestros) derechos y los de las siguientes generaciones de trabajadores y trabajadoras. Especialmente agradezco a los pescadores de Puerto Quequén: que el sufrimiento, el frío, el temor, la humedad y la sal de su trabajo se hagan presentes.

Quiero agradecer infinita y eternamente a Miriam y Manuel. Sembraron el gusto por el conocimiento, instauraron el espíritu crítico y me dieron la libertad y la confianza para que como persona fuera e hiciera lo que quisiera.

A Mikel y Beltrán, en ellos la palabra familia se traduce en contención, alegría, fuerza. A Mikel le quiero agradecer la disposición de acompañarme, pero también por la invaluable ayuda en las desesperantes cuestiones en técnicas, de formato y en los mapas. A Beltrán, que me ayudó a poner esta tesis en otro lugar, mirarla con ojos lúdicos, el desafío con "T".

José y Alicia, incondicionalmente tuvieron palabras de aliento para conmigo. La generosidad de ambos, tanto en el vínculo personal como en el laboral sientan invaluables modelos de lo que lo que es ser buena persona y buenos profesionales. Mi admiración, respeto y agradecimiento.

En Mar del Plata, el GESMar fue un grupo de referencia, la posibilidad de aprender del trabajo de compañeros y compañeras. Las cenas en el Museo del Hombre del Mar quedarán como un recuerdo imborrable. También el seminario sobre Puertos y los primeros congresos de la REDEP en Necochea y Mar del Plata quedan guardados como 
memorables instancias de formación. En los momentos más difíciles agradezco la confianza que inspiró José (y que me costó tomar) dando la orientación (y la vía de interpretación) siempre justa. Mis intermitentes estadías en la "la feliz" durante los años de becaria Conicet y la participación en las actividades mencionadas fueron cálidamente propiciadas por Chiche y Tere, a ellas también agradezco cariñosamente.

En Necochea agradezco a los pescadores y a sus familias que me brindaron generosamente su tiempo, sus palabras y sus sentires. Agradezco a Luis Nogueira, me acompaño y alentó, charlar con él es detener el tiempo. A Nora, de quien primero pude ver de qué se trataba ser profesional del conocimiento. Al personal de Prefectura Nacional Argentina delegación Puerto Quequén, especialmente a la oficina Polinave. A Alejandra que me facilitó acceder al Archivo de Ecos Diarios.

Quiero agradecer a los y las docentes de los Seminarios que cursé -especialmente a Amalia- quienes acompañaron el proceso formativo con la discusión, sus aportes bibliográficos y las correcciones que enriquecieron esta tesis. A los grupos de trabajo en los que participo, por más de una vez aliviar la catarsis de ser tesista. Pero también porque las discusiones que en cada ámbito se dieron acompañaron mi crecimiento. A la Cátedra de Antropología Cultural y Social de la Facultad de Psicología de la Universidad Nacional de La Plata, especialmente a Roberto, Ofelia, Cristina, Silvia, Adriana y Diana. A les compañeres de la asignatura Conocimiento y Ciencias de la Salud de la Universidad Arturo Jauretche, especialmente a Mariche y María. A las compañeras del Equipo de Intervención en Género de la UNAJ, Nora, Ana, Azul, Luciana y Felicitas. A Silvia y Alejandra con quienes compartí 15 años de proyecto de investigación. Agradezco especialmente a CONICET que financió el desarrollo de esta tesis.

Mis amigas, compañeras y familia de Merendero y Búsqueda del Tesoro ese inclasificable grupo de mujeres con quienes comparto desde las mejores y más productivas argumentaciones teóricas hasta los encantos y desencantos más triviales y mundanos. Gracias Ale, Feli, Alfon, Geor y Gime por apuntalarme y sostenerme.

Ya sea en el cuidado de mi hijo, en el trabajo o con el inglés, Euge, Mer, Lupi, Pana, Ando, Luci, Ciro, Javi, Laura, Diego, Magalí y Nadia también fueron parte de la condición de posibilidad para la escritura. 


\section{Resumen}

La presente tesis se inscribe en el ámbito de la antropología social y cultural, especialmente en la discusión de la antropología marítima y de la pesca. También establece un diálogo con los aportes de otras disciplinas de las ciencias sociales. Partimos de considerar que la apropiación del medio marino por parte de los seres humanos ha asumido diferentes formas en función del lugar y del momento histórico y, en ese sentido, nos interesó relevar la particularidad del caso de estudio. El referente empírico está constituido por los pescadores de la pesca costera en Puerto Quequén, Provincia de Buenos Aires, República Argentina en el período 1975-2001. Se problematiza el desarrollo de la pesca comercial marítima argentina y, en su evolución, cuál fue el lugar de la flota costera de Puerto Quequén y de los trabajadores que llevan adelante la actividad.

El objetivo general de la investigación consistió en caracterizar la actividad pesquera de este puerto, sus agentes sociales, sus estrategias, tanto a nivel individual, familiar y de la unidad productiva, y las representaciones simbólicas sobre su trabajo durante una de las etapas del ciclo de expansión de la pesca comercial marítima en Argentina, entre 1975 y 2001. Para dar cuenta del fenómeno a estudiar se estableció un diseño cualitativo que articuló la observación con participación; entrevistas en profundidad; encuestas; fuentes de archivos, de prensa y de organismos públicos; y relevamiento bibliográfico.

Si bien los pescadores de Puerto Quequén están presentes desde los inicios del puerto, llevan adelante su actividad en un puerto en el cual la actividad pesquera no es la central dado que el puerto se ha orientado hacia la salida de la producción agropecuaria de su zona de influencia. En este marco, se analizaron las características técnicas más importantes, el desarrollo histórico y el rol económico, geográfico y cultural portuario en relación con la integración a las localidades de Necochea y Quequén en las que se emplaza. Además, el puerto y los pescadores, con sus lanchas amarillas, constituyen parte del imaginario de la ciudad en virtud de ser un espacio con diferentes connotaciones -según sea 
de día o de noche-, constituir un atractivo turístico, e incluso una fuente de inspiración para representaciones artísticas.

La pesca es una actividad sumamente incierta, entre otras cosas por las características de movilidad e imprevisibilidad que tienen los recursos marinos. Otra peculiaridad radica en que la propiedad del recurso no es de tipo privado, lo que conlleva particularidades en la forma en que se accede al mismo. Los pescadores de la flota costera de Puerto Quequén realizan su actividad orientada a la venta comercial de lo producido, por lo que ubicamos su actividad en relación con la conformación de un mercado primero interno, y luego internacional que incidió en las condiciones en las que participaron. La evolución nacional de la actividad, con sus ciclos de expansión y crisis, constituyó el marco en el que los pescadores costeros anclan sus percepciones e interpretaciones sobre su propio trabajo y sobre la finitud del recurso natural que sirve de base, el riesgo que implica el trabajo en el mar y los conocimientos necesarios para afrontarlos. Además, analizamos las representaciones que ellos tienen sobre el trabajo en altamar, donde se conjugan, articulan y tensionan nociones como las de dureza, riesgo, libertad, juego y aventura.

Para apropiarse del medio marino y obtener del mar sus recursos los pescadores lo hacen en embarcaciones, que constituyen la unidad productiva en la que trabajan. Los barcos de la flota costera cambiaron durante el período de interés la autonomía de trabajo en altamar de un día a tres días y medio, en parte por la mejor tecnología disponible, pero también, por la mayor dificultad de completar la carga de la embarcación y, por lo tanto, para que la salida de pesca resulte rentable. La forma de organización del trabajo comporta una estratificación marcada en la que los participantes tienen una estrecha cohesión sustentada en el efectivo trabajo conjunto y en preceptos ideológicos que favorecen esa cohesión. La noción de familia aparece así representada en la materialidad de los vínculos familiares que se dan entre algunos de los miembros de la tripulación, pero también en la metáfora con la que explican su trabajo. Se reconoce que el trabajo en el mar comporta una temporalidad y una espacialidad diferenciada de la vida doméstica o de otros trabajos en tierra.

Mientras las capturas de pescado a nivel nacional se incrementaron y la participación de la flota costera se mantiene relativamente constante desde hace décadas; en el caso de la flota de Puerto Quequén su participación sobre el total nacional se halla en retroceso, tanto en volumen de capturas como en cantidad de embarcaciones. Durante el período disminuye el desarrollo de la industria de pescado en tierra con la consiguiente baja en demanda local de pescado que esto implica. En este contexto las trayectorias laborales y familiares de los pescadores están marcadas por la decisión de trabajar en la pesca costera en la localidad, trabajar en la pesca en otros puertos o desempeñarse en otros trabajos en 
tierra. La pequeña flota pesquera que opera en Puerto Quequén constituye entonces una opción para una pequeña proporción de los trabajadores-pescadores radicados en Necochea y Quequén, aquellos que tienen barco propio, familiar o poseen lazos familiares o de amistad con los propietarios. Es mayor el número de pescadores-trabajadores con residencia local que los que efectivamente trabajan en Puerto Quequén, está reflejando que estos, aunque no trabajen las localidades, continúan ligados a las actividades marinas al abastecer la demanda laboral de la flota pesquera global que desarrolla su actividad en el Mar Argentino.

La tensión en la trayectoria laboral entre realizar pesca costera, de altura u otras actividades laborales es examinada respecto de la organización doméstica y la configuración de las estrategias familiares. En la mayoría de los hogares la participación monetaria es aportada por el varón pescador. Además, analizamos lo que implica para los pescadores ser "hombres de mar" en los ámbitos del trabajo y del hogar como espacios donde se legitima su masculinidad.

Finalmente, proponemos distinguir tres espacios, material y simbólicamente diferenciados: el mar, la tierra y la banquina configurado cada uno de ellos por características distintivas y la puesta en acción de tipos particulares de lazos sociales. 


\section{Abstract}

This dissertation is done on the field of Social and Cultural Anthropology. It focuses mainly in maritime anthropology and in the anthropology of fishing. In addition, it intertwines with contributions from other disciplines of Social Sciences. As a starting point, we considered the fact that human appropriation of the marine environment has adopted different means according to the moment in history and to the location in which it took place. In that sense, we found it was important to highlight the distinctive feature of the case study. The empirical referent is constituted by coastal fishermen at Puerto Quequén, in the Province of Buenos Aires, Argentine Republic, during the period 1975-2001. The development of Argentine commercial maritime fishing and, during its evolution, the role that played the coastal fleet of Puerto Quequén and the workers that performed the activity are posed as a problem.

The overall aim of our research was to distinguish the activity of fishing in this port, its social agents and their individual strategies, also those ones concerning the household and the means of work, as well as the symbolic representations of their work during one of the stages of the expansion cycle of commercial maritime fishing in Argentina from 1975 to 2001 . In order to account for the phenomenon subject of this study, a qualitative model was used: it combined observation and participation, interviews, surveys, documents, press documents and documents issued by public entities, and also bibliographic research.

Even though fishermen have been settled in Puerto Quequén ever since the creation of the port, they work in a port where fishing is not the main activity. This port is dedicated to export agricultural goods from their area of influence. The most important technical features, historical developments as well as the economic, geographical and cultural roles of the port have been analyzed within this scope, considering its integration to Necochea and Quequén, the two towns that harbor it. Besides, the port and the fishermen with their lanchas amarillas ("yellow boats") make up the landscape of the town, the port imprints different connotations -depending on whether it is contemplated in the light or 
day or at night-, it is a tourist attraction and even a source of inspiration for artistic representations.

Fishing is an extremely unforeseeable activity, this is, in part, due to the mobility and unpredictability of marine resources. Besides that, another special feature of fishing is that it is not carried out in a private environment, so the means used to perform the activity also have some distinctive features of their own. In Puerto Quequén, the coastal fleet aims their work to selling fish in the market. Because of this, fishing is related to the creation of an internal market, in the first place, and, subsequently, with the integration to international markets, which had an impact on the conditions in which the activity was performed. The nationwide evolution of fishing with its expansion and recession cycles has set the framework for the perception coastal fishermen have (and for the interpretations they make) of their own activity and of the finiteness of the natural resources, of the risks working at sea entails and of the knowledge they need in order to face those risks. In this dissertation we also analyze their own representations about working in the open sea, which include notions such as harshness, freedom, hazardousness, game and adventure, all combined and strained together.

Fishermen dominate the marine environment and gather the natural resources in their boats, their means of work. During the period of interest for this study, the boats of the coastal fleet have changed their capacity of autonomy in the open sea from one day to three and a half. Partially, this is due to the availability of better technologies, but also to the fact that gathering enough natural resources to max the load capacity of the vessels, and therefore making the activity profitable, has become more difficult. The activity of fishing has a clear-cut layered organization where participants are closely connected, and such close connection is supported by effective teamwork and by ideological precepts that favor that connection. The notion of family is thus represented in the family ties that some of the members of the crew have with one another, but it is also present in the metaphor they use to explain their work. It has been acknowledged that work at sea involves a notion of time and space different from the one in a household or in other jobs on land.

Even though the nationwide gathering of fish has increased, and the involvement of the coastal fleet has been stable for decades, Puerto Quequén has showed a decrease in involvement nationwide, both in the volume of catches and in the number of vessels. During this period, the development of the fish industry on land has decreased, which has resulted in a decrease in the local demand of fish. In this context, the path of fishermen when it comes to work and family is defined by their decision to fish on the coast of the town, to fish in other ports or to do other work on land. The small fishing fleet operating at Puerto Quequén is thus an option for a small number of fishermen/workers located in Necochea and 
Quequén, for those who own their own boat or a family boat, or for those who are related either by blood or friendship to the owners of the boats. The number of fishermen/workers residing in town is greater than the number of fishermen/workers actually working at Puerto Quequén. This reflects the fact that even when they are not working in town, they are still involved in maritime activities in response to the labor demand of the global fishing fleet that exploits the Argentine Sea.

The strain in choosing to work in coastal fishing, in open sea fishing or in other fields of work is examined in the light of household organization and the makeup of family strategies. In most of the households, the male figure that works in fishing provides the financial support. In addition, we analyze what it means to these fishermen being "men of the sea" both at work and at home, the environments where their masculinity is legitimized.

Finally, we propose to distinguish three materially and symbolically clear-cut areas: the sea, the land and the harbor, each of which is made up of distinctive features and special social relations that come into play. 


\section{Índice}

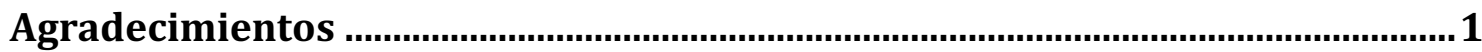

Resumen

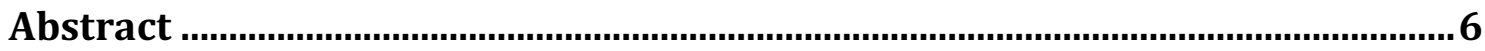

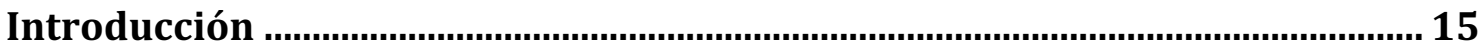

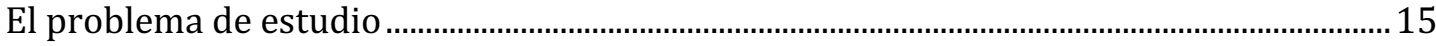

Estructura de la tesis ................................................................................................................... 18

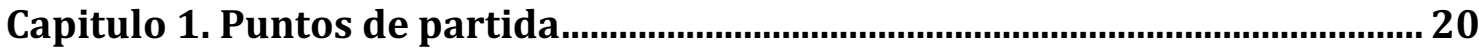

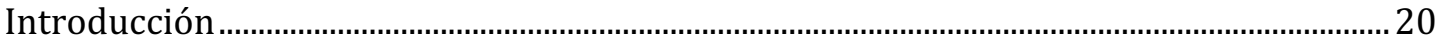

1.1. Antecedentes del tema y la perspectiva de estudio...........................................................20

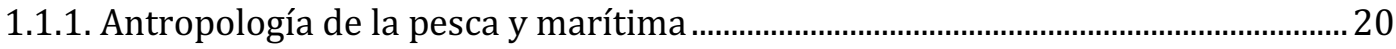

1.1.2. Antropología marítima en América Latina y la región ................................................22

1.1.3. Aproximaciones antropológicas a la pesca y pescadores en Argentina.................2 24

1.1.4. Estudios sobre pescadores y la actividad pesquera en Argentina ...........................2 27

1.2. Perspectiva epistemológica y aproximación metodológica ................................................30

1.2.1. Cuestiones teóricas y epistemológicas......................................................................... 30

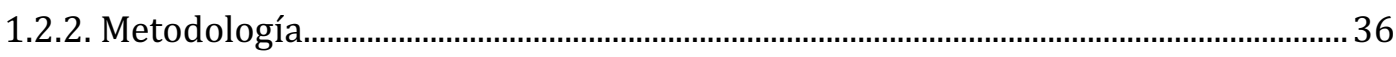

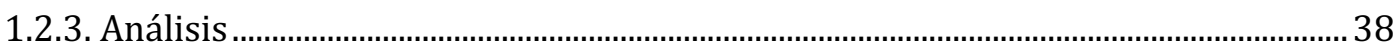

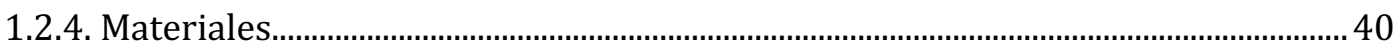

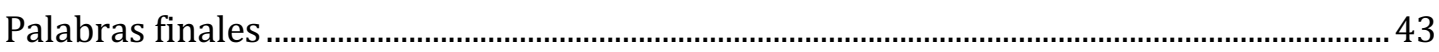

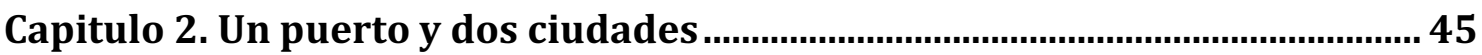

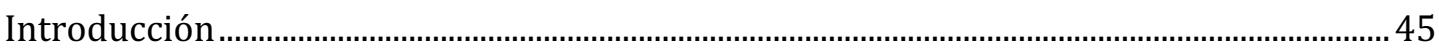

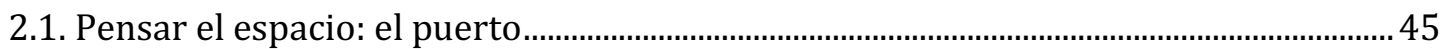

2.2. Puerto Quequén: localización y características.................................................................... 48

2.3. El río que une y separa: Necochea y Quequén …………………………………………...... 51

2.4. Población y evolución demográfica de Necochea Quequén ...............................................58

2.5. Mil intentos y un puerto: fundación y desarrollo de Puerto Quequén ............................66

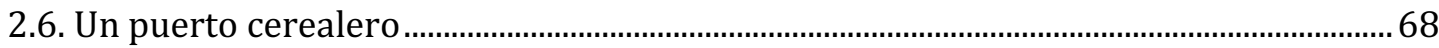


2.8. Entre lo local y lo global, impacto de la globalización y el neoliberalismo en

Puerto Quequén (1975-2001) ..................................................................................................... 71

2.9. Puerto Quequén en la trama: tierra, río, mar y mundo ....................................................... 75

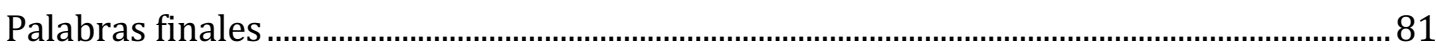

\section{Capitulo 3. La actividad pesquera marítima comercial, caza sofisticada}

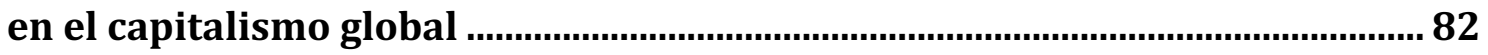

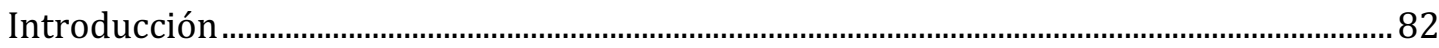

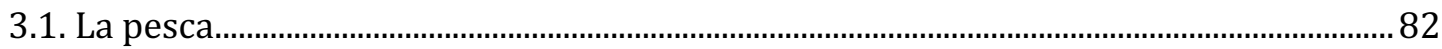

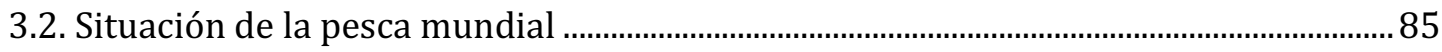

3.3. La pesca ¿un recurso de libre acceso o un recurso común?...............................................89

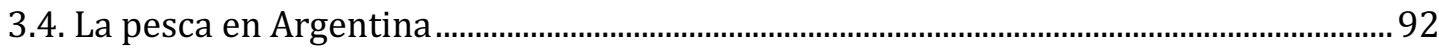

3.4.1. La pesca hasta comienzos del siglo XX.................................................................... 92

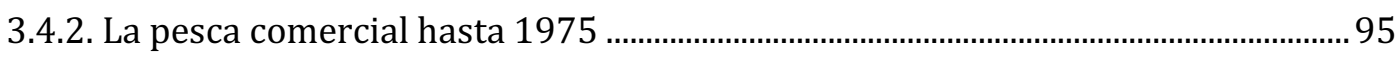

3.4.3. Del país con pesca al país pesquero: 1975 - 2001 ………………………………........ 99

3.4.4. La actividad pesquera y la crisis del sector en clave local ..................................... 104

3.5. Representaciones locales sobre la situación del recurso pesquero ............................. 110

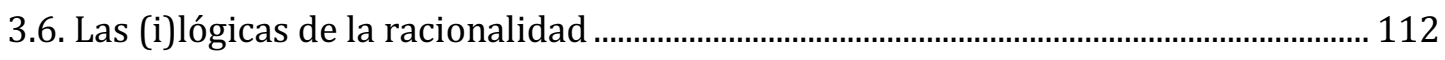

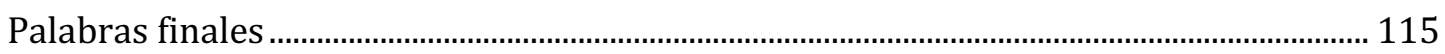

Capitulo 4. Ir a la pesca en Puerto Quequén ...................................................116

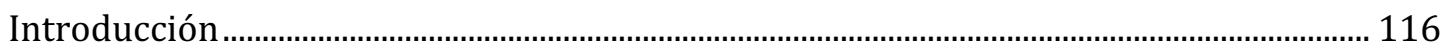

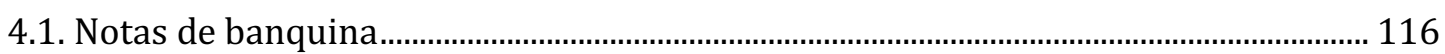

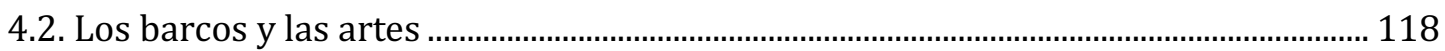

4.3. Aporte de la flota pesquera de Puerto Quequén a la pesca comercial marítima

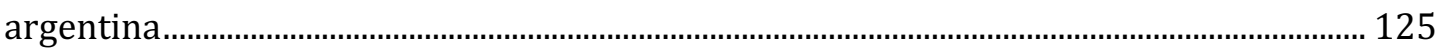

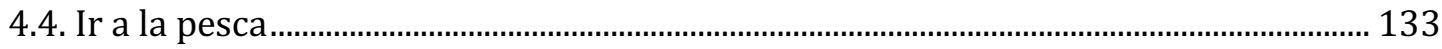

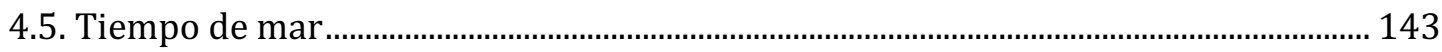

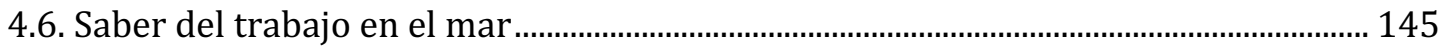

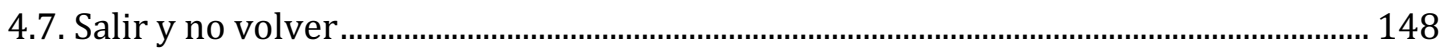

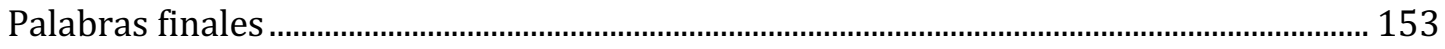

\section{Capitulo 5. Entre el mar y la tierra: los pescadores costeros de Puerto}

Quequén .............................................................................................................154

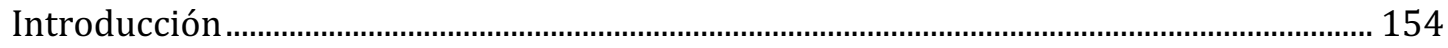

5.1. Los inicios del trabajo de los pescadores en Puerto Quequén ....................................... 154

5.2. Origen local y extra local de los trabajadores-pescadores en Puerto Quequén....... 159 
5.3. Patrón de asentamiento y características de las viviendas de los trabajadorespescadores

5.4. Características de las familias de los pescadores, organización doméstica y estrategias familiares 166

5.5. Los pescadores como trabajadores, una distinción analítica ........................................ 175

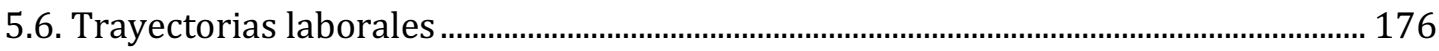

5.7. ¿Quiénes pueden pescar? ¿quiénes pescan? ...................................................................... 181

5.8. Las representaciones sobre el trabajo en el mar............................................................... 187

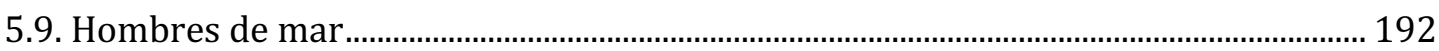

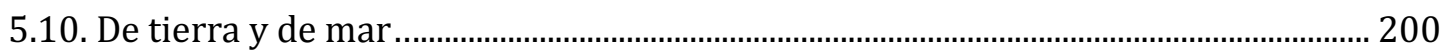

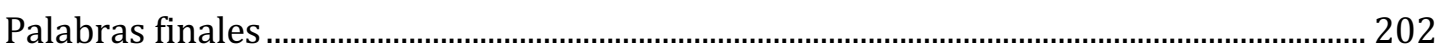

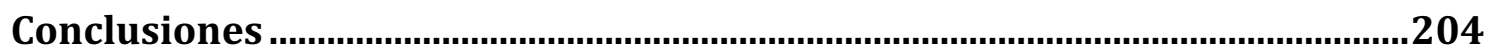

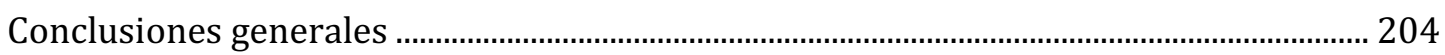

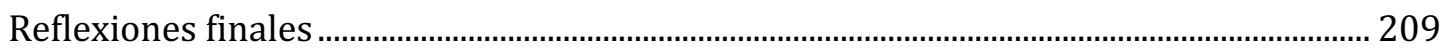

Posibles nuevas vías de indagación ........................................................................................... 210

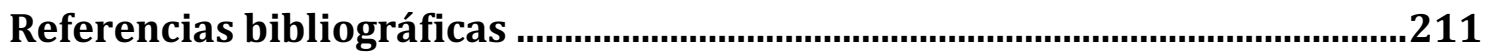

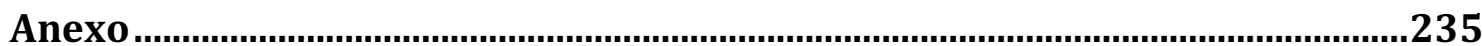




\section{Índice de Figuras}

Figura 1. Ubicación de Necochea, Quequén y Puerto Quequén en relación con el país y la provincia de Buenos Aires.

Figura 2. Imagen satelital de la zona de Puerto Quequén, con la ubicación de los distintos Sitios 50

Figura 3. Ubicación de referentes geográficos y lugares mencionados en el capítulo. 53

Figura 4. Partido de Necochea, se observa la posición del aglomerado Necochea-Quequén en relación al resto del partido y las restantes localidades que lo componen. Elaboración propia a partir de IGN. 55

Figura 5. Pilotes y restos del puente ferroviario que unía ambas márgenes del río Quequén que se destruyó en el año 1980...................................................................................... 56

Figura 6. Vista de los restos del Puente carretero Ignacio Ezcurra............................................. 57

Figura 7. Crecimiento proyectado de Necochea (eje principal) y provincia de Buenos Aires (eje secundario) entre los años 197 y 2001. 60

Figura 8. Hinterland de Puerto Quequén. 62

Figura 9. Vista de Puerto Quequén hacia el mar.. 63

Figura 10. Volúmenes exportados (eje principal) y embarcaciones giradas (eje secundario)

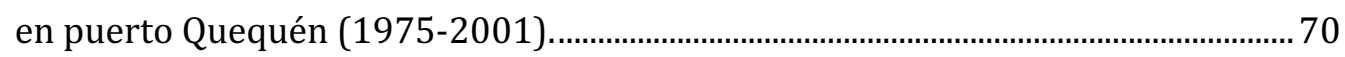

Figura 11. Modelo “Any port" de Bird (1963) …………................................................................ 76

Figura 12. Modelo de Laubé (2014)................................................................................................

Figura 13. Ejemplo de propagandas de pescaderías de Necochea............................................... 79

Figura 14. Producción de pesca marítima a nivel mundial y sudamericana. ............................. 88

Figura 15. Ubicación de Puerto Quequén en relación con el mar argentino, los restantes puertos del país y las zonas y limites definidos dentro del mar argentino. .............91

Figura 16. Evolución de los desembarcos totales anuales de productos pesqueros entre los años 1898 y 1929. Para el periodo entre 1913 y 1919 no se cuenta con el dato de desembarcos anuales. 94

Figura 17. Evolución de los desembarcos totales anuales de productos pesqueros entre los años 1930 y 1974. 
Figura 18. Comparación de las capturas en el mar argentino de las flotas costeras y de altura entre los años 1937 y 2001. 98

Figura 19. Evolución de los desembarcos totales anuales de productos pesqueros entre los años 1975 y 2001. 100

Figura 20. Evolución de los desembarcos totales anuales de productos pesqueros de las flotas costeras, fresqueras y congeladoras, entre los años 1975 y 2000. 103

Figura 21. Barcos pesqueros de Puerto Quequén amarrados en la banquina. 120

Figura 22. Radio de alcance en millas náuticas de las embarcaciones costeras de Puerto Quequén 121

Figura 23. Gráfico de tipos de barcos de la flota pesquera argentina desde 1961 a 1997.124

Figura 24. Comparación de la pesca de cazón entre Mar del Plata, Necochea y demás localidades entre los años 1940 y 1952. 129

Figura 25. Gráfico de capturas totales de pescados en Puerto Quequén en toneladas desde 1976 a 2001. 130

Figura 26. Gráfico de capturas de pescados en Puerto Quequén según flota costera y de altura, en toneladas desde 1976 a 2001. 130

Figura 27. Gráfico de capturas de pescados en Puerto Quequén según flota costera y de altura, en porcentajes desde 1976 a 2001. 131

Figura 28. Gráfico de participación porcentual de Puerto Quequén sobre el total del país entre los años 1976 y 2001. 132

Figura 29. Vista de la lancha El Tordillo en el año 2006, ubicada sobre la banquina de pescadores 153

Figura 30. Localización de los trabajadores pescadores para el año 1987. 164

Figura 31 Localización de los trabajadores pescadores para el año 2001 165 


\section{Índice de Tablas}

Tabla 1. Evolución demográfica del Partido de Necochea según los censos nacionales. .....58

Tabla 2. Datos demográficos del conglomerado Necochea-Quequén entre los censos

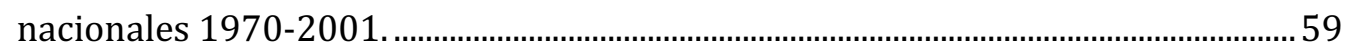

Tabla 3. Comparación del peso relativo del conglomerado Necochea-Quequén en la provincia de Buenos Aires entre los censos nacionales 1970-2001.........................60

Tabla 4. Destino de las exportaciones de Puerto Quequén (1975-2001).................................. 73

Tabla 5. Artes de pesca utilizadas para la captura de especies en Puerto Quequén. .......... 124

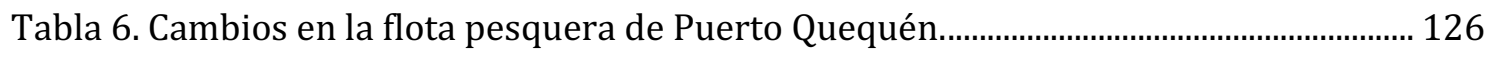

Tabla 7. Pesca realizada en la zona bonaerense durante el año 1920 ..................................... 126

Tabla 8. Especies capturadas en Puerto Quequén entre los años 1999 y 2001................... 133

Tabla 9. Lanchas pesqueras hundidas en la zona de Puerto Quequén.................................... 149

Tabla 10. Movimientos según tipos de embarcaciones en Puerto Quequén en los años 1987

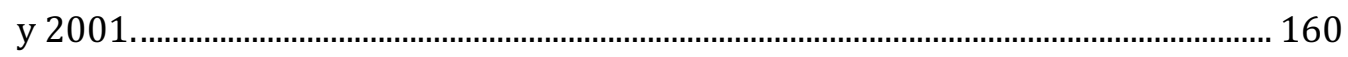

Tabla 11. Localidades de procedencia de los pescadores embarcados en Puerto Quequén en los años 1987 y 2001. 161 


\section{Introducción}

\section{El problema de estudio}

Para empezar, quisiera expresar que situamos el problema de estudio que se aborda en esta tesis en el marco de la Antropología Social porque partimos de una pregunta que consideramos antropológica y, además, durante todo el trayecto investigativo tuvimos presente esta perspectiva. Pero, a su vez, lo situamos en el amplio campo de las ciencias sociales, ya que intentamos establecer diálogos con los aportes específicos de otras disciplinas. A partir del conocimiento de numerosas comunidades que tienen como sustento principal la pesca, se argumenta que "las sociedades de pescadores suelen elaborar complejos sistemas técnicos, sociales y simbólicos para apropiarse del medio marino y para obtener de él su sustento" (Mateo, 2004b). La recurrencia de estos sistemas, hacen necesarias, por un lado, ciertas técnicas de observación y modelos de análisis particulares (Pascual Fernández, 1991b) y, por otra parte, impregnan los problemas teóricos que se abordan. Como sostiene Acheson (1981ํ) "la pesca plantea problemas similares en todo el mundo, y las contribuciones significativas de la antropología de la pesca provienen de estudios que focalizaron en el modo que los seres humanos se han adaptado a ganarse la vida en un ambiente marino".

En Argentina el desarrollo de la pesca marítima comercial estuvo íntimamente vinculado con las poblaciones migrantes europeas que se establecieron en parajes marítimos y que trajeron y adaptaron sus conocimientos a la realidad de nuestras costas. El producto de su trabajo abasteció primero al mercado interno, y luego, más adelante, al mercado internacional.

En Necochea-Quequén, en la costa del sudeste bonaerense, se estableció en momentos relativamente tempranos un pequeño grupo de pescadores, pero el desarrollo de la actividad pesquera nunca estuvo en el centro de la realidad local, aunque durante algún corto período histórico marcó un énfasis con mayor incidencia. Si bien los pescadores

\footnotetext{
${ }^{1}$ Mi traducción.
} 
de Necochea-Quequén están allí desde los inicios de la actividad portuaria, históricamente han sido relegados o desplazados dado que el puerto se ha orientado hacia la salida de la producción agropecuaria de su zona de influencia.

Según la Secretaría de Agricultura, Ganadería, Pesca y Alimentos entre 1966 y 1996 se sextuplicaron las capturas de pescado a nivel nacional. La multiplicación estuvo vinculada, entre otras cuestiones, a la internacionalización del mercado del pescado, a las medidas de fomento y subvención a la actividad y a los convenios con países europeos y asiáticos para operar en la Zona Económica Exclusiva de Argentina. Este marcado incremento fue sucedido por la crisis más grande del sector. En esta trama se plantea necesario saber cómo incidió el aumento de la productividad en la dinámica propia del sector. Aparte de la mencionada expansión de la actividad extractiva y la crisis del recurso pesquero, la relevancia del período definido para el análisis está dada por fenómenos de índole política y económica que, a nivel nacional, generaron una ruptura de las características estructurales de la economía prevalecientes en la etapa sustitutiva de importaciones. A mediados de la década de 1970 se inició un modelo rentístico financiero que se terminó de consolidar en la década de 1990, durante el gobierno menemista con la aplicación de las reformas estructurales propuestas por los organismos internacionales de crédito $\mathrm{y}$, posteriormente, por el denominado "Consenso de Washington". Hubo una apertura de la economía al comercio internacional con un cambio en el perfil exportador: una mayor concentración de productos provenientes de la explotación de recursos naturales, entre ellos, aumentaron las colocaciones del sector pesquero (Rapoport, 2007). En el plano social, las medidas estructurales implementadas en este período -desregulación económica, apertura comercial y financiera, privatización de empresas públicas, convertibilidad entre el peso y el dólar, alta dependencia del endeudamiento externo, modificación de la estructura impositiva, reforma laboral, educativa, en salud y previsión social-, tuvieron un profundo efecto en la estructuración de un entramado social más desigual. Por su parte a partir de 2001 se dio un punto de inflexión económico y político que llevó a que pueda identificarse el inicio de un ciclo con características diferenciadas (Gambina, 2007; Rapoport, 2007). La crisis política e institucional del 2001 trajo aparejado una serie de cambios en los parámetros macroeconómicos -principalmente a través del abandono del esquema convertible y devaluación de la moneda nacional, y posteriormente cambios sociales que nos permiten diferenciarlo del período precedente. Resulta también interesante señalar que el marco temporal definido se ajusta al de la transmisión de la profesión y el patrimonio de una generación a otra, permitiendo rastrear cómo se transmite el "oficio" de pescador en su dimensión institucional, en aspectos sociales y prácticos de transmisión del saber, en la incorporación de aspectos simbólicos sea como insignia de 
estatus o como señal de identidad (Breton, 1990). Otro aspecto tiene que ver con la inclusión de la elección laboral dentro de una "estrategia" más amplia de los individuos y las familias para asegurarse su subsistencia y reproducción (Torrado, 1983; Rispoli, 2005), por lo que un enfoque biográfico centrado en la intersección de las trayectorias de vida y laborales de individuos adultos y sus familias facilitará acceder a la subjetividad, identificar los comportamientos estructurados y las fugas a esa estructura según las coyunturas históricas y económicas que se identifiquen.

En este escenario, las preguntas que orientaron esta tesis fueron ¿cómo incide el trabajo en la subjetividad de los trabadores-pescadores?, ¿qué particularidades tienen los trabajadores-pescadores de la flota costera en Puerto Quequén?, ¿cómo organizan su trabajo y su vida?, ¿qué características asume el trabajo de los pescadores en función del devenir de la actividad pesquera argentina en general, y de su ubicación en un puerto no centrado primordialmente en la actividad pesquera?, ¿qué papel tiene Puerto Quequén en las ciudades de Necochea y Quequén en el que se emplaza?

Entonces, el objetivo general de la investigación cuyos resultados en esta tesis se exponen, consistió en caracterizar la actividad pesquera de Necochea-Quequén, sus agentes sociales, sus estrategias, tanto a nivel individual, familiar y de la unidad productiva, y las representaciones simbólicas sobre su trabajo durante una de las etapas del ciclo de expansión de la pesca comercial marítima en Argentina, comprendida entre los años 1975 y 2001.

En pos de concretar el antedicho objetivo general, los objetivos específicos que seguimos fueron:

- Analizar la historia y características de Puerto Quequén y su integración con las ciudades de Necochea y Quequén.

- Caracterizar la situación de la actividad pesquera nacional y local en vísperas de la expansión de la actividad extractiva en Argentina y cómo fue su desarrollo durante el período 1975-2001.

- Identificar las características técnicas que definen a la flota pesquera costera de Puerto Quequén, cuál fue su evolución y su aporte al total de la producción pesquera durante el período en cuestión.

- Relevar la composición socio-demográfica del universo de los pescadores de Necochea y Quequén.

- Establecer en qué condiciones ingresaron a la actividad laboral, qué vínculos sociales, materiales y simbólicos- han establecido con ella y de qué formas se ha producido la reproducción social de los trabajadores-pescadores costeros. 
- Identificar las trayectorias laborales de los trabajadores-pescadores y ponderarlas en relación con las estrategias familiares de vida.

- Analizar las manifestaciones del universo simbólico de la actividad pesquera y del trabajo entre los pescadores.

\section{Estructura de la tesis}

La presente Introducción expone y delimita el problema de estudio. En ella además se explicita el objetivo general y los objetivos particulares perseguidos durante la investigación.

En el primer capítulo, Puntos de Partida, situamos el problema de estudio en el campo general de la Antropología marítima y de la pesca. A su vez, recuperamos los aportes de la tradición latinoamericana de estudios sobre pescadores, de los trabajos nacionales de corte antropológico que toman como objeto de estudio a la pesca y aquellos que lo hacen desde otras aproximaciones de las ciencias sociales. También explicitamos los puntos de partida epistemológicos, teóricos y la aproximación metodológica en la construcción del objeto de estudio.

El segundo capítulo, Un puerto y dos ciudades, está centrado en Puerto Quequén (como waterfront) y las localidades adyacentes. Partimos de una consideración social del espacio para presentar su localización, características técnicas más importantes, su desarrollo histórico y el rol económico, geográfico y cultural en relación con la integración en las localidades en las que se emplaza, de su hinterland y su foreland. En este capítulo se hace énfasis en los aspectos generales que exceden a la actividad pesquera, pero que constituyen el concreto escenario en el que los trabajadores-pescadores desarrollan su actividad.

En La actividad pesquera marítima comercial, caza sofisticada en el capitalismo global, que es el tercer capítulo, presentamos el desarrollo de la actividad pesquera marítimo comercial argentina en su carácter histórico y en la vinculación con en el contexto más amplio del desarrollo pesquero internacional. La evolución de esta actividad, sus ciclos de expansión y crisis, constituye el marco en el que los pescadores-costeros desarrollan su actividad laboral y anclan sus percepciones e interpretaciones sobre su propio trabajo y sobre el recurso que sirve de base, que tiene la particular característica de ser un recurso renovable, no predecible y sujeto a normas de propiedad común y no privada.

El cuarto capítulo Ir a la pesca en Puerto Quequén, se centra en las embarcaciones, la unidad productiva en la que trabajan los pescadores. Se describe y caracteriza el tipo de flota costera, sus artes de pesca y el tipo de especies marinas recuperadas, distinguiéndola 
de otros tipos de flota. Se analiza y pondera la participación en la producción de pescado de esta flota en relación con otros tipos de flota para el período estudiado y la producción nacional. Se presenta un análisis de la organización del trabajo, las relaciones de producción y la forma de retribución en la que participan los pescadores que trabajan en la pesca costera. Se presentan vías de interpretación sobre lo que representa simbólicamente la embarcación y el trabajo en el barco para los trabajadores-pescadores en cuánto a los riesgos, la cohesión con el grupo de trabajo, el conocimiento y la temporalidad durante el trabajo en el mar.

En el quinto capítulo, Entre el mar y la tierra, los pescadores de Puerto Quequén, posicionamos a los trabajadores-pescadores en su ámbito histórico, geográfico y social, en sus relaciones familiares y en la relación simbólica con su trabajo como pescadores. Para ello se analiza el origen local y extra local de los trabajadores-pescadores, su patrón de asentamiento y las características de sus viviendas. En cuanto a la caracterización de las familias se analiza y problematiza en función de las particulares características de la actividad y la división familiar del trabajo, la organización doméstica y la existencia de redes de ayuda o contención. Desde la perspectiva de la trayectoria laboral se recuperan y analiza las formas de ingreso y permanencia en la actividad pesquera, las decisiones en el plano de lo laboral en relación con la actividad pesquera y/u otras actividades fuera del ámbito, teniendo en cuenta la relación con momentos familiares o del ciclo de vida. También se analizan desde la perspectiva de las representaciones sociales los sentidos dados al trabajo y al "ser hombre de mar". Por último, se pone en consideración los resultados con la perspectiva de la antropología marítima sobre los espacios de mar y tierra.

Por su parte, en el capítulo Conclusiones recuperamos los aportes de cada capítulo y los integramos en una discusión que permite pensar la situación de los trabajadorespescadores en el contexto de desarrollo de la actividad en nuestro país y específicamente en Puerto Quequén. Además, realizamos unas breves reflexiones finales y establecemos posibles nuevas vías de indagación.

La presentación de los resultados y su discusión se realizó pensando en una complementariedad entre capítulos para acceder a una visión de conjunto del problema abordado. Una tesis, interpretamos, si bien aborda y presenta los diferentes temas en capítulos, es una unidad. Sin embargo, consideramos también que es plausible leer cada capítulo de forma independientemente, sin por ello perder aquella unidad. 


\section{Capitulo 1.}

\section{Puntos de partida}

\section{Introducción}

Este capítulo tiene dos objetivos. En primer lugar, explicitar los puntos de partida que sustentaron el desarrollo de la investigación. En ese sentido, los antecedentes recuperados en primer lugar permiten situar el trabajo realizado dentro de la perspectiva de la antropología marítima y de la pesca, y en la tradición latinoamericana de estudios sobre pescadores. También recuperamos los trabajos de corte antropológico que toman como objeto de estudio a la pesca y aquellos que lo hacen desde otras aproximaciones de las ciencias sociales. Un segundo objetivo consiste en explicitar la perspectiva epistemológica y la aproximación metodológica en la construcción del objeto de estudio.

\subsection{Antecedentes del tema y la perspectiva de estudio}

\subsubsection{Antropología de la pesca y marítima}

En el plano teórico, el análisis de la especificidad del tema pesquero se nutre de la confluencia de conceptualizaciones provenientes de diferentes disciplinas. Particularmente, desde la Antropología Social, la Antropología Marítima ha constituido un campo de investigación con un alto grado de desarrollo de los estudios.

Según Acheson (1981) los antropólogos interesados en la antropología marítima se ocuparon de temas recurrentes como las pesquerías, la vida a bordo y la adaptación al medio marino. Por su parte, Breton (1981) plantea que el camino seguido por la antropología para dar cuenta de las actividades de la pesca en su desarrollo teórico permite establecer tres períodos que se corresponden con el proceso seguido por la propia disciplina antropológica en la conformación de su corpus teórico. En un primer momento, los trabajos de Boas (1964), Kroeber (1960) y Wissler (1940) proporcionaron una descripción de la tecnología de ciertos grupos que se dedicaban a la actividad pesquera. 
Malinowski (1948) en 1922 con Los Argonautas del Pacífico Occidental y Firth (1975) en 1946 con Malay Fishermen: their peasant economy, desde una perspectiva funcionalista, pusieron de manifiesto el valor adaptativo de los medios de trabajo y la vinculación entre actividad pesquera y relaciones de producción. A su vez, Firth fue el primero en sostener que el proceso de trabajo de los pescadores reúne ciertas características que, a pesar de su carácter a veces contrapuesto al de los agricultores, permite que sean abordados desde una misma perspectiva. Rubio Ardanaz (1994) distingue unos puntos en la obra de Firth que se refieren a lo específico del mundo marino:

“- El aspecto cotidiano y más continuo de la producción pescadora, en comparación con la agricultura.

- En comparación con el medio rural, la inseguridad mayor a la que se enfrenta el pescador que obtiene un dinero en su labor.

- La división del trabajo en la pesca que da lugar a formas de cooperación flexibles y genera un sistema de distribución relativamente complejo.

- La necesidad de una rápida transformación del pescado. Ello hace que sea necesario un trabajo y útiles con los que trabajar más aprisa en comparación con la agricultura.

- Los pescadores no viven solamente de pescado y deben participar en una economía de cambio" (Rubio Ardanaz, 1994).

Un nuevo interés en las comunidades de pescadoras marcará un nuevo período, de énfasis funcionalista con los trabajos de Barnes (1954), Blehr (1963) y Barth (1966) que supusieron un avance significativo en cuanto a la consolidación de la antropología de la pesca como disciplina específica. Recuperamos aquí el aporte de Barnes que en su análisis sobre los pescadores de Bremnes, una pequeña localidad noruega, sostiene que los vínculos entre las personas permiten distinguir diferentes campos sociales. El reconoce un campo fluido, en el que se asienta la actividad de la pesca, que es masculino, de relaciones personales variables; un campo estable que corresponde a la organización doméstica; y un tercer campo que no es fijo ni tiene límites y corresponde al de los lazos sociales, representa un campo de oportunidades en torno a lazos que se sustentan en la amistad y el parentesco (Barnes, 1954).

La década de 1970 supuso la consolidación en la construcción de un corpus teórico que daría entidad a la antropología marítima como un subcampo disciplinar (Breton 1981) y como un campo de investigación que incluiría diversas perspectivas teóricas y estrategias de investigación incluyendo dos tendencias, una que se orienta a la ecología y la economía liberal, y otra que se inspira en la perspectiva marxista (Alegret, 1989). Breton (1981), 
Alegret (1987) y Rubio Ardanaz (1994) coinciden en marcar éste como un tercer momento, en la que tienen un valor preponderante los estudios monográficos y las obras colectivas, tanto regionales como comparativas, entre ellas las de Andersen y Wadel (1972), Casteel y Quimby (1975), Smith (1977), Spoehr (1980). Es también en este período que Faris (1977) y Breton (1981), retomando la propuesta inicial de Firth, pretenden "conjugar el desarrollo teórico elaborado para el estudio de las sociedades campesinas con la teoría marxista, para aplicarlo al estudio de las sociedades pesqueras" (Alegret, 1987). A partir de esta línea y, sumando los aportes de la ecología de sistemas, se da una consolidación de la especificidad del campo de estudio con los trabajos de Alegret (1987), Pascual Fernández (1991a), Sánchez Fernández (1992), Montes del Castillo (1999) y Rubio Ardanaz (2006).

Reconocemos que fueron de especial interés y resultaron muy estimulantes en términos de interpretación teórica de las realidades particulares las lecturas fundantes de Acheson y Barnes. También tuvieron gran influencia los trabajos referidos a la pesca catalana de Alegret (con quien realicé una Estancia de Formación ${ }^{2}$ ), los trabajos de la pesca canaria de Pascual Fernández (1991b) y los aportes a la investigación de la pesca en Euzkadi planteados por Rubio Ardanaz (con quien cursé un Seminario de Postgrado) ${ }^{3}$.

\subsubsection{Antropología marítima en América Latina y la región}

En este apartado reseñamos algunos de los desarrollos de la antropología marítima en América Latina, con énfasis en aquellas lecturas que resultaron disparadoras de temas de interés, que acompañaron y marcaron el ritmo de pensamiento.

Una mención destacada merece el trabajo realizado por Graciela Alcalá Moya en México, quién analiza a los grupos domésticos de pobladores pescadores en un pequeño poblado de Veracruz mostrando el lugar que ocupa la pesca en la economía local (Alcalá Moya, 1985). En otro trabajo, con perspectiva de género, analiza la división sexual del trabajo en la pesca tradicional de camarón en la laguna de Cuyutlán, México y la experiencia del intento de acelerar el cambio de los roles tradicionales de hombres y de mujeres en una comunidad de pescadores. Un grupo de mujeres con el apoyo de un delegado local iniciaron un proceso de transformación por el que se intentó que las mujeres realizaran la pesca del camarón. Aunque no se logró transformar las costumbres locales y el proyecto no prosperó, las mujeres desarrollaron un interesante proceso de visibilizaron de su rol (Alcalá Moya,

\footnotetext{
2 Durante el mes de noviembre de 2011 se realizó una estadía de formación en la Càtedra d’Estudis Martims de la Universidad de Girona con la dirección de Juan L. Alegret.

${ }^{3}$ Realidades y manifestaciones socio-culturales en Euskal Herría: panorámica antropológica. FCNyMUNLP, 2005.
} 
2003). Es significativo el trabajo de edición de una obra fundamental, Pescadores en América Latina y el Caribe: Espacio, Población, Producción y Política (Alcalá Mota, 2011), que, en dos tomos, recopila cuarenta artículos que recorren la problemática de los pescadores y la pesca desde México hasta Argentina. Los temas que se discuten en transversalidad geográfica tienen que ver con el trabajo cotidiano de los pescadores, dinámicas espaciales y temporales de la actividad de pesca, la relación con la configuración de los paisajes, con la conformación de territorios y la conflictividad.

Pesca e turismo: etnografias da globalização no litoral do Atlântico Sul, el libro compilado por Rial y Godio (2006) resulta un atractivo aporte no sólo para pensar la antropología de la pesca marítima sino, en el marco del uso de los espacios costeros, pensar la actividad de los pescadores en relación con otra de las actividades con las que potencialmente debe competir: el turismo. Explorando relaciones de complementariedad y competencia en el marco actual de la globalización y de los procesos de apropiación de los espacios costeros.

En El mundo sumergido. Una investigación antropológica de la pesquería del mejillón en Piriápolis y Punta del Este D’Ambrosio y colaboradores (2010) presentan los resultados de una investigación etnográfica realizada sobre el trabajo y la vida de los buzos mejilloneros que realizan una actividad de tipo artesanal en la costa de Uruguay. Resulta interesante porque este libro condensa la apertura de la Antropología Marítima en el vecino país de Uruguay y la oportunidad de puesta en diálogo con los desarrollos de Chile, Argentina y Brasil. En un país con una tradición agrícola y ganadera, y en una zona que las políticas públicas están puestas en las actividades turístico-recreativas del verano llaman la atención sobre el lugar relegado que tuvo la investigación sobre el medio costero, proponiendo no sólo una descripción sino también un diagnóstico.

Povos e coletivos pesqueros. Estudos etnográficos e perspectivas socioantropologicas sobre o viver e o trabalhar compilado por Adomilli, D'Ambrosio, Carreño y de Souza Miller (2012) es un buen referente del estado de desarrollo de la Antropología Marítima y de la Pesca en la región. Recupera las discusiones suscitadas en la Reunión de Antropología del Mercosur de 2009 con trabajos de México, Brasil, Chile, Uruguay y Argentina que recurrentemente hacen referencia a cuestiones relativas al modo de vida y prácticas de trabajo, sobre todo del ambiente marino, pero en también de poblaciones costeras lacustres o de río. Se destaca el interés de varios de los trabajos por problematizar los procesos de apropiación o desterritorialización de algunas de esas poblaciones frente a las transformaciones e impactos socioambientales.

Los trabajos de Aguirre Munizaga y colaboradores (2014), De pescador artesanal a tripulante pesquero. Pesca industrial y transformaciones sociales en Tarapacá. Norte de 
Chile (1950-1990), y de Aguirre Munizaga y Moya (2014) La vida en un lance: el trabajo de pescador industrial en el norte de Chile, desde una perspectiva cualitativa analizan las relaciones sociales, las formas de trabajo y la percepción que del mismo tienen la tripulación abocada a la pesca industrial chilena en el contexto de los cambios acontecidos a nivel nacional y global.

\subsubsection{Aproximaciones antropológicas a la pesca y pescadores en Argentina}

En Argentina los estudios contemporáneos sobre pescadores desde la perspectiva antropológica han focalizado mayormente en los pescadores de río y de forma más reciente en pescadores marítimos "artesanales". En ambos casos se destacan la recurrencia de disputas medioambientales en el centro de los análisis.

Entre los análisis de pescadores de río destacamos como iniciadores de una tradición sobre la actividad de este tipo de pesca trabajos como el de Rosato (1988) quién realiza una caracterización de las prácticas económicas que desarrollan los habitantes del delta bonaerense. Define el proceso productivo como un sistema "cazador-pescador", en el que las unidades domésticas funcionan como unidades productivas, sin una especialización, sino que combinan varias actividades. En el caso de la pesca el productor vende al acopiador quien impone el precio y controla la operación, aunque a principios de la década de 1970 funcionaron cooperativas de pescadores. Destaca que la mayor productividad proviene de la caza de la nutria, pero cómo no es posible reinvertir el excedente en la misma actividad, se reinvierte en la ganadería y la pesca.

Por su parte, Benencia y Forni (1988) dan cuenta del proceso de diferenciación en hogares asentados en los espacios costeros e isleños del Río Paraná, Santa Fe, en el área de influencia del proyecto (nunca concretado) de la represa del Paraná Medio. Describen las transformaciones que se dan a partir de la penetración de una actividad de tipo capitalista, el acopio de pescado fresco, en un área de producción de autoconsumo. Analizan las estrategias de supervivencia-producción a través de la relación que se da entre la diversificación de actividades de los miembros del hogar y el grado de capitalización alcanzado por los hogares. Caracterizan tres situaciones: la primera de menor capitalización con una mayor diversificación de actividades para la supervivencia; otra, de mayor capitalización de los pescadores con una diversificación de actividades para lograr un beneficio mayor; y una tercera situación de equilibrio, en el caso de la capitalización media donde prevalecería una especialización en la actividad pesquera.

Balbi (1990) plantea para el caso de la producción pesquera no empresarial del departamento de Victoria, Entre Ríos, ciertos puntos de referencia para comparar al 
pescador con el campesino desde el punto de vista del proceso de valorización del capital global, en tanto que ambas actividades se desarrollan en base a un recurso natural, los productores son propietarios de sus medios de producción, cuentan con un acceso limitado pero relativamente libre al recurso y tienen bajos niveles de acumulación. Lo que singulariza el proceso productivo que estudia es que no presenta una unidad inmediata del proceso de valorización con un proceso de trabajo, sino que el proceso de producción está dividido en varios procesos de trabajo subsumidos de manera diferente e interdependientes por el capital: el proceso de captura, llevado a cabo por unidades "no capitalistas" y el traslado realizado por comerciantes capitalistas o "acopiadores". En otro trabajo (Balbi, 1995), examina la necesidad de regularidad en la actividad productiva para que los actores organicen sus actividades y relaciones con otras ramas de actividad. El interés por la coordinación de las actividades de captura y traslado desemboca en la intervención en el proceso productivo de otros actores, los intermediarios, quienes se ocupan de la coordinación de los procesos de trabajo. Mientras el acopiador necesita organizar el proceso de captura y el pescador se beneficia de la reducción de riesgos e incertidumbres, los intermediarios, sin necesitar de medios de producción, basan su posición en una capacidad personal e intransferible. Destaca como esta regularidad genera ciertas paradojas, por ejemplo, que si bien las relaciones son construidas para servir a las actividades productivas acaba por llevar a los actores a organizar sus actividades productivas de acuerdo con las estructuras de sus relaciones. En relación con la existencia de un discurso de tipo ecologista entre los pescadores, Balbi (2007a) analiza las condiciones sociales de su uso, con el objetivo de explicar la contradicción que supone el hecho de que los pescadores estén preocupados por la preservación del recurso, pero no hayan tratado de implementar medidas conservacionistas (una paradoja que como veremos se repite en otros espacios). En este sentido, plantea cómo las apelaciones moralizantes en torno a la defensa del recurso operan como formas de exposición simbólica del orden social: el intercambio desigual entre pescadores y acopiadores y la competencia entre intermediarios. Profundizando en el aspecto de los valores morales, y la posibilidad de su estudio etnográfico considera la relación entre moralidad e interdependencia en los miembros de la cooperativa de pescadores y la necesidad de la existencia de un objetivo común y perdurable, que suponga la necesidad de confiar entre los miembros de la cooperativa para llevarlo a cabo, que en el caso de los pescadores cooperativizados estaría dado por evitar el trato con el acopiador local (Balbi, 2000). Siguiendo con la cuestión referente al análisis de las connotaciones morales en otro artículo revisa la apelación a expresiones ambientalistas por parte de los pescadores en la década de 1980 para traducir 
en términos morales las oposiciones centrales a procesos que pueden ser considerados ambientalistas (Balbi, 2007b).

Más recientemente, en la tesis de licenciatura Río liberado. Emergentes culturales en el sistema ambiental Paraná Medio, Ortiz (2006) realiza un interesante análisis de la situación del Paraná con categorías antropológicas desde una perspectiva sistémica con énfasis en los estudios ecológicos y ambientales. Su trabajo se centra en uno de los eventos de oposición al proyecto de represamiento del Río Paraná. Una de las aristas que analiza tiene que ver con el cambio ocurrido en los pescadores luego de la experiencia organizativa de la marcha de protesta anti-represa.

Prol (2008) examina el sector pesquero en la provincia de Santa Fe a partir de su inserción en el mercado internacional como exportador de pescado. Realiza una reflexión sobre el tipo de conocimiento que los organismos del estado requieren para diseñar regulaciones para este sector productivo que tiene como característica basarse en recursos renovables. Mientras que Prol y Ortiz (2009) analizan la actividad pesquera del Paraná Medio e inferior en relación con conflictos ambientales y regulaciones estatales. Observan que a partir de la década del 90 los ambientes en los que se desenvuelven los pescadores se han revalorizado y forman parte de la agenda de ambientalistas no sólo por la crisis en los recursos que provee sino también por la crisis más general de los humedales. Llaman la atención sobre cómo con la implementación del Mercosur y el aumento de la demanda la actividad pesquera se convierte en un tema de agenda pública, y la pesca "comercial" pasa a considerarse entre las principales causas de problemas socioambientales.

En Pescadores artesanales del Bajo Paraná argentino: entre la complejidad y la tragedia de los comunes, Ferrero y Arizpe Ramos (2015) analizan la situación de los pescadores artesanales de la zona de la cuenca del bajo Paraná desde una perspectiva de la gestión de los recursos. La pesca artesanal en esta zona es una actividad de acceso abierto, basada en relaciones comunitarias y que contaba con restricciones basadas en la tradición hasta que esta modalidad fue afecta y el acceso se vio reducido por la privatización de áreas isleñas. Este artículo está publicado en un Dossier de la Revista Avá sobre “Organización y conflictos en torno a la actividad pesquera" presentado por Carlos Abraão Moura Valpassos.

Noceti en el artículo ¿Reserva, puerto o ría? Conflicto socioambiental en el estuario de Bahía Blanca, Argentina (2017) problematiza la discusión en la intersección naturaleza/cultura. La autora desde una mirada etnográfica distingue tres schematas la ría, el puerto y la reserva en los que se pueden reconocer los diversos actores que, con sus particularidades, luchan por el acceso y control de territorios y recursos naturales en un escenario donde también es posible reconocer asimetrías políticas. En una ponencia partiendo de un enfoque etnográfico presenta la riqueza de saberes de los pescadores 
artesanales de Villa del Mar, y de la relación de equilibrio que sustentan en el ecosistema en el que pescan (Noceti, 2014).

Desde la perspectiva de la gestión de los recursos Amato Uriburu (2014) en Conflictos socioambientales. Una experiencia de gestión comunitaria de recursos naturales analiza con un enfoque etnográfico la gestión de los recursos naturales en una comunidad de pescadores artesanales en la provincia de Chubut y la experiencia de organización de la comunidad para obtener reconocimiento estatal para el manejo territorial para la gestión de los recursos pesqueros.

En La fragilidad de las especies: tensiones entre biólogos y pescadores artesanales en torno a la conservación marina Carman y Gonzalez Carman (2016) desde una perspectiva antropológica e interdisciplinaria se analiza el modo en que los pescadores artesanales de San Clemente del Tuyú clasifican las especies animales en relación con la posibilidad de ser explotadas como recurso y, también, negocian con los biólogos la protección de algunas de ellas.

En La crisis pesquera de la flota de lanchas amarillas del puerto de Mar del Plata: una mirada hacia las instituciones (Alonso, 2015), analiza la situación de la flota costera de las lanchas amarillas en Mar del Plata considerándolas como una forma de pesca artesanal, aunque reconoce la ambigüedad que supone la orientación comercial del producto de su captura. En la coyuntura crítica post crisis del recurso pesquero analiza la acción de organismos estatales y organizaciones pesqueras analiza la posibilidad del establecimiento de cuotas de pesca y su incidencia para el sector.

Aunque los desarrollos de la antropología de la pesca en Argentina, y a diferencia de otras zonas del mundo o Latinoamérica, no llega a constituir un campo autónomo de discusión en sí mismo, en los últimos años es posible identificar interesantes aproximaciones con perspectiva etnográfica que permiten anticipar mayores desarrollos. Temas clásicos como las formas de trabajo y organización, la disputa en apropiación de los recursos y de los territorios aparecen en el centro de interés.

\subsubsection{Estudios sobre pescadores y la actividad pesquera en Argentina}

En la Argentina, a diferencia de las sociedades rurales, las poblaciones costeras, tanto urbanas como rurales, no generaron un interés constante para los científicos sociales. Según Mateo (2003) esto puede deberse a factores económicos, demográficos y también culturales, en relación con el grado de inserción de la actividad en la sociedad. En cuanto a los pescadores marítimos Mateo (2004a, 2004b, 2004c y 2006) estudia, desde una perspectiva histórico-antropológica, la formación de la comunidad de pescadores del 
puerto de Mar del Plata desde fines del siglo XIX. Describe el rasgo distintivo de la construcción del puerto "desde cero y en un espacio que requería que éste fuera artificial en su totalidad" asimismo "la traza original de los que sería años más tarde el barrio puerto o "pueblo de pescadores" fue realizada por la empresa constructora del puerto" (Mateo, 2004b). A partir de los años 1940 se da un punto de inflexión en la actividad pesquera, la guerra potenció la industria conservera simultáneamente a la "fiebre del tiburón". En este contexto analiza como los "pescadores 'artesanales' que existían en la época anterior al boom del tiburón dejaron de serlo para convertirse en un eslabón de una pujante cadena que traccionaba la próspera empresa de la industria conservera" (Mateo, 2004a y 2006). Esta coyuntura permitió una fase de acumulación aprovechada de diferentes formas por los pescadores, "fue una de las pescas que más influyó en el mejoramiento e incremento de la flota costera marplatense de aquellos años" (Mateo, 2006). Realiza un detallado análisis de las relaciones productivas, teniendo en cuenta factores como la migración, el crédito, las redes sociales, y la religiosidad (Mateo, 2005a y 2005b).

Masid (2004 y 2005) analiza el impulso que le dio al desarrollo de la pesca de altura marplatense la llegada a principio de los años 1950 de un grupo de familias belgas, que durante más de una década lideraron el campo de la pesca de altura y aportaron experiencia en pesca a mar abierto, los cuadros jerárquicos y tecnología relativamente avanzada para las embarcaciones. Es de resaltar que Masid pone en relevancia los factores que influyeron en ello: tanto la especialidad como la etnicidad, y cómo la transferencia de la red de relaciones a la sociedad de destino favoreció la continuidad de las prácticas culturales domésticas y profesionales. Sostiene que estos factores van a definir un campo social distinto del campo preexistente de la pesca costera, el campo de la pesca de altura.

El libro Un acercamiento a la problemática Pesquera Marplatense, (Pradas, 2006) constituye una referencia sustancial para entender en clave económica-social la estructura del desarrollo de la actividad pesquera siguiendo unos ciclos de auge, depresión y crisis. Analiza la incorporación de Argentina al mercado mundial de pesca y el impacto en la clase obrera de los cambios, presionando siempre en favor de la disminución de costos laborales. Desde una aproximación geográfica, los trabajos de Cóccaro y colaboradores (2002) y Gómez Lende (2015) plantean la reestructuración de la pesca marítima marcando un proceso de acumulación por desposesión, en éste se consolida la depredación del recurso marítimo en un modelo extractivo que favorece la concentración de capital en pocos agentes y predominantemente extranjeros.

Laura Ruocco (2008), con perspectiva intersectorial de clase y género, marca la situación de las obreras de la industria conservera en Mar del Plata en el período histórico en el que se da el auge de esta industria. Mientras que Schultze (2013) en su tesis de 
Licenciatura Trayectorias de clase e identidades obreras. Los trabajadores/as en tierra del puerto de Mar del Plata (2007-2012) está preocupada por recuperar los orígenes sociales de los trabajadores del puerto. Analiza las identidades socioculturales de los trabajadores/as en tierra de la industria pesquera de Mar del Plata a partir de reconstruir sus trayectorias biográficas y socio-ocupacionales, tiene en cuenta también las condiciones sociales de vida y las representaciones colectivas sobre sus condiciones laborales.

El informe Precarización y fraude laboral en la industria pesquera marplatense El caso de las 'cooperativas' de fileteado de pescado Estado actual de la situación y evolución histórica de la rama 1989 - 2010, (Mateo et al., 2010) que recibiera el premio Bicentenario de la Patria: Premio Juan Bialett Massé "El estado de la clase trabajadora en la Provincia de Buenos Aires" ubica la posición de la condición obrera de precarización laboral y pauperización social en el marco del establecimiento de un nuevo patrón de acumulación capitalista. Además, el impacto de esta situación y la conflictividad obrera en Mar del Plata fueron el centro de varios análisis historiográficos, ya sean centrados en la experiencia gremial o desde una perspectiva más general (Colombo y Nieto, 2006; Yurkievich y Nieto, 2014; Colombo, 2011a; Contreras, 2008; Cutuli, 2010).

En la tesis De la revolución productiva a la crisis de la merluza: El conflicto social en la industria pesquera marplatense. Años 1989-2001, Colombo (2014) analiza la movilización colectiva de los trabajadores y trabajadoras del pescado en la década de 1990 y la dinámica conflictual que se dio en el contexto de implementación de políticas para la pesca que produjeron transformaciones laborales que tendieron a bajar los costos laborales.

En el libro Entre anarquistas y peronistas. Historias obreras a ras del suelo, Nieto (2018) reconstruye el proceso de formación de la clase obrera de la industria del pescado que tuvo lugar entre las décadas de 1940 y 1960 en Mar del Plata. Con agudeza y solidez empírica en este libro que recopila los avances de su tesis doctoral, el autor recorre el modo en que lxs obrerxs del pescado construyen sus subjetividades en la fábrica y en otros ámbitos de sociabilidad. Analiza también las disputas entre fracciones gremiales.

Nogueira (2019a) en la tesis Entre la precarización y la autogestión: estrategias laborales y subjetividades inherentes a las y los trabajadores de la industria pesquera de Mar del Plata y Necochea-Quequén, 1997-2012 problematizó la evolución de la actividad de la industria pesquera en tierra de Necochea-Quequén a partir de la experiencia autogestiva de un grupo de obreros y obreras que "recuperaron" una fábrica de pescado y su comparación con experiencias similares en Mar del Plata. Además, estudió el cambio de significación de la tradicional fiesta de los pescadores (Nogueira, 2018a) y exploró las reconfiguraciones en las subjetividades inherentes a los trabajadores de las empresas pesqueras recuperadas de Necochea y Quequén (Nogueira, 2019b). 
El trabajo fotográfico Mujeres de la industria pesquera. El trabajo en Engrau-coop, una fábrica recuperada por sus trabajadoras y trabajadores en Quequén, Buenos Aires, Argentina de Malleville (2018) permite acercarnos visualmente al trabajo en la preparación de la anchoa en la fábrica, una actividad con un sesgo de género notable en todo el mundo.

El Instituto Nacional de Investigación y Desarrollo Pesquero constituye un importante polo de producción de conocimiento sobre la actividad pesquera argentina. Los relevamientos realizados sobre la flota, los pescadores y la situación del recurso pesquero resultan de un marcado interés. Destacamos en función de nuestro interés los trabajos Flota costera. Descripción de las principales características en la región bonaerense de Errazti y Bertolotti (1998) que analiza las características de la flota costera en la Región Bonaerense (y que incluye a Puerto Quequén). El libro Principios de política y economía pesquera (Bertollotti et al., 2008) condensa tanto aspectos generales como específicos de la actividad pesquera en Argentina.

Con la conformación del Grupo de Estudios Sociales y Marítimos (GESMar) dirigido por José Mateo se desarrollaron varias líneas de investigación en torno a la pesca comercial marítima bonaerense y la discusión portuaria. Los libros Hablemos de Puertos (Mateo y Nieto, 2010) y Los Puertos y su gente: pasado, presente y porvenir (Cañete et al., 2011) recopilan trabajos de sobre la problemática portuaria desde las ciencias sociales, desde un enfoque integral que incorpora tanto el trazado humano que lo compone, las comunidades que forman parte y los vínculos que se establecen en las zonas portuarias como espacios de trabajo, de vida, de lucha. Por su parte, el surgimiento de la Revista de Estudios Marítimos y Sociales $^{4}$ (REMS) en el año 2008 favoreció la producción de un espacio específico para nuclear la discusión temática nacional e internacional sobre puertos y comunidades portuarias y marítimas, con apertura a todas las ciencias sociales.

\subsection{Perspectiva epistemológica y aproximación metodológica}

\subsubsection{Cuestiones teóricas y epistemológicas}

Partimos de considerar que, en el proceso de investigación y de producción de conocimiento, cabe la necesidad de hacer una constante revisión de las relaciones que se establecen entre los procedimientos, las teorías, los materiales y la posición de la analista.

Analizar lo social implica dar cuenta de la estructura objetiva de la sociedad, pero también de la necesidad de reintroducir la experiencia inmediata y vívida de los agentes con

4 Revista de Estudios Marítimos y Sociales (REMS), publicación del Grupo de Estudios Sociales Marítimos (GESMar), Universidad Nacional de Mar del Plata, Argentina. ISSN 2545-6237. 
el fin de explicar las categorías de percepción y apreciación (disposiciones) que estructuran su acción desde el interior (Bourdieu y Wacquant, 2008). Bourdieu (1990) sostiene que "la teoría más resueltamente objetivista debe integrar la representación que los agentes se hacen del mundo social y, más precisamente, su contribución de la visión de ese mundo y, por lo tanto, a la construcción de ese mundo por medio del trabajo de representación (en todos los sentidos del término) que efectúan sin cesar para imponer su propia visión del mundo o la visión de su propia posición en ese mundo, de su identidad social”.

El marco de pensamiento en el que se formula un problema y se realiza una investigación no es del todo ajeno de los posicionamientos y trayectorias personales. Formular y llevar adelante una investigación implica implícita o explícitamente contar con unas hipótesis generales sobre el mundo y otras particulares sobre la sociedad y las personas. Como ha sido ampliamente tratado la constitución del objeto de estudio, el marco analítico, las hipótesis de trabajo no son independiente del investigador o investigadora y su contexto (Perrot y Preisewerk, 1982). En ese sentido, esta investigación no es la excepción y creo necesario mencionar que durante mi infancia y adolescencia viví en la ciudad de Necochea. Que mi padre fue un inmigrante italiano ${ }^{5}$, y que no tengo lazos familiares con los pescadores de Puerto Quequén. Qué recuerdo de mi infancia a una compañera de primaria cuyo padre trabajaba embarcado y representaba para mí un gran misterio por qué a veces estaba en la casa y por largos períodos no. Que al "irme" de la ciudad para estudiar en La Plata, en algún momento y con la distancia física se volvió "problematizable" ese conjunto de lanchas amarillas amarradas en el gran puerto cerealero local y los pescadores que en ellas trabajaban. Consideramos que la construcción del objeto de estudio, y de la teoría con que el mismo se aborda son indisociables entre sí (Bourdieu y Wacquant, 2008) preferimos discutir los conceptos utilizados en los capítulos y plantearemos las reelaboraciones necesarias para dar cuenta, de forma más completa y acabada, el fenómeno a tratar.

Desde la perspectiva de las relaciones sociales dominantes no es lo mismo estudiar a un grupo subalterno que a uno hegemónico. Sin embargo, sostiene Menéndez (2010) que es posible invertir las relaciones asimétricas características del trabajo antropológico y que esto lleva a modificar el rol y las técnicas de quién investiga. El género (junto con la edad, la clase social y la etnia) atañe a uno de los principales ejes ordenadores de las interacciones sociales (Moreno, 1991), investigadora e investigados/as responden a lugares en la estructura social, cuestión que es imposible de disociar. Por ello resulta pertinente dar

\footnotetext{
${ }^{5}$ Que llegó a Buenos Aires como un niño a mediados de la década de 1950 y se mudó a Necochea en su adultez.
} 
cuenta del marco estructural en que esas relaciones se establecen, ya que los momentos de encuentro y producción de conocimiento conforman, también, situaciones de interacción social y, cómo tales, ambos términos están realizando una mutua clasificación y se ponen en juego parámetros subjetivos y culturales en los que el género resulta imposible de abstraer (Harding, 2004). Consideramos, también, que la antedicha no es la única instancia en la que el género se pone de manifiesto en una investigación y nos centramos en la necesidad de comprender el papel de los valores en la construcción del conocimiento científico, de que todo conocimiento científico es situado, de que las valoraciones permean en diferentes instancias y momentos del proceso de investigación, o sea en la formulación del problema, la elección de las hipótesis de trabajo o del marco teórico (Perrot y Preizwerk, 1982; Longino, 1990; Harding, 2004, Haraway, 2004). Por ello, pensamos junto con Harding (2008) que el género no atañe sólo roles sociales, sino que es una lente teórica, metodológica y analítica a través de que podemos examinar instituciones, prácticas y que proporciona, tanto como la clase o la etnia, un marco conceptual desde el cual se examinaran los fenómenos de interés.

Por su parte, Branz (2017) retoma la discusión sobre el condicionamiento que representa estudiar hombres siendo (o creyendo ser hombres), cuestión naturalizada a tal punto que muy pocas veces hay un ejercicio reflexivo al respecto. Lo interesante es que esta discusión nos habilita a ponderar el lugar y el aporte que puede tener el ser mujer estudiando un universo masculino. Apreciar qué implica en los diferentes momentos de la investigación ser mujer (y joven al momento del trabajo de campo) al entrevistar u observar en torno a un universo de hombres adultos, implica -también- pensar que elementos se abrieron y cuáles se cerraron a tratar. En este sentido, consideramos que en los primeros encuentros la diferencia de posición estructural en torno a grupo etario y género, como generalidad en principio puso una distancia. En los sucesivos encuentros, y en los casos de entrevistas extensas y en profundidad esa distancia se disolvió, se encontraron formas de salvarla. Haciendo uso de la propia posición nos permitimos preguntar obviedades, repreguntar muchos temas, focalizar en la posición de extrañamiento. En términos de reflexividad resulta sugestivo cuestionar qué elementos socialmente compartidos sobre el lugar representado como investigadora contribuyeron a construir un marco de confianza para preguntar sobre decisiones y situaciones personalísimas, en la habilitación de charlas que muchas veces se transformaron en emotivos raccontos de vida; cómo la posición de género pudo haber contribuido a una situación de confidencia que potenció la apertura de las entrevistas. Al mismo tiempo, estimamos que otras posibilidades se han visto limitadas por esta misma razón, por ejemplo, en la banquina o en las charlas en los barcos, al hacer referencias a ciertos chistes, vocabulario asumido como impropio y censurado o 
autocensurado entre risas o vergüenzas seguramente limitaron algunas de las posibles vías de indagación.

Estimamos que otro de los aspectos en los que puede radicar un interés situar la presente investigación, responde a extender el alcance de la consideración de Gutman (1999) acerca de que "la antropología siempre se ha ocupado de hombres hablándole a hombres sobre hombres. Sin embargo, hasta hace poco tiempo, fueron contados aquellos quienes dentro de la disciplina del "estudio del hombre" realmente examinaron a los hombres como hombres" 6 . Recuperando esta perspectiva resulta interesante considerar la contribución que pudiera representar la investigación sobre un ámbito considerado masculino siendo llevada adelante por una investigadora. Creemos oportuno en esta instancia diferenciar una posición de investigación femenina (o sea llevada adelante por mujeres) de una investigación con perspectiva de género -con la que nos identificamos-, focalizada en generar un corpus crítico para cuestionar la naturalización de roles y estereotipos socialmente compartidos, desnaturalizar no sólo la subordinación femenina sino también al mismo tiempo visibilizar los mecanismos en que se sustenta la constitución de las masculinidades usualmente llamadas tradicionales o hegemónicas, reconociendo el carácter relacional de los vínculos entre los géneros situadas en su particularidades culturales, de época y sociales (Balandier, 1975; Connel, 1997).

Queremos hacer explícito que, aunque la propuesta de la teoría antropológica en general, y de la antropología marítima en particular representan el punto de partida desde el cual se aborda el tema, no estaríamos siendo consistentes con nuestra propia concepción de producción de conocimiento si nos quedáramos en la exclusividad de los aportes de un solo campo disciplinar. Mientras que la antropología se constituyó como un campo de estudios diferenciable del resto de las ciencias sociales, resulta difícil asociarla con un objeto exclusivo (Neufeld y Wallace, 1999). Coincidimos en el planteo de estos autores en que no existen fundamentos epistemológicos que distingan a la antropología de otras ciencias sociales, siendo las diferencias que reconocemos de tradición formativa y técnico metodológicas. Por ello decidimos también centrar el análisis en el ámbito más amplio de las ciencias sociales. Aunque tradicionalmente la antropología se focalizó en los fenómenos de pequeña escala, cada vez fue más difícil opacar la estrecha interrelación entre diferentes escalas de análisis y la dependencia de las particularidades de contextos más abarcativos. Tal como plantea Banton (1980) fue necesario establecer niveles de inclusión e interrelación entre los fenómenos, también considerando ámbitos locales, regionales,

\footnotetext{
${ }^{6}$ Las cursivas y las comillas internas son del autor. En la actualidad han crecido significativamente los estudios que recuperan esta posición.
} 
nacionales y transnacionales. Esta vinculación en escalas se da en consonancia con las actuales tendencias en ciencias sociales, que se orientan a desarrollar los campos disciplinares en forma interrelacionada para dar cuenta de los desafíos que representa el estudio de problemáticas particulares en las que se intersectan aspectos territoriales, económicos, sociales y culturales. En este sentido nos resultó útil resituar los temas tratados no sólo en la antropología sino pensar el referente empírico considerando conceptos provenientes de otras tradiciones académicas y ámbitos de discusión. Desde la perspectiva histórica y geográfica, con aportes conceptuales de la sociología podemos situar la pregunta antropológica sobre la "alteridad de los pescadores" (Krotz, 1994) una alteridad marcada por la actividad de la pesca en un puerto cerealero, la del trabajador no obrero.

Una de las intenciones que aporta la antropología como disciplina corresponde a considerar el criterio de totalidad cultural, aunque la visión clásica de los modelos culturales únicos ha resultado de gran relevancia, también comporta limitaciones al perder vista inconsistencias internas o contradicciones al favorecer la búsqueda de modelos compartidos (Rosaldo, 2000). En ese sentido a lo largo del análisis tratamos de marcar las tensiones de sentidos y las particularidades. La perspectiva que adoptamos en la elaboración de nuestro análisis intenta recuperar el espíritu generalizador de la antropología social al tiempo que recupera el papel particularizante de la historia, necesario para dar cuenta de las sociedades contemporáneas (Commarof y Commarof, 1992, Fernández de Rota Monter, 1987).

Durante el tiempo que implicó trabajar en la reflexión de nuestro referente empírico, distinguimos etapas (temporales) de momentos (teórico-analíticos) que implicaron diferentes aperturas. La primera pregunta de investigación sobre los pescadores, su trabajo y sus familias, nos llevó luego a pensar sobre la identidad y el género. Cóccaro y Agüero (1998) nos interpelan “¿cómo disociar el tiempo y el espacio de un lugar si el espacio situado es instancia y/o propiedad de los ritmos de tiempo de la espacialidad de los procesos involucrados? ¿Acaso los biomas depredados, los suelos disminuidos en su capacidad productiva, las pesquerías sobreexplotadas no son expresión situada de los desajustes entre los ritmos de tiempo de reproducción del capital con los ritmos de tiempo de la reproducción natural de los ecosistemas?". La inquietud sobre el espacio tomó y articuló diferentes escalas, como espacio geográfico, económico, social y como espacio subjetivo. A partir de este posicionamiento pretendemos en esta tesis esbozar una interpretación y conceptualización. Siempre teniendo presente, que todo concepto es un instrumento para ser usado y en ese sentido es provisional, lo que no implica falta de precisión ni tampoco que sean reificados (Menéndez, 2010). 
En este sentido, queremos dedicar unas líneas a explicitar la forma en que entendemos las representaciones sociales, un concepto que resultó transversal al análisis de los discursos recuperados y que sirvió de base para la interpretación analítica. De las diferentes conceptualizaciones planteadas acerca de las representaciones sociales, recuperamos la que plantea Farr, quien nos dice que se trata de “...sistemas cognoscitivos con una lógica y un lenguaje propios. No representan simplemente "opiniones acerca de", "imágenes de" o "actitudes hacia" sino "teorías o ramas del conocimiento" con derechos propios para el descubrimiento de la organización de la realidad. Sistemas de valores, ideas y prácticas con una función doble: primero, establecer un orden que permita a los individuos orientarse en su mundo material y social y dominarlo; segundo, posibilitar la comunicación entre los miembros de una comunidad proporcionándoles un código para el intercambio social y un código para nombrar y clasificar sin ambigüedades los diversos aspectos de su mundo y de su historia individual y grupal" (Farr, 1984, citado por Araya Umaña, 2002). Este enfoque, tal como sostiene Giménez (2005), demostró ser efectivo para el estudio de las "formas interiorizadas" o simbólicas de la cultura. Si tenemos en cuenta que las personas conocen la realidad en la que viven por las explicaciones que extraen de los procesos comunicativos y por el pensamiento social, entonces podemos entender a las representaciones sociales como una síntesis de esas explicaciones y, por lo tanto, en referencia a un tipo específico de conocimiento que juega un papel crucial sobre cómo la gente piensa y organiza su vida cotidiana: el conocimiento del sentido común.

Las representaciones se construyen a partir del fondo cultural acumulado en la sociedad, por mecanismos como el anclaje y la objetivación, y circulan por medio de prácticas sociales que se encuentran relacionadas con diversas modalidades de la comunicación social (Araya Umaña, 2002). Para el caso que nos ocupa, nos detendremos en la objetivación: proceso vinculado a la transformación de conceptos abstractos en materializaciones concretas. En este proceso sensu Jodelet (1984, citado por Araya Umaña, 2002) intervienen tres operaciones: la construcción selectiva, el esquema figurativo y la naturalización. Particularmente, nos interesa dar cuenta de cómo el discurso se estructura y objetiviza por medio de un esquema o núcleo figurativo, que se caracteriza por ser sintético, condensado, simple, concreto, es decir cómo las ideas abstractas se convierten en formas icónicas. Por lo que durante el análisis retomamos estas formas icónicas para la interpretación. 


\subsubsection{Metodología}

Entendemos la metodología como el camino del pensamiento y de la práctica ejercida en el abordaje de la realidad, incluimos en ella tanto las concepciones teóricas del abordaje, como el conjunto de técnicas que posibilitan la construcción de la realidad, así como el potencial creativo del investigador (sensu de Souza Minayo, 2004a). Sostenemos que la recurrencia de ciertos aspectos de la organización de las poblaciones de pescadores impregna los problemas teóricos y favorecen la aplicación de técnicas de observación y modelos de análisis particulares. Es en este sentido que se constituye el campo de investigación como recorte que el investigador realiza en términos de espacio -entendido como lugar que ocupan las personas y los grupos en una dinámica de interacción social-, representando una realidad empírica a ser estudiada a partir de las concepciones teóricas que fundamentan el objeto de la investigación (de Souza Minayo, 2004b).

Siguiendo el planteo de Ferreira Deslandes (2004) consideramos la metodología como las opciones y la lectura operacional que el investigador realiza del marco teórico. Rescatamos los principales elementos para tener en cuenta para la definición de esta durante el transcurso de una investigación, siendo ellos la recolección de datos, la definición de la muestra y, la organización y el análisis de estos. Aunque estos tres ejes no constituyen momentos propiamente temporales en una investigación, consideramos necesario delimitarlos y caracterizarlos para definir la metodología.

En cuanto a la recolección de datos, las técnicas de recolección de la información y las fuentes utilizadas fueron variadas. Se efectuó un relevamiento teórico bibliográfico de la discusión científica (a nivel nacional e internacional) en función de las problemáticas planteadas. En relación con el "trabajo de campo" propiamente dicho, se realizó una indagación heurística de las fuentes documentales, económicas y estadísticas, tanto oficiales, periodísticas, como privadas sobre el tema.

Se elaboró e implementó una encuesta estructurada y de respuesta cerrada que se adjunta en la sección Anexo. Esta encuesta sirvió para conocer la población referente, establecer sus características demográficas, laborales y de organización doméstica. Temporalmente fue la primera etapa, y permitió no sólo elaborar una caracterización de la población objeto de análisis, sino también contar con un marco desde el cual formular las siguientes etapas de trabajo.

Se elaboró un modelo de entrevista, para tener los ejes a preguntar. Estos ejes en términos sintéticos correspondieron a tres grandes núcleos temáticos: el trabajo ${ }^{7}$, las

\footnotetext{
${ }^{7}$ Que incluyó preguntas sobre las pautas de participación por sexo en el mercado de trabajo,
} características relativas a la ocupación en la pesca, la estabilidad y estacionalidad del empleo, formas 
trayectorias de vida ${ }^{8}$ y la organización doméstica ${ }^{9}$. Sin embargo, el modelo de entrevista no fue utilizado a rajatabla, sino que ofició como una guía de temas a cubrir durante las mismas. Las entrevistas realizadas adoptaron un enfoque biográfico, en el sentido dado por Bertaux (1993) de recolectar relatos de vida siguiendo unos marcos pasibles de ser cuestionados, esta perspectiva o enfoque, que permite conciliar la observación con la reflexión, resultó adecuado para recuperar las trayectorias individuales y familiares. Consideramos también a la entrevista como un método de recolección de información que refuerza la importancia del lenguaje y el significado del habla (Cruz Neto, 2004), por lo que se obtienen tanto datos objetivos como subjetivos. La entrevista constituye un proceso de interacción social con diferentes finalidades y significados para el entrevistador y para el entrevistado. Este proceso comunicativo de obtención de información depende tanto de elementos internos de la situación de la entrevista: entrevistador, entrevistado y tema en cuestión, así como de los elementos externos: factores extra-situacionales que relacionan la entrevista con la sociedad, la comunidad o la cultura (Valles, 1997). Tanto el entrevistador como el entrevistado tienen su propia visión de la entrevista, por eso el entrevistador debe estar atento a lo que aporta a la situación de la entrevista. Las entrevistas se plantearon con diferentes niveles de estructuración, tanto en relación con los intereses de la información a buscar, como del momento en la investigación y en la relación entre entrevistador y entrevistado (Guber, 2004).

También se planteó la necesidad de incluir observaciones. La observación respondió a un plan previo, aunque elástico, y fue tomada de forma activa en el proceso de investigación, sirviendo como guía, también para clasificar datos, para redirigir el foco de la investigación. Varios autores plantean que este método constituye un patrón para medir otros métodos, mientras que la entrevista se encuentra en el campo del decir del hacer, la observación nos permite indagar sobre el campo propio del hacer, permitiendo captar fenómenos o situaciones que no son obtenidos mediante preguntas. Este punto es altamente significativo en la elaboración de conocimiento antropológico. En este sentido, Goode y Hatt

de ingreso al trabajo y la utilización de redes sociales para ello, comportamientos relacionados con los desplazamientos geográficos tendientes a mejorar las formas de inserción en el mercado laboral. Se dio especial énfasis a las preguntas motivacionales y de indagación sobre el trabajo en el sentido más amplio posible (Torrado, 1981).

${ }^{8}$ Focalizado en los relatos de vida, en poder captar los hitos vitales más significativos para los y las entrevistadas, a partir de la narración de lo vivido actualizar el pasado, considerando que cobra sentido en un presente. Incluimos en este eje las preguntas abiertas sobre la vida de la persona, sobre decisiones de vida y sus valoraciones. También se realizaron preguntas de proyección propia o familiar (Torrado, 1983; Bertaux, 1993).

${ }^{9}$ Enmarcamos aquí las preguntas tendientes a dar cuenta de la distribución de las responsabilidades de producción de ingresos y de mantenimiento cotidiano del grupo familiar, y cómo se organiza en torno a la actividad de la pesca (Cariola, 1992). 
(1990) nos llaman la atención sobre el hecho de que para realizar observación participante el investigador debe buscar un rol que sea aceptable para el grupo, siempre recordando que el observador forma parte del contexto, lo modifica y es modificado por este.

Como formas privilegiadas de registro se utilizaron la grabación y los apuntes, generalmente llamado "cuaderno de notas"10. En algunas ocasiones también se utilizó la fotografía, pero esta no tuvo la misma importancia en la recolección de información cualitativa.

El análisis de documentación se hizo en relación con toda la comunidad de Puerto Quequén, incluyendo tanto las localidades de Necochea como la de Quequén. Teniendo en cuenta que una buena muestra es aquella que permite abarcar la totalidad del problema investigado en sus múltiples dimensiones, la elección de los sujetos a quienes se entrevistó se hizo teniendo en cuenta no sólo el criterio numérico sino principalmente qué individuos sociales tienen una vinculación más significativa con el problema a ser investigado, estrategia llamada de "muestreo teórico" (de Souza Minayo, 2004b). Por ejemplo, para seleccionar a los entrevistados se tuvieron en cuenta variables como, el lugar que ocupan en el proceso productivo y en la estratificación de la actividad, si son propietarios cuál es su nivel de capitalización, los niveles de capacitación, si pertenecen a "familias de pescadores" o son "nuevos pescadores", si se dedicaron exclusivamente a trabajar en algún tipo de flota, entre otros. Se utilizó el como criterio de "saturación" de la información teniendo en cuenta el potencial del aporte de nuevos casos para contribuir a comprensiones teóricas, por lo que se define un cierre de la muestra cuando las nuevas entrevistas no producen una comprensión nueva al tema, teniendo en cuenta también que se trabajó con un universo pequeño, relativamente acotado.

\subsubsection{Análisis}

Para la organización y el análisis de los datos se trabajó mediante el análisis de categorías. Se privilegió la articulación entre categorías teóricas, generales, así como de las surgidas desde el análisis de la recolección de datos. Para sistematizar la información cuantitativa se utilizaron planillas de cálculo y nos valimos del programa de análisis de datos cualitativos Atlas-ti para procesar una parte de las entrevistas. Esto nos permitió sistematizar los relatos en la búsqueda y relación entre categorías surgidas de los propios

\footnotetext{
${ }^{10}$ En mi caso no fue un cuaderno sino una carpeta, a la que sumé hojas y notas de audio en el grabador.
} 
actores. Otra porción del trabajo cualitativo fue analizada de modo "artesanal" en procesadores de textos.

Durante todas las etapas del análisis se trabajó teniendo en cuenta el análisis de contenido, considerando que "todo texto puede ser objeto de una doble lectura: directa del sentido manifiesto, al pie de la letra, y soterrada del sentido latente, entresacado del otro" (Ruiz Olabuénaga, 1999). Por medio del análisis de los discursos en términos de Alonso (1998) lo que se trata es "realizar la reconstrucción del sentido de los discursos en su situación -micro y macrosocial- de enunciación (...) encontrar un modelo de representación y de comprensión del texto concreto en su contexto social y en la historicidad de sus planteamientos, desde la reconstrucción de los intereses de los actores que están implicados en el discurso" (Alonso, 1998). Las entrevistas en profundidad y las charlas repetidas en contextos de interacción social (observación participante) implican una fuente privilegiada para acceder al universo simbólico de los actores sociales, aún más en contextos de reflexión sobre la propia trayectoria laboral y de vida. Pero más allá de la práctica de la interacción social que supone tanto la entrevista como la observación, en una y en otra obtuvimos discursos textualizados (las notas de campo o la desgrabación), que luego trabajamos analíticamente. Sobre estos discursos pudimos recuperar no sólo los temas, sino también los modos teniendo en cuenta las unidades de significación que llevan la entrevista al extremo de la significación, en las que se condensan significados sociales o dan cuenta de una relación social, en otras palabras, para sostener las interpretaciones hicimos foco en el tropo. En este sentido, este enfoque adoptado tuvo por objetivo aprehender el punto de vista usualmente llamado "nativo" o emic considerando que los sujetos "saben" un saber no específico, práctico, de la vida cotidiana que es enunciado y plausible de ser recuperado en el análisis.

Consideramos que un papel fundamental en esta etapa tiene que ver con la importancia de la imaginación creativa, enriquecida por la utilización de analogías y metáforas. Nos valimos de la misma para corrernos de los márgenes estrechos de la neta descripción empírica para fortalecer el análisis y la interpretación. El punto en común de la hermenéutica y de la fenomenología es insistir que la mirada y la escritura están conceptualmente determinadas, entonces cada texto no es el reflejo de una realidad sino el de una sensibilidad (Ghasarian, 2008). Además de establecer articulaciones entre teoría y metodología, también establecimos la necesidad de la reflexividad, de identificar qué respuestas subyacen a nuestros propios interrogantes y también deslindar a qué preguntas responden implícitamente los informantes (Bourdieu y Wacquant, 2008; Cruz Neto, 2004; Guber, 2004; Ghasarian, 2008). Durante todo el trayecto de investigación, intentamos producir un conocimiento situado que diera cuenta de la perspectiva de los actores sin 
desconocer las posiciones estructurales y con una fuerte carga fuerte de la interpretación que aporte a una mayor comprensión del fenómeno de interés.

\subsubsection{Materiales}

Partiendo del supuesto de que durante el proceso de investigación se estructuran los datos obtenidos, consideramos apropiado describir los materiales con los que trabajamos considerando que los mismos no son un a-priori, sino que ellos están imbricados con las preguntas de investigación.

\section{* Cuestionario:}

El cuestionario ${ }^{11}$ con preguntas cerradas y semicerradas fue aplicado en junio de 2003 sobre 18 pescadores que en ese momento estaban saliendo embarcados en Puerto Quequén. En el mismo se consignan diferentes secciones: preguntas sobre del informante y los componentes de su hogar; preguntas sobre sobre definición y caracterización del trabajo (días y horas trabajados, actividades que realiza, cómo consiguió la ocupación, antigüedad, aportes y beneficios sociales, si tiene otra ocupación, etc.); información sobre organización del trabajo doméstico; preguntas sobre el uso de redes de colaboración extrafamiliar (dar y/o recibir ayuda a/de familiares y amigos) y de recursos gubernamentales (beneficiarios de planes sociales, comedores escolares, entre otros) y otros recursos del hogar. Además, se preguntó sobre las condiciones de la vivienda. Este material permitió construir una aproximación en el terreno del perfil sociodemográfico de la población de pescadores de Puerto Quequén.

\section{* Observaciones:}

Entre 2007 y 2010 se realizaron observaciones con diferentes grados de participación durante más de 90 horas, en la banquina de la margen Necochea. Una primera etapa de observaciones se realizó en paralelo al trabajo de archivo (2007-2009) y estuvo focalizada en poder marcar ritmos de trabajo y uso de la banquina. El otro período de observaciones realizado en 2009 y 2010, es indisociable de las entrevistas y se describe con ellas.

\footnotetext{
${ }^{11}$ Elaborado en el marco de un taller de investigación (Taller de Pobreza: discusiones teórico y metodológicas) de la UNLP. Fue aplicado con la colaboración de Luis Nogueira, Técnico del Conicet de la Estación Hidrobiológica de Puerto Quequén.
} 


\section{- Entrevistas:}

Una primera etapa de entrevistas fue realizada en 2003, consistente en 12 entrevistas, de las cuales ocho corresponden a pescadores encuestados. Una entrevista fue realizada en la casa del pescador e incluyó a su esposa, mientras que las restantes fueron realizadas a los pescadores en la banquina del puerto. De las cuatro restantes, una corresponde a un patrón (capitán de pesca de baja altura) y otra, a un dueño de barco (armador), que anteriormente fue marinero y patrón. También se realizaron entrevistas a gente especializada en la pesca de altura ya que, además de pertenecer en sentido amplio al sector que interesa estudiar, también contribuyen a caracterizar la problemática específica que se aborda. Por lo que las últimas dos entrevistas fueron realizadas a marinos de altura (capitán de pesca y conductor naval y a sus respectivas esposas).

Entre julio de 2009 y noviembre de 2010, en tres etapas se realizaron otras series de entrevistas. Muchas de las charlas empezaron de modo informal detonadas por mi presencia en la banquina, y por ello resulta difícil establecer los límites entre una observación con participación y alguna de las entrevistas en profundidad. Generalmente tenía el grabador prendido, y apuntaba en audio algunas impresiones. Los pescadores empezaron a estar familiarizados con la presencia de "miradas" por mi recurrencia, los horarios poco frecuentes para los turistas y variables (temprano en la mañana, por ejemplo); el verme charlar con uno y otro, con alguien de prefectura, con un estibador, etc. generó las consiguientes dudas sobre mi rol. En algunos casos unos me mandaban a hablar con otro "preguntale a tal si es asî" y en otros, si es posible decirlo así, alguno celó de que luego de hablar con él fuera con otro, como una suerte de traición. Pero de este modo se fue articulando relativamente rápido una suerte de espiral que permitió charlar con diferente grado de profundidad con 14 pescadores (algunos en actividad, otros no) y excluyendo las charlas informales (no clasificamos como entrevistas las charlas cortas y que no llegaban a cubrir, aunque sea de modo desordenado, los temas planteados en los ejes). Tres de las entrevistas se realizaron en los mismos barcos, como una "visita" que se dio en relación con mis "rondas" en la banquina. Otras fueron realizadas en la banquina. Con alguno de ellos se contactó en banquina para luego entrevistarlos en sus casas particulares.

Durante tres cortas temporadas me confundí con ese paisaje. Tal vez pensaba que no me veían, pero seguro estaba ahí. Uno de esos días, un pescador me alcanza dos estrellas de mar, no me dice nada. Le agradezco y me señala un barco saliendo. Un jovencito me saluda desde arriba.

En días cálidos y en días muy fríos, algunos con aire calmo, pero muchos ventosos, los pescadores estaban allí. Si el viento era más fuerte, tenía más posibilidad de encontrar ánimos para la charla porque los pescadores no salían o salían más tarde, o volvían más 
temprano. Hubo días que no hablé con nadie, pero siempre quedaba ver y seguir el equilibrio sobre alguna de las cuerdas de amarre. Si todos los barcos habían ido a la pesca, la banquina estaba vacía. En esas ocasiones hablé con el personal de Prefectura que, aburridos en su cabina, me aportaron su visión sobre el trabajo de los pescadores, tan cercano en y tan diferente al suyo. Hable con los estibadores, esforzados, en movimiento y cansados me contaron su visión del puerto, del trabajo en mar, ellos se sentían seguros en tierra, "mejor no subir al barco ni una vez". Miré desde más lejos, un poco más abajo sobre la margen Necochea, frente a los restos del puente Ezcurra. La vista de puerto y banquina es otra.

Transversalmente en términos temporales (2008-2010), se realizaron un número más pequeño de entrevistas que corresponden a un representante gremial, una esposa y madre de dos pescadores, un pescador retirado, un propietario-armador y la viuda de un pescador; en estos casos llegué a entrevistarlas y entrevistarlos por referencias. El encuentro con las mujeres fue en sus casas particulares, el del armador que fue en un bar y el del representante gremial en su oficina.

De los resultados de esta etapa se nutre la mayor parte del análisis de que refiere a cuestiones como el espacio de trabajo, el oficio, las trayectorias laborales y representaciones sobre el trabajo e identificaciones.

Con respecto a los aspectos éticos contemplados en esta Tesis, se acordó con los entrevistados proteger sus identidades, por lo que no se consignan los nombres de las personas. Asimismo, los entrevistados fueron informados de que las entrevistas y charlas serían utilizadas para generar un texto de carácter público.

\section{Archivos:}

Durante los períodos de febrero y marzo de 2007, noviembre 2007, marzo y abril de 2008, y septiembre y octubre de 2008 se relevó el Archivo de Prefectura Naval Argentina delegación Puerto Quequén. La información allí recabada resultó ser una fuente original y privilegiada de información sobre el tema, proveyendo un registro exhaustivo de los movimientos de los barcos y los trabajadores a través de "libros y hojas de rol", "libros de banquina" y "libros de embarque y desembarque".

En los "libros de embarque" se asienta el embarco (ingreso) de los tripulantes a cada barco. Estos libros, con valor de declaración jurada y contractual consignan la siguiente información: apellido y nombre del tripulante, número de libreta, localidad de residencia, domicilio, embarca como (rol o función), nombre de la embarcación, matrícula, tipo de buque y título que posee. Además, la información se asienta en las hojas de rol y en las libretas de embarque de cada tripulante. La información que provee esta fuente permite 
analizar en escala temporal, por ejemplo, la composición local y extra-local de la fuerza de trabajo, reconstruir el patrón de asentamiento de los pescadores en el aglomerado Necochea-Quequén; caracterizar el perfil sociodemográfico de la tripulación, la estabilidad del trabajo, las relaciones familiares presentes entre los tripulantes y la dispersión de roles (estratificación). Los "libros de banquina" contienen la siguiente información de la salida y la entrada de las embarcaciones con la matricula, el tonelaje, el nombre y apellido del patrón, de los tripulantes. También se consigna información sobre el rumbo y sector de pesca, la clase de pesca.

Se examinó el archivo del diario local "Ecos Diarios" en la búsqueda de noticias sobre el puerto y los pescadores. También se recopilaron datos de fuentes secundarias y de organismos públicos, por ejemplo, del Ministerio de la Producción de la Provincia de Buenos Aires, Ministerio de Agricultura Ganadería y Pesca de la Nación, Dirección Provincial de Pesca de la Provincia de Buenos Aires, de la Organización de las Naciones Unidas para la Alimentación y la Agricultura (FAO).

En noviembre de 2011, en el marco de una estadía de investigación se accedió al archivo bibliográfico Documare (Palamós, Girona). Este archivo representa un punto de referencia bibliográfico y documental especializado en temas marítimos y pesqueros, vinculado al servicio de Bibliotecas y la Universidad de Girona; que cuenta con una de las bibliotecas más completas y actualizadas en pesca marítima del Mediterráneo Occidental y de temas sociales pesqueros a nivel internacional. A Partir de la información recabada se pudo fortalecer el análisis del caso de Puerto Quequén en aspectos como tradición, flota, tipo de pesca, estratificación y organización de la tripulación, retribución, forma de comercialización.

\section{Palabras finales}

En síntesis, munidas de la formación y de la información obtenida como profesional en antropología zarpamos procelosamente al principio y cada vez con mayor certeza del destino hacia el territorio de la pesca y de los pescadores de Necochea/Quequén. En el trayecto fuimos recabando las bitácoras de otros viajes realizados por diferentes cientistas sociales en otros tiempos y espacios que nos permitieron comprender cuánto de especificidad tienen el ser y el hacer pescador más allá de las aguas en que ejerzan su oficio. También ir perfilando un patrón para medir y evaluar las particularidades existentes entre aquellos y los actores de mi proceso investigativo. Como aparejos, las encuestas, las entrevistas, la observación, los registros documentales y la prensa fueron las artes para identificar la percepción, la autopercepción y finalmente la mirada académica sobre los 
pescadores marítimos que ejecutan su oficio milenario en las riveras de Necochea y Quequén. 


\section{Capitulo 2.}

\section{Un puerto y dos ciudades}

\section{Introducción}

Los pescadores de Puerto Quequén realizan su actividad en un puerto que tiene una historia y características distintivas, donde la centralidad no está puesta en la actividad pesquera.

El objetivo de este capítulo es presentar a Puerto Quequén, su localización y rasgos característicos. Se hace énfasis en los aspectos generales que exceden a la actividad pesquera. Desde una perspectiva histórica y geográfico-socioespacial analizaremos la inserción del puerto en las dos ciudades -Quequén y Necochea- en las que está emplazado.

\subsection{Pensar el espacio: el puerto}

Dar cuenta de los pescadores de Puerto Quequén supone también pensarlos en un espacio, ya que todas las relaciones sociales y económicas se inscriben en un territorio. En este caso, un territorio sumamente complejo como el que representa un puerto. Alicia Lindón llama la atención sobre lo frecuente que ha sido eludir la dimensión espacial de lo social "o en el mejor de los casos negarle relevancia bajo el supuesto -casi siempre implícitode que la espacialidad sólo da cuenta de una referencia empírica no problematizable" (Lindon, 2012). En nuestra consideración, el espacio ha sido durante todo el trayecto de investigación un referente transversal en las dimensiones de aproximación consideradas. Las nociones de espacio físico, social, económico y espacio subjetivo, con sus particularidades y marcos de referencia, anudan una trama de sentidos que pueden pensarse de modo transversal. En este sentido, al retomar el análisis del espacio simbólico de los pescadores podremos observar que, aunque pueda reconocerse una matriz general en el espacio simbólico de "ser pescador" esta cobra real significación en el ser pescador desde Puerto Quequén. Como analizaremos más adelante encontraremos una tensión para 
los sujetos entre el desarrollo de la actividad en el puerto local y la decisión de hacerlo desde otros puertos.

Específicamente en este capítulo en el que abordamos el espacio en su dimensión geográfica, partimos de considerar y explicitamos el presupuesto de que el modo en que se desenvuelven los fenómenos está enlazado también con el lugar donde ocurren. Así considerado, el espacio geográfico resulta de una específica configuración territorial y organización espacial (Donato Laborde, 2009) y no sólo de un escenario. Se hace necesario, sensu Cóccaro et al. (2002), interpretar las imbricaciones territoriales del espacio, el tiempo y las subjetividades como un texto dentro de un contexto.

Ciertas visiones de la Geografía de fines del siglo XIX y comienzos del siglo XX llevan a interpretar el territorio como un segmento de la superficie terrestre sobre la que se detenta un poder -estatal, asociado a este momento histórico particular- y por tanto como patrimonio de quién detente ese poder. Según Silveira (2008), ya desde principios del siglo XX empieza a considerarse también una perspectiva más amplia según la cual el territorio implica el conjunto de los elementos físicos sumados a los humanos; y por tanto además de ser espacios sobre los que se ejerce el poder, pueden ser pensados como espacios de diferenciación (Tobio, 2012). Con el reingreso académico del concepto de territorio a fines del siglo XX, el éste pasa a ser entendido como superficie terrestre utilizada por todos los actores y no sólo por el Estado Nacional. Sin embargo, el actor estatal resulta relevante para entenderlo ya que constituye el agente fundamental de transformación, difusión y dotación e intermediación entre los agentes externos e internos de un territorio (Santos, 2000).

Desde la perspectiva a la que adscribimos, pensar Puerto Quequén implica considerarlo como expresión de la espacialidad de lo social, por tanto, es un espacio historizado que oficia como producto y cómo condición para la producción, reproducción y transformación de las relaciones sociales. Específicamente podemos reconstruir cómo, a partir de las tensiones sociales por la apropiación de un territorio quedan marcas, de las cuales las infraestructuras mismas no son un hecho menor. Y desde esta postura, nos diferenciamos de otras definiciones clásicas qué limitan la definición de puerto a lo funcional, por ejemplo, considerándolo solamente como el conjunto de obras, instalaciones y servicios que proporcionan el espacio de aguas tranquilas necesarias para la estancia segura de los buques mientras se realizan las operaciones de carga, descarga y almacenaje de las mercancías y el tránsito de viajeros.

Según lo planteado por Domínguez Roca (2006) los puertos pueden entenderse como estructuras técnico-sociales localizadas, lo que implica dar cuenta de la interrelación de tres niveles: 
- uno corresponde al "físico" o "espacial" propiamente dicho (conjunto de elementos materiales en una localización determinada);

- un nivel "funcional" equivalente a lo que se realiza en ese espacio y que se expresa en flujos de materia y energía; y

- un nivel "social" conformado por el conjunto de las relaciones sociales, políticas, económicas, culturales que se establecen entre los actores vinculados a ese espacio o actividad.

Mientras que los dos primeros niveles pueden asimilarse a lo que Santos (2000) caracteriza como "fijos" y "flujos"; Yurkievich (2009) llama la atención que lo que está localizado es la base física sobre la que se define la estructura y no el conjunto de actores involucrados, y que más allá de la distancia forman parte de la estructura: los múltiples aspectos que al actuar en un territorio determinado y en un momento histórico configuran las especificidades que lo caracterizan.

Si pensamos la necesidad de despojar de esencialidad a la noción de espacio debemos poner a Puerto Quequén en una doble tensión/relación con lo local y lo global. Peyrelongue plantea que el puerto actúa como un espacio de frontera de vínculo entre lo interno y lo externo, entre lo local y lo global, contando además con peso en la reestructuración territorial. Se destaca el hecho de que los puertos tienen un rol privilegiado en la estructuración territorial y en la articulación espacio-temporal de redes que vinculan ámbitos territoriales diversos y distantes (Peyrelongue, 1999). Por tanto, "la potencialidad de un análisis con eje en un puerto aporta tanto al análisis histórico en un contexto local y regional como a una perspectiva amplia de la historia mundial. El puerto presenta una estructura compuesta por tres escenarios vinculados a su funcionamiento y ordenación funcional. El hinterland, o sea el territorio con el que se comunica un puerto como vía comercial y entendida como su área de influencia. El foreland, que representa el espacio marítimo del puerto hacia el exterior definido por las vías de comunicación generadas por los tráficos marítimos vigentes y potenciales. Estos se asocian al análisis global. Por su parte el tercer escenario denominado waterfront refiere a la escala local y constituye los espacios urbanos asociados a los frentes de aguas de las ciudades costeras portuarias (Eraso, 2009). Dos vertientes de estas perspectivas son especialmente relevantes: una de ellas atañe a la relación entre los puertos y entre los puertos y sus hinterlands y forelands. La otra se enfoca sobre las relaciones sociales y culturales entre los agentes sociales dentro de los puertos y de las ciudades portuarias", el waterfront (Mateo, 2014a). Al tiempo que los puertos representan un lugar clave por antonomasia del intercambio de mercancías, también ofrecen el marco de intersección entre culturas y 
personas. El puerto debe ser pensado y explicado como punto de ruptura: frontera geográfica, tecnológica y cultural. Y, como toda frontera, también tiene que ser entendido y pensado como lugar de encuentro, intersección de rutas comerciales, zona de confluencia de personas, ideas, valores, tecnologías, zona de intensa producción cultural. Rosaldo (2000) nos invita a repensar la coherencia y la homogeneidad que implican las normas antropológicas clásicas para revalorizar los estudios en las fronteras culturales en esos puntos de "invisibilidad cultural". En el mismo sentido, Mateo (2010) propone pensar las fronteras y los puertos, como activos lugares de producción cultural.

En este sentido, preferimos el uso de la noción de espacio que nos remite al espacio territorial pero interpretado como una instancia relacional, producto de complejas construcciones históricas en constante mutación (Tobio, 2012:27). Pensar el territorio como espacio geográfico, económico, político, social y cultural para ubicar la forma en que los actores sociales se ubican en el espacio social sensu Bourdieu (1990). Esta perspectiva nos permitirá, además, en otros momentos de este estudio ahondar en las dimensiones sociales y simbólicas dadas a la noción de espacio.

\subsection{Puerto Quequén: localización y características}

El Puerto Quequén (Figura 1) está localizado en la posición geográfica $38^{\circ} 33^{\prime} \mathrm{S}$ y $58^{\circ} 43^{\prime} \mathrm{O}$, sobre las riberas de las ciudades enfrentadas de Quequén, en la margen este, y Necochea, en la margen oeste, en la desembocadura del río Quequén Grande en el mar argentino. Actualmente depende administrativamente del Consorcio de Gestión del Puerto de Quequén, un ente público no Estatal creado en el año 1993 y en forma efectiva desde el 1 de marzo del año 1994, luego del traspaso de la órbita de la Nación a la Provincia de Buenos Aires. Por su parte, la seguridad está a cargo de la Prefectura Naval Argentina (PNA), apoyada por la Municipalidad de Necochea.

Este puerto se encuentra en una zona estratégica de la llanura templada argentina, y se ha constituido en uno de los principales puertos cerealeros de la Argentina. A sólo 1,5 $\mathrm{km}$ de la boca del puerto cuenta con una profundidad natural de 46 pies (15 metros), permitiendo el acceso de buques con calados de hasta 45 pies. Además, está localizado en un área de costa de la provincia de Buenos Aires donde se depositan escasos sedimentos, lo que facilita su operatividad, ya que sólo requiere de trabajos de dragado para su mantenimiento, sin embargo, estos tienen que ser recurrentes debido a que se realizaron sin claros estudios de las costas ni se tuvieron en cuenta problemas como la acumulación de arena o las corrientes marítimas, al momento de construirlo (González, 2013). En la zona se registran mareas semidiurnas mixtas, con un promedio de 1,02 m de amplitud de marea, 
y un máximo de 1,78 m (Isla et al., 2009). Puerto Quequén es el segundo puerto profundo de la zona pampeana, sólo superado por el puerto de Bahía Blanca. Sin embargo, posee una menor amplitud de cota de mareas que aquel, la que se incrementa en el litoral atlántico argentino al ascender en la latitud sur.

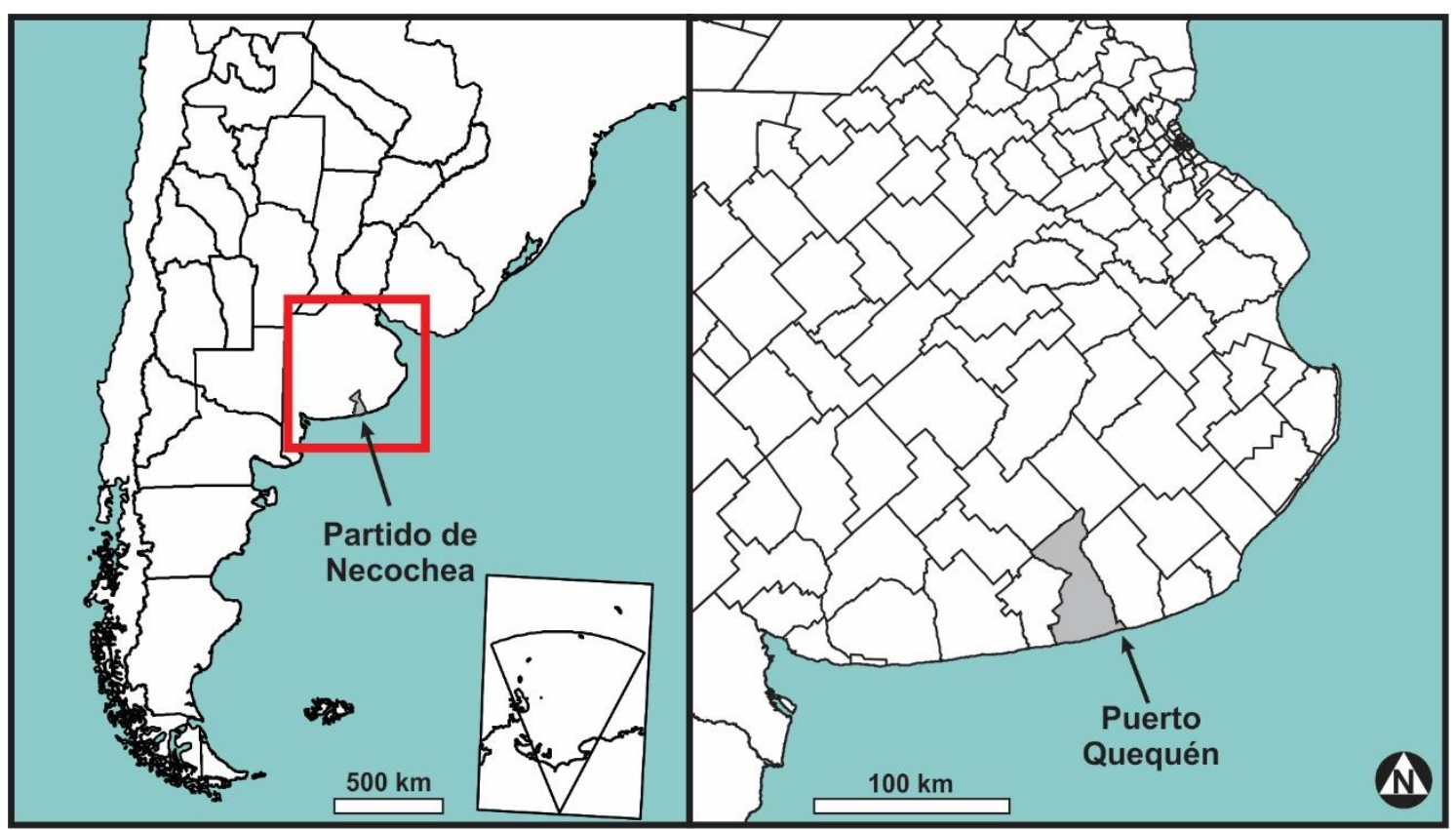

Figura 1. Ubicación de Necochea, Quequén y Puerto Quequén en relación con el país y la provincia de Buenos Aires.

Elaboración propia a partir de IGN12.

Se trata de un puerto natural de ultramar que se encuentra encerrado por dos importantes escolleras: la norte, también llamada a veces este, se encuentra en la margen Quequén del río homónimo; mientras que la escollera sur, u oeste, se halla en Necochea. El recinto portuario lo componen ambas márgenes de Puerto Quequén. Sobre la margen que da a la localidad de Quequén es donde se realiza el movimiento de mayor envergadura, como son los embarques vinculados con la actividad agroindustrial, además es donde se han emplazado las distintas terminales. Los Sitios 1 y 2 se emplean para el embarque de oleaginosos y subproductos; en el Sitio 3 se encuentran las instalaciones de embarques de las terminales privadas: Asociación de Cooperativas Argentinas (ACA) y la Federación Argentina de Cooperativas Agrarias (FACA) para el transporte de granos y subproductos; en los Sitios 4, 5 y 6 opera Terminal Quequén (concesionaria del elevador de la ex Junta Nacional de Granos) para embarque de granos aceites y subproductos, y es donde se desarrolla el mayor movimiento portuario. Mientras que en la margen de la ciudad de

12 http://www.ign.gob.ar/NuestrasActividades/InformacionGeoespacial/CapasSIG 
Necochea se desarrollan actividades de carga general, en especial vinculadas con la pesca y exportación de otros productos. En esta margen se hallan los Sitios 7, 8, 9 y 10, que están destinados a la exportación de rollizos de madera, pescado congelado e importación de fertilizantes; y los Sitios 11 y 12 son utilizados para cargas generales ${ }^{13}$. La última gran obra de infraestructura fue la incorporación hace pocos años del sitio 0 (concesionado a la empresa Sitio 0 de Quequén S.A.) también para el embarque de cereales y oleaginosas (Figura 2).

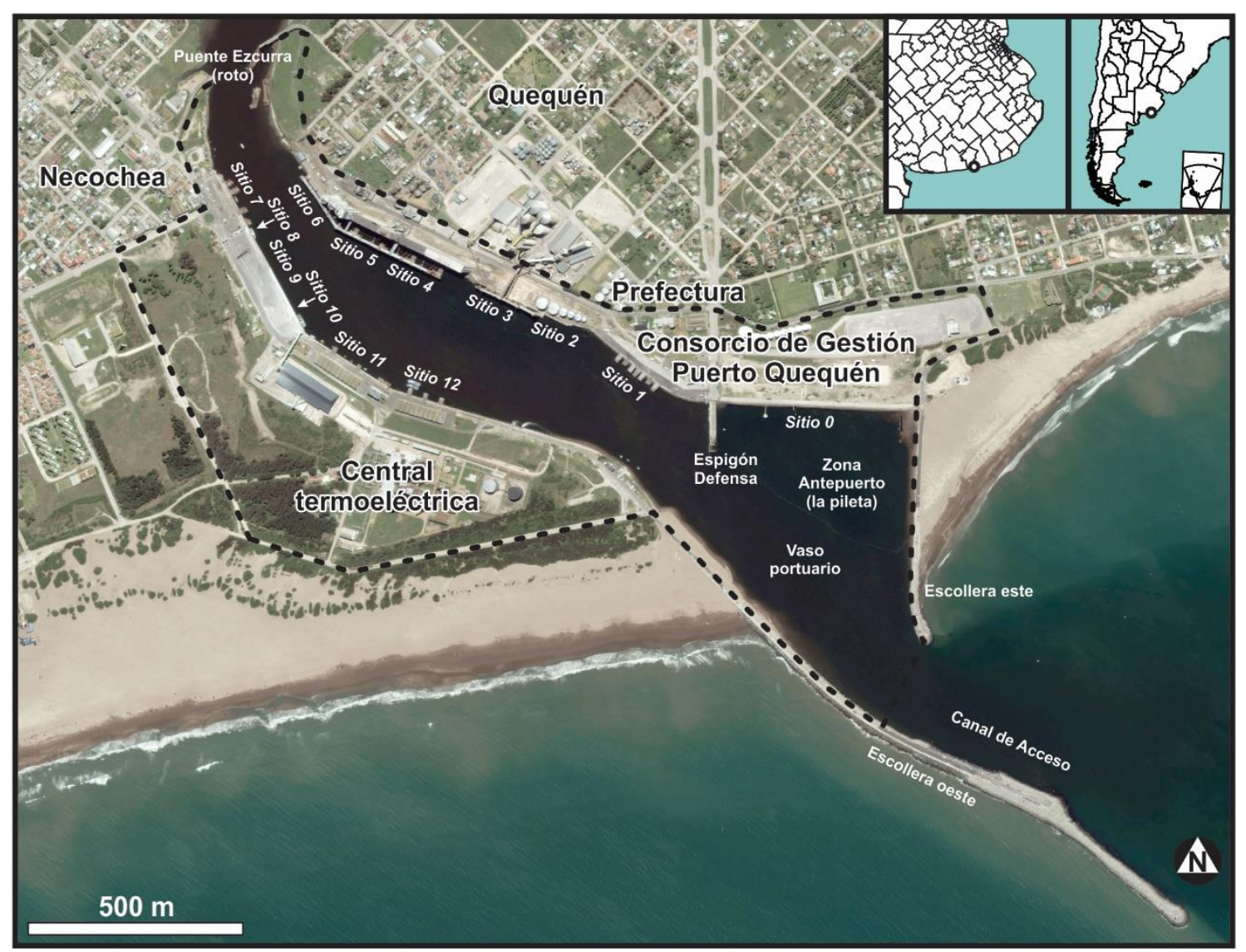

Figura 2. Imagen satelital de la zona de Puerto Quequén, con la ubicación de los distintos Sitios. Elaboración propia a partir de Google Maps y Consorcio de Gestión de Puerto Quequén ${ }^{14}$.

Puerto Quequén se emplaza en una región de clima templado y húmedo, con precipitaciones en torno a los 800 o $900 \mathrm{~mm}$ anuales, distribuidos en todos los meses, aunque con mayor incidencia en época estival. La temperatura promedio a lo largo del año es de $14^{\circ} \mathrm{C}$, aunque con marcadas diferencias entre verano -cuando las temperaturas máximas pueden exceder los $40^{\circ} \mathrm{C}$, e inviernos fríos con mínimas que bajan del punto de

\footnotetext{
${ }^{13}$ Consorcio de Gestión de Puerto Quequén: https://www.puertoquequen.com/

${ }^{14}$ https://www.puertoquequen.com.
} 
congelación (Merlotto y Piccolo, 2009). En este sentido, al tratarse de una ciudad costera los inviernos tienden a ser más suaves que en el interior. Los vientos, que tienen un promedio en verano de $26 \mathrm{~km} / \mathrm{h}$, se caracterizan, como toda la costa bonaerense, por la gran variabilidad sinóptica con repentinos y frecuentes cambios del clima (García y Piccolo, 2006). Los temporales que afectan la zona son las sudestadas (vientos del sudeste y este) y el Pampero (vientos del oeste y sudoeste), los cuales constituyen episodios de fuertes vientos (estigma que carga la villa balnearia) y frecuentemente se manifiestan acompañados por precipitaciones.

\subsection{El río que une y separa: Necochea y Quequén}

Las primeras referencias históricas de la zona de la desembocadura del río Quequén corresponden al jesuita español José Cardiel, quien tenía una formación como naturalista y cartógrafo y que recorrió la región en el año 1748 (Martínez Martín, 1994). A este río le dio inicialmente el nombre de San José, aunque en el tiempo ha quedado la denominación araucana Kem Kem que significan "barrancas altas” (Mateo y Rispoli, 2015).

El río Quequén Grande hidrográficamente forma parte del Sistema de Cuencas de Arroyos del Sur de Buenos Aires, que se caracterizan por ser cursos con sentido norte-sur que tienen nacientes en las sierras bonaerenses. El Quequén Grande es uno de los ríos más importantes del sur de Buenos Aires, originándose en las Sierras de Tandilia, y presenta un régimen permanente y discurre de forma meandriforme. Tiene un caudal medio de $36 \mathrm{~m}^{3} / \mathrm{s}$, con un mayor caudal en los meses de verano (Teruggi et al., 2005; Isla et al., 2009). Tiene una extensión aproximada de entre 150 y $180 \mathrm{~km}$ entre sus nacientes y la desembocadura en el Puerto Quequén (Quiroz Londoño et al., 2013). Su cuenca, que es asimétrica dado que recibe afluentes principalmente por su ribera izquierda, es de casi $10.000 \mathrm{~km}^{2}$, dentro de la cual comprende varios arroyos tributarios, como Pescado Castigado, Quelacintá, Quequén Chico, Calaveras, El Chancho y Tamangueyú. En épocas de lluvias intensas en su cuenca, el río Quequén Grande puede sufrir crecidas extraordinarias que hacen crecer enormemente su caudal. También puede aumentar su volumen en la desembocadura -y generar inundaciones- por efectos de los vientos constantes y prolongados de las sudestadas (provenientes de los cuadrantes este y sudeste) que impiden que el agua del río fluya normalmente hacia el mar.

A ambas orillas de la desembocadura del Quequén se erigen las ciudades de Necochea y Quequén (Figura 3). El INDEC se refiere a ellas como aglomerado ${ }^{15}$ Necochea-

15 Según la definición del INDEC se entiende por aglomerado urbano a las localidades que atraviesan los límites de provincias, departamentos o partidos, o áreas de gobierno local y que forman áreas 
Quequén. Estas localidades sólo hace 40 años que integran formalmente el mismo partido, aunque en las últimas décadas Quequén lucha por su autonomía ${ }^{16}$. En función de la circulación de personas, estructura social, económica y continuidad geográfica interrumpida por el río, las dos ciudades conforman un núcleo urbano único. La mayoría de las grandes ciudades costeras deben su desarrollo a los puertos junto a las que están situadas. También suelen deber su existencia sus principales conflictos ambientales a la pérdida de valor inmobiliario en áreas aledañas al puerto y a la erosión costera debida al dragado (Núñez Sánchez, 2013).

El aglomerado Necochea-Quequén posee una estructura productiva en la que se destaca el sector agropecuario, y en menor proporción la construcción, el sector comercial, los servicios de transporte y la industria manufacturera. En este contexto el sector pesquero aporta, a nivel local junto con los servicios de transporte y la industria manufacturera el $34 \%$ del PBG del partido. Si bien el partido produce $0,7 \%$ del PBG provincial, la pesca aporta el 6,5\% del producto provincial del sector y del Interior, siendo el tercer mayor aporte entre los partidos de la región. Por otra parte, los servicios de trasporte ocupan el quinto lugar entre dichos partidos aportando el 2,5\% del producto del sector (Dirección Provincial de Estadística 2004).

En cuanto a la historia del conglomerado Necochea-Quequén, la localidad de Quequén, perteneció al partido de Lobería hasta que el 2 de mayo de 1979, por Decreto Ley 9327 del gobierno militar en funciones y refrendada por el gobernador de la provincia de Buenos Aires Ibérico Saint Jean, pasó a conformar -junto con el balneario Costa Bonita ubicado a $5 \mathrm{~km}$ al noreste- el partido de Necochea. En un comunicado oficial, el gobierno bonaerense destacaba que "los argumentos de esta medida se centran en el hecho de que Quequén, por su quehacer industrial, comercial, de servicios, actividades portuarias, etc. está más ligada que separada por el río Quequén a Necochea", así como que "la importancia del puerto de Quequén hace indispensable una revitalización y un reordenamiento de la ciudad hoy deprimida en su potencial desarrollo", siendo esta medida de "interés superior de la Provincia y por ende, de la Nación"17.

\footnotetext{
urbanas que pueden abarcar total o parcialmente a dos o más de estas últimas. De esta forma, los aglomerados reúnen dos o más componentes que pueden ser localidades, barrios u otro tipo de agrupamiento poblacional según cada caso en particular (INDEC 2019).

${ }^{16}$ Por ejemplo, “Avance para la autonomía de Quequén", La Nación, 13 de junio de 2011

17 "En 1979 se unen dos ciudades", Ecos Diarios, 3 de agosto de 2003.
} 


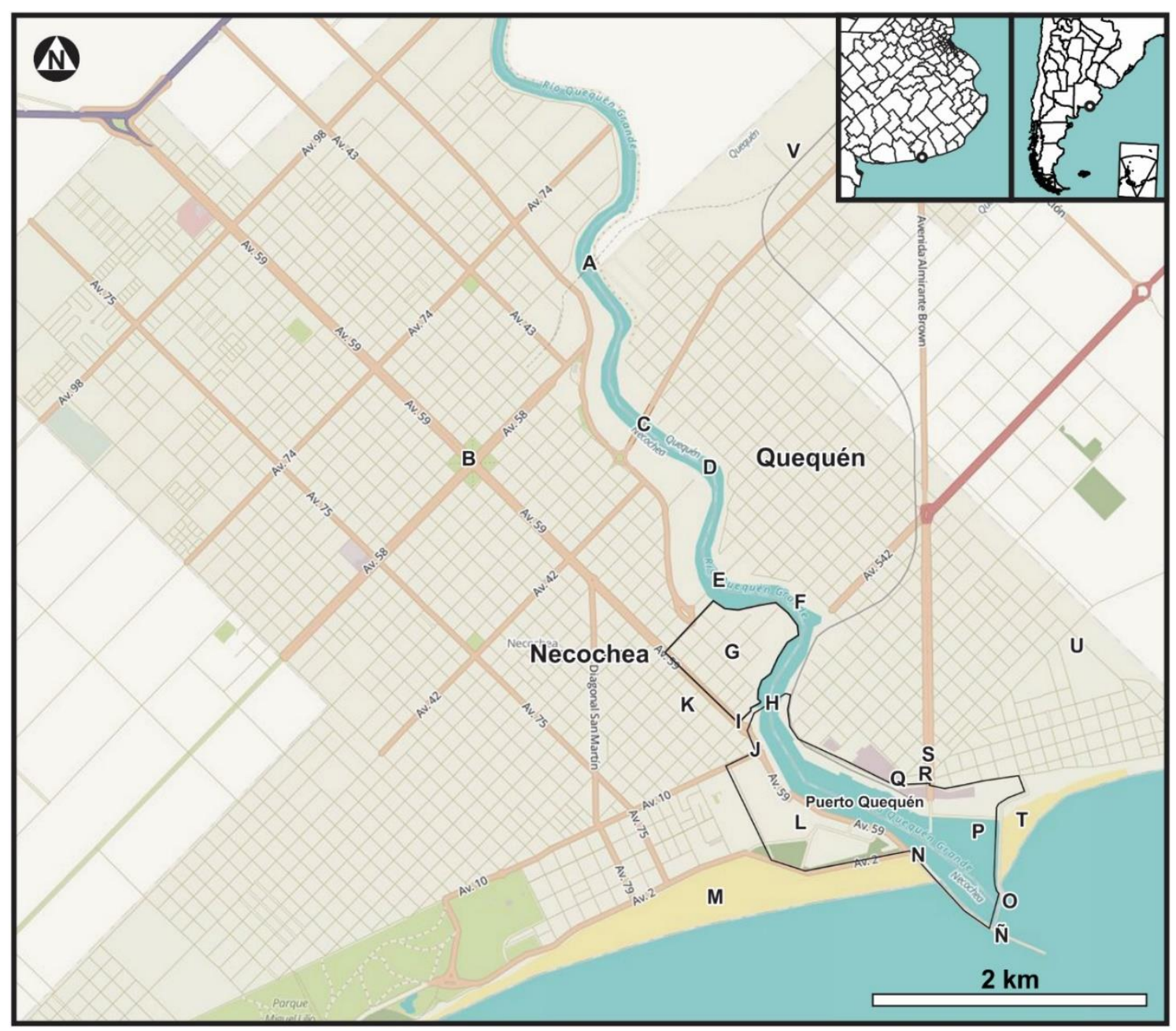

Figura 3. Ubicación de referentes geográficos y lugares mencionados en el capítulo.

Elaboración propia a partir de OpenStreetMap ${ }^{18}$. Referencias: A = puente ferroviario de 1896, destruido en 1980; $\mathrm{B}=$ centro histórico de Necochea; $\mathrm{C}=$ Puente Colgante Hipólito Yrigoyen; $\mathrm{D}=$ placa conmemorativa del primer embarque de productos de la zona en 1870; E = puente Dardo Rocha; F = Astillero Vanoli; G = barrio del puerto; H = Puente Ignacio Ezcurra, destruido en 1980; I = monumento al pescador; $\mathrm{J}=$ monumento a la familia del pescador; $\mathrm{K}=$ Parroquia Nuestra Señora de la Medalla Milagrosa; $\mathrm{L}=$ Central Termoeléctrica de la Costa Necochea; $\mathrm{M}=$ playas de Necochea; $\mathrm{N}$ = colonia de lobos marinos de un pelo; $\tilde{\mathrm{N}}$ = escollera sur; $\mathrm{O}=$ escollera norte; $\mathrm{P}=$ la pileta (vaso de acceso a Puerto Quequén); Q = Prefectura Naval Argentina; R = Estación Hidrobiológica de Puerto

Quequén; $\mathrm{S}$ = Monumento Gesta de Malvinas; T = playas de Quequén; U = Faro Quequén; $\mathrm{V}=$ Antigua estación Quequén de ferrocarril.

El partido de Lobería fue creado en el año 1839, pero no contó con ciudad cabecera hasta 1866, cuando el gobierno de Buenos Aires fundó la ciudad del mismo nombre, ubicada a aproximadamente $45 \mathrm{~km}$ de la costa. A mediados del siglo XIX, más específicamente el 3 de agosto de 1854, surge un pedido de fundación de un pueblo entre la costa del mar y la desembocadura del río Quequén. Esto es, varias décadas antes de que surgiera la localidad de Necochea. Esta fecha es la que, desde el año 1995 se reconoce en Quequén como la primera fundación, sin embargo, recién en 1889 fue cuando se levantó el pueblo en las

18 https: //www.openstreetmap.org/ 
tierras de la desembocadura del río. La crisis económica de 1890 y la quiebra de la Sociedad Anónima "Ciudad de Quequén" que impulso la fundación, motivaron que el crecimiento fuera escaso y caótico en sus inicios. La llegada del ferrocarril en 1892 pudo aportar una mejora a su situación.

La economía estuvo siempre íntimamente relacionada con el puerto y las actividades allí desarrolladas o las subsidiarias. En sus inicios, la exportación de la producción agro ganadera de parte del sudeste bonaerense constituyó el impulso inicial para el puerto y para la región circundante y de influencia -el hinterland de Puerto Quequén (Mateo 2014a). Este logró crecer y consolidarse a pesar de los avatares, como la crisis del año 1929 y depresión de la década siguiente (Mateo 2014b). Posteriormente, también la industria alimentaria asociada a la pesca llegó a tener notoria relevancia, como más adelante trataremos. El turismo también ofrece una fuente económica marcadamente estacional. Actualmente la industria del acopio y acondicionamiento de cereales y oleaginosas son fuente laboral, siendo representativa la presencia de empresas como Cargill, Nidera, Ponal.

Al mismo tiempo que se fundaba la ciudad de Lobería se creó el partido de Necochea, a pesar de que allí ya se encontraban viviendo varios estancieros -entre ellos, Eustoquio Díaz Vélez, un destacado militar que participó en las Invasiones Inglesas, la Revolución de Mayo y la guerra de independencia- que se habían establecido en las cercanías del río Quequén hacia la década de 1820. La ciudad de Necochea fue oficialmente fundada el 12 de octubre de 1881 por Ángel Ignacio Murga, junto con las gestiones realizadas por Victorio de la Canal. Esta se localiza sobre la margen derecha de la desembocadura del río Quequén Grande, prevaleciendo el criterio de los estancieros que pedían por una ciudad con puerto, por sobre el de los que deseaban una ciudad mediterránea. Como muchas de las ciudades fundadas en la provincia de Buenos Aires durante la década de 1880, Necochea fue planificada en su diseño urbanístico y para ser la cabecera del partido homónimo. En el año 1894 quedó unida a la red ferroviaria que existía en ese momento. Posteriormente, a medida que las vías de ferrocarril se extendían por el territorio, se fueron fundando otras localidades en el partido de Necochea, como Claraz, Ramón Santamarina, Nicanor Olivera y Juan N. Fernández (Figura 4). 


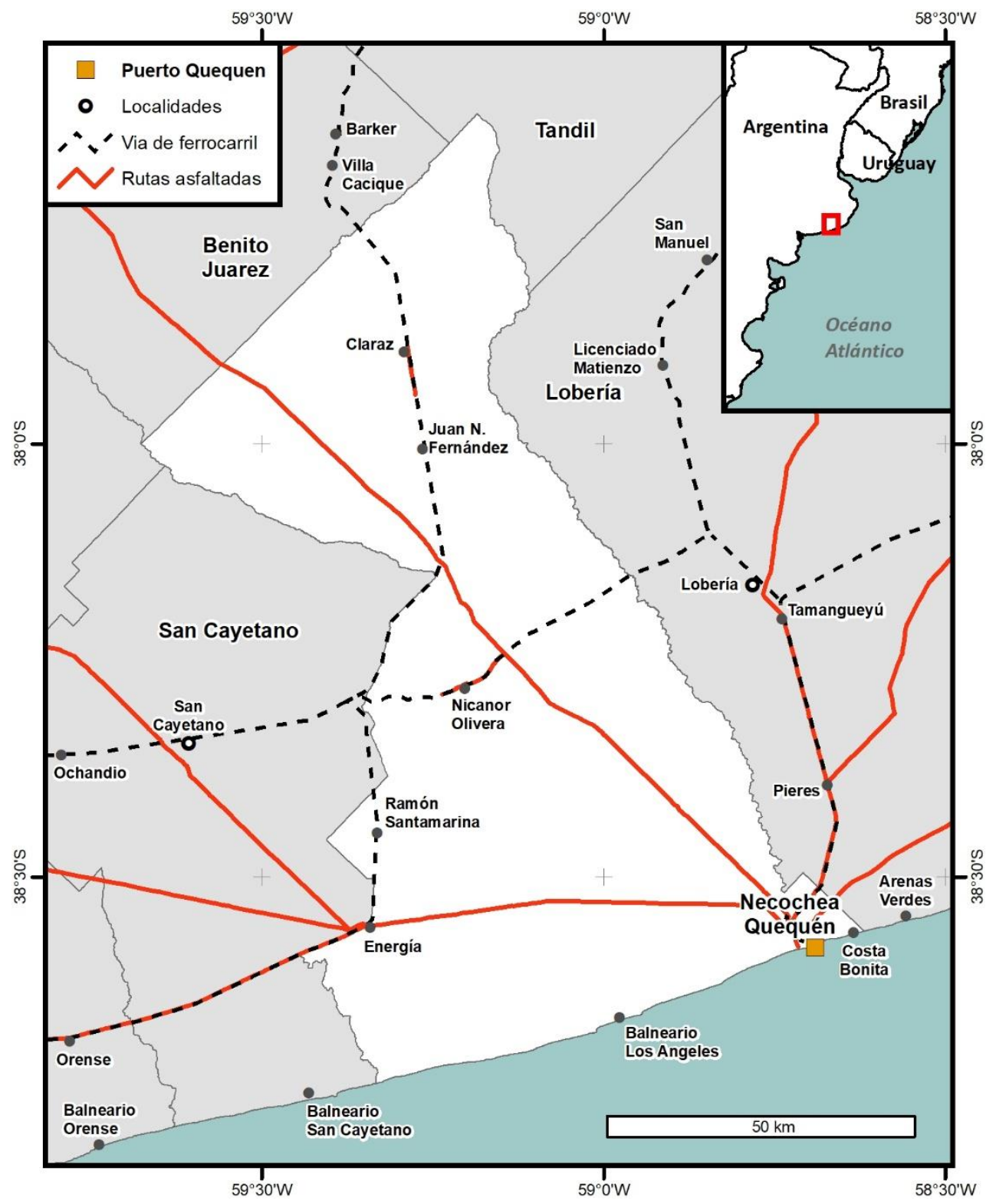

Figura 4. Partido de Necochea, se observa la posición del aglomerado Necochea-Quequén en relación al resto del partido y las restantes localidades que lo componen. Elaboración propia a partir de IGN ${ }^{19}$.

En cuanto a la conectividad entre ambas ciudades, estas se encontraban unidas por el puente ferroviario desde el año 1894, cuando el tren llegó a Necochea. Este puente fue cerrado al paso de trenes en el año 1968 y se cayó producto de la crecida del río Quequén por las intensas lluvias que ocurrieron durante el mes de abril de 1980 (Figura 5).

${ }^{19}$ http://www.ign.gob.ar/NuestrasActividades/InformacionGeoespacial/CapasSIG 


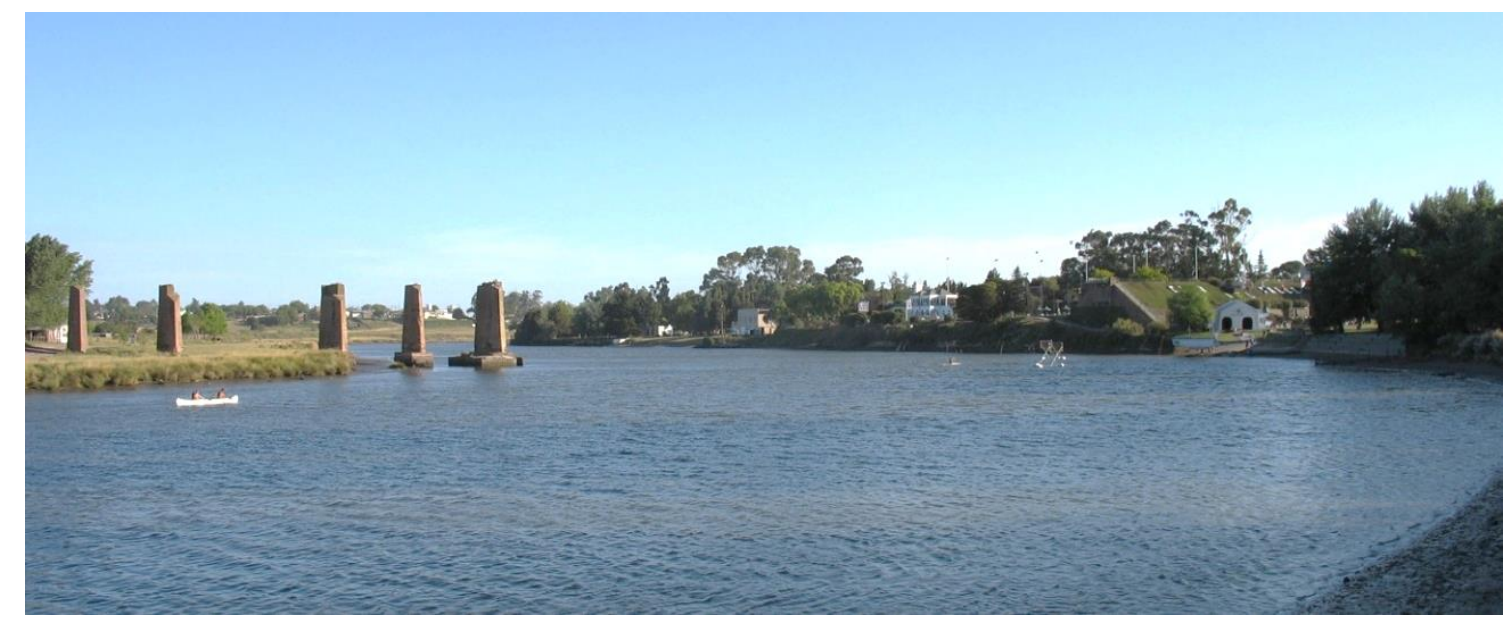

Figura 5. Pilotes y restos del puente ferroviario que unía ambas márgenes del río Quequén que se destruyó en el año 1980.

(Foto enero 2007).

A comienzo del siglo XX ambas márgenes del río Quequén estaban unidas por un sistema de balsas, aunque estaban sujetas a ser destruidas por las recurrentes inundaciones, como en los años 1914 y 1925²0. También existieron varios puentes que unían a las incipientes ciudades de Necochea y Quequén, tanto para el paso de vehículos como de ferrocarriles, algunos de ellos construidos durante las obras del Puerto Quequén. De estos, algunos fueron destruidos o sufrieron daños estructurales por inundaciones, como en 1915, pero principalmente en el año 1980.

En el año 1924 se hizo un primer puente carretero a partir de la utilización de la estructura de otro puente ferroviario temporario de las obras de la construcción de las escolleras del Puerto Quequén y que había sido desvinculado en 1922. Ya durante la década de 1940, cuando este puente comenzó a quedar obsoleto, se decidió sustituirlo por otro más moderno. Luego de numerosas gestiones que se sucedieron durante varias décadas y gobiernos, las obras comenzaron en 1969 con posterioridad a que se destruyera en una inundación uno anterior. Finalmente se inauguró en el año 1972 el "Puente Ignacio Ezcurra", denominándolo en homenaje a un periodista argentino fallecido el 22 de mayo de 1968 mientras cubría la Guerra de Vietnam. Lamentablemente, este puente tuvo corta vida, ya que se cayó durante la gran crecida del río Quequén en 1980 y no volvió a ser reconstruido 21 (Figura 6).

20 "Cuando las dos orillas se unían en balsa”, Ecos Diarios, 8 de julio de 2007.

${ }^{21}$ Hoy en día existe un movimiento fuerte para la reconstrucción de este puente, impulsado en gran medida por el Consorcio de Gestión del Puerto Quequén (ver, por ejemplo, Ferreiro, 2018). 


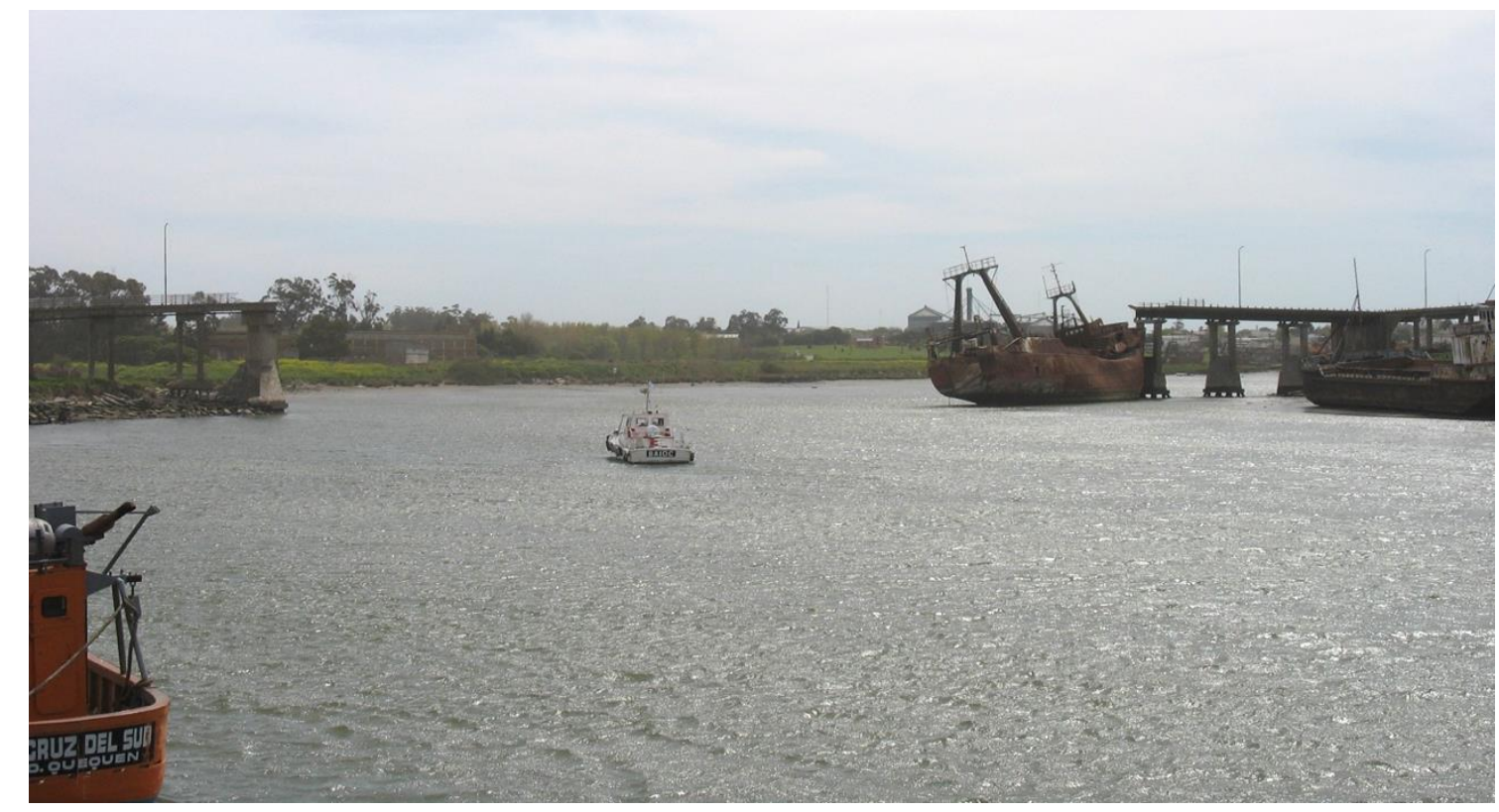

Figura 6. Vista de los restos del Puente carretero Ignacio Ezcurra.

A la izquierda se observa el barco Ribera Gallega parcialmente hundido contra uno de los pilares del antiguo puente (foto enero de 2006).

A fines de la década de 1920 se erigió el puente colgante Hipólito Yrigoyen, que fue inaugurado el 21 de julio de 1929 y que, con una extensión de 270 m de largo -y un vano central de 150 m de luz- une ambas orillas del río Quequén. El mismo fue construido en Francia y transportado en partes hasta el Puerto Quequén, desde donde eran llevadas hasta la obra por embarcaciones menores. En su momento sólo existían pocos puentes de su tipo en el mundo, lo que constituyó todo un logro y orgullo para la localidad (Natali, 2014).

El último puente carretero construido entre Necochea y Quequén ${ }^{22}$ fue inaugurado en diciembre de 1980, cuyas obras se iniciaron apenas el cauce del río Quequén volvió a la normalidad después de la creciente excepcional de abril de dicho año. El objetivo del mismo fue aliviar la congestión y el cuello de botella vehicular. Se lo denominó “Puente Dardo Rocha" -en honor al gobernador de la provincia de Buenos Aires al momento de la fundación de Necochea- y que, si bien fue construido luego de la inundación como provisorio para restablecer el vínculo entre Necochea y Quequén, debido a problemas de gestión estatal, existe hasta el día de hoy (Ferreiro, 2018).

Como hemos visto, prácticamente desde los inicios de ambas localidades han existido múltiples y fuertes vínculos -balsas, puentes temporarios y permanentes- que han unido a las ciudades, aunque con distintos avatares, ejemplificados principalmente por la

22 En este repaso histórico de los puentes que unen a las ciudades dejamos de lado al puente Domingo José Taraborelli -nombre dado en el año 2000, antes llamado Pedro Eugenio Aramburu-, dado que se encuentra marginado de los núcleos urbanos Necochea y Quequén y es utilizado principalmente para el transporte de carga pesada y tránsito vehicular que no ingresa en las mencionadas localidades. 
destrucción de varios puentes producto de inundaciones, aunque igualmente no pudieron cortar los fuertes lazos entre las comunidades.

\subsection{Población y evolución demográfica de Necochea Quequén}

Desde la fundación de las ciudades de Necochea y Quequén, estas no han cesado de crecer, en especial hasta la década de 1980, momento en el cual se desacelera la tasa de crecimiento, adquiriendo valores bajos desde entonces (Tabla 1). Podemos inferir que durante la primera etapa tuvo un fuerte impulso poblacional procedente de inmigración, tanto interna como de extranjeros- y que en las últimas décadas presenta mayormente un crecimiento vegetativo. Durante la mayor parte del siglo XX, Necochea fue adquiriendo un rol de importancia en el sudeste de la provincia de Buenos Aires, posicionándose como la segunda ciudad costera al principio por delante y luego por detrás de Mar del Plata.

Tabla 1. Evolución demográfica del Partido de Necochea según los censos nacionales.

Fuente: Población de la provincia de Buenos Aires registrada en los Censos Nacionales y en el Censo Provincial de 1881, por partido según sexo (http://www.ec.gba.gov.ar/Estadistica/Poblacion por sexo Censos1869-2010.xls)

\begin{tabular}{|c|c|c|c|c|c|c|c|c|c|c|c|}
\hline Año & $\mathbf{1 8 6 9}$ & $\mathbf{1 8 8 1}$ & $\mathbf{1 8 9 5}$ & $\mathbf{1 9 1 4}$ & $\mathbf{1 9 4 7}$ & $\mathbf{1 9 6 0}$ & $\mathbf{1 9 7 0}$ & $\mathbf{1 9 8 0}$ & $\mathbf{1 9 9 1}$ & $\mathbf{2 0 0 1}$ & $\mathbf{2 0 1 0}$ \\
\hline Población & 1.129 & 3.361 & 10.057 & 21.292 & 49.449 & $43.500^{23}$ & 51.145 & $73.634^{24}$ & 85.581 & 89.096 & 92.933 \\
\hline
\end{tabular}

Según la información aportada por los censos nacionales, en el año 2001, último del periodo considerado dentro de esta tesis (1975-2001), el partido de Necochea contaba con 89.096 habitantes, de los cuales 64.459 residían en la ciudad de Necochea, 14.524 en Quequén y 9.113 en las otras localidades del partido o en la zona rural. Sin embargo, vemos como la mayoría de la población del partido $(89,7 \%)$ vive en el aglomerado NecocheaQuequén.

Si analizamos los cambios demográficos ocurridos entre los censos 1970 y 2001, observamos que la diferencia poblacional en las tres décadas consignadas es de 25.591 habitantes para Necochea, lo que representa un 39,1\% más. Por su parte Quequén aumentó su población en 5.225, que en términos porcentuales presenta un valor levemente menor

\footnotetext{
${ }^{23}$ En el año 1958 se produce la creación del partido de San Cayetano mediante ley provincial 5921 con tierras de los partidos de Necochea, así como también de Adolfo Gonzales Chaves y Tres Arroyos, lo que produce un descenso en la cantidad de habitantes en el partido de Necochea entre los censos 1947 y 1960 (https://normas.gba.gob.ar/ar-b/ley/1958/5921/9342).

${ }^{24}$ Un año antes se produce la incorporación de la ciudad de Quequén al partido de Necochea, por lo que en el aumento de población ocurrido entre los censos 1970 y 1980 se le debe sumar el de dicha localidad. En el caso del partido de Lobería se observa un descenso poblacional de 28.466 habitantes en 1970 a 17.475 en 1980 como producto de este cambio.
} 
$(35,9 \%)$. Por lo que podemos observar que el crecimiento fue equitativo a ambas márgenes del río, como se observa en la Tabla 2, ya que ambas localidades presentan valores de representación porcentual muy similares dentro del aglomerado Necochea-Quequén. Como ya dijimos, las tasas de crecimiento poblacional natural o vegetativo (apenas superior al 4\%) desde la década de 1980 - son inferiores a las que tuvo en décadas anteriores (ver Tabla 1).

Tabla 2. Datos demográficos del conglomerado Necochea-Quequén entre los censos nacionales 1970-2001.

(http://www.ec.gba.gov.ar/Estadistica/Poblacion por sexo Censos1869-2010.xls)

\begin{tabular}{|l|c|c|c|c|c|}
\hline \multicolumn{1}{|c|}{ Referencia } & $\mathbf{1 9 7 0}$ & $\mathbf{1 9 8 0}$ & $\mathbf{1 9 9 1}$ & $\mathbf{2 0 0 1}$ & $\begin{array}{c}\text { Diferencia entre } \\
\text { 2001 y 1970 }\end{array}$ \\
\hline Necochea & 39.868 & 51.069 & 59.151 & 65.459 & $25.591(39,1 \%)$ \\
\hline \% aglomerado N-Q & $81,09 \%$ & $81,26 \%$ & $80,72 \%$ & $81,84 \%$ & - \\
\hline Quequén & 9.299 & 11.774 & 14.125 & 14.524 & $5.225(36 \%)$ \\
\hline \% aglomerado N-Q & $18,91 \%$ & $18,74 \%$ & $19,28 \%$ & $18,16 \%$ & - \\
\hline Aglomerado N-Q & 49.167 & 62.843 & 73.276 & 79.983 & $30.816(38,5 \%)$ \\
\hline Partido de Necochea & $\begin{array}{c}51.145 \\
(96,1 \%)\end{array}$ & $\begin{array}{c}73.634 \\
(85,3 \%)\end{array}$ & $\begin{array}{c}85.581 \\
(85,6 \%)\end{array}$ & $\begin{array}{c}89.096 \\
(89,8 \%)\end{array}$ & $37.951(42,6 \%)$ \\
\hline
\end{tabular}

Por su parte, si analizamos el peso relativo del aglomerado Necochea-Quequén en relación con la población total de la provincia de Buenos Aires (Tabla 3), observamos que el mismo presenta valores relativamente homogéneos a lo largo de las tres décadas, con un leve pico en la década de 1980 (Figura 7).

Sin duda, a partir de la observación de la evolución de la población en los censos para el período analizado (1975-2001) se desprende que la escala de la ciudad cabecera del Partido, y del núcleo urbano que conforma con Quequén -el aglomerado NecocheaQuequén- se inscriben dentro de una escala que corresponde a una ciudad media o intermedia, al menos ya desde la década de 1970. Las ciudades de rango medio desde las definiciones formales suelen clasificarse, como expresan Gravano y colaboradores (2016) como aquellas que entre 50.000 habitantes y menos de un millón de habitantes, que no son capitales de provincia, y que permiten contraponerse con lo metropolitano y lo rural. Estos autores analizan la clasificación numérica para problematizar los imaginarios en las ciudades de este rango, al tiempo que destacan la vacancia de producción y problematización teórica sobre estas ciudades. En este sentido, resulta interesante pensar cómo el interés por dar cuenta de la especificidad de los pescadores de Necochea-Quequén nos dio la oportunidad de pensarlos en el marco de su inscripción en un núcleo urbano de este rango. 
Tabla 3. Comparación del peso relativo del conglomerado Necochea-Quequén en la provincia de Buenos Aires entre los censos nacionales 1970-2001. (http://www.ec.gba.gov.ar/Estadistica/Poblacion por sexo Censos1869-2010.xls)

\begin{tabular}{|l|c|c|c|c|}
\hline \multicolumn{1}{|c|}{ Censo } & $\mathbf{1 9 7 0}$ & $\mathbf{1 9 8 0}$ & $\mathbf{1 9 9 1}$ & $\mathbf{2 0 0 1}$ \\
\hline Población Buenos Aires & 8.774 .529 & 9.766 .030 & 12.594 .974 & 13.827 .203 \\
\hline Pob. aglomerado N-Q & 49.167 & 62.843 & 73.276 & 79.983 \\
\hline \% Necochea-Quequén & $0,56 \%$ & $0,64 \%$ & $0,58 \%$ & $0,58 \%$ \\
\hline
\end{tabular}

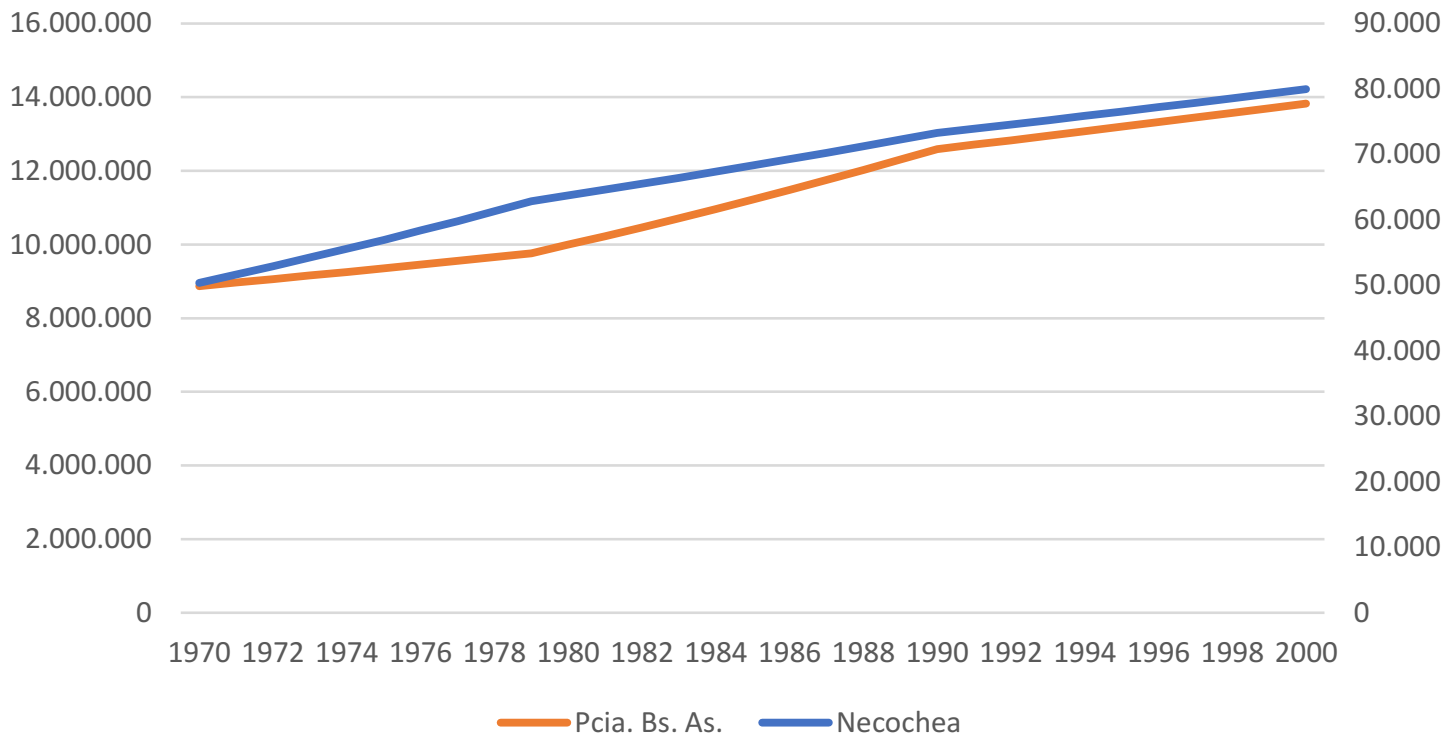

Figura 7. Crecimiento proyectado de Necochea (eje principal) y provincia de Buenos Aires (eje secundario) entre los años 197 y 2001.

(http://www.ec.gba.gov.ar/Estadistica/Poblacion por sexo Censos1869-2010.xls)

En las ciudades costeras, que además basan su economía en la actividad portuaria, las funciones urbanas y portuarias están en permanente tensión por los usos del suelo y la competencia que se genera por el uso de la franja costera, el nivel de polaridad y centralidad que adquiere la ciudad y los conflictos ambientales y sociales generados por el puerto (Núñez Sánchez, 2013). Para Necochea-Quequén, Merlotto et al. (2012) consideran que la distribución de los usos del suelo urbano observados en el año 1967 aún reflejaba una ocupación ligada a las actividades agropecuaria y balnearia (casco, villa, puerto) y al desarrollo de las vías de comunicación y medios de transporte ya que la dualidad económica de la aglomeración se plasmó fuertemente en el desarrollo urbano en el pasado. Sin embargo, la promoción en favor del desarrollo del turismo desde la segunda década del siglo XX y sobre todo en la segunda mitad de este (Pastoriza, 2008), permitió que la ciudad se constituyera en un destacado centro turístico a nivel nacional, atenuándose las diferencias urbanas entre el centro y la villa (Merlotto et al., 2012). Por su parte la ocupación urbana de Quequén está mayormente vinculada con el puerto y a las actividades industriales 
derivadas, las cuales también se reflejaron en la expansión y densificación del núcleo urbano en torno al puerto y las vías de comunicación de este con las rutas que conectan con otras localidades (Merlotto et al. 2012).

Siguiendo lo planteado por Núñez Sánchez (2013) -quienes compararon el crecimiento de la ciudad con patrones típicos de ciudades pampeanas, turístico-costeras y portuarias- al considerar las fundaciones y el desarrollo de ambas ciudades puede sostenerse que el núcleo urbano Necochea-Quequén se consolidó como una ciudad mixta, compleja, fluctuando entre períodos de ciudad portuaria, períodos de ciudad pampeana e intentos de convertirse en ciudad costera turística. Por tanto, el núcleo urbano no responde a una sola lógica de crecimiento, ni el puerto tiene en la configuración urbana y de comunidad al de otros puertos, como es el caso que plantea Mateo sobre la fundación y la consolidación de la comunidad portuaria de Mar del Plata (2004a).

Las principales actividades económicas de núcleo urbano de Necochea-Quequén están relacionadas con el sector agropecuario (con énfasis en la actividad cerealera y en menor medida pecuaria) en relación con la exportación portuaria de las mismas. En este sentido, el Puerto Quequén es parte fundamental para la exportación de la producción agropecuaria no solo del partido de Necochea, sino de toda la zona de influencia de dicho puerto, el denominado hinterland (Figura 8), que abarca aproximadamente los partidos de Azul, Balcarce, Benito Juárez, General Alvarado, General Pueyrredón, González Chávez, Lobería, Necochea, San Cayetano, Tandil y Tres Arroyos (Mateo, 2017). De esta forma, el aglomerado Necochea/Quequén es la terminal portuaria del hinterland agrario del sudeste bonaerense, al que suma por su calado el top off (completado de carga) de los embarques iniciados en los puertos fluviales de la zona núcleo (de Rosario a La Plata) (Mateo, 2017).

Por su parte, en Necochea la actividad industrial es escasa. El sector comercial y de servicios se correlacionan con el de una localidad de mediana escala. El turismo es otra de las actividades significativas, y presenta un carácter marcadamente estacional. Los circuitos de uso del espacio marcan en la ciudad un triángulo en el cual el Puerto queda excluido para quienes no viven o trabajan en la zona. Esta situación resulta levemente revertida en el verano, entre los meses de enero y febrero principalmente, cuando ocurre el auge del turismo de playa que convirtió a Necochea en uno de los principales centros turísticos, especialmente durante las décadas de 1970 y 1980, decayendo como tal posteriormente (Testa, 2017), siendo relegado por otras localidades y zonas ubicadas en el Partido de la Costa, al norte de Mar del Plata. 


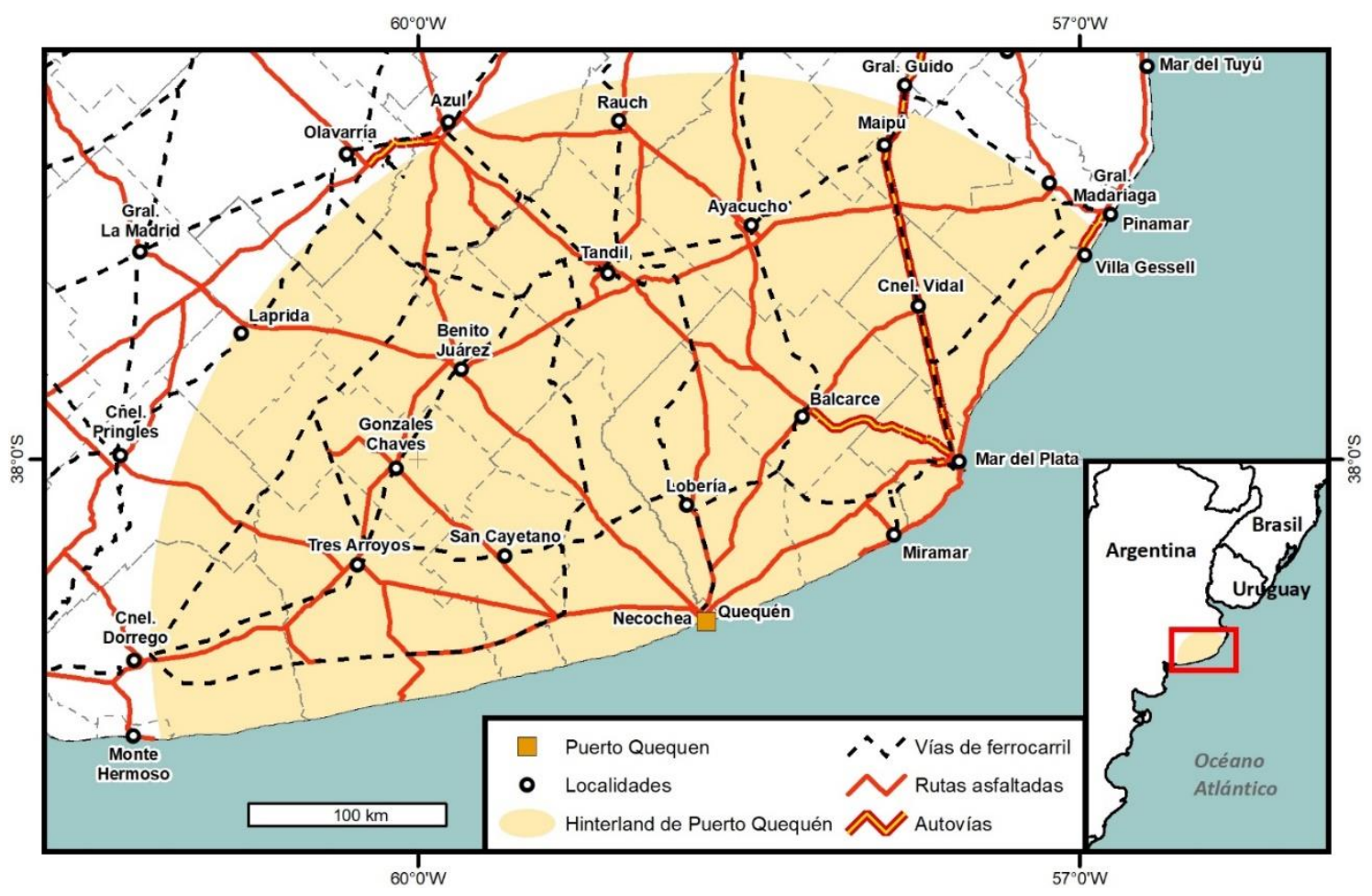

Figura 8. Hinterland de Puerto Quequén. Elaboración propia a partir de Mateo (2014a).

Este circuito estacional, que tiene un marcado correlato geográfico en la circulación de personas (tanto locales como turistas venidos de otros lugares del país) en el espacio con la distinción de zonas "playa" y "centro" (véase en la Figura 3 la distancia que separa a ambos lugares y cómo se desarrolló la ciudad para "llenar estos espacios") reserva en la época estival un lugar a la zona Puerto, que es incorporada al circuito turístico de forma marginal. Por ejemplo, el trencito "El Charito" en su recorrido turístico lo incluyó durante generaciones entre los puntos del paseo, mostrándolo como un atractivo más de la ciudad, en la temporada estival las empresas de colectivos urbanas incorporan recorridos que unen los trayectos.

Es interesante resaltar que, a pesar de la relevancia como puerto cerealero -uno de los más importantes del país, que cuenta con una notoria infraestructura que destaca en el horizonte y el paisaje local-, la típica postal turística, de Puerto Quequén pone en primer plano a las pequeñas lanchas amarillas amarradas en la banquina de la margen Necochea (Figura 9), constituyendo además un clásico paseo de las tardecitas veraniegas el ver regresar las lanchas y la descarga de pescado. También solía haber en la banquina -sobre todo en la época estival- un puesto de venta de caracoles y artesanías de recuerdos (luego 
del cierre portuario ${ }^{25}$ se emplazará en la entrada al puerto). Acompañan a los barcos de pesca costera algunas lanchas dedicadas a la pesca deportiva de embarcado. Al típico paseo por la banquina de los pescadores y la escollera sur, cercana a la llamada playa de Los Patos, se suman en los últimos años las actividades de pesca deportiva en ambas escolleras y la de pesca de embarcado, que sin ser masivas cuentan con sus adeptos. El paseo de la banquina de los pescadores que se continuaba hasta la escollera sur se interrumpió con el cierre de la zona portuaria.

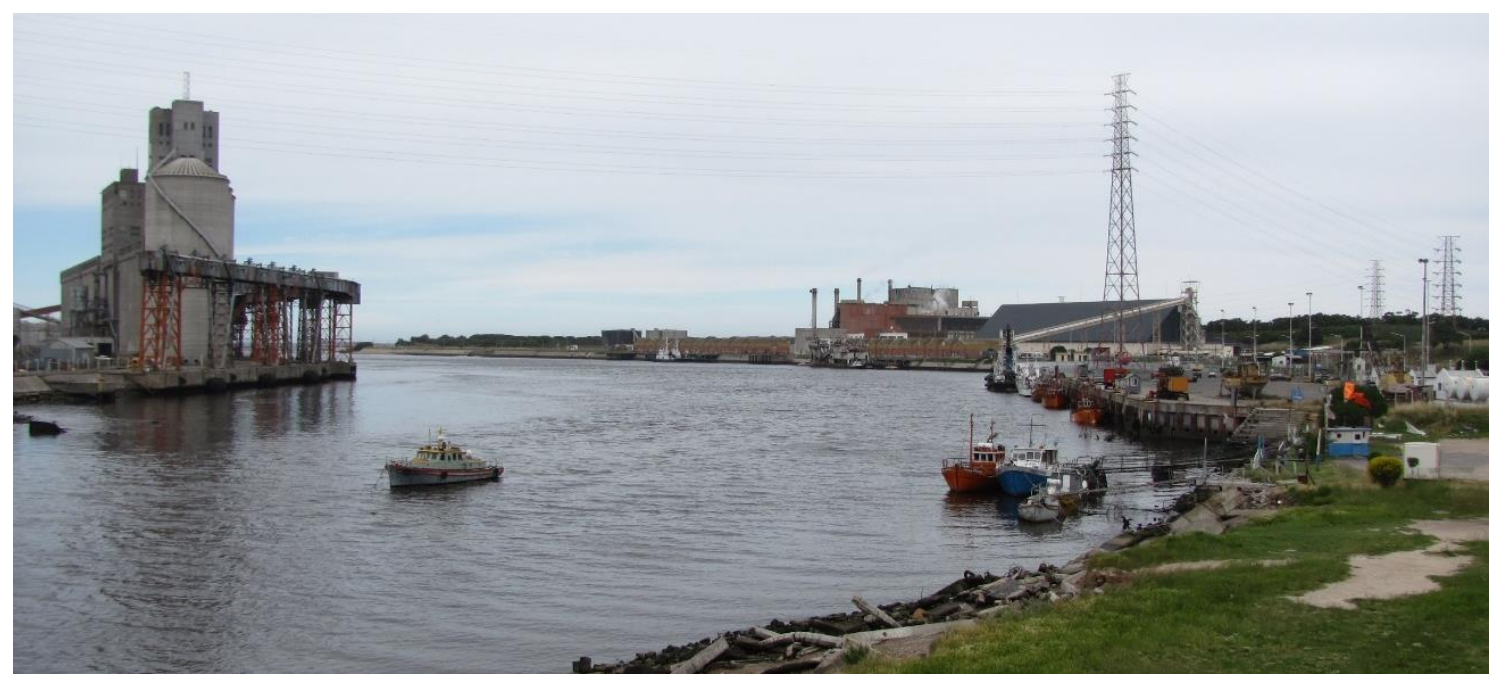

Figura 9. Vista de Puerto Quequén hacia el mar.

A la izquierda se observa el complejo cerealero y a la derecha los Sitios 7, 8, 9, y 10, donde se ubica la banquina de los pescadores.

En las últimas décadas la colonia de lobos marinos asentada en la margen sur de la escollera sur en Puerto Quequén creció considerablemente constituyéndose en otra postal característica y, también en fuente de tensiones. Se trata de una colonia de lobos marinos de un pelo (Otaria flavescens), habitada exclusivamente por machos que se desplazan continuamente entre esta colonia y la asentada en el puerto de la ciudad de Mar del Plata (Giardino et al., 2009).

El puerto y las escolleras también son lugares propicios para la circulación turística y de pesca recreativa. Se puede acceder casi al extremo de las mismas para observar el mar, la entrada y salida de embarcaciones, la salida o puesta del sol (que en verano ocurren ambas sobre el mar). La escollera sur delinea el puerto en la margen Necochea, en su inicio y en continuidad con la llamada Playa de los Patos. Se integra en un circuito de paseo que integra las zonas playa y puerto bordeando la zona de médanos.

25 Producto de cambios en las normativas de seguridad en espacios portuarios luego de los ataques terroristas a las Torres Gemelas de Nueva York el 11 de septiembre de 2001. Más adelante se explica con mayor detalle estos cambios y algunas de sus consecuencias. 
Aledaño a este camino se emplaza la Central Termoeléctrica Necochea. Una de las emblemáticas lanchas amarillas de casco de madera (construida en el siglo XIX) y desde hace unos años fuera de circulación, El Tordillo, se suma al paseo de la rotonda portuaria que vincula las avenidas 10 y 59.

Frente a la escollera sur, la norte delinea el puerto en la margen Quequén. A ella se accede desde las avenidas 502, 521 y Almirante Brown, esta última rodea en parte el puerto. La escollera norte enmarca un espacio denominado localmente como "la pileta", zona de gran profundidad luego de ser dragada y que cuenta con varios barcos encallados que ha sumado algunas víctimas fatales en su uso como zona de nado por ser de aguas tranquilas, a pesar de estar prohibido su uso recreativo.

Entre los lugares significativos que se destacan en la zona portuaria margen Quequén está la Estación Hidrobiológica de Puerto Quequén (EHPQ) dependiente del Museo Argentino de Ciencias Naturales "Bernardino Rivadavia" de Buenos Aires. El mismo funciona en una antigua casona de madera de origen europeo. En 15 febrero de 1938 Ecos Diarios publicó un artículo sobre la inauguración del Museo de la Estación Hidrobiológica de Quequén. En el mismo se explicaba que la casa donde se asentaba la Estación Hidrobiológica había sido traída desde Holanda por la misma empresa que construyó el Puerto de Quequén unos años antes. Al retirarse dicha empresa de Necochea, la casa fue abandonada y fue adquirida por la Inspección General de Puertos en el año 1926 con el objetivo de demolerla. Sin embargo, oportunamente fue cedida al Museo Argentino de Ciencias Naturales "Bernardino Rivadavia" en 1928. En esos años, dicha institución era dirigida por el biólogo Martín Doello Jurado, y tenía entre sus planes instalar una estación hidrobiológica en la costa bonaerense para realizar estudios sistemáticos de los moluscos y peces que existen en la costa bonaerense (Fermepin y Villemur, 2004). La ubicación de Puerto Quequén hacía de éste un punto estratégico para la instalación de la Estación, ya que permitía al personal del museo desarrollar investigaciones sobre la fauna marina de un importante sector costero. Es de destacar que ésta fue la primera instalación de una estación hidrobiológica dedicada a la investigación de biología marina en toda América del Sur ${ }^{26}$. A la vez que constituye un polo en la investigación científica de las ciencias del mar y en la formación de recursos humanos, a nivel local tiene gran presencia en instalar temas marinos y portuarios en la comunidad, por medio de su Museo de Fauna Regional, al que concurren la población local, turistas y escuelas. Un aspecto interesante de este museo es que gran parte de las colecciones que lo conforman fueron creadas a partir de donaciones realizadas sobre todo por pescadores locales, mientras que el resto fue obtenido por

\footnotetext{
${ }^{26}$ Ecos Diarios, 27 de septiembre de 2009.
} 
personal del Museo y de la Estación Hidrobiológica a lo largo de más de 80 años desde su fundación.

El biólogo Enrique Balech (1912-2007), investigador del Museo Argentino de Ciencias Naturales "Bernardino Rivadavia”, se destacó como una personalidad en relación a este espacio desde dónde desarrolló su carrera profesional aportando conocimiento sobre las llamadas "mareas rojas"27. Director emérito de la institución, desde su retiro en 1982 continuó velando y manteniendo el Museo de Fauna Regional de la Estación Hidrobiológica de Puerto Quequén y de la histórica casa de madera. En la zona también está emplazada la Delegación Quequén de Prefectura Naval Argentina, los edificios de la Administración portuaria y la Aduana.

Sobre la margen Quequén del río, unos 800 m aguas arriba de Puerto Quequén, se encuentra emplazado el Astillero Vanoli, que fuera fundado en el año 1954 por Aníbal A. Vanoli, uno de los primeros técnicos navales del país. Este astillero, que se dedicó desde sus orígenes a la reparación y mantenimiento de distintos de embarcaciones, como mercantes, remolcadores y lanchas pesqueras, es reconocido por la calidad de sus trabajos dentro y fuera de la localidad, habiendo construido hasta el año 2005 más de 55 embarcaciones, muchos de ellos pesqueros para suplir la flota local.

Siguiendo el camino de sirga de la margen Quequén, a unos 3,5 km aguas arriba del actual puerto podemos encontrar una placa que conmemora el primer embarque de tasajo, cueros y lanas país procedente del saladero de Pedro Luro, el 4 de octubre de 1870. Para ello construyó un embarcadero con muros de mampostería, de los cuales aún quedan en pie algunos restos al pie de la barranca (Natali, 2014).

En síntesis, Necochea-Quequén constituyen actualmente la vía de salida de la producción agrícola de buena parte del sudeste bonaerense por medio de su terminal portuaria. Es a su vez, una ciudad con turismo, no turística, como la mayoría de la costa atlántica y con escasa o nula actividad industrial. Ante el escaso empleo que genera el campo y la actividad portuaria y, al tener un limitado desarrollo del turismo (mayor vía para incrementar la demanda laboral), ha sufrido los embates del desempleo producidos durante la oleada neoliberal iniciada con la última dictadura militar (Basualdo y Arceo, 2006). La actividad pesquera por su parte ha quedado subsumida o a ser una subsidiaria de la

\footnotetext{
${ }^{27}$ Se trata de la proliferación de una o distintas microalgas en cualquier cuerpo de agua en una zona determinada y que tiene un efecto nocivo en otro organismo. En la costa argentina, algunas especies de microalgas que generan potentes toxinas pueden ser consumidas por moluscos (bivalvos o gasterópodos) y acumularse en su carne, sin que afecten a los mismos. Cuando estas son consumidas por los humanos, no notan un cambio en el olor, color o sabor, pero pueden provocar una intoxicación que puede llegar a ser grave e incluso causar la muerte. No existen antídotos para este tipo de intoxicaciones (SENASA 2019).
} 
industria pesquera marplatense, o destinada al limitado mercado local que se incrementa algo en la temporada estival. Sus pescadores han debido optar entre la escasa actividad local, ser empleados en las flotas de altura en otros puertos (Mar del Plata, Puerto Madryn, Río Gallegos, Puerto Deseado, etc.) o a abandonar la actividad por otro tipo de empleo o iniciar algún trabajo autónomo. Incluso a combinar algunas de estas opciones.

\subsection{Mil intentos y un puerto: fundación y desarrollo de Puerto Quequén}

En su recorrido de 1774, con la primera mención histórica de la zona de la desembocadura del río Quequén, el jesuita José Cardiel remarca el potencial del área para establecer un puerto mercante.

Durante la segunda mitad del siglo XIX -y antes de la fundación de Necochea en 1881- se registran por parte de los ganaderos de la región de Lobería varios pedidos para la fundación de una ciudad puerto en la costa sobre la desembocadura del río, ya que les facilitaría sacar la producción de carne salada para enviar a los mercados esclavistas (Cuba, Estados Unidos y Brasil). Es así como en 1870 se realizaron los primeros embarques en un muelle construido por Pedro Luro ${ }^{28}$ dos kilómetros aguas arriba de la desembocadura del río (Mateo y Rispoli, 2015). Sin embargo, los pedidos no prosperaron y luego, con la abolición de la esclavitud y el cese de la demanda de carne salada consecuente, se produciría un cambio en el perfil productivo de la región. Se necesitaba de un lugar entre Bahía Blanca y Buenos Aires para dar salida al tasajo de varios saladeros que funcionaban en la región. En esos momentos la actividad productiva principal era la ganadería para la producción de tasajo, que era enviado a Cuba, el sur de Estados Unidos y Brasil, así como lanas a Bélgica (Sábato, 1989) y cueros a Hamburgo (Halperín Donghi, 1963). Mientras que, de regreso de Buenos Aires, las embarcaciones traían alambres, maderas y todo tipo de herramientas e incluso mobiliarios, y también por supuesto, pasajeros (Mateo y Rispoli, 2015).

Al tiempo que se cierra el mercado de la carne salada, en Europa se empieza a consolidar el proceso de industrialización dejando relegada la producción de granos y carne generando una expansión de la demanda mundial de alimentos. A esto se sumó las óptimas condiciones que representa la región pampeana para el desarrollo de estas actividades.

En términos generales, la fundación de los puertos en la región pampeana estuvo regida por el interés de colocar productos agropecuarios en el exterior por parte de los sectores dominantes terratenientes, al tiempo que se insertaba la economía del país en un

\footnotetext{
28 Terrateniente, colonizador y comerciante, tenía tierras y negocios en Quequén, conocido por ser uno de los impulsores de la fundación de Mar del Plata (Cova, 1966).
} 
sistema de división internacional del trabajo en el lugar de proveedora de materias primas y alimentos. Según Silvia Lázzaro (1992) “en nuestro país, a partir de la segunda mitad del siglo XIX, asistimos a la génesis de una economía fuertemente integrada al mercado mundial" y en este sentido, en la región pampeana la exportación de productos agropecuarios fueron los que motorizaron la construcción de los puertos de la región "ferrocarriles y puertos son los esenciales elementos de infraestructura que -en un país con las características del nuestro- requiere el comercio agropecuario de exportación".

Tal como sucede en muchos otros puertos del país, y como atentamente señala Lázzaro, la construcción de Puerto Quequén está ligada a la presencia de capital extranjero que privilegia las obras de infraestructura que sirven a las demandas del comercio exterior, y a su vez contribuyen a consolidar el proceso de acumulación capitalista por parte de los países centrales que exige la búsqueda de nuevas posibilidades de inversión.

En 1888, se instaló un muelle y un depósito para mercaderías en el lugar donde hoy en día se halla la banquina de pescadores en la margen de Necochea, lo que facilitó la carga y descarga de las embarcaciones que arribaban al Quequén. Poco después, en 1890 hay un intento de explotar con un puerto artificial la desembocadura del río Quequén con la conformación de la Sociedad Rural Puerto y Ciudad de Quequén, pero en esta ocasión lo único que se realizó fue el loteo de las tierras que hoy ocupa Puerto Quequén. Otro intento fallido ocurre en 1900 con la concesión dada al empresario Ángel Gardella quién propone transformar la desembocadura del río Quequén para eliminar la entrada dificultosa que representaba, en esta gestión se nombró oficialmente como Puerto Quequén. En 1905 estando las obras ya avanzadas, un temporal destruyó las instalaciones y en 1906 controvertidamente se canceló la concesión dada a Gardella. Otro factor para destacar en detrimento del puerto de Gardella es el papel jugado por Ferrocarril Sud y la presión ejercida sobre las tarifas para que las exportaciones continúen realizándose por el puerto de Bahía Blanca (Mateo y Rispoli, 2015).

La expansión agrícola presente en la región y ya distante del puerto de Bahía Blanca (Lázzaro, 1992) presiona sobre la necesidad de construir un puerto exportador en esta localización. Una ley nacional de 1908 autoriza al Poder Ejecutivo para contratar empresas particulares para construir el puerto en Quequén, y en 1910 se abren las propuestas para la construcción del puerto entre las que se acepta la de Societé Grand Trabaux de Marseille de capitales franceses. Los trabajos comienzan en 1911 y, aunque se prevé un plazo de ejecución de cinco años para el desarrollo del proyecto, debido a la Gran Guerra, recién en 1917 se terminan los trabajos y en 1921 -diez años después del inicio de la obra- la empresa termina el contrato, Al año siguiente la Dirección General de Navegación y Puertos inicia obras de ampliación por vía administrativa, sobre todo para profundizar el 
calado que es llevado a 23 pies (Lázzaro, 1992). Como obras relacionadas, en 1921 se comienza con la construcción del Faro de Quequén; en 1924 se inauguró un puente de madera que reemplazaría el servicio de balsas; se trazan casi todos los ramales ferroviarios (que sin embargo no estuvieron pensados para proveer de cereal al puerto) y en 1928 se inaugura la Estación Hidrobiológica de Puerto Quequén, y en 1929 se crea una Comisión Pro Ampliación de Puerto Quequén.

En 1922, el primer año de actividad el puerto despacha 16.845 toneladas de cereal cargando 85 buques $^{29}$. En adelante, los principales hitos y obras portuarias se refieren principalmente a su actividad como terminal exportadora mayormente de cereales. Entre estos hechos significativos se puede mencionar la inauguración de las obras del Elevador Terminal Ministro De Tomaso en 1945, que llegaría a su capacidad de almacenamiento planificada recién en 1962, la puesta en servicio del muelle corrido de 413 m de longitud en la margen Necochea en el año 1981, o el inicio de las exportaciones de madera de eucaliptos en 1988.

En cuanto a las vicisitudes en torno a la fallida construcción de Puerto Quequén con capitales privados, Mateo (2014a) llama la atención sobre lo onerosa que resulta la construcción y el mantenimiento activo de un puerto de ultramar por lo que sólo el Estado suele afrontarlo. En la provincia de Buenos Aires, en el período entre 1911 y 1921 el Estado se hizo cargo de dos puertos de ultramar distanciados en pocos kilómetros: Puerto Quequén y el puerto de Mar del Plata, generando cambios en los circuitos productivos y en la producción misma. Estos puertos configuraron trayectorias diferentes en torno a su actividad económica.

\subsection{Un puerto cerealero}

Si bien el puerto fue habilitado hacia 1922, demoró siete años más en reunir las condiciones para ser operable por embarcaciones de porte estándar del comercio de granos: como dijimos, la orientación productiva del hinterland del mismo. Sin embargo, en este lapso la producción fue conducida por embarcaciones menores (que la terminología portuaria denomina actualmente feeders) hacia otros puertos (Bahía Blanca, Mar del Plata y Buenos Aires), donde su carga fue reembarcada para su exportación. Desde la apertura de Puerto Quequén, este debió competir con aquellos que ya existían en la costa bonaerense y posicionarse como alternativa a los mismos como lugar para el embarque de la producción agrícola del interior. Parte de la competencia y desafíos que tuvo que enfrentar se

\footnotetext{
${ }^{29}$ Según registro de Prefectura Naval Argentina.
} 
relacionan con, por un lado, la oferta: las tarifas ferroviarias, la red de accesos terrestres, así como la logística operativa del puerto mismo, y el volumen y la tipología de la producción de su hinterland (entre ellos trigo, lino, avena y cebada); mientras que por el lado de la demanda: la capacidad de carga de la bodega de los barcos que podían atracar en el puerto, las operaciones de los grandes exportadores y las vicisitudes del mercado exterior (Mateo, 2014b).

En los primeros años de funcionamiento del puerto como exportador de ultramar se incrementaron los envíos, mayormente el envío de la producción hacia el puerto era realizado por "chatas" a caballo y por camión. Sin embargo, durante los primeros años el porcentaje de lo transportado por ferrocarril pasó de representar sólo un 1,2\% del total en 1925 a incrementar ese valor al 48\% en 1931. Según lo analizado por Mateo (2014a) en función de los barcos que operaron entre 1921 y 1932³0, el año 1929 representó un cambio en el perfil de Puerto Quequén, consolidándose como puerto exportador. Este punto es central en la configuración del puerto que define sus características. Junto con el de Bahía Blanca, Puerto Quequén es uno de los puertos más importante de exportación de cereales y oleaginosas, no sólo por el volumen que manejan sino porque en ellos se completa la carga de los buques graneleros. "El cereal con el que se completa la carga en Puerto Quequén proviene de su propio hinterland de unos 4.000.000 de hectáreas destinadas históricamente -luego de ser despobladas de sus habitantes originarios e incorporadas al Estado Nacionala la producción agraria. Este puerto adquiere entonces su importancia en el comercio exterior de cereales por dos razones: es uno de los dos puertos finales de exportación granelera y su hinterland sigue el compás de la demanda externa dominante" (Mateo, 2017). El puerto presenta en las últimas décadas volúmenes de exportación creciente (Figura 10), así como una mayor diversificación de productos despachados. Los cereales y las oleaginosas han sido el producto de mayor exportación. A partir de 1982 se destaca el lugar que adquieren los aceites, lino y girasol sucesivamente y hasta 1992, situación que cambia en 1993 con la relevancia que cobra el aceite de soja, acompañados por los pellets y expellers (subproductos de la soja). Con respecto a los cereales y oleaginosas el trigo tiene continuidad en la relevancia de las exportaciones para el período de interés, complementado con la avena, el maíz y el girasol. Fuera del período de interés el trigo fue desplazado por la soja. En 1998 se registró un récord histórico en la operatoria del puerto, con una movilización de 6 millones de toneladas de cereal en casi 300 buques $^{31}$.

\footnotetext{
${ }^{30}$ Sean de bandera nacional y moviéndose desde y hacia otro puerto argentino (de "cabotaje"); o si lo hicieron desde o hacia un puerto extranjero( "ultramar") aunque fueran de bandera nacional.

${ }^{31}$ Archivo Ecos Diarios.
} 


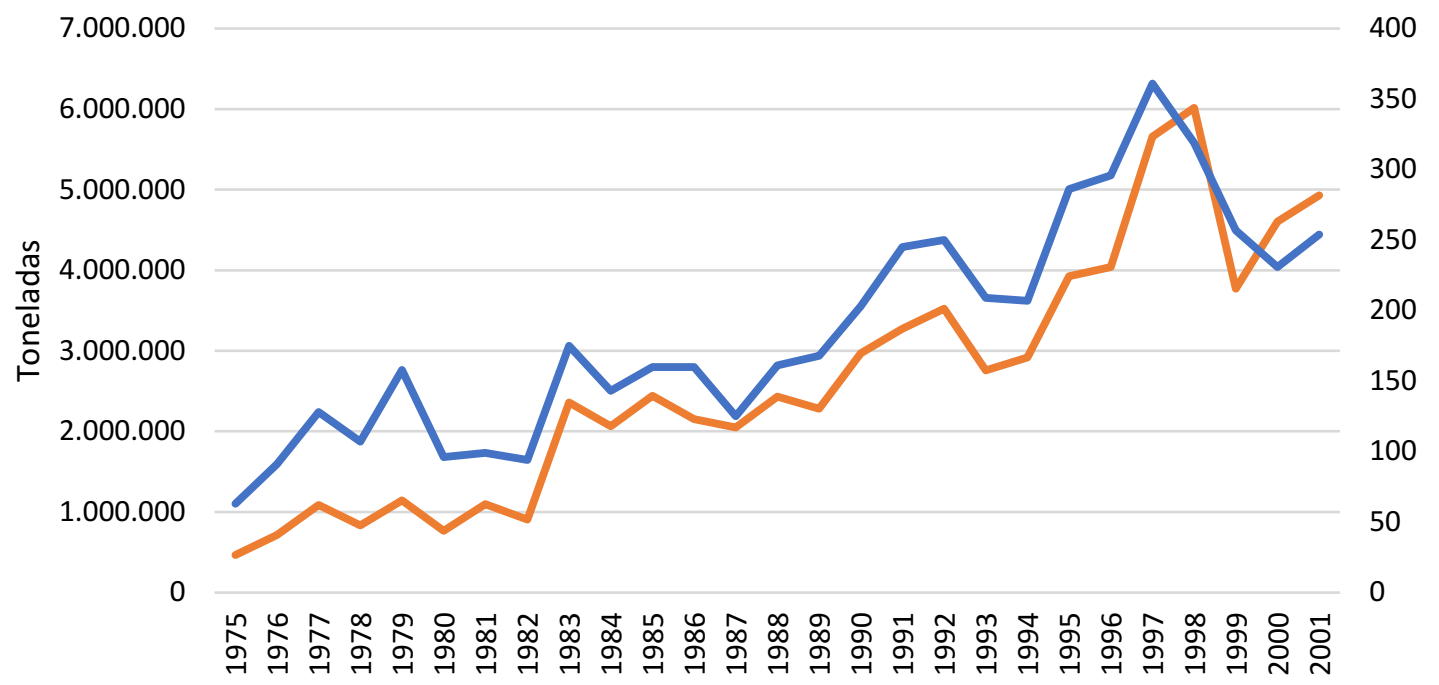

Volumen exportado Buques

Figura 10. Volúmenes exportados (eje principal) y embarcaciones giradas (eje secundario) en puerto Quequén (1975-2001).

Elaboración propia a partir de Fuente Prefectura Nacional y Aduana de Puerto Quequén.

\subsection{Impacto de la inundación de 1980}

Con lluvias que comenzaron el 20 de abril de 1980 se produjo un período de intensas precipitaciones en gran parte del territorio bonaerense. En ocho días cayeron en la zona unos 30.000 millones de toneladas de agua. El agua naturalmente se encauzó hacia el río buscando una salida al mar y la zona se anegó. A fines de ese mes, el río Quequén Grande comenzó a desbordarse y su curso se volvió incontrolable. Entre los numerosos daños que ocasionó se destaca la destrucción del Puente Ignacio Ezcurra en el puerto y el puente ferroviario que se hallaba inactivo desde el año 1968. La crónica del diario local repara que "la imparable correntada tuvo como inevitable etapa previa a su desembocadura en el Atlántico la zona del puerto, en la que produjo serios daños, socavando los añejos muelles y banquinas y cortando las amarras de más de una embarcación, que quedó a la deriva en el mar -al menos tres se hundieron y otras tantas encallaron-, obligando al trabajo a destajo de la Prefectura Naval Argentina y Defensa Civil”32. El avance del agua destruyó el puerto. La corriente, cargada de troncos, animales muertos, muebles y otros elementos, arrastró muelles y embarcaciones. El Caribea, conocido como el barco fantasma, fue arrastrado y quedó varado en cercanías de la Colonia Pinocho, en Quequén, el Pesquera III

\footnotetext{
32 Archivo Ecos Diarios.
} 
quedó frente a Bahía de los Vientos. En el antepuerto quedaron varados y con serios daños el Pesquera II, Santa Elena I, Santa Rosa, el buque costero San Cayetano II y el buque factoría Knossos. El buque de bandera griega Anna $C$, con su tripulación a bordo quedó varado en la escollera sur.

El impacto de la inundación tuvo sus consecuencias tanto en el inmediato como en el largo plazo, y dejó su marca más firme con la postal de Puente Ezcurra roto, una metáfora del quiebre del puerto y del río que separa. Las lógicas turísticas, portuarias y de sociabilidad en la zona del puerto quedaron truncas. Incluso en relación con las operaciones del puerto, dado que la distancia a recorrer entre ambas márgenes del Puerto de Quequén era de sólo dos kilómetros usando el puente Ezcurra, pero al usar el puente Dardo Rocha construido poco después para suplir la falta del Ezcurra y ubicado un kilómetro aguas arriba- la distancia aumenta a 4,7 km³ 3 . Las gestiones suscitadas para la reconstrucción de este resultaron infructuosas, poniendo en evidencia la escasa voluntad política de que la obra se concrete y la consolidación de un patrón disperso en torno a la figura de puerto.

\subsection{Entre lo local y lo global, impacto de la globalización y el neoliberalismo en Puerto Quequén (1975-2001)}

El período 1975-2001 está marcado por una serie de grandes procesos en el plano de la organización político-económica mundial y nacional que junto con las coyunturas locales implicaron cambios en la organización y operatoria de los puertos mundiales en general y del puerto local. En este sentido se destaca el rol que adquieren los puertos tanto en la reestructuración territorial vigente en el período como en la articulación espaciotemporal de redes que vinculan ámbitos territoriales diversos y distantes (Peyrelongue, 1999).

El domingo 12 de enero de 1975 Ecos Diarios publicó su editorial sobre Puerto Quequén. Inicia destacando la importante posición del puerto local en los envíos de cereal argentino al exterior el año anterior (aunque sin alcanzarse el máximo de otros años). Esta nota editorial tiene como objetivo preguntarse e instalar en la sociedad local la pregunta “¿Por qué no se hace un aprovechamiento completo de Puerto Quequén?” Planteando que "las exportaciones quedan limitadas a la exportación de granos y a esporádicas y reducidas importaciones de maderas". Destaca que la economía de la zona se vería beneficiada por la exportación de carne pero que no tuvo eco esa propuesta y que, en las ocasiones de intentar

\footnotetext{
33 Por ejemplo, para unir las playas de Necochea y Quequén hacía falta recorrer $4 \mathrm{~km}$ usando el Puente Ezcurra; actualmente y usando el Puente Dardo Rocha, esta distancia se incrementa a casi 7 $\mathrm{km}$.
} 
introducir otros productos, tropezó con la "dificultad de que debían comercializarse a través del puerto metropolitano" 34 .

El desarrollo del puerto debe ser puesto en juego tanto con sus propias particularidades, en un contexto local, como como con el resto de los puertos con los que establece una relación de tensión-competencia en la que son significativos los lugares de los puertos de Buenos Aires, Bahía Blanca y Mar del Plata y, también, desde la perspectiva de la historia y estructuración geográfica mundial. En este último plano, se destacan desde la década de 1950, fenómenos sucesivos como la aparición de los mega-graneleros, la containerización ${ }^{35}$ y el intermodalismo ${ }^{36}$ empezaron a cobrar relevancia y resultaron claves en la configuración de un "nuevo" paradigma portuario que revolucionaron el transporte de cargas del mundo (Broeze, 2002; Zuidwijk, 2001).

El período temporal considerado está marcado por una crisis y reestructuración capitalista de escala global. La disminución de la rentabilidad relativa del sector empresarial impulsó el desarrollo del llamado "consenso neoliberal", que mantuvo su predominio explicativo hasta principios de la década del 2000. Estos procesos configuran un escenario donde se (re)estructuran desigualdades (Williamson, 2004).

En este contexto, los flujos comerciales internacionales siguen siendo en su mayor parte marítimos, y los puertos constituyen un componente fundamental en el funcionamiento de la economía global. Pero las actividades de transporte, transbordo y almacenamiento se vuelven, cada vez más, operaciones que buscan maximizar la eficiencia. Retomando la metáfora de Marc Augé sobre los "no lugares", los puertos han tendido no sólo a una indiferenciación espacial entre ellos, sino también a una indiferenciación temporal dentro del puerto que los vuelve operativos las 24 hs del día los 365 días del año (sensu Dominguez Roca, 2006). El puerto de la globalización es un puerto de integración de redes, de movimientos rápidos que se diferencia del puerto lento del "proteccionismo" 37 . En el puerto de la globalización el tiempo revaloriza al espacio, le da contenido, forma y sustancia como lugar diferenciado que permite enlazar y, a la vez, marcar diferencias entre lo interno y lo externo (Peyrelongue, 1999).

\footnotetext{
34 “Puerto Quequén”, Ecos Diarios, 12 de enero de 1975.

35 Con el desarrollo y la implementación de los contenedores se dio un cambio significativo en el transporte y almacenaje de mercaderías en puerto. La optimización repercutió profundamente en la organización portuaria mundial.

${ }^{36}$ Se refiere al movimiento de mercancías en unidades cerradas, generalmente contenedores, en dos o más medios de transporte diferentes.

${ }^{37}$ En referencia a la doctrina político-económica que privilegia la producción nacional de una nación tomando medidas para protegerla de la competencia externa.
} 
Concomitantemente con el establecimiento y consolidación del nuevo régimen de acumulación capitalista desde mediados de los '70 se dio una profundización en la transnacionalización de la economía argentina. Desde las actividades portuarias podemos pensar qué lugar ocupa en esa estructuración nuestro país y particularmente Puerto Quequén. Se consolida y afianza el modelo agro-exportador tradicionalmente asumido por nuestro país, y a nivel ideológico desde las editoriales del diario, por ejemplo, se reforzó esa ubicación.

Tabla 4. Destino de las exportaciones de Puerto Quequén (1975-2001). Es interesante notar que China no pesaba en el foreland de Quequén. Brasil era el principal destino de las exportaciones y el trigo el principal producto. Fuente Mateo (2017).

\begin{tabular}{|l|c|c|}
\hline \multicolumn{1}{|c|}{ Destino } & Buques & \% \\
\hline África & 402 & 7,8 \\
\hline Aguas internacionales & 1 & 0,02 \\
\hline Argentina (otros puertos) & 872 & 17,0 \\
\hline Asia & 715 & 13,9 \\
\hline Centroamérica & 151 & 2,9 \\
\hline Encalló & 1 & 0,02 \\
\hline Europa & 921 & 17,9 \\
\hline Norteamérica & 93 & 1,8 \\
\hline Oceanía & 5 & 0,1 \\
\hline s/d & 32 & 0,6 \\
\hline Sudamérica & 1947 & 37,9 \\
\hline Total & $\mathbf{5 1 4 0}$ & - \\
\hline
\end{tabular}

En los años previos y en el inicio de nuestro período de interés (1975) las instalaciones portuarias no tuvieron grandes obras hasta las realizadas luego de las inundaciones de 1980. En mayo de 1972 se suspenden los trabajos de profundización del puerto, sin alcanzar el Canal de Acceso, dejando las siguientes profundidades al cero portuario: Vaso Portuario Anterior 12,20 m (40 pies) Ante Puerto 9,15 m (30 pies) Canal de Acceso 8,23 m (27 pies) Recién en 1992 se aprobó la obra de la Escollera sur, profundizándose todos los componentes portuarios. En el Vaso Portuario Anterior un calado operable de 12,20 m. En el Antepuerto un calado operable de 9,15 m y en el Canal de acceso un calado operable de $8,23 \mathrm{~m}$.

Sin embargo, a nivel institucional registramos uno de los cambios más significativos en la historia de Puerto Quequén. Las transformaciones que se produjeron a nivel internacional como nacional a partir de la reestructuración portuaria de la década de 1990 tuvieron su incidencia en los espacios litorales. La inquietud, planteada aquí y retomaremos más adelante tiene que ver con la incidencia de este cambio para el desarrollo de la pesca y el trabajo de los pescadores en Puerto Quequén. 
Acompañando los fenómenos de globalización económica y de redefinición del rol de los estados nacionales, la tendencia internacional ha sido la modernización de los puertos estatales privilegiando la acción del mercado como un ordenador eficaz de la actividad económica. Los procesos de privatización portuaria a nivel mundial se caracterizaron más por la introducción de la participación privada a través de contratos de concesión que por la venta total de activos. Los cambios en el desarrollo portuario tienen que ver también con la función que prestan para el comercio exterior.

Hasta la sanción de la Ley $\mathrm{N}^{\circ}$ 24.093/92 de Actividades Portuarias, Puerto Quequén era administrado y explotado por la Administración General de Puertos en su carácter de Empresa del Estado. En el marco de los ajustes estatales y de las transformaciones estructurales de la década de 1990 y, especialmente, en relación a los servicios de apoyo a la exportación, como transporte, puertos y vías navegables, se generaron cambios que implicaron el traspaso de los servicios y la infraestructura tradicionalmente de propiedad y administración estatal- hacia una modalidad que comprende la concesión y/o la venta de las instalaciones, servicios y vehículos, dando al sector privado la posibilidad de participar en su explotación. Esta ley contempló la creación de cinco puertos autónomos: tres fluviales (Buenos Aires, Rosario y Santa Fe) y dos marítimos, los de Bahía Blanca y Quequén.

Para alcanzar la autonomía, la Ley dispuso la transferencia de los puertos del Estado Nacional a las provincias en que se encontraban situados los mismos, previa constitución de sociedades de derecho privado o entes públicos no estatales que asumirían la administración y explotación de cada uno de los puertos. Los nuevos entes debían garantizar la participación de la provincia, el municipio, los trabajadores y los sectores privados interesados en el quehacer portuario, condición que para el caso de Quequén quedó consagrado mediante la sanción de la Ley $\mathrm{N}^{\circ} 11.414$ de la Provincia de Buenos Aires, por la que se creó el Consorcio de Gestión de Puerto Quequén. En enero de 1993 comenzó su operatoria Terminal Quequén S. A. (un consorcio empresario que resultó adjudicatario por 30 años del elevador portuario de la ex Junta Nacional de Granos). El 10 de marzo de 1994 la Nación transfiere al Estado bonaerense los inmuebles y muebles de Puerto Quequén, que inmediatamente son traspasados al flamante Consorcio de Gestión, integrado en su mayoría por la actividad privada, y reafirmando el proceso de transformación del sistema portuario argentino. El puerto pasó a ser administrado por dicho Consorcio, un ente de derecho público, no estatal, autofinanciado, cuyo objeto primario es administrar y explotar el Puerto manteniendo el destino comercial, la actividad portuaria específica y el uso público del mismo. En junio de 1997 comenzó a operar la planta de Terminal Fertilizantes S. A. que erigió la empresa Nidera en un terreno de $15.000 \mathrm{~m}^{2}$ próximo a la 
central Termoeléctrica de Eseba ${ }^{38}$. En 1998 se abre la convocatoria para la licitación internacional de la obra de la extensión de la escollera necochense, que será la obra de más envergadura en el final del período de interés.

Los análisis sobre el desarrollo de Puerto Quequén, luego de su privatización, en el contexto portuario mundial ponen de relevancia la importancia de la interdependencia y coordinación modal en la competitividad y desarrollo portuario; se ponen de relevancia la articulación con otros servicios vinculados, como ser el transporte terrestre o por ferrocarril. En este sentido, la localización y especialización productiva asociada a las ventajas comparativas estáticas a través de embarques de commodities sin diferenciación y en grandes volúmenes, debilita la posición de este puerto frente a otros ubicados en las rutas marítimas más dinámicas e integrados a las redes globales de producción y consumo (Costa et al., 2006).

Luego de la consorciación, se ponen en evidencia transformaciones tanto territoriales como en las representaciones del mismo. La reestructuración de Puerto Quequén en tanto un puerto autónomo de gestión público-privada implicó cambios en la apropiación del espacio del puerto, con una reducción y fragmentación de las prácticas espaciales en torno al puerto por parte de la comunidad local. El puerto fue cerrado en su perímetro para el año 1995. Además, el año 2001 también resulta un punto de inflexión de relevancia. Después del atentado a las Torres Gemelas en Estados Unidos, y ante el temor a nuevos atentados terroristas en espacios vitales de interconexión internacional, como son los puertos, hubo cambios en las regulaciones y usos de estos espacios regidos por nuevas normativas internacionales que afectó a las zonas portuarias. Durante generaciones el paseo por la zona del puerto, por la escollera, acercarse a ver el arribo de los barcos en las tardecitas cálidas fue una característica tanto de locales como de turistas. Estos hechos que se configuran hacia el final de nuestro período de estudio y se profundizan más adelante tendrá incidencias en cambios en las representaciones por parte de la población local, por ejemplo, la Asamblea Ciudadana Ambiental de Necochea y Quequén (ACANYQ) resulta un emergente de esta situación (Donato Laborde, 2009).

\subsection{Puerto Quequén en la trama: tierra, río, mar y mundo}

A partir de la década del 1980 hay un creciente interés por problematizar las ciudades en contextos globales (Sassen, 1998) en la que cada vez más se devela que hay una red de ciudades principales que funcionan como centros de coordinación y control para el

\footnotetext{
${ }^{38}$ Archivo de Ecos Diarios. El gran libro del milenio. 31 de diciembre de 1999.
} 
capital global. Estas ciudades son las grandes metrópolis o megalópolis que tienen características similares a pesar de los diferentes lugares tanto geográficos como estructurales en los que se emplazan. Desde esta perspectiva la escala les permite detentar ciertos rasgos comunes. A la par de estas ciudades que conllevan el foco del interés, otro rango de ciudades con otras funciones en lo local, regional y la integración internacional mantienen su rango. En este sentido resulta significativo pensar la ubicación del aglomerado Necochea-Quequén como de rango medio, con una escala de mediana que la diferencia de los poblados rurales y de los grandes conglomerados y a partir de allí pensar la particularidad que asume. La presencia del puerto marca un punto de integración más amplia no necesariamente experimentado por los habitantes.

A través de los puertos, de la especificidad que en un momento histórico asume su articulación con el territorio más cercano y con aquel territorio lejano del que es nexo podemos reconstruir el modelo de sociedad que ese puerto representa. Como bien sostiene Mateo (2010) los puertos son puertas a la historia y, por qué no, a la sociedad. Los puertos, sus actividades y fenómenos asociados constituyen un lugar privilegiado desde donde observar la integración de escalas territoriales en relación con fenómenos globales como a coyunturas locales. En este sentido, se han propuesto diversos modelos de relación puertociudad, destacamos entre ellos los de Bird (1963) y Laubé (2014) (Figura 11¡Error! No se encuentra el origen de la referencia. y Figura 12).

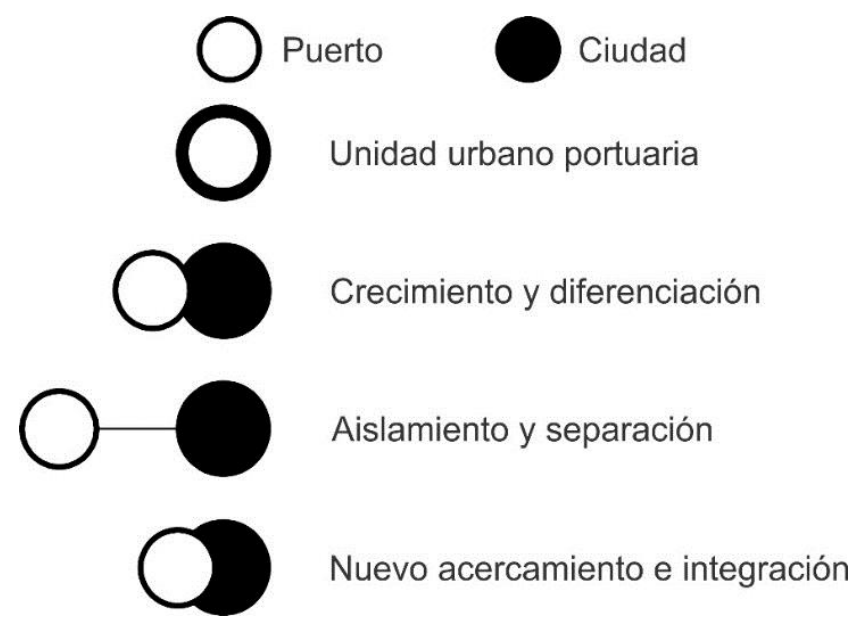

Figura 11. Modelo “Any port” de Bird (1963)

A lo largo de este capítulo fuimos describiendo como el puerto propiamente dicho y la zona llamada puerto, constituyen un punto de referencia para el núcleo urbano. Según Santos (1994) el paisaje es como un palimpsesto, resultado de una acumulación en la que algunas edificaciones ( $u$ objetos, podemos pensar en las embarcaciones encalladas) permanecen, otras se modifican y otras desaparecen, al tiempo que aparecen nuevas, por lo 
que siempre estamos frente a un paisaje y a un territorio sobre el que se constituye acción y significación. El puerto se constituye como lugar de trabajo. Su actividad excede su localización motorizando actividades, estatales, fabriles y comerciales asociadas incluyéndose así en la economía local y regional. El puerto también se posiciona como un punto en las referencias culturales y sociales. En el verano de 1975, Prefectura Naval Argentina publicaba un comunicado ante el incesante flujo de turistas que diariamente concurren y o transitan por la jurisdicción portuaria para resguardar su seguridad. Como espacio social el puerto también implica un espacio de disputa para diferentes actores sociales. Pero también ofrece un punto de referencia, un anclaje en las significaciones sociales que lo toman de sustento. Una de las formas que asume la apropiación simbólica de este espacio es a través del arte. Numerosos artistas locales toman como objeto de referencia el puerto (y la pesca en algunos casos) como fuente, insumo para el desarrollo de su actividad. Una justa referencia nos permite poner en relevancia el consolidado trabajo del pintor y artista Nicasio Díaz Llanos (2011), que toma al puerto y los barcos como uno de los grandes temas de su obra, expuesta en galerías y museos tanto nacionales como internacionales e inscribiéndose en una tradición pictórica argentina que toma al puerto como objeto para su obra y que encuentra otros grandes referentes en Benito Quinquela Martín en la Boca y Cleto Ciocchini en Mar del Plata.

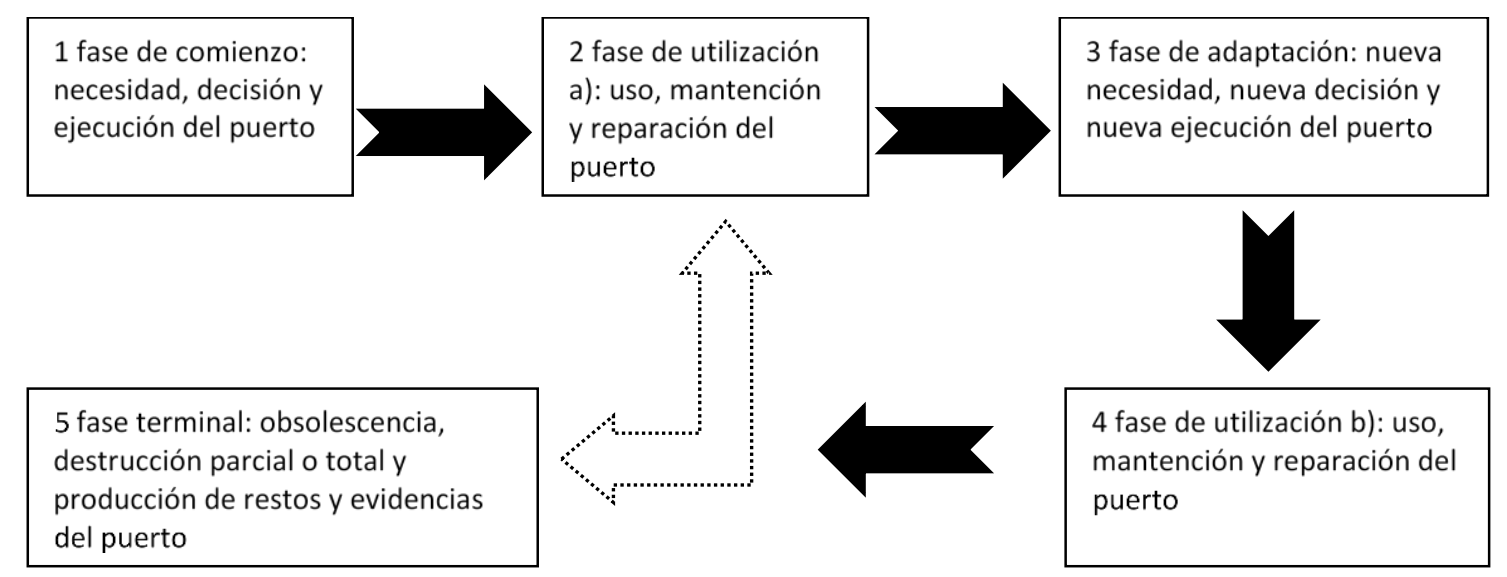

Figura 12. Modelo de Laubé (2014).

Puerto Quequén representa un lugar de trabajo, una fuente de ingreso económico, un interesante espacio de disputa política. Es la sequedad de la playa de camiones sobre Quequén, pero también es para los turistas una postal de la colonia de lobos marinos asentada en la margen Necochea y cuya observación se vio interrumpida durante varios años por las medidas de cercado del puerto. El puerto es trabajo diurno y nocturno, pero también el paisaje mar adentro desde las escolleras y la práctica de pesca deportiva. El 
puerto es la fiesta de los pescadores y un barco hundido. La postal naturalizada de un puente interrumpido y el imponente monumento a la Gesta de Malvinas inaugurado en 1999 que se erige con una madre patria de cara al mar de Quequén. Como contraparte en Necochea, encontramos otros dos monumentos de menor escala. En la intersección de Av. 59 y 10 el monumento a la Familia del Pescador, representado por una mujer con un bebe en brazos y una niña y un niño agarrados a sus faldas, mirando al puerto. A su vez, en la intersección de la Av. 59 y calle 14, sobre una pirámide de piedra truncada se encuentra el monumento al Pescador, cuyo escultor fue Donato Siro Matula (ver la ubicación de estos monumentos en torno al espacio portuario en la Figura 3), obra inaugurada en 1973 y donada por la Sociedad de Pescadores Necochea-Quequén. A sus espaldas quedan las ruinas y el esqueleto de una inoperativa fábrica de procesamiento de pescado. También merece una mención la primero Capellanía y luego Parroquia de Nuestra Señora de la Medalla Milagrosa, que es el referente religioso católico del barrio Puerto, del que se encuentra muy cerca. Desde mediados de la década de 1950 y a pedido de la Diócesis de Mar del Plata, el entonces presbítero de la Iglesia de la Villa Diaz Vélez (zona de la playa de Necochea) comenzó a dar misa en el barrio del puerto que se iba delineando. Poco más adelante una familia donó el terreno de la calle 61 y 22 donde se erigió una modesta capillita y pronto un galpón donde se oficiaba la misa ${ }^{39}$. En 1976 llegaría Jesús José Domaica quien estaría a cargo de la capellanía hasta fines del período de interés. Este religioso pasó a ser un referente no sólo para la Parroquia sino para el barrio y la comunidad local. A principios de la década de 1980 se impulsó la construcción de una capilla de material que completó su techado definitivo en $1996^{40}$.

La zona puerto también concentró gran parte de las pescaderías que venden y procesan el pescado recibido de la flota local, La Portuguesa, Santa Cecilia. El pescado fresco y los restaurants especializados son una tríada clásica de los puertos. Las propagandas de estas y otras pescaderías en el diario Ecos Diarios son habituales (Figura 13), por ejemplo, una conocida pescadería en enero 1975 invita:

"Por fin se puede saborear en la zona portuaria la exquisita "picada" Don Carmelo. Cazuelas, empandas, pescaditos fritos y otros apetitosos platos preparados con la mejor selección de productos del mar, y el inconfundible "gusto a buen gusto" que caracteriza a Don Carmelo. Su lugar de cita, entonces... Pescadería "El Dorado". Banquina Puerto Necochea".

\footnotetext{
${ }^{39}$ Recuperado de un testimonio manuscrito de la historia de la Parroquia Nuestra Señora de la Medalla Milagrosa (https://sites.google.com/site/medallanecochea).

${ }^{40}$ Archivo Ecos Diarios.
} 


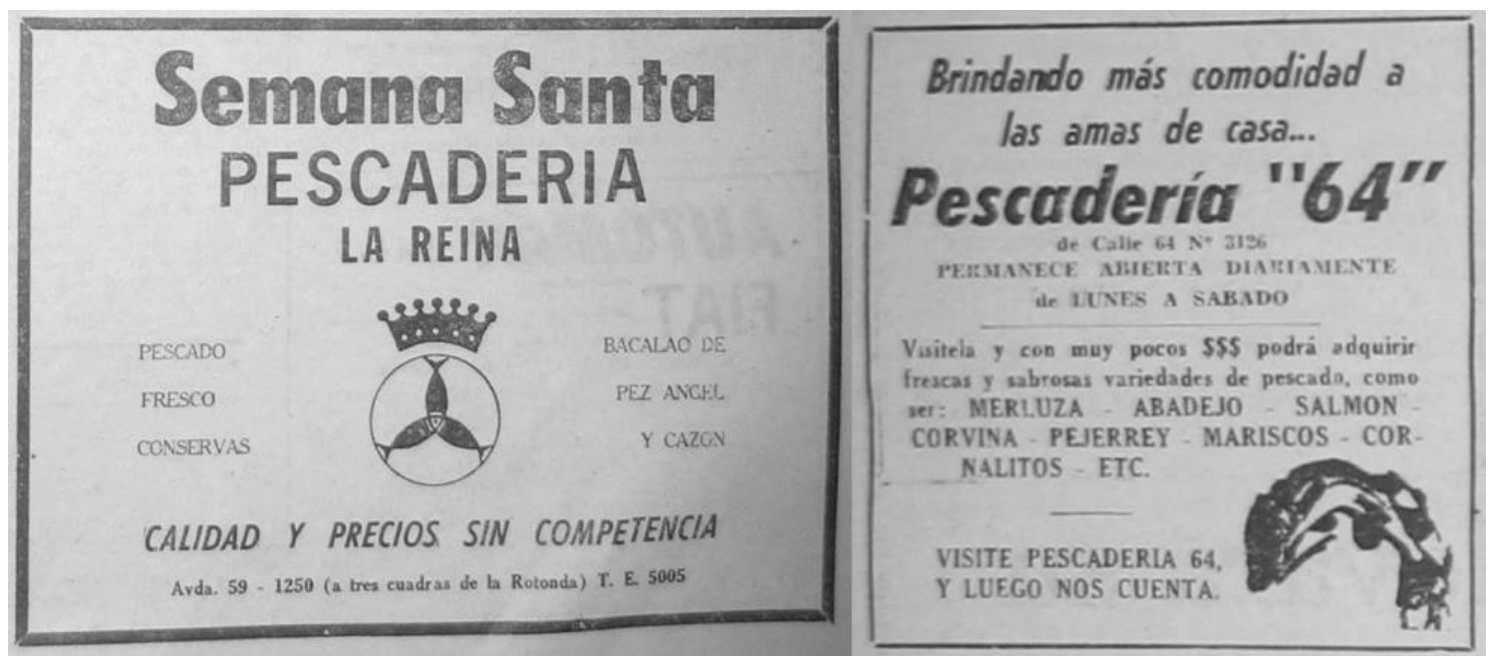

Figura 13. Ejemplo de propagandas de pescaderías de Necochea.

Fuente: Ecos Diarios: 10 abril 1976 (izquierda) y 27 noviembre de 1976 (derecha).

Cantinas como la de Mario, Stella Maris y Venecia durante el período se constituyeron en verdaderas instituciones del comer en la zona del puerto. El espacio geográfico, que como bien dijimos anteriormente, es siempre espacio social e histórico, y también le podemos añadir como coordenadas de análisis la luz y el género. Día y noche, masculino/femenino son variables que particularizan el uso y la significación de los espacios, del espacio portuario para este caso. Compartiendo en continuidad espacial con las cantinas familiares encontramos otro tipo de locales que recorta diferente en función del género. El puerto aparece como un espacio predominantemente masculino. Esto no quiere decir que no circulen mujeres, pero es poco frecuente encontrar mujeres en la zona portuaria, o "buenas mujeres solas". Con algunas excepciones en el comercio, los ámbitos de trabajo con presencia en el puerto son mayoritariamente masculinos. Las zonas circa portuarias son tradicionalmente asociadas a prostíbulos y piringundines $^{41}$, y Puerto Quequén no resulta ajeno a los estereotipos: en la zona puerto, Carlitos, el de la Cordobesa, Los Pinos, Los Toneles, Los Rengos, Blue Star, Fialelei, Imperio, Siete Esquinas y El Paraíso fueron durante el período estudiado lugares de referencia para satisfacer los deseos sexuales, lugares de entretenimiento y sociabilidad de varones locales y allegados.

El puerto, la noche, y un marinero de lejanas tierras que no sabe el idioma local parecen elementos para el escenario de novela policial. Puerto Quequén tiene su propio caso histórico que no tiene nada que envidiarle a la ficción. Un caso policial que implicó años hasta su resolución y que tuvo trascendencia extra-local, también por la trama de los involucrados. El 8 de mayo de 1978 el marinero yugoslavo de 23 años Milivoje Pesic. Con

${ }^{41}$ Del lunfardo, bar, cabaret, prostíbulo (Espíndola 2002). 
otros tripulantes fue a beber al bar "Elsa" del puerto en la margen Necochea, y cuando sus compañeros se fueron él se quedó un poco más, siendo testigo de una pelea entre dos prostitutas y otros dos clientes. Quiso intervenir y quedó inconsciente de un golpe. Al despertar Mirta Godoy, una de las alternadoras del bar yacía muerta en el piso, ensangrentada, mientras la otra, Rafaela -o Roxana- Villavicencio, pedía ayuda y los otros dos hombres ya no estaban. Pesic fue detenido cuando subía a su barco, Mavro Vetranic, donde trabajaba como cocinero de segunda. En un juicio plagado de irregularidades fue declarado culpable a 16 años de prisión. Dice la crónica que "al escuchar la sentencia el marino se agarró la cabeza y juró en su idioma que era inocente”, luego se echó a llorar. En prisión Pesic dibujaba dos rostros, luego se sabría que correspondían a Carlos Alberto Farnos y Juan Hankel. En 1983 luego de cumplir un tercio de su condena, y por buena conducta pudo abandonar la cárcel y retornó a su país, donde escribió un libro "Mi tango argentino", relatando su estancia en el país. Detenidos por robo en España en 1983, Farnos (hombre de confianza del conocido sindicalista local Gerónimo Momo Venegas) y Hankel confesaron su responsabilidad en el asesinato de Godoy ${ }^{42}$.

Para finalizar este capítulo nos interesa resaltar el sentido de analizar desde una perspectiva geográfico-social la inscripción del objeto de estudio. Nos permite situar y analizar geográficamente el referente, potenciando la articulación con otros conceptos. En etnografía, como en lo conceptualizado como geografía del paisaje sensu Santos, lo que se "ve" constituye el punto de partida para la interpretación, pero si abandonamos la premisa positivista de que el ver reduce la interpretación podemos empezar a pensar lo visto como punto de partida y anclaje para la explicación, la búsqueda de sentidos. Lo presente de lo que se ve necesita ser puesto en diálogo con el pasado, no en el sentido de buscar determinaciones sino para comprender las génesis, continuidades, rupturas y transformaciones de las fuerzas sociales, recuperando el sentido en que lo estableció Wright Mills para la imaginación sociológica (Tobío, 2012). Así, como estuvimos detallando, el puerto integra una gran cantidad de actividades, funcionalidades y usos del espacio y representaciones. Desde actividades deportivas, económicas, sociales y turísticas donde la actividad pesquera se suma como una más y no representa a la preponderante. En el próximo capítulo nos centraremos en la pesca como actividad humana y económica, y especialmente las características de la pesca en Puerto Quequén.

\footnotetext{
42 "El Tango de Pesic", Ecos Diarios, 6 de julio de 1997; "Historias del Crimen. El caso Pesic", Clarín, 4
} de diciembre de 2003; y “Momo, Farnos y el caso Pesic”, Página12, 14 de abril de 2008. 


\section{Palabras finales}

En este capítulo hemos ubicamos geográficamente a Puerto Quequén y describimos sus características históricas y técnicas más sobresalientes. Ponderamos su continuidad y consolidación como puerto cerealero y exportador, establecida desde sus inicios, aunque cambian algunos de los productos más representados, se incorporan nuevos en función de la demanda internacional y de los cambios productivos en el área de influencia.

Situamos al puerto en su integración con las ciudades en las que está emplazado. En relación con la integración puerto-ciudades observamos fenómenos que tienden a aislar el puerto de la lógica de las ciudades. Destacamos la ruptura del puente de la zona puerto en la década de 1980 y la consorciación en la década de 1990 como fenómenos que contribuyeron a reconfigurar la lógica de la integración puerto-ciudades. Mientras al inicio del período los usos del puerto, además de en sus funciones específicas podemos encontrar relatos y reseñas en el diario de otros usos por personas no vinculadas al mismo. Hacia el final del período el espacio estrictamente portuario de ver restringido para el uso de trabajadores y operarios. A su vez, la ruptura del puente, el cercado del puerto durante el período con imposibilidad de circular por la banquina implicó una mayor segmentación del uso del espacio. Pero, por otra parte, recuperamos cómo el puerto está presente en el imaginario de la ciudad de otras formas, como por ejemplo inspiración para las obras artísticas locales. 


\section{Capitulo 3.}

\section{La actividad pesquera marítima comercial, caza sofisticada en el capitalismo global}

\section{Introducción}

Los pescadores de Puerto Quequén trabajan orientados a una economía de mercado, su actividad se inserta en el marco de normas explicitas e implícitas que regulan y orientan su actividad. En la confluencia y articulación del plano internacional, nacional y la situación local, este capítulo tiene por intención presentar la evolución de la situación pesquera durante el período 1975-2001 en la que los pescadores trabajan y anclan sus percepciones e interpretaciones. Este período, además, coincide con la expansión de la industria pesquera nacional y con una de las mayores crisis del sector.

\subsection{La pesca}

Tradicionalmente cuando se diserta sobre la pesca, se la incluye entre las actividades económicas primarias. Con este tipo de actividades, desde la Economía, se hace referencia a la actividad humana destinada a la obtención de bienes o servicios que sirvan para satisfacer las necesidades ${ }^{43}$ de la humanidad. Dicha actividad humana puede referirse a la extracción directa de los bienes de la naturaleza o a su posterior transformación y/o traslado hasta ponerlos en condiciones de ser utilizables para la satisfacción de las necesidades en cuestión. La actividad aplicada a la obtención de los bienes de la naturaleza se llama comúnmente actividad primaria, para diferenciarla de la actividad de transformación de esos bienes (actividad secundaria) o de las actividades de traslado y organización de esos bienes para cubrir necesidades, sin producción de estos (actividad terciaria). La actividad primaria remite a la extracción de bienes naturales, de aquellos no

43 Sobre el carácter de la definición de estas "necesidades" mucho de ha discutido desde la Antropología, véase por caso la crítica de Geertz a las posiciones funcionalistas (Geertz, 1973). 
renovables (como los minerales) así como también de los renovables (tala, caza, recolección). El desarrollo de la actividad primaria condiciona el desarrollo general de una economía dada. En el caso de la pesca, como actividad primaria, constituye una muy importante fuente de proteínas para el consumo directo de las poblaciones humanas. Además, sustenta una importante actividad económica a nivel mundial (FAO 2019), que genera empleos e ingresos sobre todo en los países en vías de desarrollo, en los cuales la pesca suele ser una actividad de gran importancia, tradición y profundidad histórica, primero como actividad de subsistencia y luego integradas a los mercados nacionales e internacionales. En este sentido, quisiera resaltar las palabras de Alegret (1987) quien nos recuerda "entre un pez y un pescado siempre hay un pescador". Por ello, la pesca -la comercial como la de subsistencia, en mar abierto o la acuicultura- cumplen la doble función de ser una fuente de alimentos y un medio de vida (FAO 2019). En este sentido evaluaremos las características de este tipo actividad económica y su impacto en el mundo, en la Argentina y en Necochea-Quequén.

Los recursos marinos sobre los que se sustenta la actividad pesquera marítima se caracterizan por su movilidad en un terreno que no está delimitado de la misma forma que la tierra, por lo que no pueden ser apropiados de igual modo que otros recursos. Uno de los rasgos que más sobresale es el carácter de ser recursos "imprevisibles", dado que la fluctuación de la concentración de peces no puede ser prevista debido a la cantidad y complejidad de factores etológicos, ecológicos, y de otra índole, que influyen en su comportamiento. Es en este sentido que la pesca mantiene su estatus de "caza" 44 , aunque hoy en día cuenta con un alto grado de tecnologización. Esto implica que, en algún punto, los peces como recursos no puedan ser "racionalmente" manejados como, por ejemplo, los cultivos o las aves de corral. Esta incertidumbre sobre el recurso supone un riesgo, real o potencial, sobre la producción. Otro factor de gran importancia que puede generar incertidumbre y, por lo tanto, riesgo, es el precio de venta de la producción. La pesca, en tanto actividad económica, depende para su desarrollo de causas físicas como el ritmo de crecimiento de las especies, la mortalidad natural y la mortalidad causada por los seres humanos (Bertolotti et al., 2008). Estos factores operan en la renovación del recurso e implican sincronizar y articular tiempos "naturales" y tiempos "económicos". En este sentido es necesario ubicar los temas pesqueros en la intersección de las cuestiones sociales más amplias, la economía y las ciencias naturales.

\footnotetext{
${ }^{44}$ Entendida esta de forma simple como la acción en la que se captura o mata un animal en estado salvaje.
} 
Esto es especialmente importante, sobre todo, para la flota costera de pequeña escala como la tomada de referencia en esta investigación, ya que esta no se encarga del procesamiento del pescado, ni tiene suficiente capacidad para almacenarlo y, así, especular sobre el precio. Por lo tanto, tampoco va a influir de forma significativa en generar una sobreexplotación del recurso, como si lo puede hacer la pesca industrial. Otro plano de factores de riesgo tiene que ver con las condiciones en que se realiza la actividad, por ejemplo, condiciones meteorológicas desfavorables que limitan las salidas al mar y que generan periodos en que deben quedarse en tierra, o incluso roturas y, en última instancia, la perdida -por hundimiento- de los propios medios de producción, como son las embarcaciones.

Desde la Antropología y la etnografía, podemos recuperar con la descripción de diversos grupos y sociedades el peso que tuvo la pesca -tradicional o de subsistencia- en el sustento y desarrollo de distintos grupos humanos. Muchos de los antropólogos usualmente llamados clásicos en el origen y por su peso en el desarrollo de la disciplina como Malinowski (1948), Firth (1975), Boas (1910), basaron sus descripciones y teorizaciones en sociedades pescadoras. Son muchos y diversos los grupos sociales en diferentes partes del mundo que vivieron y se organizaron en torno a los recursos provenientes del mar, de los ríos y de lagunas. Algunos grupos desarrollaron complejos sistemas simbólicoculturales para hacerse de estos recursos. Sin embargo, durante gran parte de la historia de la humanidad esta actividad fue de escala reducida, de nivel local y sin un significativo impacto ecológico sobre el medioambiente donde la practicaban. Hasta los albores del siglo XX la pesca que se desarrollaba era mayormente pesca costera, pero junto con el desarrollo y la implementación de tecnología, en concordancia con fenómenos de índole económica y política llevó al establecimiento de un mercado globalizado del pescado (Holm, 1998). Estos procesos confluyeron en integrar a una de las formas más antiguas de obtener sustento de la naturaleza a una economía altamente globalizada e intensificando la extracción del recurso base.

La pesca marítima se refiere a aquella realizada en aguas de mares y océanos, y se la puede distinguir de la pesca continental o de agua dulce. La pesca supone la captura y extracción de las aguas de peces y otras especies acuáticas como moluscos y crustáceos. Los caladeros son áreas del mar con gran cantidad de peces, en la que los pescadores "calan", esto es, arrojan sus redes. Por su parte, también se denomina pesquería a las áreas del mar donde es posible pescar especies distintivas, en este caso se las suele llamar por el nombre de la especie objetivo o por el nombre de la zona en la que se practica. La pesca marítima puede, según su finalidad, distinguirse en pesca de subsistencia para la alimentación, comercial (con destino a la comercialización para la alimentación humana), deportiva, 
experimental o de investigación. De acuerdo con la lejanía con la costa donde se capturan los peces la actividad pesquera marítima puede clasificarse como de baja altura, bajura o costera, de media altura o costera lejana, o de altura para aquella que se realiza en altamar. Como veremos más adelante cada una de ellas implica diferente tipo de barcos y una organización del trabajo específica. En tanto actividad económica, implica tres etapas o momentos diferenciables: la captura del pescado, su procesamiento y la comercialización de este. En esta tesis nos centramos en las particularidades de los trabajadores abocados a la primera etapa (de extracción), sin embargo -y cómo veremos- las vicisitudes de los mismos están directamente relacionadas con la situación correspondientes a las etapas del procesamiento y la comercialización, ya que requiere la colocación de lo producido.

En nuestro país las especies más representadas para la captura marítima comercial son la merluza hubbsi, la polaca, la merluza de cola, la merluza negra, el abadejo, la anchoíta y la corvina. Por su parte, el calamar illex es el más representado de los moluscos, y el langostino entre los crustáceos (Madaria, 1999; Sanchez et al., 2012). Las especies recuperadas pueden clasificarse según la profundidad en las que se encuentran. Las pelágicas, o de baja profundidad, circulan cerca de la superficie. Entre estos se puede incluir al atún, el salmón, la anchoa, la sardina y el arenque. Se desplazan en grandes bancos y migran estacionalmente. Por ejemplo, la anchoa se desplaza desde las aguas del sur de Brasil, adonde se quedan durante los meses finales del invierno y parte de la primavera, hacia el sur de la Provincia de Buenos Aires en verano, y luego a la plataforma externa y aguas del talud continental frente a la costa bonaerense durante el otoño. Mientras que se denomina especies demersales a aquellas que se encuentran en los fondos marinos, como el bacalao, el lenguado, entre otras.

\subsection{Situación de la pesca mundial}

Desde principios del siglo XX la pesca costera y la de altura muestran un marcado incremento de las capturas, en cuyo contexto es significativo el lugar que tiene Japón con el desarrollo de su flota de altura (Holm, 1998). También hay que resaltar el papel que desempeñaron las Guerras mundiales en el desarrollo del mercado pesquero, ya que estas sirvieron para que en los caladeros tradicionales -algunos de ellos, como el Atlántico Norte, fueron parte de escenarios de guerra- se recuperaran las poblaciones de peces. A su vez, al finalizarse ambas guerras, las flotas pudieron ser recompuestas y se beneficiaron con los desarrollos e implementación de nuevas tecnologías, que se comenzaron a aplicar para la de localización de pescado (como el sonar o la ecosonda). 
A inicios del período de interés, la situación de la pesca mundial experimentaba un crecimiento sostenido (Figura 14). Por ejemplo, la FAO (1976) consigna que la producción pesquera mundial ascendió en un 6\% en 1974, como resultado de mayores capturas en Chile y Perú producto de la recuperación de la anchoíta -cuyas poblaciones habían disminuido en los años previos- y por el desarrollo de flotas de amplio radio de acción, principalmente de la U.R.S.S. y de otros países de planificación centralizada, que otorgaban grandes subsidios a la industria pesquera. Gran parte de este aumento estaba constituido por pescado utilizado para la obtención de harinas de pescado (que se emplean como alimento balanceado para aves y cerdos) y aceites, aunque también aumentaron los desembarques para el consumo humano directo.

En la década de 1970 se realizó en Ginebra un encuentro de la Tercera Conferencia de las Naciones Unidas sobre los Derechos del Mar45, en la cual, en su última sesión en Jamaica ell 30 de abril de 1982 se aprobó la Convención de las Naciones Unidas sobre el Derecho del Mar ${ }^{46}$. Hasta ese momento y al no existir acuerdo, los diferentes países toman medidas unilaterales, por ejemplo, mediante acuerdos bilaterales, mientras que un grupo compuesto por unos cuarenta países reclamaban zonas exclusivas de entre 15 y 200 millas náuticas mar adentro. En esta convención se decide reconocer una Zona Económica Exclusiva de cada país con costa, entendida esta como un área que se encuentra más allá del mar territorial adyacente a éste hasta una distancia de 200 millas marinas (aproximadamente $370 \mathrm{~km}$ ) desde las líneas de base a partir de las cuales se mide la anchura del mar territorial. De esta forma, las ZEE desde ese momento se encuentran sujetas al régimen jurídico específico establecido en la Convención, pero a su vez, el país con una ZEE pasa a tener derechos sobre la misma. Entre estos se destaca la soberanía para la exploración y explotación, conservación y administración de los recursos naturales, vivos y no vivos, de las aguas suprayentes al lecho y del lecho y el subsuelo del mar, así como sobre otras actividades derivadas, como la producción de energía derivada del agua de las corrientes y de los vientos. También pasa a su jurisdicción, respetando las disposiciones de la Convención, para establecer y usar islas artificiales, instalaciones y estructuras, la investigación científica marina y la protección y preservación del medio marino. Esta Convención, y la definición de las ZEE constituyen un hito de gran importancia y un punto de inflexión en la jurisprudencia marítima internacional.

\footnotetext{
45 Esta conferencia fue convocada por la Asamblea General de Naciones Unidas en diciembre de 1970, y se realizó a lo largo de casi 10 años entre 1973 y 1982.

46 Convención de las Naciones Unidas sobre el Derecho del Mar. 1982. Disponible en https://www.un.org/Depts/los/convention agreements/texts/unclos/convemar es.pdf
} 
La situación económica generalmente favorable de la industria pesquera tuvo altibajos durante la década de 1970. El contexto positivo duró hasta el año 1974, cuando la industria pesquera tuvo que afrontar unos costos que aumentaban rápidamente y una contracción de la demanda. La situación internacional de la pesca a principios de 1975 marcaba que la rentabilidad de las operaciones pesqueras empeoró en general, produciendo una fuerte presión por parte de la industria en la mayoría de los países solicitando ayuda estatal y obteniéndola generalmente. Para 1977 las capturas mundiales de peces, crustáceos y moluscos disminuyeron significativamente, siendo la principal causa, según lo que consigna el informe de FAO, la menor producción de peces pelágicos gregarios, insumo para procesarlos en harina y aceite. Aunque durante toda la década de 1970 hubo fluctuaciones en las capturas, en 1977 esta variación se dio por el efecto de la introducción de las Zonas Económicas Exclusivas. Por ejemplo, en Europa oriental y en la U.R.S.S fue la primera caída en diez años y se debió a la exclusión o limitación de las capturas en sus tradicionales zonas de pesca. Por su parte, la India, Indonesia y Malasia, y en menos medida también Latinoamérica tuvieron un crecimiento de las capturas que destinó directamente a la alimentación (FAO, 1979). Durante la década de 1980 se observa un crecimiento constante de la producción pesquera, seguido luego por un amesetamiento en las últimas décadas (Figura 14). Sí existe un crecimiento fuerte y sostenido de la acuicultura, o sea, la crianza de especies marinas, que actualmente representa casi el $40 \%$ de los productos del mar. Más allá de estas consideraciones, desde mediados del siglo XX el crecimiento sostenido de la producción de pescado a nivel mundial ha aumentado de forma notable desde mediados del siglo XX. A esto han colaborado de forma significativa la explotación de nuevas regiones poco utilizadas hasta entonces -como el caso del Mar Argentino- así como también mejoras en las cadenas de comercialización, impulsadas por el desarrollo del transporte y las comunicaciones. Otros factores que han incidido de forma importante han sido los avances técnicos, entre los que destacamos aquellos vinculados con la refrigeración y conservación de los pescados, de los barcos para la captura de los mismos -con los barcos factoría con procesado a bordo como símbolo máximo de esta industria- y, junto con esto último, de las artes de pesca.

A su vez, se observa que la situación internacional es muy variable, considerando fenómenos globales tanto como locales. Hay que tomar en cuenta cambios en la variable de demanda, ubicación de los mercados, disponibilidad de recursos, entre otros factores. Por ejemplo, para el año 1991 el comercio internacional de los productos pesqueros creció menos en valor que en volumen. Esto se debió a la baja de los precios de algunos productos como el camarón o el salmón (FAO, 1993). La región del Pacífico Noroccidental representa la principal zona de pesca en relación con el volumen y el valor económico de las especies 
capturadas. Con la desaparición de la U.R.S.S que subvencionaba la flota en aguas distantes, en 1996 Japón pasa a ser el principal productor (FAO, 2019; Madaria, 1999). En 1996 se alcanzó la captura de 94,6 millones de toneladas de pescado, y el 90\% de este valor correspondió a la pesca marítima. Los países que mayor participación tuvieron en esta producción fueron China, Perú, Chile, Japón, Estados Unidos, Rusia e Indonesia (Madaria, 1999). Para fines del período de estudio -y a diferencia del aumento del ritmo de capturas de las décadas de 1950 y 1960- las capturas de peces marítimos fueron desacelerándose, con una estabilización o incluso disminución de las capturas.

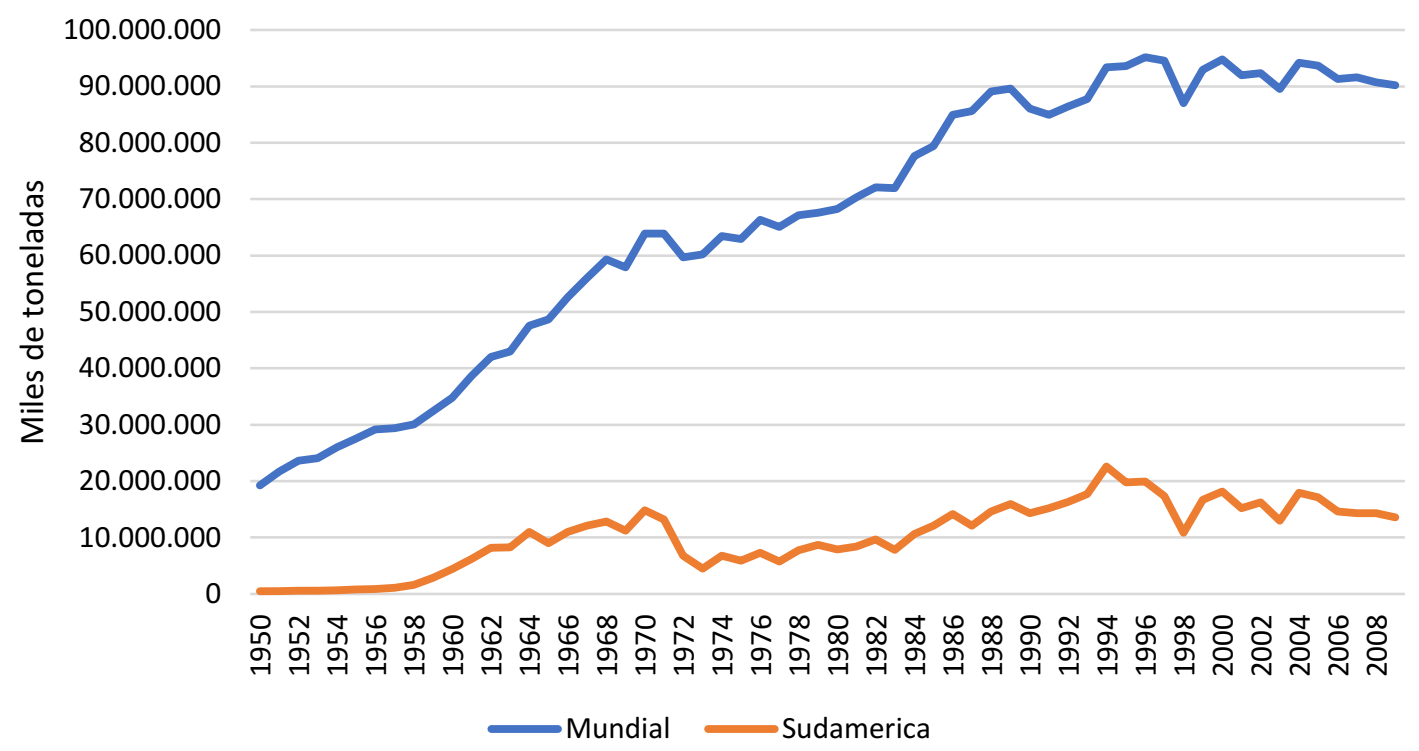

Figura 14. Producción de pesca marítima a nivel mundial y sudamericana. Elaboración propia a partir de datos disponibles en $\mathrm{FAO}^{47}$.

Este crecimiento experimentado a nivel mundial en las últimas décadas también se evidencia en Sudamérica. En nuestro continente se encuentran tres de los grandes ecosistemas marinos altamente productivos con gran cantidad y diversidad de especies. De estos, el más importante y uno de principales a nivel mundial, es el Sistema de la Corriente de Humboldt en la costa Pacífica, del cual forman parte los mares de Chile, Perú y Ecuador. Este contribuye con casi el 20\% del total de pesca de captura mundial. Los dos restantes sistemas de importancia son la Plataforma Patagónica -compartida entre Argentina y Uruguay- y la Plataforma Sur del Brasil. En América Latina a partir de la década del 1960 también se experimentaron cambios en la demanda y en el consumo del pescado como alimento, acompañados por el crecimiento demográfico en la región lo que hizo que se intensifique la demanda, principalmente durante la década de 1960 y luego nuevamente en

${ }^{47}$ http://www.fao.org/fishery/topic/16140/es 
las siguientes décadas hasta el año 1995 cuando alcanza el máximo de desembarques (Figura 14). En los últimos años, América Latina aporto cerca del 14\% del total producido a nivel mundial, aunque aproximadamente el $70 \%$ de esto corresponden a capturas realizadas por Perú y Chile; mientras que casi todo el 30\% restante es aportado por México, Brasil, Argentina y Ecuador.

\subsection{La pesca ¿un recurso de libre acceso o un recurso común?}

Los recursos marinos y pesqueros se caracterizan por tener como condición ser de libre acceso, esto quiere decir que para su explotación no hace falta pagar un precio por ellos. Técnicamente, el régimen de los derechos de propiedad puede ser de cuatro tipos: libre acceso, propiedad comunal, propiedad estatal o propiedad privada. En la práctica constituyen diferentes regímenes que se pueden interrelacionar y hasta superponer, como sostiene Sánchez Fernández (1992). Para varios países, las pesquerías son "en teoría" propiedad estatal, pero "de hecho" suelen convertirse en recursos de libre acceso. Aunque, en general, los individuos no pueden apropiarse de forma particular del mar, existen formas como la limitación del esfuerzo pesquero o las licencias, que en la práctica suponen una privatización.

Debemos llamar la atención, también, sobre el hecho de que las áreas de pesca no son totalmente recursos de libre acceso, sino que los grupos humanos históricamente desarrollaron diferentes formas de acceso restringido y regulación del uso del mar. Una forma de territorialidad, por ejemplo, puede estar dada por el "secreto" de la localización de los recursos ictícolas (Pascual Fernández, 1991a). En este caso cobra importancia el sistema de parentesco y las redes de circulación de la información, por lo que el espacio marino se convierte así en un espacio social (Sánchez Fernández, 1992). Otros factores que intervienen en la delimitación del espacio marítimo explotado son el tipo y la autonomía de la embarcación, y las técnicas de pesca. Tal y cómo vimos anteriormente, en nuestro país los cambios significativos se dieron cada vez que se incorporó un nuevo tipo de flota, con mayor capacidad extractiva.

El problema radica en quién accede a los recursos, y cuando existe una disparidad notoria que genera accesos diferenciales. En los últimos tiempos por la intensificación y la orientación al mercado - principalmente externos, para exportación- se ha hecho necesario problematizar quién tiene acceso a los recursos. Muchas veces las poblaciones locales o nacionales tienen menos recursos y formas de acceso a sus propios recursos que actores sociales o grupos corporativos que disponen de medios técnicos y financieros mayores. Esta situación implica una fuente potencial y real de conflictos. Muchas veces los modelos 
extractivistas (Cóccaro et al., 2002; Gómez Lende, 2015) como el que se erige a partir de la pesca comercial se basan ideológicamente en nociones de desarrollo.

En Argentina, a partir de la reforma del Código Civil realizada en el año 1968 mediante la Ley $17.711 / 68$, los mares territoriales pasaron a ser comprendidos como "bienes públicos". Con este cambio, los peces dejaron de ser tratados como "recursos de libre acceso", o sea sin dueño de los cuales era factible su apropiación a ser "recursos de propiedad comunal". A partir de este cambio de concepción jurídica también cambia el lugar del Estado en relación con los recursos y con los actores que se apropian de él. Como bien económico, el recurso pesquero tiene dos características, la de ser un bien "rival" o sea que una vez pescado ya no estará disponible, y también la de ser un bien "no excluible" ya que es muy difícil evitar que otro pescador lo pesque. La primera característica permite diferenciarlo como un recurso común y no como de libre acceso. En esta etapa, la explotación pesquera se guio por el llamado "sistema olímpico" por el que los barcos que tenían permiso de pesca para trabajar en aguas nacionales competían por los recursos. Como observa Cañete (2011) "prevalecía la concepción de que el Estado debía limitarse a promover y administrar los medios necesarios para fomentar la explotación de unos recursos 'ilimitados' o, en el peor de los casos, 'sub-explotados', cuyo desarrollo redundaría en la satisfacción de necesidades colectivas".

Estos cambios fueron, en parte producto de los problemas originados durante estos años -entre las décadas de 1960 y 1990- relacionados con la intensificación de la capacidad de pesca, que pone en juego la sustentabilidad de los recursos. Los mismos, es necesario recordar, no se dieron únicamente en Argentina, sino que fue una problemática mundial que, en gran medida, continúa hoy en día (FAO, 2018). También son una característica del período los esfuerzos en diferentes planos para desarrollar estrategias para manejar (y controlar) la capacidad de pesca.

En este sentido, en el año 1973, Argentina subscribió el Tratado del Río de la Plata con Uruguay que permitió poner fin a las disputas que existían en relación con los límites en las aguas del Río de la Plata. En el artículo $\mathrm{N}^{\circ} 73$ del mismo, se creó una Zona Común de Pesca (ZCP) en la cual pueden operar las flotas de ambos países en el frente exterior marítimo del río de la Plata más allá de las 12 millas costeras. Esta se definió a partir de dos arcos de circunferencia de 200 millas marinas de radio, uno ubicado en Punta del Este en Uruguay, y el otro en Punta Rasa en Argentina (Figura 15).

Durante esa década, más específicamente en el año 1977, además se creó Instituto Nacional de Investigación y Desarrollo Pesquero (INIDEP), un organismo estatal dependiente del ministerio de Agroindustria. Se trata de un organismo descentralizado que tiene como funciones asesorar a la Subsecretaría de Pesca y Acuicultura de la Nación 
(SSPyA), y a la Cancillería Argentina ${ }^{48}$ en el uso racional de los recursos pesqueros con el objetivo de preservar el ecosistema marino para las generaciones futuras.

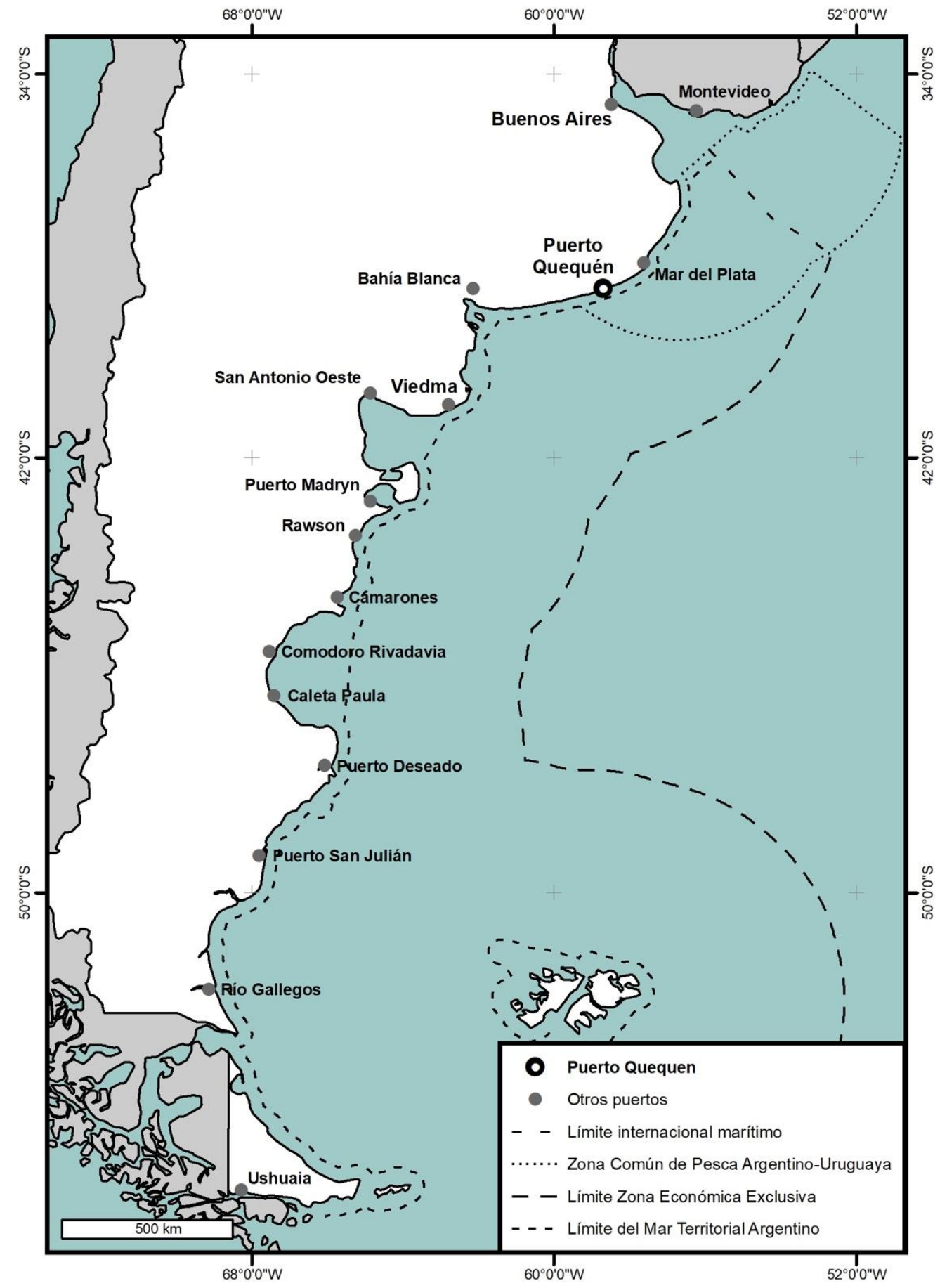

Figura 15. Ubicación de Puerto Quequén en relación con el mar argentino, los restantes puertos del país y las zonas y limites definidos dentro del mar argentino.

Elaboración propia a partir de IGN ${ }^{49}$.

${ }^{48}$ Además, luego de sancionada la Ley Federal de Pesca en 1997, también asesora al Consejo Federal Pesquero (CFP).

${ }^{49}$ http://www.ign.gob.ar/NuestrasActividades/InformacionGeoespacial/CapasSIG 
En el año 1997, y tras arduas negociaciones, se sancionó la Ley 24.922/97 conocida como "Ley Federal de Pesca". Esta surgió ante la evidente necesidad de controlar la sobrepesca que estaba ocurriendo en el Mar Argentino durante esos años. En esta ley se reconoció la jurisdicción provincial hasta las 12 millas y desde allí la jurisdicción nacional en la ZEE (Figura 15), y el carácter industrial de la actividad. Además, se creó el Consejo Federal Pesquero (CFP) -una Comisión Asesora honoraria- e introdujo un cambio profundo en la gestión pesquera al incorporar la administración por cuotas individuales transferibles de captura (CITC), lo que implicaba que el ejercicio de la pesca quedaba sujeto al pago de un derecho único de extracción por especie y modalidad de pesca, dejando sin efecto los permisos gratuitos que se realizaban hasta entonces. EL CFP estaba integrado por cinco representantes provinciales (uno por cada provincia con litoral marítimo) y cinco representantes del Estado Nacional. Entre sus objetivos se destaca el establecimiento de la política pesquera y de la política de investigación pesquera nacional, la planificación del desarrollo pesquero nacional, el establecimiento de la Captura Máxima Permisible (CMP) por especie y las cuotas de captura. El CFP también debía aprobar los permisos de pesca comercial y experimental, fijar las pautas de coparticipación en el Fondo Nacional Pesquero, establecer los derechos de extracción y fijar los cánones por el ejercicio de la pesca.

En cuanto al nuevo régimen de "Administración por Cuotas Individuales Transferibles de Captura" que se comenzó a utilizar a partir de la Ley 24.922/97, esta debía mejorar la administración del recurso y asegurar la sustentabilidad, no sólo biológica, sino también la económica y social. Sin embargo, desde su aplicación ha generado una serie de problemas y conflictos que van desde un abandono del Estado en su rol de administrador del recurso que quedó librado a los empresarios, no ha auspiciado la radicación territorial e industrial, mientras que, si ha fomentado los descartes en el mar, la sub-declaración de las especies cuotificadas, una mayor concentración empresarial y la pérdida de empleos. A su vez, no se ha cumplido con uno de los mandatos de la ley, que es fomentar la investigación, que según se expresa en la misma, constituye un pilar básico para la elaboración y diseño de la política de gestión de los recursos pesqueros (Defensor del Pueblo de la Nación 2011).

\subsection{La pesca en Argentina}

\subsubsection{La pesca hasta comienzos del siglo $\mathrm{XX}$}

El consumo de pescado cualquiera fuera su origen (fluvial, lacustre o marítimo) era habitual en el territorio que será la Argentina. Fue sin duda una actividad conocida por los pobladores originarios que vivían en el actual territorio argentino. Numerosos pueblos 
hicieron uso del recurso íctico desde tiempos prehistóricos, como dan cuenta de ello la gran cantidad de sitios arqueológicos ubicados tanto en el extremo austral (Vázquez y Zangrando, 2017), la costa patagónica (Gómez Otero, 1996) y bonaerense (González de Bonaveri, 2005), así como en los litorales de los grandes ríos.

Luego de la llegada de los españoles, en tiempos de la colonia, las costas atlánticas y sus recursos fueron poco aprovechados. Sin embargo, la colonización agregó un elemento novedoso como la interdicción del consumo de carne por motivos religiosos los días de cuaresma, advientos y para los más piadosos los viernes recordando así la Pasión de Cristo y su muerte en la Cruz.

Recién en las postrimerías de la colonia, fines del siglo XVIII, se observa un verdadero interés por parte de la corona española por aprovechar los recursos disponibles en el mar ante la progresiva pérdida de influencia en la pesca atlántica, como producto del accionar de barcos balleneros, loberos y pescadores de origen británico. Ante esto, la corona española decidió focalizar sus esfuerzos en consolidar su posición en la costa patagónica fundando varios asentamientos con dispar fortuna (Carmen de Patagones, Fuerte San José, Floridablanca) y un emprendimiento industrial basado en la pesca de ballenas y pinnípedos patagónicos: la Real Compañía Marítima de Pesca de Carlos IV en Puerto Deseado (Silva, 1978). Todas estas fundaciones fueron parte de un programa orgánico y ambicioso que tenía entre sus objetivos el estímulo de formar una marina mercante y la producción pesquera. Esta Compañía existió entre los años 1789 y 1807, cuando es abandonada definitivamente por la baja rentabilidad y dificultades de tipo logístico, climático y el ataque de ingleses (Silva, 1978; Schávelzon, 2008).

Por otra parte, no es ocioso recordar que el control de la sociedad criolla sobre la costa atlántica se produjo recién luego de la independencia en momentos en que la exportación de derivados pecuarios (cueros, sebo y tasajo) se constituyó en la actividad económica más importante. La carne ovina y bovina se constituyó así en la forma privilegiada de consumir proteínas animales y el consumo de pescado fue siendo relegado a las élites. Recién a partir de la segunda mitad del siglo XIX comienza, de forma tibia inicialmente, un uso y explotación de los peces disponibles en enormes cantidades en el mar argentino. En este caso, la pesca comercial se habría producido como un efecto secundario de la expansión agraria ocurrida -principalmente- en la provincia de Buenos Aires y del proceso inmigratorio masivo que acompañó al crecimiento económico ocurrido por el auge de la agroexportación (Mateo, 2003). Aunque es interesante resaltar que los procesos de inmigración no redundaron en un incremento en el consumo de pescado a partir de las costumbres que traían los inmigrantes, que gran parte de ellos provenían de lugares con una tradición culinaria y de pesca arraigada en miles de años. Los inmigrantes arribados y 
sus descendientes se adaptaron rápidamente a las pautas gastronómicas locales, y la interdicción religiosa que se mantenía desde la colonia fue decayendo casi a solo el viernes santo y las modalidades reducidas a las "empanadas de vigilia", el filete empanado, algunos enlatados, y poco más. Es interesante resaltar que los inmigrantes si bien lograron modificar las pautas de comida tradicionales del país -como la pasta italiana como máximo ejemplono ocurrió lo mismo con aquellas pautas culinarias centradas en los pescados.

Recién a fines del siglo XIX en que se puede afirmar que surge en la Argentina la pesca marítima de corte mercantil (Mateo, 2003; Mateo et al., 2010). Este hito ocurre cuando llegan unos pescadores oriundos del sur de Italia (Campania y Sicilia), quienes, junto con sus lanchas para la captura costera de pescados y, a pesar de que no contaban con la experiencia de pesca existente en el mediterráneo desde hace miles de años, se establecen y empiezan a desarrollar la actividad en el abierto mar argentino. Sin embargo, lograron superar las dificultades del nuevo territorio y una actividad poco conocida mediante la práctica cotidiana (Mateo, 2011a). Estos inmigrantes se asientan en la incipiente ciudad de Mar del Plata (Lahille, 1895), con el tiempo y el crecimiento de la actividad pesquera se produjo la motivación a otros inmigrantes -pescadores y navegantes de profesión- que vivían en los puertos de la Boca y el Tigre a cambiar de residencia y radicarse en la ciudad costera (Mateo, 2011c). De esta forma, durante esta época se observa un crecimiento constante en la producción pesquera (Figura 16).

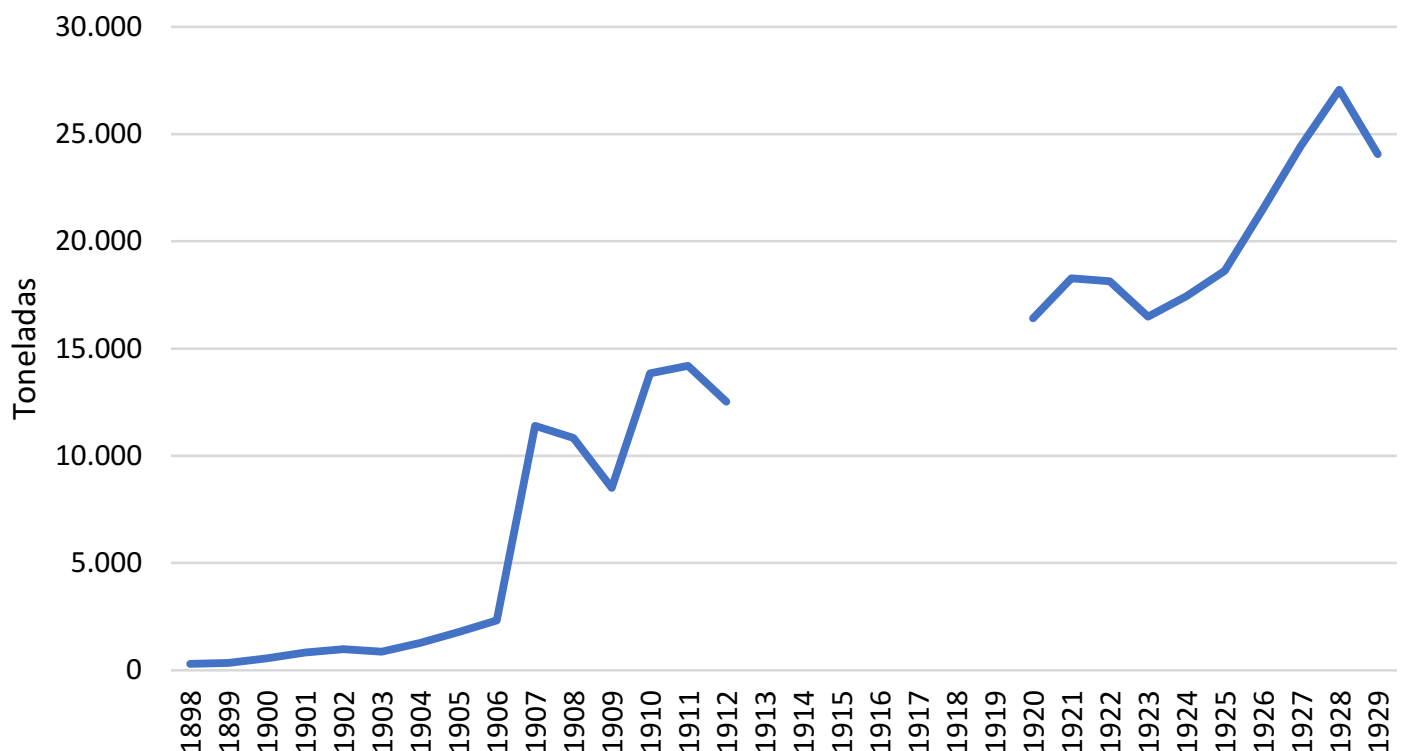

Figura 16. Evolución de los desembarcos totales anuales de productos pesqueros entre los años 1898 y 1929. Para el periodo entre 1913 y 1919 no se cuenta con el dato de desembarcos anuales. Elaboración propia en base a Cordini (1960) y Sánchez et al. (2012). 
Esta actividad se desarrolla a partir de los requerimientos de productos marinos por las nuevas clases dominantes que comenzaban a llegar a Mar del Plata y que exigían en las mesas de los hoteles y restaurantes del balneario durante sus estadías de verano (Mateo, 2006, 2011a). Otro elemento de importancia en la demanda fue cuando la ciudad quedo conectada por ferrocarril desde el año 1886 con el principal mercado del país: la ciudad de Buenos Aires.

Recordemos que, a partir del modelo centralista de país creado en la etapa nacional, si se pudo generar un mercado para el pescado -así como también de otros productos del interior del país- es debido a la concentración de la población en áreas urbanas, principalmente Buenos Aires. En efecto, alcanzar el mercado porteño fue condición sine qua non para el desarrollo de cualquier industria dentro del mercado interior, como la de los pescados, pero también de los vinos, cervezas, yerba mate, etc. El transporte del pescado desde Mar del Plata ocurría en condiciones muy precarias y a veces desventajosas para los pescadores marplatenses, quienes debían competir con los productos llegados desde Montevideo, las lagunas bonaerenses e incluso desde Europa en barcos con frigoríficos (Mateo, 2011c). Sin embargo, esto permitió el establecimiento de una colonia de pescadores que, al ubicar sus productos en la capital de forma rápida, pudieran operar a lo largo de todo el año.

\subsubsection{La pesca comercial hasta 1975}

A partir de la década de 1930, en el marco del proceso de sustitución de importaciones producido luego de la crisis mundial del año 1929, se observa un aumento de la actividad pesquera producto del creciente consumo de pescado requerido por los nuevos y numerosos establecimientos de elaboración de conservas. El estallido de la Guerra Civil Española consolido el crecimiento de la industria pesquera local, logrando sustituir a dicho país en el mercado mundial (Mateo et al., 2010).

En el año 1938, a su vez, se inauguró la ruta carretera que une a Mar del Plata con Buenos Aires, lo que permitió desvincular el transporte del pescado del horario de los ferrocarriles y propiciando una mejor llegada del producto al mercado porteño. Al mismo tiempo, también facilitó en contrapartida, el arribo de un mayor número de turistas a Mar del Plata, principalmente miembros de la incipiente clase media que la industrialización sustitutiva iba generando. Para este momento, se dan las condiciones para que la actividad pesquera sea una actividad de todo el año (Mateo, 2011a).

La industria pesquera -más allá de la extracción para el consumo inmediato del pescado en fresco- se orientó desde la década de 1920 hacia las conservas saladas o 
enlatadas, que se ajustaba mejor para las características del territorio y la particular distribución de los mercados y los lugares de producción en los puertos pesqueros (Mateo, 2004c). El fuerte de esta actividad estaba dado por el salado de la anchoíta, que se hacía en forma estacional cuando llegaban los cardúmenes en primavera. Posteriormente, y ya durante los primeros gobiernos de Perón, con la expansión del mercado interno, la industria pesquera se orientará hacia el desarrollo de la rama de conservas enlatadas (Cordini, 1960), entre los cuales las principales especies empleadas para tal actividad eran las sardinas (en realidad anchoas, Engraulis anchoita) y caballas (Pradas, 2006).

Un nuevo salto cuali-cuantitativo en la producción pesquera se producirá a partir de la consolidación del modelo de sustitución de importaciones potenciado por la acumulación económica y social de factores productivos durante la Segunda Guerra Mundial. Dentro de este proceso, se destaca la denominada "fiebre del tiburón" entre los años 1944 y 1947, y que fuera analizada por Mateo (2006). Esta fue generada a partir de un fuerte aumento de la demanda estadounidense de vitaminas A y D presentes en el hígado de los cazones -requeridas para agudizar la visión de los pilotos de aviones de guerra- en el marco de la contienda bélica. Dado que la fuente principal de esta vitamina era el hígado de bacalao, cuyos caladeros históricos se hallaban en el hemisferio norte dentro del teatro de operaciones de la Segunda Guerra Mundial, se sustituyó por los cazones del hemisferio austral. Esta mayor demanda permitió consolidar la flota pesquera y un crecimiento general del sector pesquero, ya que generó que personas ajenas al mundo de la pesca se incorporaran a la pesca -debido a las altas ganancias-, así como permitió acumular capital y modernizar la flota 50 (Mateo, 2006, 2011c).

Esta coyuntura particular generó un círculo virtuoso entre la demanda, la industria y la flota costera que se realimentó durante un tiempo. La flota se incrementaba, financiada con las ganancias que se producían por la producción de tiburones, primero, y la mayor demanda después, mientras que los astilleros instalados en Mar del Plata intentaban suplir la necesidad de barcos. Es en esta época, aproximadamente entre los años 1940 y 1975 en que se produce el denominado, por José Mateo (2005a) periodo heroico de la pesca costera en argentina.

Dentro de la pesca en el mar argentino, es entre fines de la década de 1950 y comienzos de 1960 en que se da un salto cualitativo de gran significación, ya que hasta este momento el pescado que se pescaba en Argentina se consumía en dentro de esos límites

50 En contrapartida, muchos perdieron la vida, o quedaron desocupados al final de dicha fiebre. Además, propició la injerencia de las agencias estatales para regular la captura del tiburón, ya que fue la primera especie marítima sometida a estrés de sobrepesca en el caladero argentino (Mateo, 2006). 
modestos de demanda. Fue a partir de esos años, y en el marco de políticas desarrollistas que la pesca comercial marítima comenzó a alcanzar los mercados internacionales un insumo para hacerse de divisas al punto de superar a las exportaciones de carne (en volúmenes y en valores) durante los años que analizamos. Se ha planteado incluso, que la verdadera pesca comercial en Argentina se inició a comienzos de la década de 1960, cuando se consolida un fuerte crecimiento de las capturas de pescados (Figura 17), una reducción de las importaciones de los productos del mar y una reorientación de la producción hacia lso mercados externos (Pradas, 2006).

Hasta esta época podemos decir que el grueso de la producción pesquera estaba en manos de numerosas firmas familiares locales que se vinculaban con todas las esferas de la producción: captura, procesamiento y comercialización. En cuanto a la flota pesquera que existía, en su mayoría se trataba de naves costeras (Allen, 1999; Solimeno, 2015).

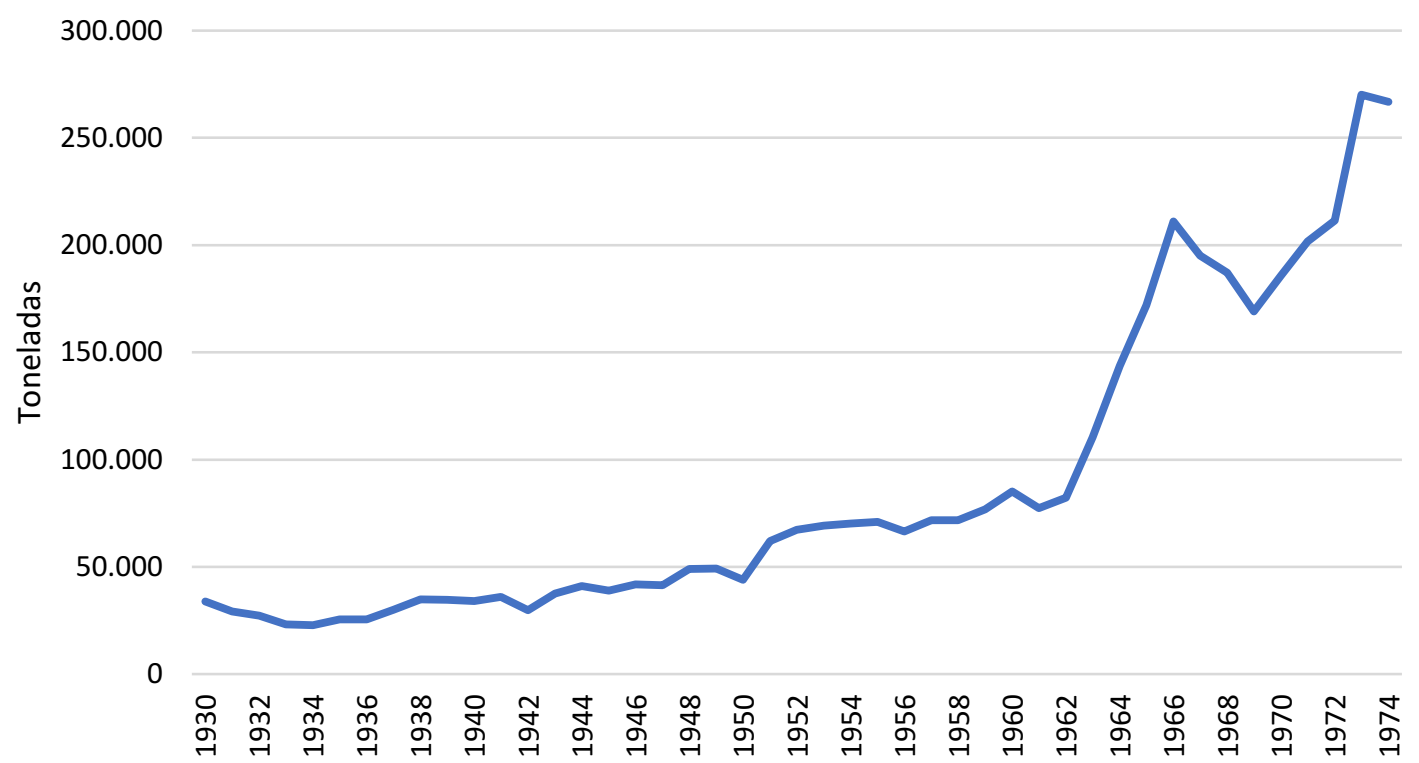

Figura 17. Evolución de los desembarcos totales anuales de productos pesqueros entre los años 1930 y 1974.

Elaboración propia en base a Sánchez et al. (2012).

Dentro de la pesca en el mar argentino, también entre fines de la década de 1950 y comienzos de 1960 se producen una serie de cambios significativos: la flota costera es sobrepasada por la flota de altura y la producción conservera fue sobrepasada por la producción de frescos y congelados (Bertolotti, 2001) (Figura 18). Hasta este momento, la flota costera -radicada principalmente en Mar del Plata- abastecía de pescado fresco al mercado interno para consumo o para los establecimientos conserveros.

A partir de la radicación en el período de posguerra de pescadores flamencos de origen belga que se asentaron en Mar del Plata entre los años 1950 y 1952 comienza a 
operarse otro cambio en la pesca marítima nacional. Los inmigrantes belgas trajeron sus propios barcos pesqueros -de altura-y se instalaron en el puerto marplatense, comenzando con la explotación de altura de pescado para consumo en fresco, que hasta ese momento había tenido escaso desarrollo en Argentina (Masid, 2004). Este grupo de familias inmigrantes contaban con amplia experiencia en la pesca en mar abierto -a diferencia de los pescadores de origen italiano acostumbrados al mar Mediterráneo-, conservaron fuertes vínculos familiares y con el mercado pesquero europeo de donde provenían. Además, trajeron consigo adelantos técnicos innovadores para el país, como motores diésel, cámaras frigoríficas y medios electrónicos de detección de cardúmenes. Los pescadores belgas se dedicaban a la pesca de altura, la cual tenía escaso desarrollo en la Argentina, lo que significó un importante impulso a esta rama de la industria pesquera, la cual recién pudo crecer de forma definitiva con el aporte brindado por esta comunidad. Con el tiempo, los pescadores belgas impulsaron también, luego de fracasos y decepciones iniciales, la emergencia de redes empresariales locales y del sector de altura en la ciudad de Mar del Plata (Masid, 2004).

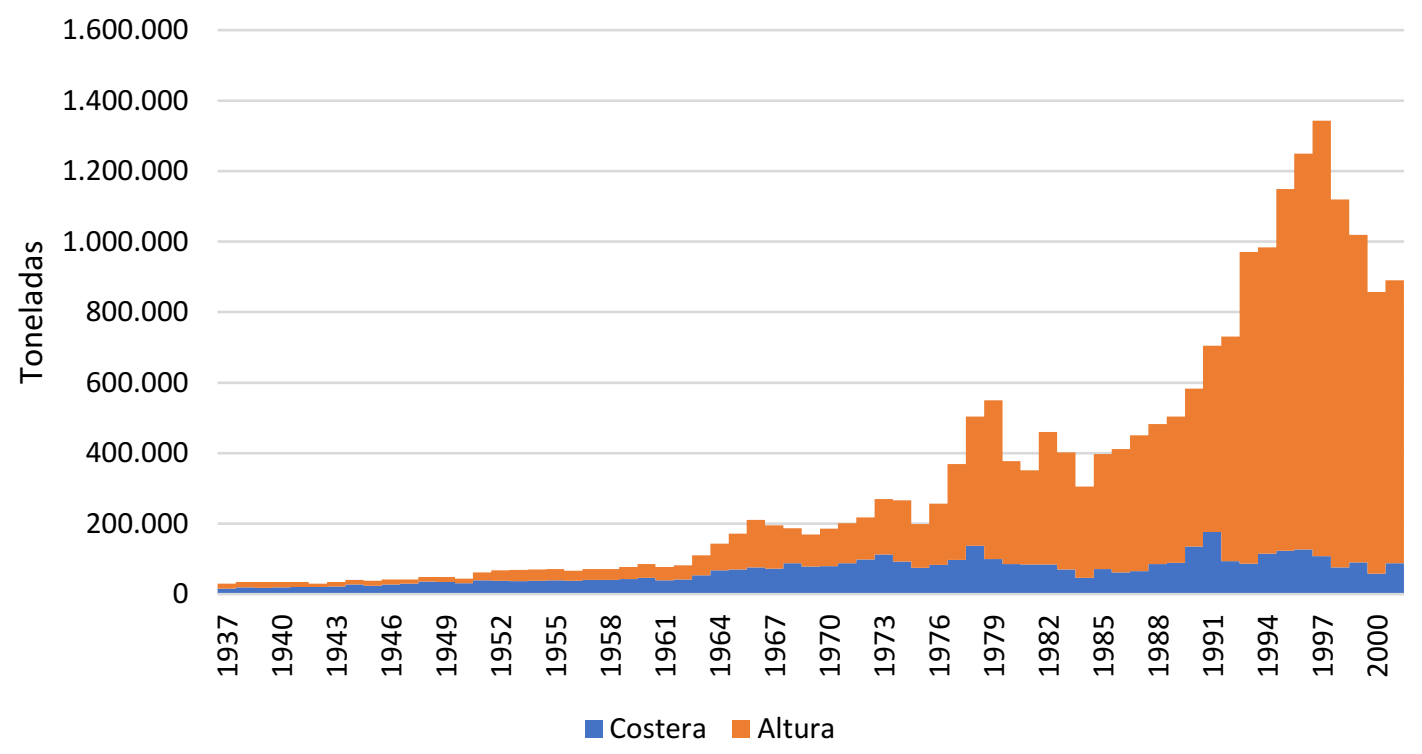

Figura 18. Comparación de las capturas en el mar argentino de las flotas costeras y de altura entre los años 1937 y 2001.

Elaboración propia a partir de Cordini (1960); Bertolotti et al. (2001, 2017); Errazti y Bertolotti (1998) y Lasta et al. (2001).

En cuanto a la industrialización del pescado en la argentina de la primera mitad del siglo XX estuvo asociada, principalmente, a la conserva de la anchoíta y la caballa; siendo luego reemplazado -durante la década de 1960- por un creciente predominio del procesamiento de la merluza (Merlucius hubbsi), cuyas capturas comenzaron a crecer a la par de la flota de altura, impulsada a partir del aporte dado por los pescadores belgas 
(Masid, 2003). Esto se vio potenciado también por un cambio fundamental en la forma de procesar y vender la merluza, ya que se pasa de la venta entera -siendo el vendedor quien lo evisceraba y fileteaba- a la venta como filete ${ }^{51}$ (Mateo et al., 2010). Esto impulsó, además, que las plantas procesadoras de filet de merluza se impusieran a las plantas conserveras, lo que desencadenó toda una serie de transformaciones en las fábricas y procesadoras. Además, como producto del agotamiento de los caladeros de pescado blanco en el hemisferio norte, se produjo una oportunidad para introducir la merluza argentina en los mercados del norte (Pradas, 2006).

Para la misma época se observa una reorientación de la producción pesquera hacia el mercado externo, con lo que se comienza a depender de la demanda y los precios internacionales (Masid, 2005). Junto con esto, la anchoíta y la caballa, principales especies explotadas hasta este momento por la flota costera, con las lanchas amarillas como máximo símbolo (Mateo et al., 2010), son desplazadas por la merluza, en cuya pesca tienen un rol central los barcos de altura, más grandes y productivos (Masid y Mateo, 2008).

\subsubsection{Del país con pesca al país pesquero: 1975 - 2001}

Hacia mediados de la década de 1970 se produce otro cambio significativo en la producción pesquera nacional, en parte producidos por la apertura económica generada por el Gobierno Militar surgido del golpe de estado de 1976. Con el mayor desarrollo de la industria pesquera los barcos congeladores y factorías llegados de otras partes del mundo sobrepasan a los barcos conserveros (Solimeno, 2015). Este cambio, sin embargo, se realizó continuando con la explotación de la merluza, la cual reforzó aún más su rol preponderante como materia prima del mar argentino. Esta especie, que es capturada tanto por la flota costera como por buques de altura, tanto fresqueros como congeladores, así como en la región bonaerense y patagónica, se convirtió en la principal especie objetivo. En general, durante todo el periodo se observa un aumento en los desembarcos, aunque se destacan varias situaciones de crisis en los que se comprueban descensos durante los años 19801985 y 1997-2001 (Figura 19).

El comienzo de este periodo -hasta la década de 1980- se caracteriza también por la firma de una serie de acuerdos que van a implicar la desnacionalización y la sobreexplotación de los recursos marítimos de la ZEE argentina, a pesar de que es un momento en el cual se sanciona y formula gran cantidad de legislación que pretende regular

\footnotetext{
51 Un filete es un corte longitudinal de casi toda una mitad lateral del pescado, del cual quedan excluidas la cabeza, cola y agallas. De esta forma, constituyen la mayor parte de la masa muscular del animal. Se obtienen así, dos filetes de similar tamaño y simétricos, por pescado.
} 
la actividad y propiciar la producción pesquera (Masid, 2005). Una particularidad de la última dictadura militar argentina fue que su principal socio económico fuera la ex Unión Soviética. En efecto, las malas cosechas en la U.R.S.S. la llevó a la compra de trigo argentino compensada con el acceso a la ZEE para la pesca de la potente flota subsidiada soviética.

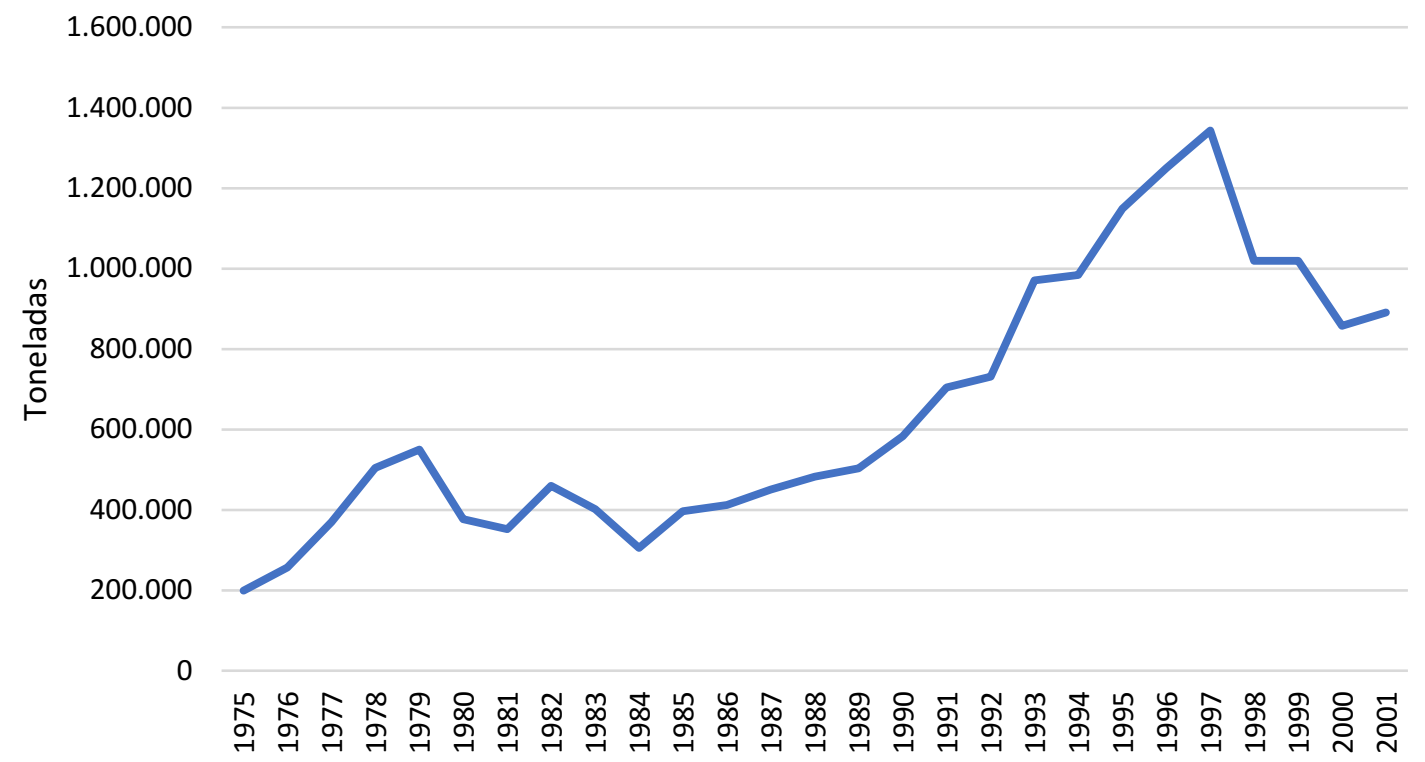

Figura 19. Evolución de los desembarcos totales anuales de productos pesqueros entre los años 1975 y 2001.

Elaboración propia en base a Sánchez et al. (2012).

Otro cambio ocurrido al mismo tiempo conllevó una reorientación de la localización de la producción pesquera. Hasta esta década, la ciudad de Mar del Plata -y la provincia de Buenos Aires- concentraban la gran mayoría de las fábricas y las embarcaciones; pero durante la década de 1970, los puertos patagónicos (Puerto Madryn, Comodoro Rivadavia, Puerto Deseado) comienzan a tener un mayor protagonismo ya que se radican distintos establecimientos y embarcaciones (Mateo et al., 2010). El impulso de los puertos patagónicos fue parte de una política dirigida desde el estado nacional. De esta forma, se generaron legislaciones destinadas a fomentar la pesca en el sur del país. Estos nuevos emprendimientos se caracterizarían por las exenciones impositivas, subvención a la compra de combustibles, ventajas para la exportación, infraestructuras, pero que se orientaron principalmente para recibir productos congelados de buques factorías (Solimeno, 2015). Estos puertos patagónicos comienzan a centralizar las plantas de fileteado y congelado, vinculados con empresas nacionales asociadas a extranjeras cuya producción se destina casi exclusivamente a la exportación (Cóccaro et al., 2002).

Es partir de este momento en que se consolida el tipo de pesca con predominio de los barcos de altura, la fuerte explotación de la merluza -vs. otras especies que 
predominaron en otros momentos-, la producción de filetes de merluza en las plantas en tierra, y un descenso relativo de Mar del Plata como puerto de entrada y sede de establecimientos pesqueros, con una creciente importancia de los puertos patagónicos. Este desarrollo de los puertos pesqueros, tanto los bonaerenses como los patagónicos, es estimulado por las demandas de los mercados externos a los mismos, ya sea por la ciudad de Buenos Aires en los primeros, como la demanda internacional, como en el caso de los segundos, así como también los bonaerenses.

Como vemos, todos estos cambios ocurridos a partir de mediados de la década de 1970 y consolidados en la siguiente, implicaron que las formas tradicionales que se venían desarrollando desde principios del siglo XX decayeran en importancia y se vieran reemplazadas por formas orientadas al mercado externo (Pradas, 2006; Solimeno, 2015).

Sin embargo, en la década de 1990 sobrevendría otra gran transformación en el mundo de la pesca. Durante esos años, se produce un fuerte impulso de la actividad, consolidándose un modelo productivo basado en la valorización financiera, la flexibilización laboral y la relativa expansión interna comercial que benefició y concentró a las principales empresas del sector (Pradas, 2006; Mateo et al., 2010; Colombo, 2011b; Perrota, 2008). Un mecanismo que se comienza a emplear a partir de la década de 1990 es el de los joint ventures, que constituye la formación de sociedades mixtas o asociaciones transitorias. Estos son acuerdos entre empresarios nacionales con grandes capitales de empresas extranjeras, principalmente de Europa -entre estos españoles y en menor medida italianos, japoneses y coreanos, entre otros, que les permitía acceder al mar argentino, mientras que por la parte nacional se propiciaba -en teoría- renovar y reconvertir la flota argentina ${ }^{52}$. De esta forma, los joint ventures le permiten al capital -de origen europeo mayormente, aunque también asiático- dominar la empresa local a través del control tecnológico, al mismo tiempo que se asegura mayor participación de capital, y más altos porcentajes de utilidades y ventas. Si bien existió al principio una división entre los empresarios argentinos a esta entrada y absorción por parte de los capitales extranjeros, terminaron por aceptarlo y aliarse, expandiendo y monopolizando aún más las capturas, la industrialización y la comercialización interna (Pradas, 2006). Esto conllevó también una gran acumulación de ciertos grupos económicos locales y extranjeros privilegiados a partir de la absorción de gran parte de los establecimientos industriales pesqueros que existían en Mar del Plata

\footnotetext{
52 En este sentido, es paradigmático el caso de la flota pesquera española, que a fines de la década de 1980 había perdido sus caladeros históricos en el hemisferio norte, por lo que quedó sobredimensionada, ante lo cual tuvo que optar por dos salidas: el desguace o salir a buscar nuevos caladeros con disponibilidad en otras partes del mundo. Esta última opción fue la elegida para evitar la pérdida de miles de puestos de trabajos en España (Pradas, 2006).
} 
(Colombo, 2011a), la ciudad en la cual esta industria tuvo y tiene mayor influencia y que concentra la mayor producción aún hoy en día. Mientras que en Necochea esta crisis generó el paulatino desguace del sector pesquero (Nogueira, 2018b).

En cuanto a los avances técnicos y la demanda de los mercados internacionales, se produjo un viraje hacia una menor incidencia de sistemas productivos de pesca con fresqueros y el procesamiento en tierra, los que perdieron influencia frente a los barcos congeladores y factoría, en los que se realizaba el procesado a bordo. Según Bertolotti et al. (2001), este representa un cambio principal y estructural en la pesca argentina. Junto con esto, se produjo durante las décadas de 1980 y 1990 un aumento en la extranjerización de la flota de altura, mediante diferentes mecanismos -como el alquiler de permisos de pesca a barcos de terceros países para que extraigan las especies excedentarias- o acuerdos con otros países, como la Comunidad Económica Europea ${ }^{53}$ (Mateo et al., 2010). De esta forma, al final del periodo considerado, las capturas producidas por los buques factorías significaban el porcentaje más alto de lo extraído en el mar argentino (Figura 20). Junto con esto, comienza la explotación comercial en gran escala de calamar y langostinos ${ }^{54}$, para lo cual los buques congeladores (tangoneros para el langostino, poteros para el calamar y arrastreros para la merluza) son de suma importancia (Pradas, 2006).

Ya hacia mediados de la década de 1990 se hace patente que el modelo de explotación del mar se enfrenta a una crisis producto de la incapacidad de renovación del recurso, lo que condujo a su vez a una sobrecapitalización. La orientación de la política pesquera aplicada durante esta década si bien había asegurado un crecimiento importante de la producción y exportación, se basó en la sobreexplotación del recurso principal -la merluza-, la apertura indiscriminada a buques extranjeros, la expulsión de los lideres tradicionales del sector, y la precarización laboral de la mano de obra (Pradas, 2006; Colombo, 2011a).

Como símbolo máximo de la precarización y flexibilización laboral podemos mencionar a las cooperativas apócrifas (o "truchas") que existieron en Mar del Plata durante este periodo. Luego de una ola de quiebras de empresas pesqueras a comienzos de 1990 quedan desocupados una gran parte de la fuerza laboral vinculada con la pesca -estimada

53 Este acuerdo fue producto de negociaciones que llevaron mucho tiempo y trabajo, firmándose en el año 1994. Este facilitó en el otorgamiento irrestricto de permisos de pesca al norte de la zona de exclusión de Malvinas. Luego, ante el evidente colapso del caladero de merluza a los pocos años, no fue renovado en el año 1998.

54 Este último llegó a ser denominado el "oro marítimo", ya que se trataba de un recurso prácticamente desconocido para la industria pesquera comercial argentina hasta comienzos de la década de 1980, pero que al agotarse en los caladeros europeos comenzó a ser explotado en el Atlántico Sur. El mismo permitió aportar al sector enormes divisas (Pradas, 2006). 
en unos 6000 trabajadores- quienes serán utilizados cuando se reactiva la actividad unos pocos años después para flexibilizar el conjunto total de trabajadores pesqueros. Estas cooperativas eran controladas por los empresarios por intermedio de testaferros, a través de las cuales se empleaban trabajadores en negro o que facturaban tercerizados por medio de la cooperativa, y se eludían las legislaciones laborales, se evitaban los aportes previsionales, obras sociales y se exigía flexibilidad horaria ${ }^{55}$. Si bien el trabajo en negro había existido siempre en la industria pesquera, alcanzo un nivel preponderante durante esta década, abarcando a la mayor parte de la fuerza laboral vinculada con la pesca de Mar del Plata. De esta forma, las cooperativas truchas se constituyeron en parte fundamental y necesaria de la industria pesquera (Pradas, 2006, Colombo, 2011a).

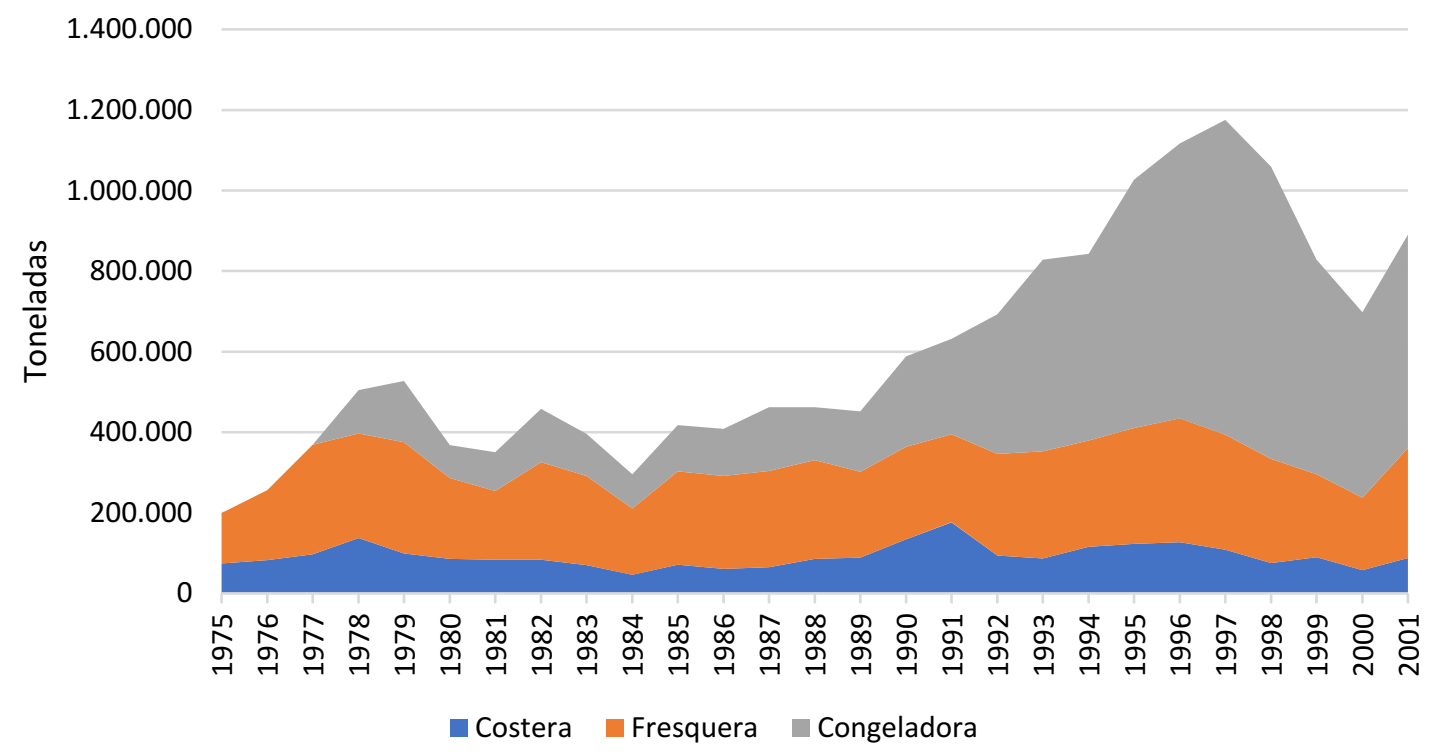

Figura 20. Evolución de los desembarcos totales anuales de productos pesqueros de las flotas costeras, fresqueras y congeladoras, entre los años 1975 y 2000.

Elaboración propia a partir de Bertolotti et al. (2001, 2017); Errazti y Bertolotti (1998); Lasta et al. (2001).

A nivel regional el impacto de la crisis de la merluza no tuvo consecuencias solamente en las instancias de captura sino sobre todo en la industria del pescado, dónde la crisis fue tomada como oportunidad para el sector capitalista empresario para aumentar la flexibilidad laboral con un contexto nacional en torno al trabajo que lo posibilitó. Se incrementó la modalidad de contratados, como trabajo tercerizado. Se dio un auge de estas cooperativas fraudulentas, apócrifas -por no constituirse bajo el ideario cooperativo- o "truchas". La conflictividad aumentó.

55 De esta forma, eran los propios trabajadores quienes debían inscribirse como autónomos, pagar impuestos, jubilación y obra social. 
En síntesis, el desarrollo del modelo pesquero argentino tomó la forma de un modelo extractivo tipo minero, como afirma Cóccaro y colaboradores (2002), de una mercancía cuya valorización la daba la demanda externa. Incluso se ha planteado que las políticas aplicadas en el mar argentino durante la década de 1990 representan un caso claro de neoextractivismo, en el cual el capital globalizado concentrado ha privatizado, mercantilizado y depredado el recurso íctico argentino. Esto generó además el drenaje de los recursos hacia mercados externos, con el consiguiente encarecimiento y escasez en el mercado interno, lo que ocurre con la venia del aparato estatal cooptado por la lógica y los intereses de las empresas hegemónicas, junto con una mayor explotación y precarización de la fuerza laboral (Gómez Lende, 2015). Además, el escaso consumo de pescado en el mercado interior argentino hace de la pesca un insumo esencial para la generación de divisas que sostuvieron el régimen de convertibilidad ${ }^{56}$. De esta forma, año a año se superaron récords de captura, llegándose a un pico en capturas y exportaciones en 1996 año al que Pradas (2006) en su obra lo denominó verdadero canto del cisne de la pesca en el Mar Argentino-. Al año siguiente se produce un descenso brutal en las capturas de merluza, claramente producto de la sobreexplotación, y la explotación máxima plena del calamar y otras especies australes. Esto afectó a ambos tipos de flota, costera y de altura. En sólo tres años se pasó de 316.000 toneladas de merluza en 1997 a 29.000 en el año 2000, menos del $10 \%$. Ante esto, se propiciaron políticas de control para resguardar el recurso, como vedas y paros biológicos. Sin embargo, no se tuvo en consideración las consecuencias económicas y sociales de la escasez y las medidas tomadas, poniendo en riesgo más de 15.000 puestos de trabajos directos sólo en Mar del Plata (Mateo et al., 2010).

\subsubsection{La actividad pesquera y la crisis del sector en clave local}

Durante el desarrollo de la actividad pesquera, la situación de Puerto Quequén en una pequeña escala se desenvolvió de forma acompasada con la situación de Mar del Plata. El producto de la pesca de la descarga de Puerto Quequén sirvió para nutrir la demanda local de consumo de pescado, proveyendo a restaurants, escuelas y pescaderías locales, y durante un período a la industria local del pescado. Además, algunas de las pescaderías, como Santa Cecilia, por ejemplo, se encargaban del procesamiento del pescado fresco, y el resto se comercializaba vía Mar del Plata. Nogueira (2019a y 2019c) registra la existencia de 24 plantas procesadores de pescado en Necochea y Quequén entre 1970 y 2012, que

\footnotetext{
56 Por decreto ley 23.928, desde 1991 y durante once años un peso era equivalente a un dólar estadounidense.
} 
llegaron a representar la ocupación de 3000 puestos de trabajo en el momento de mayor auge. Aunque algunas de las empresas tenían sus propios barcos, la flota costera también abastecía la demanda que generaba la industria del pescado. En los diarios de la época es frecuente encontrar en la sección de noticias locales "De interés para obreros de la industria del pescado" con la descripción de la cantidad de obreras requeridas, el horario y el lugar dónde presentarse ${ }^{57}$.

La industria del pescado nunca se consolidó en Puerto Quequén y su auge también representó el inicio de la decadencia. A inicios del período de interés, en enero de 1975 la prensa local necochense presentaba una serie de notas recuperando la noticia de que obreros y empresarios de la industria pesquera de Mar del Plata mantuvieron una reunión para analizar los problemas por los que atraviesa el sector de la industria pesquera y solicitaron que se declare a la actividad de "interés nacional". Los participantes de la reunión informaron que la flota de altura pesquera necochense estaba operando a un treinta por ciento de su capacidad y que ello dificultaba la ubicación de los productos argentinos en el mercado internacional ${ }^{58}$. La situación de desempleo local que se generó a partir de esto generaba la acción de gremialistas locales en Buenos Aires para exponer la situación de la industria del fileteado ${ }^{59}$. Sigamos por caso, la paradigmática situación que representó Huemul.

En diciembre de 1977 se inauguró en Quequén un complejo pesquero de la empresa Huemul, siendo una de las plantas más modernas del momento. Para 1979 la planta ocupaba a más de 500 personas, mayormente mujeres, y no tenía mano de obra especializada para cubrir todos los puestos disponibles $(700)^{60}$. La fábrica poseía una capacidad de elaboración de 2.000 filetes por día. La empresa tenía seis pesqueros de altura y dos buques factorías. Esta empresa pertenecía al grupo SASETRU ${ }^{61}$, una firma de alimentos que producía aceites, harinas, y conservas, entre otros productos, que al momento era una de las empresas de capital nacional más grandes. En 1980 se comienza a suspender obreras, y en febrero de 1981, se decretó la quiebra de varias empresas del grupo SASETRU ${ }^{62}$, entre ellas de Huemul, luego de un intento fallido de solventar la deuda

\footnotetext{
57 Archivo Ecos Diarios.

58 Archivo Ecos Diarios.

${ }^{59}$ Archivo Ecos Diarios.

60 Archivo Ecos Diarios.

${ }^{61}$ La denominación está dada por las primeras letras del nombre de los tres socios que conformaban el grupo: Jorge Salimei, Ángel Seitún y Fermín Trucco Aguinaga.

62 Diario Excelsior, 6 de febrero de 1981.
} 
estimada en 1.200 millones de dólares. Los barcos pesqueros de la firma, ya inoperativos, se trasladaron en 1983 a otro sector del puerto. Este hecho se concretó a pedido de las empresas vinculadas al puerto "cerealero". Dice la crónica que:

"los buques de la empresa Huemul son un impedimento cuando el puerto trabaja a full para que las cargas se realicen en forma normal y en muchas jornadas, se perdieron de depositar en las bodegas de los ultramarinos hasta 7.000 toneladas de cereal"63.

Por un corto período la planta volvió a estar operativa entre 1987-1988, pero sin llegar al nivel máximo de productividad. En 1998 el predio fue vendido a un valor mucho menor que el estipulado en el precio base del remate (de $\$ 8.444 .906,05$ a $\$ 550.000$ ). Incoop, la firma adquiriente, la convirtió en una planta de frío que empezó a operar en 2003.

La crónica de esta empresa nos permite reflexionar sobre los devenires del desarrollo de la actividad en Puerto Quequén y en el país. Tengamos presente que, como vimos anteriormente, esta situación se da en el marco de un proceso de extranjerización de la captura y el procesamiento de pescado.

Por su parte, con respecto a la crisis que experimentó el sector pesquero a fines de la década de 1990 se sintió de singular modo entre los pescadores en el puerto local. Del análisis de las entrevistas puede recuperarse que la coyuntura crítica del período planteó para los pescadores una situación a partir de la cual definir y redefinir la inserción laboral:

"y antes con todo el despiole del dólar, no había nadie acá casi, va no había nadie, estaban los de las lanchas y se iban porque no se ganaba nada... Sí con la suba del dólar nos benefició, ahora está estable, supuestamente ahora hay muy poco movimiento, pero antes se cambiaba de lancha en lancha acá, en Mar del Plata. Y de la época de dos años atrás se fueron mucho al sur" (pescador Puerto Quequén).

Podemos identificar cómo la crisis afectó a diversos sectores vinculados al ámbito pesquero: por una parte, las empresas que operaban con buques congeladores desde Puerto Quequén, por el otro lado, la situación de los pescadores costeros influenciada por el bajo rendimiento de tener sus precios ligados al dólar y las disminuciones en las capturas. Un patrón de pesca sostenía en 1999 sobre la situación de los pescadores de lanchas costeras "en muchas ocasiones, los marinos no ganan ni para darle de comer a sus familias. Si

\footnotetext{
63 Archivo Ecos Diarios.
} 
consideramos un salario básico en 400 pesos mensuales, se puede decir que hoy en día los marinos no ganan ese dinero"64.

Durante la primera mitad del año 1999 se declaró la Ley de Emergencia Pesquera, que dividió la explotación pesquera en general en dos zonas separadas por el paralelo $48^{a}$ de latitud sur. Al sur sólo podrían operar los buques congeladores, mientras que al norte los buques fresqueros. Además, se declaró una veda de la merluza, cuya explotación sin control habían hecho descender dramáticamente las capturas. Sin embargo, esta veda no era total, ya que se autorizaba a la flota radicada en Mar del Plata podía seguir capturando merluzas por decreto para evitar un impacto más fuerte sobre la comunidad pesquera de dicha ciudad. En este contexto, la mayoría de las notas del diario local hacen referencia a la situación crítica que atraviesan los trabajadores de la pesca local, con títulos como "La pesca local atraviesa por un momento difícil", "Más de 700 trabajadores ven peligrar su trabajo", "Trabajadores locales perjudicados". En términos del diario la "difícil” situación económica se encontraría relacionada a "la disminución de la captura asociada a los bajos precios del mercado".

En mayo de ese 1999, mientras se debatía la Ley de Emergencia Pesquera, se advierte sobre el impacto "social y laboral" que tendrá la medida para la comunidad. Estima que entre pescadores, estibadores y relacionados se perderán unos 700 puestos de trabajo. Sin embargo, recalca que la medida no afectará tanto como a Mar del Plata, ya que en Necochea y Quequén luego de una época floreciente dos décadas atrás "el sector ingresó después en una pronunciada pendiente y prácticamente las fábricas desaparecieron de escena"65. El 6 de junio, publican "unas 1700 personas de Necochea relacionadas con la pesca se perjudicarán como consecuencia de la decisión adoptada por el Congreso de la Nación, de excluir a los buques congeladores de las zonas donde habitualmente operaban en la captura de la merluza hubbsi, permitiendo que sólo lo hagan los fresqueros" de Mar del Plata. Los dirigentes del SOMU66 advierten sobre la posibilidad de efectuar una movilización a Capital Federal por considerar la medida como "discriminatoria". Según las declaraciones de los gremialistas "aquí se produjo un acuerdo político porque había que darle una salida al problema social que afectaba, en mayor medida, a Mar del Plata"67.

Las medidas implementadas por el gobierno nacional frente a la situación crítica de la merluza afectaron los intereses de empresas radicadas en este puerto, creando además

\footnotetext{
${ }^{64}$ Archivo Ecos Diarios.

65 Archivo Ecos Diarios.

${ }^{66}$ Sindicato de Obreros Marítimos Unidos.

67 Archivo Ecos Diarios.
} 
susceptibilidades el hecho de que la misma no se aplicara a la flota de Mar del Plata. El 28 de mayo de 1999 se publicó en Ecos Diarios una solicitada de página entera, dirigida al Sr. Intendente Dr. Julio Municoy con el encabezado "Crisis Pesquera" y firmado por las empresas: Vieira Argentina S.A., Armadora Latina S.A., Argemer S.A. y Pesquera Quequén S.A. En la solicitada se reclama:

\begin{abstract}
"Aplicación irrestricta de la Ley Federal de Pesca. La ley es federal y no sectorial. Puesta en vigencia de inmediato el régimen de cuotificación. La no aprobación de la ley de Emergencia pesquera, que implicará la inmediata paralización de la actividad pesquera en la ciudad como mínimo hasta fin de año. Si el recurso está en crisis, está en crisis para todos. Si se puede seguir pescando, podemos seguir pescando todos. No a la discriminación. No al manejo político del modelo pesquero"68.
\end{abstract}

Otro hito de la pesca local en crisis sucedió en el año 2000, cuando durante mayo y junio la flota costera estuvo paralizada. Las apreciaciones de los pescadores remiten a un conflicto de intereses entre los trabajadores, los dueños de barco y la representación gremial.

"El Somu de Mar del Plata decidió el paro. Pararon, jse pararon ellos mismos! Porque el barco, en realidad, no lo podés mover por presión. $Y$ por supuesto que no es por decisión propia, porque en realidad nosotros, mirá: de los cuatro marineros, dos eran dueños y los otros dos no querían saber nada con parar, pero el barco tuvo que parar" (esposa de pescador dueño de barco).

¿Cómo se vivió el conflicto en Necochea? Según una nota de Ecos Diarios del 9 de junio de 2000:

"la flota pesquera local (lanchas amarillas) se halla inactiva desde hace 40 días, agudizando la crisis económica que atraviesan alrededor de 200 familias necochenses vinculadas a la actividad. La colonia pesquera no sale a trabajar por la persistencia del problema, agravado ahora por las amenazas que vienen recibiendo los propietarios de los llamados barcos fresqueros, luego de que se originara el conflicto en Mar del Plata".

\footnotetext{
${ }^{68}$ Archivo Ecos Diarios.
} 
Uno de los propietarios amenazados cuestionó la decisión del intendente de Mar del Plata, Elio Aprile de "ponerse al frente de los reclamos (ya que) ha perjudicado a otras colonias como la nuestra" y sostuvo que "la flota necochense no tiene capacidad financiera para soportar esta situación".

En abril de 2001 el SOMU advirtió con realizar medidas de fuerza en relación con el ingreso de buques extranjeros que pescarían calamar y que según denunciaron no tienen ningún trabajador argentino. Mientras que, en junio de ese año, sectores relacionados con la actividad pesquera y empresas de servicios elevaron una nota al presidente del Consorcio de Gestión de Puerto Quequén. La nota firmada por la Cámara de Empresas de Servicios Portuarios, Cámara Comercial e Industrial de Necochea-Quequén, Engraulis, Pesqueros de Altura, Pesqueros Costeros, Sindicato de Obreros Marítimos Unidos, Sindicato de la Industria de la Alimentación, Unión Personal de Seguridad de la República Argentina, Industrial Pesquera, la Portuguesa, Apuntadores Marítimos (Seamara) y Aduana (Supara), sostiene que: "consideramos que la actividad está en franca decadencia a partir del retiro de armadoras importantes como el caso de Vieira Argentina SA y de Pereyra SA, con el consecuente abandono de las instalaciones" 69 . El detonante fue la situación por la que buques cajoneros no pudieron realizar la descarga en el puerto local, teniendo que hacerlo en Mar del Plata. En octubre la Cooperativa de Trabajo Puerto Quequén Limitada presentó un proyecto al ministro de la Producción de la Provincia de Buenos Aires, Federico Scarabino, en el que se trabajaba desde el año 2000, con la propuesta de traer a la ciudad 50 lanchas para la pesca artesanal.

En síntesis, los procesos que afectaron a la actividad pesquera en el país (por ejemplo, el incremento de la flota, de las capturas, la extranjerización, tercerización y precarización del trabajo) tuvieron en Puerto Quequén una repercusión tal que devino en la reducción de las capturas desembarcadas y en la virtual desaparición del procesamiento en tierra en el ámbito local. Los pescadores y quienes se ocupaban de la industrialización del pescado tuvieron pocas alternativas, o abandonar la actividad, o subsistir dentro de una situación hostil o migrar hacia aquellos puertos donde aún se los demandaba, aunque en condiciones precarias ${ }^{70}$.

\footnotetext{
${ }^{69}$ Archivo Ecos Diarios.

${ }^{70}$ Rispoli (2006a).
} 


\subsection{Representaciones locales sobre la situación del recurso pesquero}

Para que pueda desarrollarse la actividad pesquera tiene que haber recursos disponibles. Para que el de pescador sea un trabajo posible, para que la pesca sea una potencial actividad económica rentable se requiere una base material sobre la cual establecerla. La gran crisis pesquera de fin de siglo XX representó la pérdida de la ilusión sobre la supuesta inagotabilidad de los recursos base de la actividad pesquera. Esta ilusión atravesó diferentes actores sociales con diferentes responsabilidades desde los cuadros político-estatales, los privados-empresariales, los gremiales y de los trabajadores.

A continuación, exploramos algunas de las representaciones sobre la situación del recurso y de la causalidad-sin ponderar el peso real o figurado- de la crisis acontecida desde la perspectiva de los pescadores.

"No es que la pesca se esté quedando sin pescado, hay que dejarlos reproducirse (...) sí hay menos que antes, pero no solamente por el tema de la pesca, yo no estoy muy empapado en el tema de lo que es la ecología y eso, pero es que está cambiando todo. Antes no había mal tiempo como hay ahora, que hay viento, hay lluvia (...) y otra, los barcos extranjeros, vos fijate que siempre están agarrando barcos detrás de las 200 millas (...) ni siquiera tienen tripulación argentina, ni le dan trabajo a la gente de acá" (pescador costero, entrevista).

"La realidad que vivimos actualmente es la consecuencia de la gran depredación que tuvo lugar en nuestro mar territorial durante los últimos años, sobre todo de los pesqueros de altura y barcos factorías que desarrollaron sus actividades sin ningún tipo de control gubernamental" (patrón de pesca, archivo Ecos Diarios).

En tanto que, un propietario en una entrevista sostiene enérgicamente: "Yo creo que el origen de esto es causado por la parte política y de pesca de nación que ha permitido que en sus épocas anteriores dejar entrar a empresas extranjeras con barcos, de gran porte". Por su parte los gremialistas locales se quejan de las medidas restrictivas y sostienen que "se llegó a esta situación por las desacertadas políticas de los gobiernos nacionales que permitieron que operaran naves extranjeras sin control, denunciando casos de corrupción"71.

Entre los pescadores de Necochea-Quequén y a partir de las entrevistas -tengamos en cuenta fueron realizadas con posterioridad al momento crítico de la pesca regional y

\footnotetext{
${ }^{71}$ Archivo Ecos Diarios.
} 
local- podemos recuperar en lo discursivo una moralidad de sentido ecológico sensu Balbi (2007a) pero este sentir ecológico sobre la situación pesquera y la ubicación de los pescadores mismos como actores involucrados en la situación no aparecen en primer plano. Entre los pescadores, en primer lugar, es posible reconocer una serie de apreciaciones sobre la causalidad de la crisis que la sitúan en el plano político regulatorio nacional, en la acción de las grandes empresas y en el accionar de las empresas extranjeras. Sin embargo, nos detenemos en lo recuperado en varias entrevistas que rescatan la reflexión sobre las propias prácticas de pesca. Con la red de arrastre (arte de pesca mayormente utilizada) les resulta imposible diferenciar el pescado colectado. Recién en cubierta, donde los peces son clasificados por tipo y tamaño puede decidirse cuáles se conservarán en función de su valor económico, y también en algunos casos en función de los requisitos de tamaño tardíamente establecidos y poco controlados. Aquellos animales descartados vuelven al mar, mayormente muertos y tienen impacto en la ecología. La FAO calcula a nivel mundial para la pesca de arrastre un descarte de aproximadamente $50 \%$ del volumen pescado recuperado (Kelleher, 2008), y como forma de reducirlo se destaca como necesaria la reducción de la pesca incidental en lo que impacta positivamente el uso de tecnología; el mejor aprovechamiento de las capturas, y los incrementos de las regulaciones y formas de control. Los pescadores perciben el impacto negativo del descarte en el desenvolvimiento de la pesquería, sin embargo, no lo ubican como el elemento más significativo. Además, en las entrevistas se permea una potencialidad de lo que "deberían hacer" no se condice con lo efectivamente hecho recuperamos descripciones como "no deberíamos tirar tanto pescado al mar", "...con los juveniles pasa que no se pueden pasar, no se pueden pasar pero igual se pescan, se agarran y se tiran, ya no sirven más esos peces pero que se puede hacer...".

En relación a la extracción y disminución de recursos algo que también se plantea es una interpretación basada en el antagonismo entre barcos pequeños y barcos grandes “...cada vez hay menos recursos, pero lo que pasa es que han hecho, han dado permisos de pesca indiscriminadamente a barcos muy grandes". Y la alteridad con los barcos extranjeros "de España, la cantidad de barcos que han venido y los dejaban pescar en cualquier parte".

Durante el período también se incorporaron cambios tecnológicos que tuvieron un gran impacto tanto en la intensificación de la apropiación de los recursos como en el propio desarrollo cotidiano de lo que es salir a pescar. La incorporación del uso de GPS, la sonda, sonar, radar son destacados. También el uso de sistemas de pronósticos meteorológicos específicos. La sonda una unidad de control envía impulsos eléctricos a una placa que emite ultrasonidos cuando detecta cuerpos sólidos. Al trabajar con el rebote del sonido, puede estimarse la profundidad. Estos cambios son muchas veces referenciados en las entrevistas para marcar un tempo distinto al "ir a la pesca". Los recuerdos del tiempo del antes, de los 
mayores riesgos, del no tener comunicaciones frecuentes, de las salidas diarias y sin siquiera cocina en las lanchas marcan también un cambio en la consideración de la actividad.

Los momentos de decaimiento de la actividad, son explicados por acciones en el plano político que repercutieron en el plano ecológico, sobre todo en referencia a los acuerdos firmados por los cuales "les regalamos el mar", "nos sacaron todo", "limpiaron el mar". Aquí la "moral ecologista"72 es depositada en un otro cercano, que es asumido como el que debería hacerse cargo de la preservación del recurso: el sector político "y no hay más pescado por los políticos" y en un otro encarnado por los barcos y pescadores extranjeros aparece como lejano en el imaginario, pero que puede resultar cercano en lo físico, ya que la mayoría de los pescadores entrevistados trabajaron en varias oportunidades con pescadores extranjeros, que se significa como amenazante de los recursos "propios"73. Las enunciados de los pescadores, y sobre todo de los capitanes y patrones de pesca (que son quienes toman las decisiones sobre la producción en el barco) en referencia a la situación del recurso, son muy complejas ${ }^{74}$, destacamos que se observa tanto una externalización: "no se lo cuida al recurso" como una inclusión de la primera persona en la explicación de las causas del agotamiento "pescamos de más" "tiramos muchos pescado al mar", "cada vez agarramos más chicos".

\subsection{Las (i)lógicas de la racionalidad}

Los fenómenos sociales-económicos tienen una naturaleza compleja. Lo económico representa un campo particular de las relaciones sociales. El comportamiento de los pescadores de Puerto Quequén no puede pensarse por fuera del sistema económico más amplio en el que ellos construyen sus subjetividades y toman sus decisiones.

La discusión sobre la sustentabilidad del recurso, las formas de su apropiación, supone una complejidad en la intersección de múltiples intereses. Se hace imprescindible considerar el conocimiento científico sobre la explotación del recurso, también los

\footnotetext{
72 Para un interesante análisis de cómo pueden operar los discursos ecologistas en el caso de pescadores ver los trabajos de Balbi (2000, 2007a y 2007b).

${ }^{73}$ Las comillas enfatizan el sentido de propiedad de los recursos que aparece ligado no a lo personal sino a nacional.

${ }^{74}$ Involucran la tensión entre la necesidad de pescar más (y ejemplares más pequeños) para ganar más y la contradicción con la sustentabilidad de la preservación del recurso a largo plazo. Se destacan sentimientos como la culpa por el descarte, el no cumplimiento de las normas que se yuxtaponen con el énfasis competitivo de la actividad en términos que los actores mismos han llamado como "deportivos" por el cuál intentan pescar más, aunque no sea para venderlos sino como parte de un "juego entre los barcos".
} 
mecanismos normativos para regular su manejo y, además, considerar la efectiva aplicación que pueda darse. Cuando revisamos desde los múltiples niveles la situación en torno al desarrollo y al colapso de la pesquería de orientación comercial en Argentina, encontramos una contradicción de lógicas, entre el corto y el largo plazo, entre lógicas individuales y sociales, comerciales y ecológicas. La contradicción de lógicas que se expresa en los pescadores "hay que cuidar", "hay que aprovechar más" es necesario ponerla en la situación concreta de la vida de los pescadores.

La discusión, sobre la apropiación del medio marítimo es muy extensa y controvertida, ya que involucra a diferentes actores sociales con distintos intereses en juego y con diferentes capacidades de decisión, como por ejemplo a los propios pescadores, el estado nacional, otros estados y los investigadores. Quién y cómo se accede a recursos compartidos es un tema que ha generado amplio debate. Algunos estudios han sostenido que el mar es una propiedad comunal accesible a todos por lo que, con el aumento de la población se generaría una "crisis" en los recursos pesqueros. Esta tesis conocida como la "tragedia de los comunes" (Hardin, 1968), no es un modelo susceptible de ser universal. La interpretación de Hardin se asienta en la concepción de que la racionalidad occidental capitalista de maximización de las ganancias es la única posible y desestima las formas autogestivas que los grupos humanos tienen para regular el acceso a recursos como los peces (Acheson, 1981; Sánchez Fernández, 1992; Ferrero y Arizpe Ramos, 2015). Según el planteo de Hardin, las personas, motivadas por intereses personales, actuando de forma independiente y racional, terminan por destruir un recurso compartido finito. Más allá de que tanto individualmente, o en su conjunto no represente una decisión racional, las decisiones independientes llevan al colapso del recurso. La alternativa que Hardin plantea a esta situación formalmente implicaba una 'privatización' de los recursos, tal y como ocurrió con el establecimiento de las cuotas individuales transferibles. Muchas veces la "tragedia de los comunes" fue utilizada para justificar la intervención total en el manejo de los recursos, o para establecer derechos de uso de recursos naturales como cuotas intransferibles (Bertolotti et al., 2008), sin que esto diera el resultado esperado: un mejor reparto de los recursos y una explotación sustentable de los mismos a largo plazo. Y desconociendo las formas en que los grupos han organizado y limitado el acceso a los recursos.

El problema que se suscita radica en cómo la comunidad logra acuerdos sobre cómo manejar esos recursos comunes y de qué modo se efectiviza la apropiación sobre ellos. Las poblaciones costeras ejercen la pesca en el marco de la legalidad establecida por los Estados, y la forma que asume el control de estos recursos, el manejo y la habilitación para el acceso a los mismos implica complejas negociaciones que involucran beneficios o 
perjuicios a diferentes grupos y/o actores sociales. Muchas de las lanchas amarillas que son objeto de reflexión en esta tesis contaban con permisos de pesca de tipo nacional, estos permisos se volvieron valiosos por sí mismos por el tipo de permiso de pesca que las habilitaba a pescar, y en un momento pasaron a tener más valor que el barco en sí. Más allá de los marcos de legalidad, entre los grupos que obtienen recursos del mar suelen establecerse normas y derechos de uso regidos por la tradición y la costumbre, establecidos y regulados por las propias comunidades (Pascual Fernández, 1991b y Sánchez Fernández, 1992).

Un aspecto sobre el que debemos reflexionar a partir de las consideraciones de los pescadores sobre el recurso tiene que ver con la proyección que realizan sobre la actividad a futuro. En las entrevistas, retomamos en el imaginario la potencialidad de la finitud del recurso pesquero, pero no como una realidad factible de sucederle a ellos sino, intuimos, como una posibilidad abstracta. Discursos como "cada vez son más chicas las merluzas", “...no va haber para siempre, se nota, se nota que hay menos pez", "y que sé yo para cuántos años más hay, si ya casi no hay pescado en el mar, hay que ir cada vez más lejos, hay que trabajar más para lo mismo o para menos", aparecen entre el reconocimiento de la realidad del recurso y la actividad pesquera como oficio.

Más allá de que, como anteriormente referimos, siempre hubo normas en relación con la propiedad del mar y sus recursos; durante el período de estudio se dieron cambios significativos en la regulación de este. Pero sobre todo queremos remarcar, que los cambios se produjeron no solamente en el plano abstracto de la reglamentación sino, también, del mayor interés por el efectivo control sobre la producción pesquera, hacia el final del período con mayor interés de la Provincia de Buenos Aires, que a través de la Ley №11.449 estableció un convenio con Prefectura Naval Argentina para el control de pesca y desde la Municipalidad de Necochea a través de la Subsecretaría de la Producción, de tener control sobre las descargas de pescado en el puerto. En 1994 la provincia estableció la Ley № $11.477^{75}$, que entre otras cosas crea la Subsecretaría de Pesca en el ámbito del Ministerio de la Producción de la Provincia de Buenos Aires. Por lo que consignan los entrevistados, tradicionalmente los "partes de pesca"76, no necesariamente reflejaban o se acercaban a la realidad de la descarga ${ }^{77}$ de pescado en puerto, los porcentajes de producción "en negro"

\footnotetext{
${ }^{75}$ Reglamentada por el decreto 3237/95.

76 Corresponde a una información escrita que al finalizar cada marea remite a la autoridad cada embarcación. Consigna zona de pesca, volumen, especies capturadas, entre otros datos. Tiene carácter de declaración jurada.

77 También es interesante marcar la distinción entre "descarga" que es el valor requerido en la declaración, del valor "captura". Teniendo en cuenta que, en la pesca, sobre todo con la red de arrastre, la selectividad no está garantizada y hay un alto porcentaje de "descarte" pesquero
} 
son altos. Esta tesis toma como referencia la pesca comercial marítima, sin embargo, no podemos dejar de mencionar que al finalizar el período se estableció, y en el período siguiente hubo un auge de actividad pesquera en gomones de tipo semirrígido, un tipo de pesca de menor escala, menos y más difícil de controlar y que empezó a operar con un tipo de permiso de pesca deportivo pero que se orienta también a la comercialización, y que es definida y caracterizada como de tipo "artesanal".

\section{Palabras finales}

En este capítulo recuperamos la historicidad en la que se desarrolla y aumenta exponencialmente la explotación del recurso ictícola, tanto a nivel mundial como nacional, y la inserción de este en circuitos económicos y sociales más amplios. Además, exploramos las representaciones locales sobre la situación. Hemos visto como a lo largo del repaso histórico a distintas escalas se comprueba una intensificación en las capturas seguido por cambios en las legislaciones internacionales y nacionales, que en parte son producto y la consecuencia de crisis generadas en la explotación producidas por cambios tecnológicos y de demanda, pero que en todo caso llevaron a nuevas y más complejas crisis, y cada vez una mayor "privatización" del recurso. Como podemos evaluar para el Mar Argentino, y a contraposición de lo planteado por Hardin, la existencia de mayores regulaciones estatales no garantiza que se preserve el recurso, menos aún que las poblaciones locales tengan mejor acceso a él. De esta forma, llegamos al final del periodo analizado en el cual se comprueba una crisis que es percibida por los propios pescadores de Puerto Quequén casi como terminal. Con Alegret (1989) sostenemos que "el proceso productivo pesquero puede llegar a constituir un buen ejemplo de cómo el capitalismo actúa sobre el trabajo humano". Este autor sostiene que "la planificación económica en la pesca tanto artesanal como industrial, históricamente se ha visto obligada a apoyarse sobre dos únicos elementos 1) la ampliación e intensificación del esfuerzo de pesca y 2) el control y movilización de la fuerza de trabajo". Continuaremos explorando sobre los aspectos vinculados al trabajo en el sector pesquero, y a la forma en que los sujetos se insertan él en los próximos capítulos.

(recursos devueltos al mar por su baja rentabilidad en mercado). 


\section{Capitulo 4.}

\section{Ir a la pesca en Puerto Quequén}

\section{Introducción}

Tomando como punto de referencia los barcos de la flota costera de Puerto Quequén, este capítulo tiene por intención describir las características de esta y su producción histórica con énfasis en el periodo de estudio. En segundo término, presentar al barco como unidad productiva, destacando las singulares características que implica en él la organización del trabajo y las relaciones de producción. En tercera instancia, pero no por ello menos relevante, se presentan vías de interpretación sobre lo que representa simbólicamente la embarcación y el trabajo en el barco para los trabajadores-pescadores.

\subsection{Notas de banquina ${ }^{78}$}

Llego a la banquina, es una mañana fría y nublada. Los barcos están amarrados en filas de a tres, unas lanchas detrás de otras. Don Domingo, Puerto Quequén, Ángel Antonio, Virgen de las Nieves, Eusonia, Yguá. El Silvia Yolanda y la Cruz del Sud. También Dock Urano, Puerto Natale, y otro que no alcanzo a ver el nombre... Es el Marea. Más adelante, Volador, Don José y alguno más. En la banquina rastros de redes y el tordillo. Algún personal de Prefectura y algún estibador dando vueltas.

Llegan y desaparecen, una vez que suben al barco, ya casi no los veo. Es media mañana y pareciera que están vacíos los barcos.

El flaquito que estaba el primer día buscando "subir" a algún barco me ve y me pregunta si quiero subir a tomar mate. Hoy está en otra lancha, pero embarcado.

El joven marinero de Prefectura está fuera de la garita charlando con un viejo despachante "para matar el tiempo". Solamente pasaba a avisar que entraba al puerto, pero me quedé charlando con ellos. Me contó el despachante que sólo una vez salió al mar con su

\footnotetext{
78 Se presenta una selección de extractos de las notas de campo en la banquina.
} 
suegro que era pescador y le dio "mal de mar", no quiso saber de salir nuevamente. Mientras hablaba con ellos en la garita, veía como los barcos se preparan para salir, cargaban el hielo. No todos, las más "grandes" de las lanchas amarillas, y de ellos los que tenían la tripulación lista. Es que hasta el día anterior el tiempo era malo, según venían siguiendo el "windgurú"79. Aunque frío (es julio) a mi parecer se trata de unos días espléndidos, soleados y sin viento, pero en el mar parece que las olas son grandes como para que salgan los barcos más pequeños vaticina el servicio que también usan los surfers. El día anterior, me decía uno de los patrones del barco más chico "seguro que mañana ellos ya pueden salir, nosotros tendremos que esperar un día más”, y siendo mitad de mes, no han podido salir todavía.

Hoy son pocos los barcos que están en puerto, la mayoría está en altamar, hay buen tiempo, pero algunos por diferentes problemas dos tuvieron que volver antes. Los estibadores en la banquina me dicen que hay gente en el barco, que pase. Lo dudo, no me animo, el nivel del agua está más bajo que la vez anterior y me imagino en el agua haciendo un papelón. Al rato, no puedo evitarlo, me tengo q animar, pido ayuda y allá voy. Están todos revolucionados en el barco, se mueven de acá para allá, se quemó un motor y lo están arreglando, me invitan a bajar a la sala donde está el mecánico. Sólo pienso como cuatro o cinco hombres pueden movilizarse en un espacio tan estrecho (y eso q ahora el barco está quieto). Todavía no diferencio quienes "trabajan" en esa lancha de quienes están "de visita". El tema de conversación es que en las últimas dos salidas tuvieron que regresar antes, "primero un flaquito se descompuso, ahora el motor".

Los estibadores ayudan con las amarras para que los barcos salgan, primero el Natale, después el Don José. En otros barcos mientras tanto cargan la comida, los que van a salir.

Con el mismo ritmo (de pronto y sin aviso) dos que están abajo suben al barco, uno que estaba arriba, baja, y así, sin comentarios ni gestos, cada uno en su tarea el barco ya está saliendo. No miran hacia la banquina, están camino al mar. Los que estamos allí los seguimos con la mirada, por un rato nadie habla...

Es de tarde, llega un barco y rápidamente se descarga todo. Estaban todos listos esperándolos. Al rato llega otro.

Esta tarde hay mucho movimiento en la banquina, hay mucho buen humor. Bajaron una red rota del barco y tres están arreglándola.

Además de los pescadores, del personal de prefectura, de los estibadores, de los que están con las lanchas deportivas, en banquina siempre hay imperceptible rotación de gente.

\footnotetext{
79 En referencia al programa Windguru (https://www.windguru.cz/) que usan para seguir el pronóstico que incluye intensidad y orientación de los vientos en altamar y la altura de las olas. Usan una versión paga.
} 
Algún marinero buscando embarcar, algún viejo pescador o un muchachito que no sale en los barcos chicos porque le hace mal, no sale en los barcos grandes porque son muchos días o porque no consigue. Pero él no puede dejar de estar allí. Le regalan unos pescados para "darle una mano" y los filetea para venderlos.

\subsection{Los barcos y las artes}

En la costa argentina, durante el periodo analizado operaron y operan distintos tipos de barcos. En función de la envergadura de la embarcación se definen las zonas donde van a realizar las capturas de peces, las artes de pesca que emplean, el tiempo de permanencia en el mar que tienen permitido por la autoridad de control, la Prefectura Naval Argentina ${ }^{80}$, y la cantidad de tripulantes que se embarcan.

A partir de las definiciones realizadas por Bertolotti y colaboradores (2001), quienes emplean criterios socioeconómicos que contemplan las dimensiones de las embarcaciones, el tipo de organización empresarial y laboral, así como el sistema de retribución de la tripulación se puede clasificar a la flota pesquera marítima argentina en dos grandes categorías: industrial y de pequeña escala o costera.

Existen otras clasificaciones, ya sea según su tamaño y posibilidades de navegación, dividiéndoles en barcos de altura, media altura y costeros. También se puede considerar el tratamiento que se le da al pescado, para lo cual tenemos barcos fresqueros, congeladores y factorías. Los primeros son aquellos que desembarcan el pescado fresco solo conservado en hielo para su procesamiento en plantas en tierra; los segundos ya practican el congelamiento del pescado a bordo; mientras que los últimos realizan directamente todo el procesamiento mediante maquinarias incorporadas y pueden ser considerados fábricas flotantes (Madaria, 1999).

En la flota pesquera industrial o de altura los barcos son de medias y grandes dimensiones que operan en alta mar. La pesca seguida por estas embarcaciones tiene como orientación el procesamiento industrial del recurso. Para ello, las capturas son llevadas a cabo de forma selectiva hacia una o pocas especies, empleando complejos sistemas mecánicos de maniobra e infraestructura para poder conservar y procesar el pescado a bordo. También se la denomina de altura, haciendo referencia a la capacidad operativa de

80 Esta realiza la clasificación de las embarcaciones según tipo de flota teniendo en cuenta el radio de acción de las mismas, que es definido por las características estructurales del casco, la estabilidad, los equipos de comunicaciones, la capacidad de alojamiento y el combustible, entre otras variables (Perrota et al., 2007). 
las embarcaciones para alejarse de la costa para ir a caladeros en aguas profundas o seguir a los recursos migratorios (Azcarate, 2009).

Existen distintos tipos de barcos para la pesca industrial, cuyas variaciones y características se deben al recurso específico al que están orientados, los pasos dentro de la secuencia de producción que realizan y el volumen que pueden procesar. Es así como existen barcos con artes selectivas (tangones ${ }^{81}$, palangres ${ }^{82}$ y poteras ${ }^{83}$, por ejemplo), y dentro de la pesca industrial se pueden diferenciar dos grandes tipos de embarcaciones: los fresqueros y los congeladores.

Los buques fresqueros son barcos de más de $22 \mathrm{~m}$ de eslora, que operan como arrastreros. Poseen bodegas refrigeradas para conservar el pescado, ya sea entero o procesado, que es enfriado con hielo. Estos barcos cuentan con equipos de navegación y detección. Las capturas las realizan mediante redes de arrastre, tanto por banda como por popa. Este tipo de barcos suelen pertenecer a empresas que tienen plantas industriales en tierra.

Los barcos congeladores tienen más de $23 \mathrm{~m}$ de eslora y cuentan con una mayor autonomía que los fresqueros, llegando a poder estar en el mar durante meses. Estos poseen equipos de congelación y mantenimiento congelado de las capturas, y cuentan con equipos de procesamiento de los recursos antes de su congelamiento, logrando de esta forma generar directamente arriba del barco productos para consumo intermedio o final. Incluso algunos cuentan con tecnología que permite el supercongelado, a temperaturas que alcanzan los $-50^{\circ} \mathrm{C}$.

La flota pesquera de pequeña escala o costera constituye la categoría de barcos que emplean en mayor medida los pescadores que han sido entrevistados y son objeto de la presente tesis. A su vez, todos los barcos pesqueros asentados en Puerto Quequén pertenecen a esta categoría (Figura 21). Es por ello por lo que nos detendremos con mayor detalle en la descripción y caracterización de este tipo de flota. Corresponden a las

\footnotetext{
${ }^{81}$ Buques procesadores congeladores que emplean dos redes de arrastre de fondo, una por tangón postes que se abren a cada lado del barco desde los cuales se extienden las redes, una por cada lado. Están orientados para la captura de langostinos. En general, operan en la zona interior y exterior del golfo San Jorge.

82 Buques procesadores congeladores que emplean palangres de fondo, esto es un largo espinel del cual cuelgan anzuelos con carnada, para la captura de merluza negra, aunque ante su ausencia pueden orientarse a la pesca de abadejo o rayas. La zona de pesca suele ser el borde del talud continental.

${ }^{83}$ Buques procesadores congeladores que operan con máquinas poteras, en las que se arrojan al mar líneas con anzuelos especiales y se emplean poderosas lámparas para atraer a los cardúmenes de calamares, que son la especie para la que se emplean.
} 
conocidas comúnmente como lanchas amarillas ${ }^{84}$, aunque existen algunas diferencias entre ellas según sus dimensiones, capacidad de carga y alcance permitido (Figura 22), así como el tiempo que tienen habilitado para estar en el mar.

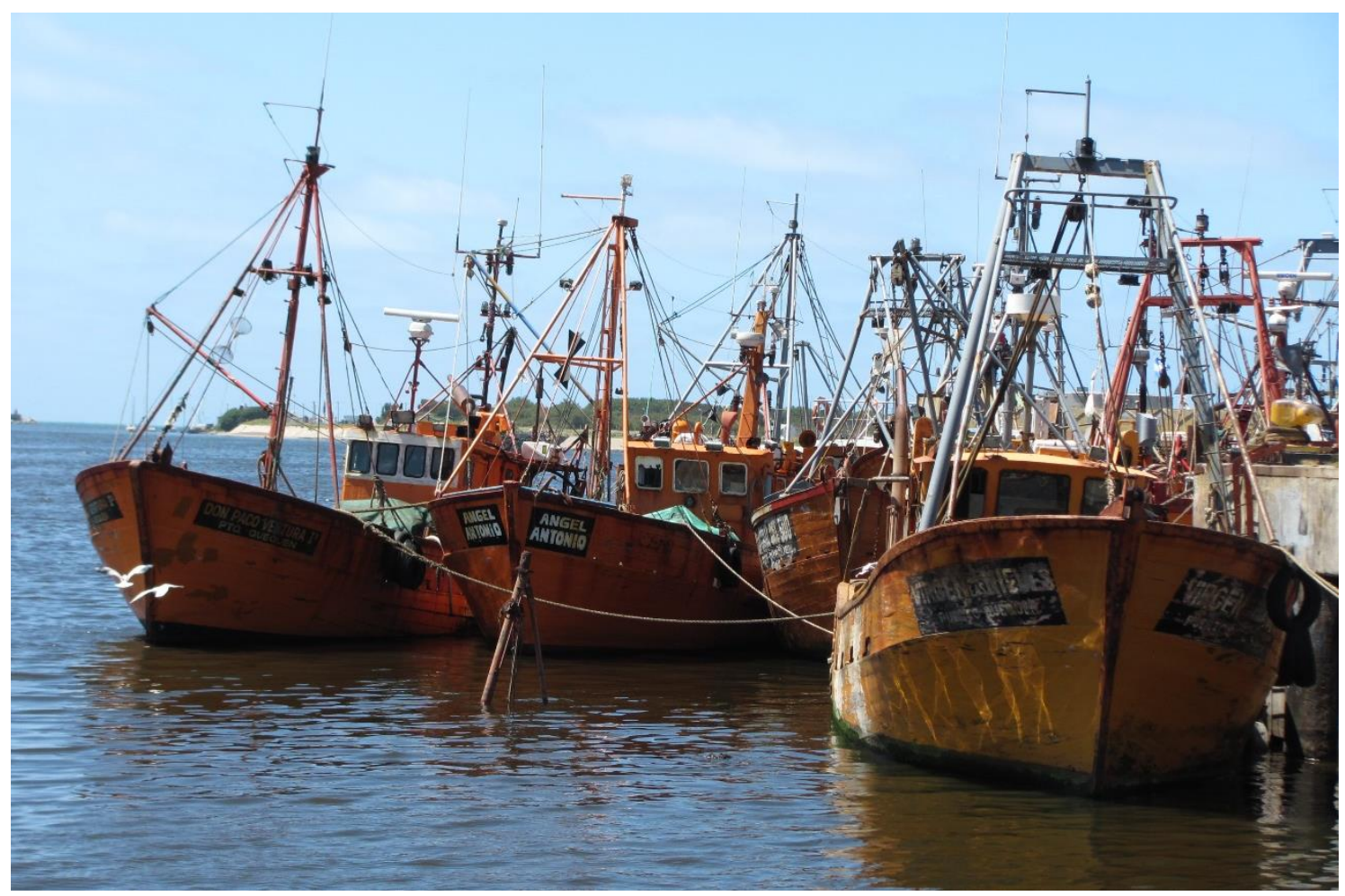

Figura 21. Barcos pesqueros de Puerto Quequén amarrados en la banquina.

Dentro de esta categoría se pueden diferenciar tres tipos de embarcaciones ${ }^{85}$ (Allega, 2012): la flota costera, la flota menor y aquellas de rada o ría, clasificación que coincide a grandes rasgos con la formulada por la Prefectura Naval Argentina (Lasta et al., 2001). Los encuestados y entrevistados se refieren a ella como los "barcos chicos", "lanchas amarillas" o simplemente "lanchas".

Las embarcaciones de la denominada flota costera o flota costera lejana tienen una eslora que varía entre 18 y $28 \mathrm{~m}$. Tienen que estar pintadas de amarillo en el casco y la superestructura, así como tener una franja vertical negra en ambos costados. Pueden estar construidas en madera o metal, y tener algunas comodidades, como baño, cocina y cuchetas

84 El color amarillo característico de estas embarcaciones -junto con sus variaciones- está reglamentado por la Ordenanza Marítima № 1/97 del Régimen de la Navegación Marítima, Fluvial y Lacustre (REGINAVE).

85 Otros autores, como por ejemplo Bertolotti y colaboradores (2001), definen dos categorías dentro de la flota costera. En este caso, elegimos la clasificación realizada por Allega (2012), dado que reconoce una variación más dentro de las embarcaciones de pesca costera cercana, y se ajusta mejor a aquellas que están presentes en Puerto Quequén. 
(Perrota et al., 2007). En general, estos barcos cuentan con equipos de navegación y detección, así como refrigeración en la bodega. Es por ello que pueden alejarse de la costa hasta 180 millas náuticas mar adentro, y pueden permanecer en el mar de 72 a 96 horas. Llevan una tripulación de entre 4 y 10 personas, y tienen una capacidad de carga de 10 a 20 tn.

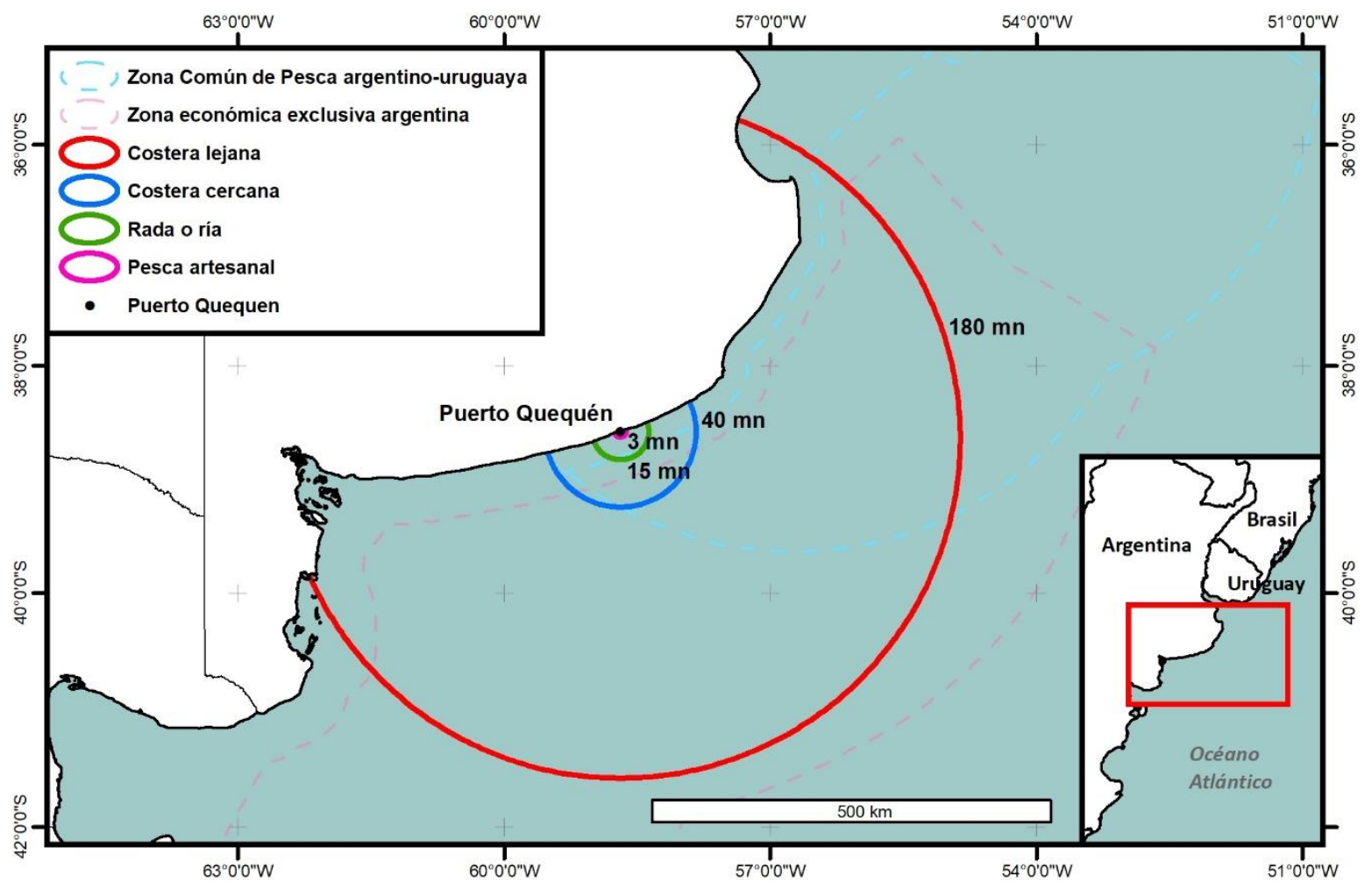

Figura 22. Radio de alcance en millas náuticas de las embarcaciones costeras de Puerto Quequén. Elaboración propia a partir de IGN86.

Extraen una importante diversidad de especies en zonas costeras, entre las que se destacan aquellas que constituyen el denominado variado costero: anchoíta, bonito, besugo, caballa, cornalito, corvina, gatuzo, camarón, langostino, lenguados, mero, pargo, pescadilla, pez ángel, pez palo, rayas y salmón de mar, entre otros. Además, al poder entrarse más en el mar, también pueden realizar la pesca estacional de abadejo y merluza, cuando estos se hallan más cerca. Pueden hacer estos tipos de capturas dado que tienen la característica de poder hacer operaciones tanto de altura como costeras. Para esto, operan con artes de arrastre y de cerco según la especie objetivo.

Las embarcaciones de flota costera menor o costera cercana, que agrupa a aquellos de 9 a 18 m de eslora, poseen una autonomía limitada ya que cuentan con un equipamiento mínimo de navegación y detección, así como carecen de equipos de refrigeración, por lo que

${ }^{86}$ http://www.ign.gob.ar/NuestrasActividades/InformacionGeoespacial/CapasSIG 
deben descargar rápidamente el pescado extraído. Tienen que estar pintadas de color amarillo, tanto en el casco como en la superestructura, junto con una franja vertical de color rojo (Allega, 2012). El material con el que suelen estar construidos es madera.

En estos barcos, debido a sus limitadas dimensiones, pueden enrolar una tripulación de entre 2 y 10 personas. En general, predomina la organización empresarial unipersonal, o familiar de las lanchas, que recuerda los modelos tradicionales empleados históricamente desde los inicios de la pesquería en Argentina (Mateo, 2004b). Junto con esto, a la tripulación se le paga a la parte o usan un modelo de cooperativa.

Estas embarcaciones pueden desplazar entre 10 y 12 tn, y se alejan no más de 40 millas náuticas de la costa, pescando hasta una isobata de $50 \mathrm{~m}$. Pueden permanecer hasta 36 hs en el mar. Se dedican casi exclusivamente a la pesca del variado costero, así como también pejerrey, lisa y mejillones, para lo cual emplean distintos aparejos y artes de pesca que varían según la época y la especie que explotan.

Otro tipo de embarcaciones costeras son las denominadas de rada o ría, que son las lanchas amarillas de menor tamaño. Deben tener el casco y superestructura amarillo con un verduguillo y regala ${ }^{87}$ color rojo, con una franja color blanco. Tienen una eslora promedio de $9 \mathrm{~m}$, y sólo pueden cargar entre 5 y 8 tn. Al ser más chicas, se pueden alejar de la costa únicamente 15 millas náuticas. Tienen habilitado permanecer hasta 24 hs en el mar, y una tripulación de entre 2 y 6 personas.

En general, en las últimas décadas existe una tendencia hacia la disminución en la cantidad de embarcaciones de pesca costera. A fines de la década de 1990 los barcos de la pesca costera representaban poco menos del $50 \%$ del total de las embarcaciones pesqueras del país (Figura 23), y empleaban al 20\% de la tripulación embarcada, aunque sólo aportaban con el 6\% de la capacidad de carga de bodega total.

Pueden identificarse distintas artes de pesca, o sea, los equipos o método empleados para la captura de peces (Madaria, 1999). Diferentes artes están adaptadas para la captura de un determinado recurso, sean peces o invertebrados, por lo que en cada puerto y cada barco suele predominar un arte de pesca orientado hacia una captura en particular. En el Mar Argentino se emplean diversos tipos, que han sido descriptos en distintos

\footnotetext{
${ }^{87}$ El verduguillo es el listón de madera que sobresale del costado y sirve para protegerlo de golpes durante las maniobras de atraque; mientras que la regala el tablón que cubre la cabeza de las cuadernas y forman la parte superior de la borda.
} 
trabajos ${ }^{88}$. En Puerto Quequén, objeto de análisis en esta tesis ${ }^{89}$, las embarcaciones de pesca costera empleaban, según Bertolotti et al. (2001) (Tabla 5):

- Red de arrastre con portones y a la pareja: consiste en el uso de embarcaciones que arrastran una red convencional, buscando atravesar a los cardúmenes para que los peces queden atrapados en la red. En el arrastre con portones se emplea una embarcación, y se utiliza para capturar peces demersales -de aguas profundas- en zonas de aguas someras o poco profundas, entre ellos corvina rubia, gatuzo, lenguado, pescadilla, pez palo. En las redes de arrastre a la pareja -en las que dos embarcaciones arrastran la red-, los pescadores de Puerto Quequén capturan también la llamada pesca variada.

- Red de media agua: es una red de forma cónica que es arrastrada y va atrapando a los peces, luego la red es izada al barco. De esta forma, en Necochea obtienen la anchoíta.

- Red de cerco: se lanza la red por el lado de proa del barco con una señal flotante, y se emplean para circundar a los cardúmenes, atrayéndolos mediante un cebo cocido o fresco. Luego la red se estrecha para que queden concentrados en un espacio reducido. Se emplea a profundidades menores a $50 \mathrm{~m}$. Se usa principalmente para la captura de anchoíta.

- Lampara, se trata de una red de cerco y tiro que tiene una forma particular y específica que impide que los peces se escapen por el costado o por abajo una vez que quedan atrapados. Es común en embarcaciones chicas, y se emplea para la captura de anchoíta y cornalito.

- Redes de enmalle, en los cuales se pretende que los peces queden enmallados o enredados en los paños de una red. Se emplean para la captura de bacota, cazón, pez ángel y tiburón.

\footnotetext{
${ }^{88}$ Por ejemplo, en relación con las artes de pesca en las lanchas amarillas se puede consultar a Mateo (2003 y 2004b); para el caso de las embarcaciones de pesca artesanal hay descripciones en Lagos (2001) y Perrota et al. (2007). Por su parte, para descripciones generales (Fermepin, 2000) y principalmente FAO (1990).

${ }^{89}$ No se presentan y describen otras artes de pesca por no ser empleadas por los pescadores de Puerto Quequén, sin embargo, queremos destacar que existen otros tipos muy diversos.
} 


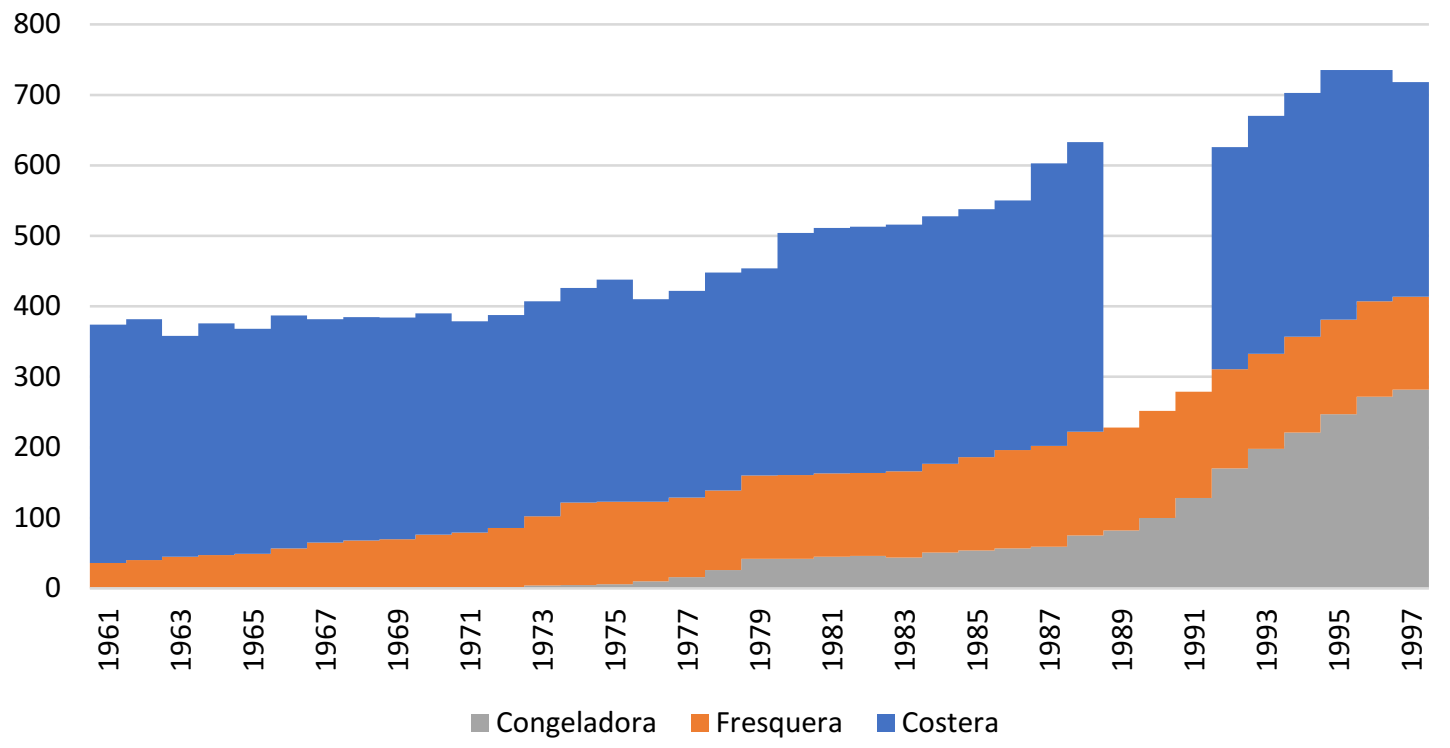

Figura 23. Gráfico de tipos de barcos de la flota pesquera argentina desde 1961 a 1997.

Entre los años 1989 y 1991 no se cuenta con el dato de barcos de pesca costera. Elaboración propia en base a Bertolotti et al. (2001), Errazti y Bertolotti (1998), Lasta et al. (2001), Bertolotti et al.

(2017).

Tabla 5. Artes de pesca utilizadas para la captura de especies en Puerto Quequén.

Elaboración propia a partir de Errazti y Bertolotti (1998), Pérez Comesaña y Nogueira (2013) e INIDEP 90

\begin{tabular}{|c|c|c|c|c|c|c|c|}
\hline \multicolumn{2}{|r|}{ Especie } & \multicolumn{4}{|c|}{ Red } & \multirow[b]{2}{*}{ Lampara } & \multirow[b]{2}{*}{ Enmalle } \\
\hline $\begin{array}{c}\text { Nombre } \\
\text { común }\end{array}$ & Nombre científico & $\begin{array}{c}\text { arrastre } \\
\text { con } \\
\text { portones }\end{array}$ & $\begin{array}{l}\text { arrastre } \\
\text { a la } \\
\text { pareja }\end{array}$ & $\begin{array}{c}\text { media } \\
\text { agua }\end{array}$ & cerco & & \\
\hline Anchoita & Engraulis anchoita & - & - & $\mathrm{X}$ & $\mathrm{X}$ & $\mathrm{X}$ & - \\
\hline Bacota & $\begin{array}{l}\text { Carcharhinus } \\
\text { brachyurus }\end{array}$ & - & - & - & - & - & $\mathrm{X}$ \\
\hline Cazón & Galeorhinus galeus & - & - & - & - & - & $\mathrm{X}$ \\
\hline Cornalito & Odontesthes incisa & - & - & - & - & $\mathrm{X}$ & - \\
\hline $\begin{array}{l}\text { Corvina } \\
\text { rubia }\end{array}$ & $\begin{array}{l}\text { Micropogonias } \\
\text { furnieri }\end{array}$ & $\mathrm{X}$ & - & - & - & - & - \\
\hline Gatuzo & Mustelus schmitti & $\mathrm{X}$ & - & - & - & - & - \\
\hline Lenguado & Xystreurys rasile & $\mathrm{X}$ & - & - & - & - & - \\
\hline Pescadilla & Cynoscion guatucupa & $\mathrm{X}$ & - & - & - & - & - \\
\hline Pez angel & Squatina guggenheim & - & - & - & - & - & $\mathrm{X}$ \\
\hline Pez palo & Percophis brasiliensis & $\mathrm{X}$ & - & - & - & - & - \\
\hline \multicolumn{2}{|l|}{ Variada } & X & X & - & - & - & - \\
\hline
\end{tabular}

${ }^{90} \underline{\mathrm{https}}$ //www.inidep.edu.ar/investigacion/pesquerias/especies/ 
A su vez, en los últimos años ha surgido otro grupo de embarcaciones que pueden incluirse dentro de la categoría de pesca costera, y es el denominado pesca o sector artesanal. Algunos autores, ubican a este tipo de pesca como actividad de subsistencia (Lasta et al., 2001) o artesanal (Amato Uriburu, 2014; Noceti, 2014). Se trata en general de pescadores que alternan esta actividad con otras, y para la cual emplean embarcaciones menores, como botes de goma o semi-rígidos con motores fuera de borda, de madera, fibra de vidrio o plástico, que tienen una eslora de entre 5 y $13 \mathrm{~m}$. Realizan la pesca a no más de 3 millas náuticas de la costa y se internan en hasta 12 horas como máximo. Suelen usar redes de enmalle a no más de una o dos millas de la costa (Lagos, 2001; Perrota et al., 2007).

En términos generales y considerando el volumen de capturas, la flota de pequeña escala costera predominó en la Argentina hasta comienzos de la década de 1960. A partir del año 1963 disminuyó su participación relativa en el total de los desembarques y fue superada por la flota industrial, representada en ese momento por los barcos fresqueros que habían comenzado a operar unos pocos años antes. Mientras que en el año 1976 hacen su aparición los barcos congeladores, que desde comienzos de la década de 1990 concentran la mayor parte de las capturas realizadas en el Mar Argentino (Bertolotti et al., 2001).

\subsection{Aporte de la flota pesquera de Puerto Quequén a la pesca comercial marítima argentina}

A continuación, vamos a realizar un seguimiento de la evolución de la flota pesquera costera de Necochea, desde sus inicios hasta el fin del periodo comprendido en esta tesis (Tabla 6). El primer dato con el que contamos es brindado por Lahille (1895), quien menciona que una comunidad de pescadores italianos se había asentado en Necochea en el año 1889, y que para 1895 existían cuatro embarcaciones con las que se realizaban pesca de forma rudimentaria.

Durante las primeras décadas del siglo XX, la producción pesquera marítima de Necochea se ubicaba en el tercer puesto a nivel nacional, que era dominada ampliamente por Mar del Plata, seguida por Bahía Blanca y, por detrás de Necochea, la zona de Ajó (Cabo San Antonio). En 1920, la producción de Necochea llegó a un estimado de 400.000 kg, que representó sólo el 2,7\% del total pescado en la zona bonaerense, porcentaje que disminuye al 2,4\% más si consideramos el total en el país sumando a lo producido en la Patagonia (Valette, 1921) (Tabla 7). 
Tabla 6. Cambios en la flota pesquera de Puerto Quequén.

Elaboración propia a partir de Lahille (1895); Fermepin y Villemur (2004); Errazti y Bertolotti

(1998); Lasta et al. (2001); Rispoli y Nogueira (2007) y Pérez Comesaña y Nogueira (2013).

\begin{tabular}{|l|c|}
\hline \multicolumn{1}{|c|}{ Año } & Barcos \\
\hline 1895 & 4 \\
\hline 1942 & 8 \\
\hline 1972 & 22 \\
\hline 1987 & 24 \\
\hline 1988 & 26 \\
\hline 1997 & 29 \\
\hline $2000-2002$ & 26 \\
\hline 2010 & 16 \\
\hline
\end{tabular}

Tabla 7. Pesca realizada en la zona bonaerense durante el año 1920.

Elaboración propia a partir de Fermepin y Villemur (2004).

\begin{tabular}{|l|c|c|}
\hline \multicolumn{1}{|c|}{ Localidad } & Pesca $(\mathbf{k g})$ & Pesca (\% del total) \\
\hline Mar del Plata $^{91}$ & 10.279 .370 & $69,5 \%$ \\
\hline $\begin{array}{l}\text { Mar de Ajó (Cabo } \\
\text { San Antonio) }\end{array}$ & 2.200 .000 & $14,9 \%$ \\
\hline Bahía Blanca $^{92}$ & 1.891 .685 & $12,8 \%$ \\
\hline Quequén & 400.000 & $2,7 \%$ \\
\hline Miramar & 30.000 & $0,2 \%$ \\
\hline Total bonaerense & $\mathbf{1 4 . 8 0 1 . 0 5 5}$ & \multirow{2}{*}{} \\
\hline Total país & $\mathbf{1 6 . 0 0 0 . 0 5 5}$ &
\end{tabular}

Durante esta década, y como producto de la inmigración luego de finalizada la Primera Guerra Mundial, llegaron nuevos pescadores de origen italiano, así como algunos españoles, al país. De estos, algunos se radicaron de forma permanente en Necochea, aunque Mar del Plata continuó siendo el principal destino para los pescadores. Es de suponer que esta inmigración que arribó a Puerto Quequén fue correlativa a un aumento en la cantidad de barcos.

En la zona de Necochea la explotación de invertebrados siempre fue de importancia y constituía la pesca central, en especial los mejillones (Mytilus platensis) (Mateo, 2004a). Inclusive, un decreto en el año 1931 prohibió la recolección de mejillones con utensilios manuales o dispositivos rastreros dentro de los límites del Puerto Quequén. Durante esta década, Necochea siguió siendo una localidad secundaria para la captura de

\footnotetext{
91 Datos estimados.

92 Datos registrados.
} 
peces, superada como siempre por Mar del Plata y Bahía Blanca (Fermepin y Villemur, 2004).

Para el año 1942 estaban radicados en Necochea ocho embarcaciones, las que comercializaban su producción a través de los intermediarios marplatenses. Todos estos barcos correspondían a las denominadas lanchas amarillas, que por viaje obtenían entre 600 y 1000 tiburones (Díaz Llanos, 2011) durante la denominada fiebre del tiburón (Mateo, 2006). Si bien Mar del Plata y algunos puertos patagónicos son los que disfrutaron principalmente de un incremento notable de ganancias, los pescadores de Necochea evidenciaron también un crecimiento a la par de sus compañeros de Mar del Plata.

Sin embargo, este auge en la captura de este tipo de pez, produjo también hechos lamentables que enlutaron a toda la comunidad de pescadores de Mar del Plata y Necochea. El 30 de agosto de 1946 se desata un violento temporal que atrapa a muchas lanchas amarillas en el mar. Entre ellas se encontraba la Quo Vadis? de Necochea que desapareció con cinco tripulantes, todos ellos argentinos de entre 25 y 38 años ${ }^{93}$. En total, como producto de la tormenta, en la costa sudeste bonaerense se hundieron seis barcos y fallecieron 35 pescadores (Mateo, 2006).

En los años que siguieron a la finalización de la Segunda Guerra Mundial, es cuando puede afirmarse que se consolida la actividad pesquera en Necochea. En este momento se radican nuevos inmigrantes pescadores de origen italiano provenientes del sur de aquel país (Calabria, Sicilia, Campania y Basilicata). Algunos de ellos llegaron a la Argentina trayendo sus propias lanchas y artes de pesca (Nogueira, 2019a). Aquí, con el tiempo, aprendieron las características particulares de esta profesión en el mar bonaerense.

En el año 1949, se llevó a cabo en Necochea el Primer Congreso Nacional de Pesquerías Marítimas e Industrias Derivadas, del cual surgió un detallado análisis de la situación y perspectivas de la pesca en Argentina. Específicamente sobre Necochea detalla que constituye un centro pesquero que puede llegar a tener mayor importancia, y recomiendan ampliar la banquina, la construcción de una planta frigorífica e instalaciones para el remate y distribución de la pesca, así como coordinar los medios de transporte para poder abastecer a los centros de consumo en condiciones higiénicas y eficientes (Fermepin y Villemur, 2004).

En la década entre 1950 a 1960, Necochea logró posicionarse como el segundo puerto del país para los desembarques de pescados, superando a Bahía Blanca que históricamente había ocupado dicho lugar. En primer lugar, se ubicaba Mar del Plata que

${ }^{93}$ Los muertos fueron: José Bonifacio Sánchez, casado de 32 años; Leopoldo Domínguez, soltero de 25 años; Natalio Fuertes, soltero de 28 años; Eliseo Simón Sánchez, soltero de 33 años y Justino Nadals, soltero de 38 años ("Naufragio", Ecos Diarios, 13 de junio de 1971; Mateo, 2006). 
concentraba más del 70\% y, seguido de Necochea, en tercer lugar, San Antonio Oeste (Mateo, 2003).

Para el año 1972, la flota de barcos costeros radicada en Necochea ascendía a 22 embarcaciones, que constituían el 7,3\% de las del país, que sumaban en total 302 buques. De esta forma, por cantidad, Necochea se ubicaba en tercer lugar, por debajo de Mar del Plata y Bahía Blanca, que contaban con 205 y 35 respectivamente (Fermepin y Villemur, 2004).

Para el año 1988 se menciona que la flota pesquera que se aloja en Puerto Quequén era de 26 barcos (Errazti y Bertolotti, 1998), mientras que en 1997 habría 29 barcos costeros. De estos, 25 correspondían a la denominada flota costera menor, con esloras de entre 9 y 18 m; mientras que sólo 4 eran más grandes (Bertolotti et al., 2001). Entre los años 1999 y 2001, un estudio realizado por Rispoli y Nogueira (2007) determinan que efectivamente operaron en promedio 23, 21 y 20 barcos, aunque en dicho periodo (20002002) se hallaban radicados en este puerto 26 embarcaciones ${ }^{94}$. Durante este periodo, los desembarques de merluza no son tan importantes, especie objeto de capturas de las embarcaciones de altura, dado que no se asientan embarcaciones de este tipo.

En cuanto a los cambios en el tipo de pesca en el Puerto Quequén, se observan algunos en los desembarques realizados a lo largo del tiempo. En general, los peces capturados son similares a los de Mar del Plata, aunque con algunas diferencias. Por ejemplo, como ya dijimos, hasta la década de 1940 en Necochea existían mayores capturas de mejillones en bancos localizados a pocas millas de la costa; décadas más tarde, el lenguado que se capturaba en mayores cantidades, eran ofrecidos en los restaurantes de Necochea, por sobre la merluza, que era más abundante en Mar del Plata.

Luego, las embarcaciones de este puerto participaron activamente de la fiebre del tiburón. Hasta el año 1943 la pesca de cazones era muy escasa y se realizaba prácticamente sólo en Mar del Plata (Figura 24). En dicho año se observa que las capturas de este pez aumentan fuertemente dado que se descubre su utilidad para proveer de fuentes vitamínicas a la industria bélica norteamericana. Sin embargo, rápidamente y a medida que el recurso comenzaba a escasear, los caladeros se fueron trasladando hacia el sur ${ }^{95}$. En tal sentido, los pescadores de Puerto Quequén para el mismo periodo concentran un

\footnotetext{
94 Este número ha descendido desde entonces, ya que en el año 2010 se contabilizaron 16 embarcaciones (Pérez Comesaña y Nogueira, 2013), y un estimado de sólo 4 barcos en el 2018 (Nogueira, 2018c).

95 Incluso en este movimiento en pos de un recurso que convenía explotar de forma rápida para aprovechar una circunstancia excepcional, se improvisaron nuevas terminales pesqueras en el sur de la provincia de Buenos Aires y en la Patagonia, incluso más al sur de Comodoro Rivadavia (Mateo, 2006).
} 
porcentaje relativamente alto de la pesca total de cazones, en torno al $20 \%$ del total pescado a nivel nacional, para disminuir notablemente luego del año 1945, cuando su participación desciende a menos del 5\%. Para estos momentos, ambos puertos, Mar del Plata y Necochea, son totalmente superados por aquellos ubicados más al sur. En la década de 1950, cuando terminó la fiebre del tiburón, las toneladas pescadas vuelven a valores previos y la participación sobre el total de Necochea es en torno al 25\% y 30\% (Mateo, 2006).

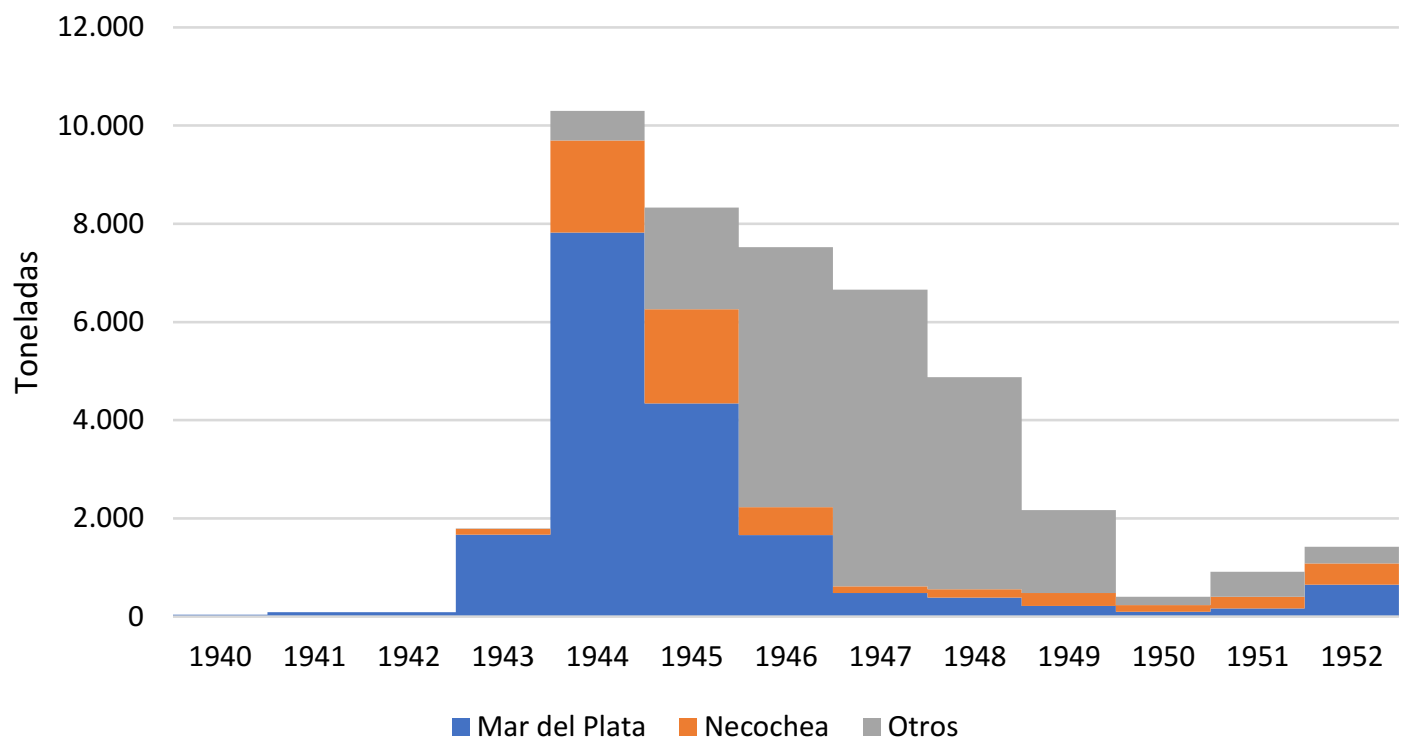

Figura 24. Comparación de la pesca de cazón entre Mar del Plata, Necochea y demás localidades entre los años 1940 y 1952.

Fuente: elaboración propia, datos modificados de Mateo (2003 y 2006). Para los años 1940 a 1942 sólo se cuenta con datos de las capturas desembarcadas en Mar del Plata.

A partir de mediados de la década de 1970 se cuenta con datos publicados sobre las capturas en Puerto Quequén. En la Figura 25 observamos que existen dos picos cuando los desembarques rondaron o superaron las 40.000 tn anuales: entre los años 1978-1979 y 1997-1999. Entre estos, la producción fluctuó en torno a las 10.000 y 30.000 tn anuales. Con posterioridad al periodo considerado en esta tesis ocurrió un marcado decrecimiento de las operaciones en Puerto Quequén, dado que los desembarques se ubican cercanos a las 5.000 tn desde entonces, como producto de la crisis general del sector y la destrucción de las industrias pesqueras en tierra (Nogueira, 2019c). Es interesante notar además que estos cambios en los desembarques se correlacionan de forma constante y estrechamente en relación con el aporte porcentual de Puerto Quequén sobre el total de los desembarques a lo largo de toda la secuencia histórica presentada. Sólo se observa que el aporte fue levemente menor durante los años 1992 y 2000 (Figura 25). 


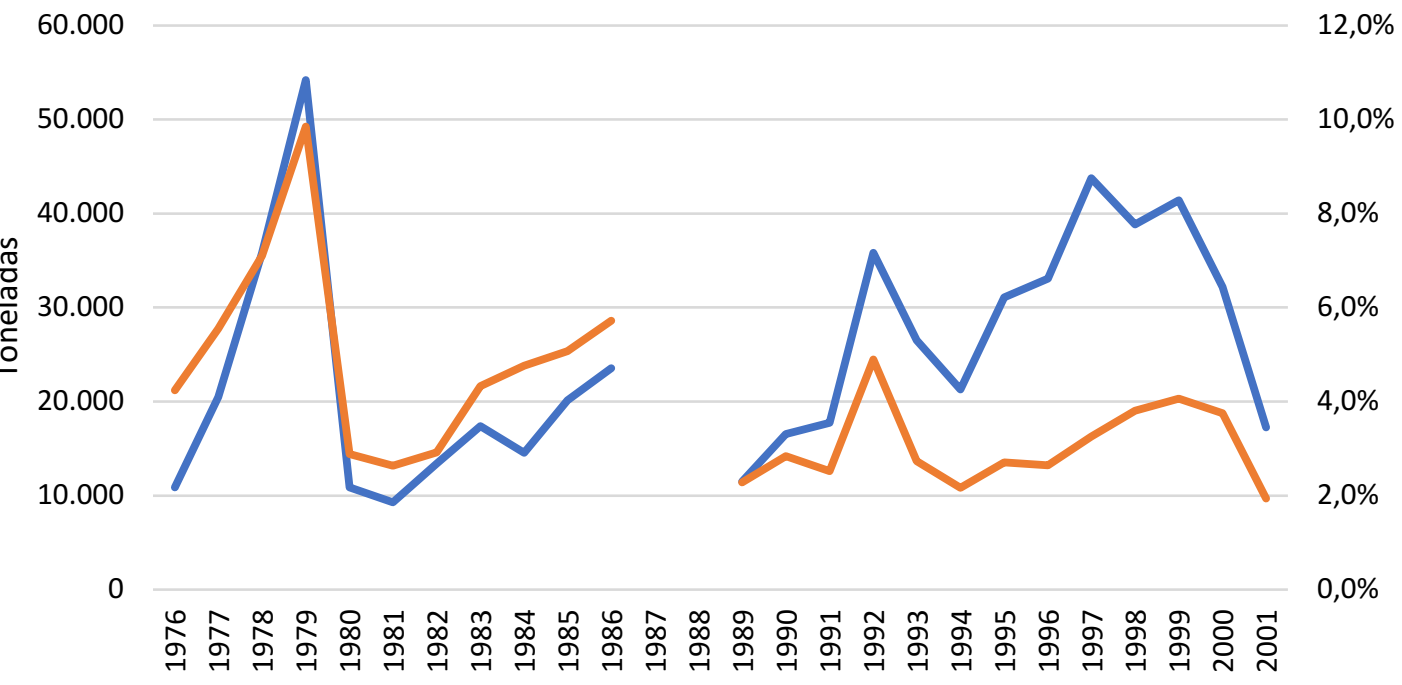

Puerto Quequén —del pais

Figura 25. Gráfico de capturas totales de pescados en Puerto Quequén en toneladas desde 1976 a 2001.

Elaboración propia en base a Bertolotti y Gil Muro (1991), Errazti y Bertolotti (1998), Sánchez et al. (2012). No se cuenta con los datos de los años 1987 y 1988.

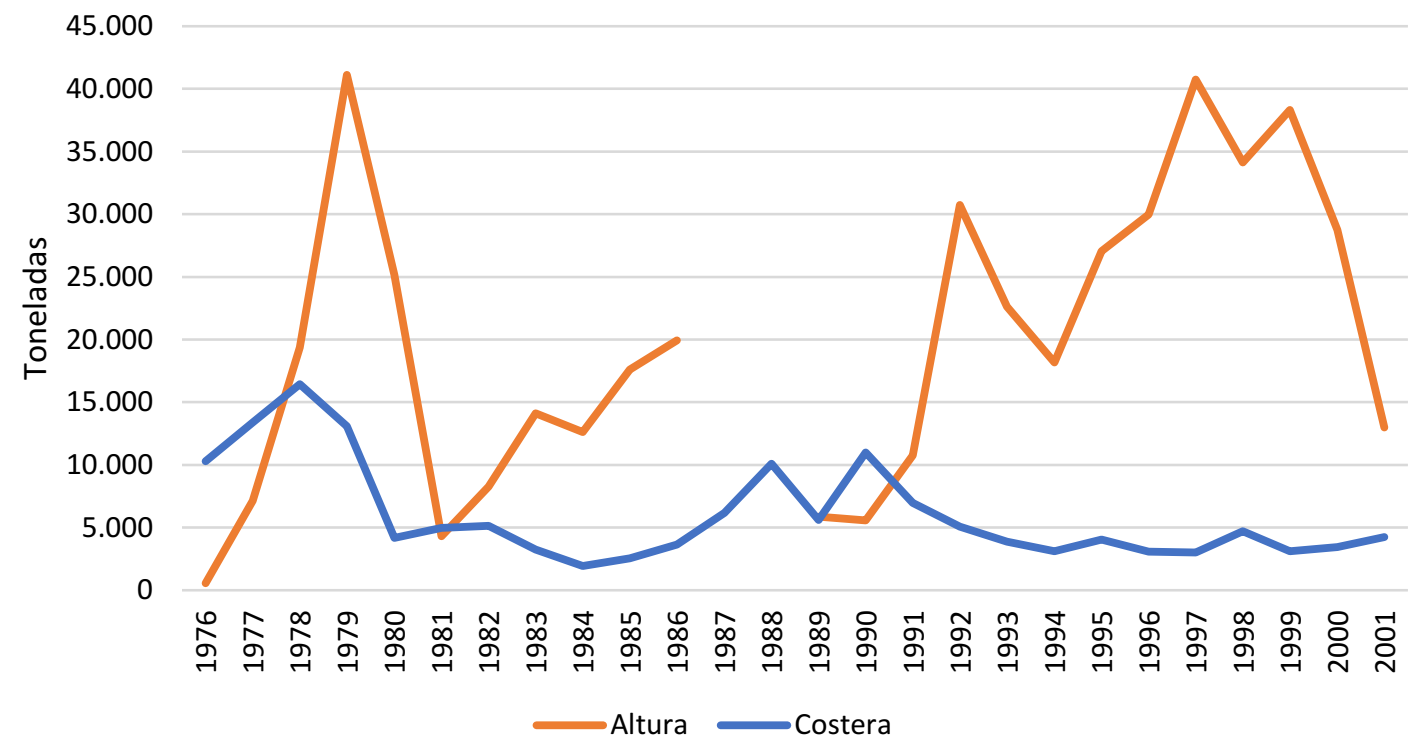

Figura 26. Gráfico de capturas de pescados en Puerto Quequén según flota costera y de altura, en toneladas desde 1976 a 2001.

Elaboración propia en base a Bertolotti y Gil de Muro (1991), Errazti y Bertolotti (1998), Sánchez et al. (2012). No se cuenta con los datos de los años 1987 y 1988 para la flota de altura.

Si analizamos los cambios ocurridos en relación con el tipo de pesca según las embarcaciones de altura o costeras, observamos en la Figura 26 un auge de desembarques de barcos de altura en los años 1978-1980 que superan ampliamente a la flota costera, así 
como un predominio moderado durante la siguiente década ${ }^{96}$. Entre los años 1989 y 1991 se registra una paridad entre ambos tipos de flotas, lo que es concordante con la crisis desatada por el aumento de los costos de producción, y la caída de rentabilidad producto de una baja generalizada de los precios internacionales del pescado, lo que desembocó en una la ola de quiebras durante esos años (Pradas, 2006; Colombo, 2014).

Luego, en los años 90, el predominio de la flota de altura es notorio producto a una mejora en las condiciones para las empresas pesqueras y la compra de nuevas embarcaciones favorecida desde el estado. Durante estos últimos años se alcanzaron desembarcos totales hasta 13 veces superiores a los de la flota costera en el año 1997. Esta superioridad es claramente notoria si observamos la Figura 27 en que se representa el aporte porcentual de cada tipo de flota en Puerto Quequén. A partir del año 2002 la situación cambió radicalmente, dado que los desembarcos de la flota de altura disminuyeron dramáticamente, manteniéndose durante los siguientes diez años en torno a las 300 y 1.000 tn anuales; mientras que la flota costera lo superó en toda la serie con desembarques de entre 3000 y 4500 tn.

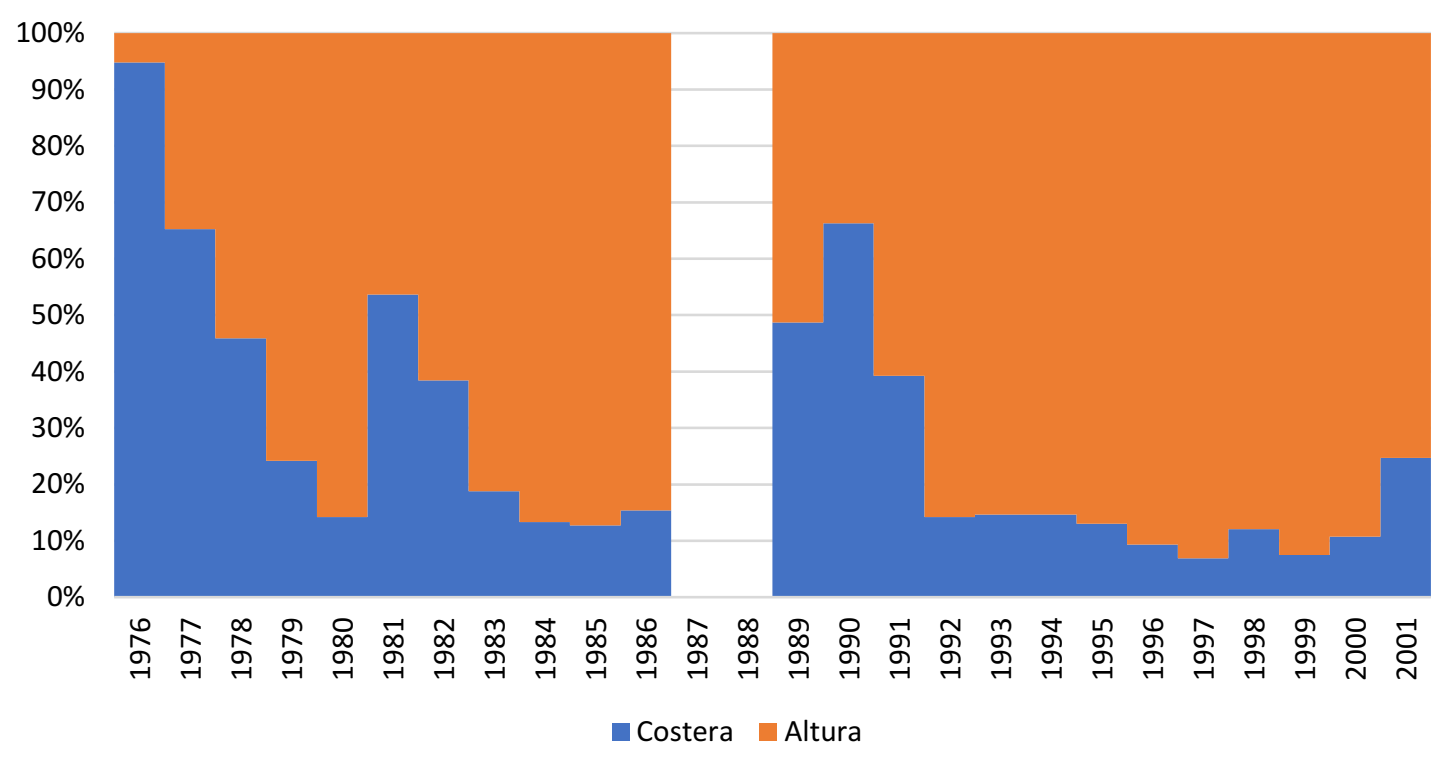

Figura 27. Gráfico de capturas de pescados en Puerto Quequén según flota costera y de altura, en porcentajes desde 1976 a 2001.

Elaboración propia en base a Bertolotti y Gil de Muro (1991), Errazti y Bertolotti (1998), Sánchez et al. (2012). No se cuenta con los datos de los años 1987 y 1988.

En toda la serie histórica considerada, vemos que la participación de Puerto Quequén en términos de desembarcos es en baja, tanto si consideramos la flota costera

\footnotetext{
96 Lamentablemente no se cuenta con los datos de desembarcos de la flota de altura de los años 1987 y 1988.
} 
como de altura o industrial (Figura 28). Entre estas dos, la primera es la que proporcionalmente aporta un porcentaje levemente mayor al total nacional de la pesca costera, que fluctúa entre un 14\% y 4\%; mientras que la de altura no alcanza en ningún momento ni al 9\%. En ambos casos se registra, además, una tendencia a la disminución del aporte de Puerto Quequén al total del país, probablemente debido al incremente en la importancia de los puertos patagónicos en detrimento de los bonaerenses.

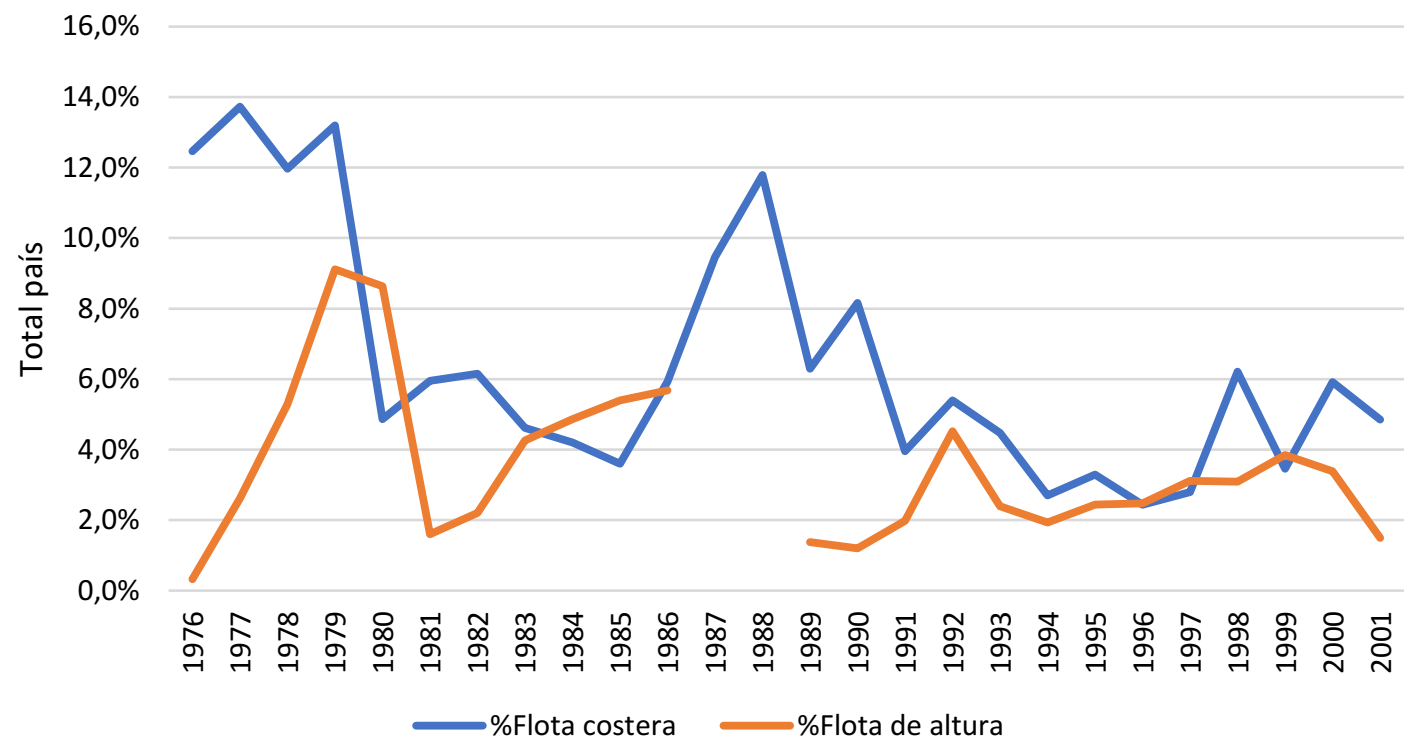

Figura 28. Gráfico de participación porcentual de Puerto Quequén sobre el total del país entre los años 1976 y 2001.

Elaboración propia en base a Bertolotti y Gil de Muro (1991), Errazti y Bertolotti (1998), Sánchez et al. (2012). No se cuenta con los datos de los años 1987 y 1988 para la flota de altura.

Por último, en relación con las especies capturadas por los pescadores de Puerto Quequén durante el final del período de interés de esta tesis, en Rispoli y Nogueira (2007) analizamos los partes de pesca de Prefectura Naval Argentina (Tabla 8). En el año 1999 las rayas dominaron los desembarques, seguidas por el caracol, los lenguados y el gatuzo. Todos estos grupos de especies superaron las 300 toneladas. Decimos grupos de especies pues, por ejemplo, enrolados en "lenguados" se cuentan al menos tres especies, y entre las rayas, cinco. En orden decreciente siguieron la corvina, el pez palo, el mero, el mejillón y la pescadilla, totalizando un 89\% de los desembarques del año. Para el año 2000, las rayas eran también el principal recurso desembarcado, pero se incorporan las anchoítas en el segundo lugar. Estos dos recursos y los lenguados fueron los únicos que superaron las 300 toneladas. Luego, siguen en orden decreciente el caracol, la corvina, el pez palo, el pez ángel, el gatuzo, el mejillón y el mero, totalizando el 91\% de la captura total anual. Mientras que en el año 2001 las rayas siguieron dominando los desembarques, secundadas por cinco especies o grupos de especies que superaron las 300 toneladas: gatuzo, anchoíta, palo, 
lenguado y ángel. Luego siguen en orden decreciente el caracol, el mejillón, el mero y la corvina, totalizando un $90 \%$ del desembarque total anual.

Tabla 8. Especies capturadas en Puerto Quequén entre los años 1999 y 2001.

Elaboración propia a partir de Rispoli y Nogueira (2007).

\begin{tabular}{|c|c|c|c|c|c|}
\hline \multicolumn{2}{|r|}{ Especies } & \multirow{2}{*}{1999} & \multirow{2}{*}{2000} & \multirow{2}{*}{2001} & \multirow{2}{*}{ Total } \\
\hline Nombre común & Nombre científico & & & & \\
\hline Rayas & $\begin{array}{l}\text { Atlantoraja cyclophora, } \\
\text { Atalntoraja castelnaui, } \\
\text { Rioraja agassizi, } \\
\text { Sympterygia bonapartii y } \\
\text { Sympterygia acuta }\end{array}$ & 457,3 & 623,1 & 537,5 & $\begin{array}{l}1.617,9 \\
(18,7 \%)\end{array}$ \\
\hline Lenguados & $\begin{array}{l}\text { Xystreuris rasile, } \\
\text { Paralichthys isosceles y } \\
\text { Paralichthys patagonicus }\end{array}$ & 372,4 & 345,6 & 325,9 & $1.043,9(12 \%)$ \\
\hline Caracoles & $\begin{array}{l}\text { Zidona dufresnei y } \\
\text { Adelomelon beckii }\end{array}$ & 381,4 & 295,7 & 211,2 & $888,3(10,3 \%)$ \\
\hline Anchoítas & Engraulis anchoita & 0 & 355,9 & 512,2 & $868,1(10 \%)$ \\
\hline Pez palo & Percophis brasiliensis & 261,4 & 246,5 & 321,8 & $829,7(9,6 \%)$ \\
\hline Pez Ángel & $\begin{array}{l}\text { Squatina guggenheim y } \\
\text { Squatina punctata }\end{array}$ & 295,7 & 225 & 288,7 & $809,4(9,3 \%)$ \\
\hline Gatuzo & Mustelus schmitii & 315,8 & 205,7 & 248,7 & $770,2(8,9 \%)$ \\
\hline Mejillones & Mytilus edulis platensis & 239,5 & 146,9 & 262,5 & $648,9(7,5 \%)$ \\
\hline Corvina & Micropogonias furnieri & 295,3 & 248,9 & 0 & $544,26,3 \%)$ \\
\hline Mero & Acanthistius brasilianus & 247,1 & 138,6 & 121,3 & $507(5,9 \%)$ \\
\hline Pescadilla & Cynnoscion guatucupa & 74,5 & 0 & 0 & $74,5(0,9 \%)$ \\
\hline Salmon de mar & Pseudopercis semifasciata & 0 & 0 & 62,6 & $62,6(0,7 \%)$ \\
\hline \multicolumn{2}{|l|}{ Total } & $2.940,4$ & $2.831,9$ & $2.892,4$ & $8.664,7$ \\
\hline
\end{tabular}

\subsection{Ir a la pesca}

Para referirse a su trabajo, los pescadores suelen decir "voy a la pesca". Es frecuente que se considere que la pesca constituye una "aventura común" para todos los participantes involucrados en la expedición. En algún sentido, esto es así en cuánto a ciertos sentires y representaciones compartidas. Los pescadores de Puerto Quequén ${ }^{97}$ caracterizan el trabajo en los barcos costeros como una familia para marcar el énfasis igualitario en las relaciones que se establecen entre los miembros de la tripulación. Sin embargo, debemos

\footnotetext{
${ }_{97}$ En trabajos previos exploramos algunos de los aspectos retomados en esta sección (Rispoli, 2006b
} y 2011). 
reconocer que en función de la propiedad de los medios de producción y de la estratificación en el trabajo, como en las familias, se distinguen diferentes posiciones.

El barco constituye una unidad de producción, o sea, un espacio donde unas relaciones organizadas de producción dan como resultado la producción de un producto deseado (Narotzky, 2004). Veamos cómo se establecen en los pescadores las relaciones de producción que permiten obtener pescado fresco.

El armador es la persona o empresa que se hace cargo y responsable por la embarcación para mantenerla en condiciones, equiparla para que esté en situación de navegabilidad, incorporar a la tripulación. Se ocupa también de las gestiones administrativas y constituye la representación del barco frente a las autoridades competentes. Puede coincidir o no con el propietario de la embarcación. El dueño puede delegar las funciones de armador en otra persona o empresa, o puede hacerse cargo él. En general en Puerto Quequén, la mayoría de las lanchas amarillas son propiedad de personas vinculadas al trabajo pesquero y el propietario, o alguien de la familia, cumple esta función. En otros casos, en el que el barco como capital es una inversión de agentes no vinculados a la actividad, en esta situación contratan el servicio a los armadores.

Los patrones de pesca son los encargados de operar o "despachar" como capitán, asumen la responsabilidad y la toma las decisiones durante la navegación, ejerce y representa la autoridad en el barco y comandan el proceso productivo. Es interesante marcar que para convertirse en patrón de "pesca menor", o de "pesca costera" el marinero debe acreditar antigüedad de embarcado y realizar una formación complementaria, que no es posible realizar en Necochea o Quequén. La formación incluye elementos de matemática, reglamentaciones, maniobras y artes de pesca, y manejo de captura. Por su parte los marineros están en la base de la estratificación laboral de la pesca, trabajan sin distinción de cargo, sin antigüedad, y son quienes realizan las tareas físicamente más agotadoras y duras.

Además, algunos barcos costeros en función de su envergadura pueden llevar también un maquinista, y entonces ampliar su radio de acción hasta 180 millas náuticas sobre la línea de costa, sino solamente pueden hacerlo 100 millas. Sin embargo, este rol no es especialmente apreciado entre los pescadores "es un marinero más, un título más pero que no sirve de nada, porque si pasa algo no sabe dónde meter las manos".

En el desarrollo efectivo del trabajo pesquero en los barcos de la flota costera no hay una estratificación del trabajo tan marcada al momento de pescar, "todos saben hacer todo, pero hay uno en cada puesto", "los marineros pueden sugerir algo y si está buena la idea la probamos". A diferencia de la flota de altura, los patrones suelen trabajar a la par de los pescadores, son capitanes-pescadores, sin embargo, se reconocen diferencias en las 
responsabilidades "una cosa es estar de marinero y otra cosa estar de patrón, tenés que mirar lo que está haciendo el marinero".

Resaltamos que esta división de funciones que se presenta como una división técnica, es por supuesto, también una división económica y social, ya que se relaciona con la forma en que se distribuyen las ganancias, la autoridad, y el status o prestigio social de los participantes en la empresa pesquera (Alegret, 1987). El acceso a los medios de producción y con ello el control y la toma de decisiones son los principales elementos para tener en cuenta para la construcción de estas relaciones de producción. Entonces, en la organización productiva se superponen diferentes divisiones del trabajo, una distinción sexual o de género y que excede la unidad productiva, todos los pescadores relevados eran varones. Dentro de esta se encuentra una división técnica del trabajo (patrón/marinero) y una económico/social (armador-trabajador).

Entre marineros y patrones hay una relativamente alta rotación de roles, al ser preguntado por su profesión la mayoría declara ser marinero mientras que otros dicen salir como patrón. Sin embargo, algunos refieren que su ocupación es marinero y el trabajo que hacen es de patrón, o que en el próximo viaje o en el anterior salieron como patrones. Además, en la tripulación de cada barco es pasible de recuperar la existencia de vínculos familiares entre algunos de sus tripulantes, (padre e hijo, sobrino y tío, yerno y suegro, hermanos, cuñados). "Somos todos familia de pescadores, mis cuñados, todos, trabajaban como patrón, algunos tenían barcos, otros no". Por lo que también es frecuente encontrar lazos familiares entre los tripulantes de diferentes barcos de la flota local. Sin embargo, no hay barcos en que toda la tripulación sea familiar, esto consideramos también un hecho importante de remarcar. Los naufragios dejaron ese aprendizaje, si son todos familia muere toda la parte masculina de la familia que estaba a bordo.

En la pesca costera de Puerto Quequén la conformación de la tripulación se da por medio de lazos familiares, de cercanía o de oportunidad, en menor medida. Cuando un marinero quiere embarcar circula por el puerto, demuestra su interés. En la banquina, se acercan a los barcos para charlar, ayudar, cebar mate en los horarios en que el barco está en tierra y mostrando su intención de trabajar. Un patrón, o un dueño que sabe que alguien está buscando embarcar lo "sube" al barco, lo "prueba" y si "no anda" no lo lleva en la siguiente salida. Destacan la intención de llevar gente "sana" refiriéndose a que no tenga -y que no lleve al barco- problemas de drogadicción o de alcoholismo. Por parte de los patrones y propietarios se demuestra mucho interés en la selección de los marineros: "buenos marineros pueden hacer una buena marea. Una mala tripulación sólo trae problemas".

El énfasis de llevar buena gente no se refiere solamente a "buenos trabajadores" sino, sobre todo, a las situaciones de convivencia, "convivis más con los marineros que con tu 
esposa, o con nuestros hijos". En el barco se dan situaciones de tensión, a veces acrecentadas por el uso de drogas o de alcohol ${ }^{98}$. Estas sustancias que actúan como desinhibidoras de la conducta pueden resultar peligrosas en altamar por las condiciones de estar en un espacio reducido compartiendo intensamente las relaciones con sus compañeros de trabajo. Suelen ser recordadas circunstancias difíciles, como la vez que un marinero alcoholizado amenazó a otro con un cuchillo y tuvieron que volver a tierra para desembarcarlo. En ocasiones reiteradas o de gravedad el patrón puede instar a que se le retire la libreta de embarque, generalmente esto no se hace, y simplemente se lo "baja" pero circula la voz rápidamente entre los pescadores. Desde una perspectiva epidemiológica Pili et al. (1993) analizaron los patrones de hábitos tóxicos como el consumo de alcohol y tabaco en una muestra de pescadores y no pescadores del barrio puerto de Mar del Plata en 1989. Estos autores, establecen la mayor prevalencia estadística de abusadores excesivos de alcohol ${ }^{99}$ para los pescadores y asocian la incidencia del alcoholismo con las condiciones de trabajo en altamar ${ }^{100}$.

Uno de los aspectos en los que se percibe el intento de establecer relaciones entre los miembros de la tripulación en base a un principio de igualdad es la forma que asume la retribución por el trabajo, llamada "a la parte". La práctica de la retribución "a la parte" se encuentra muy extendida y ha sido documentada en diversas regiones del mundo para la pesca costera. Acheson (1981) apunta al hecho de que virtualmente en todo el mundo, los pescadores son pagados con una porción de las capturas una vez realizada la venta lo que incrementa la motivación y reduce el riesgo de los armadores en una actividad incierta.

Esta forma particular de distribución entre 'capital' y 'trabajo' consiste en sumar los gastos de la salida (gasoil101, comida, hielo, traslado, etc.) y restárselo a lo obtenido por la venta de la producción. En general, la partición sigue el mismo esquema básico, lo que varía en diferentes lugares, momentos históricos, circunstancias según diferentes criterios es la cantidad de partes que se reservan para el barco o para el arte, en el caso que la aporte

\footnotetext{
${ }^{98}$ La drogadicción o al alcoholismo se registra más en buques de altura que tienen como puerto base los de la Patagonia, un motivo puede ser la lejanía del control parental de estos pescadores que además se gastan buena parte de su salario en los bares y prostíbulos de esos puertos. Mientras que los que embarcan en Mar del Plata o Necochea salen y vuelven a su casa.

${ }^{99}$ Caracterizado como aquel que bebe más del equivalente a $100 \mathrm{ml}$ de alcohol diarios en cualquier forma (vino, cerveza o bebidas blancas) y tiene más de 12 episodios de embriaguez al año (Pili et al., 1993).

${ }^{100}$ Además, destacan la falta de atención médica integral al hombre de mar y de los pescadores en particular (Pili et al., 1993).

101 Representa una parte considerable de los gastos corrientes del barco. Los entrevistados recuerdan que en un momento estaba subsidiado el combustible para los barcos, que luego se quitó ese subsidio pero que, en principio, no afectaba a los costos.
} 
algún pescador. Cada tipo de embarcación varía el número de partes con que se queda, por ejemplo, en función del porte de esta, de su capacidad en bodega, de la cantidad de tripulantes embarcados, de si llevan maquinista o algún otro rol diferenciado (Mateo, 2003 y 2004b). En la mayoría de los barcos de la flota de Puerto Quequén se divide en nueve partes, el patrón (capitán de pesca) recibe dos partes, mientras que cada marinero (varían entre tres y cuatro por barco) recibe una parte y las tres o cuatro partes restantes quedan para el propietario del barco. Si, además el propietario o alguien de su familia no administra y hace el mantenimiento de la embarcación y contrata un armador debe pagarlo de las partes del barco. En algunas situaciones, cuando la captura es muy baja, para no perder la tripulación, "el barco" renuncia a una de sus partes. Vemos, en este sentido, como esta forma de organización provee un marco de flexibilidad en la relación capital-trabajo.

A pesar de su recurrencia y aparecer ligada a una tradición, esta característica, constituye una estrategia flexible de acomodación a coyunturas particulares. La estrategia apunta a que todos se esfuercen más y en conjunto para aumentar el rendimiento, pero el hecho de que todos ganen lo mismo sin importar la antigüedad, la experiencia, el conocimiento del medio, la eficiencia individual o la voluntad de trabajo, hacen que la forma de remuneración no sea percibida favorablemente por algunos pescadores, sobre todo por los más "viejos" y más arraigados a la actividad, quienes, como en uno de los pescadores entrevistados se quejaba de la "desidia" de las nuevas generaciones por no estar interesados en aprender nuevas técnicas, o por el conformismo que supone trabajar hasta cierto punto limitando la productividad. Esto revela ciertas tensiones al interior de un sistema que, en cierta medida, lo que pretende es eliminarlas ${ }^{102}$.

Es interesante que Pascual Fernández (1991b) documentó que en Canarias existió una estratificación más marcada dentro de la flota costera, en la que sólo recibían una "parte" entera quienes trabajaban muy bien, conocían el oficio y estaban casados. Los aprendices y los solteros cobraban menos. Es de resaltar que sobre la decisión de cómo se hacía la partición participaban los marineros, y el armador casi no tenía influencia. En Puerto Quequén, cuando existía la figura de "aprendiz de marinero" le correspondía un medio o tres cuartos de la "parte" estipulada.

Las formas del sistema retributivo a la parte pueden parecer similares en el modelo capitalista y en el precapitalista, pero ocultan diferencias en cuanto a la función. Por ello es necesario poner este sistema en relación con la propiedad de los medios de producción. Como propone Sánchez Fernández (1992) el uso de este sistema dentro del modelo capitalista puede darse en una variedad de situaciones comprendidas en un

102 Rispoli (2011). 
continuum entre dos extremos. En uno de los cuales el autor coloca a la propiedad familiar de los medios de producción con un tipo de reparto hacia el interior de la familia focalizado en la reproducción del grupo, que no implica la extracción de plusvalor. En este caso el sistema a la parte colaboraría en mantener la unión y el interés por una empresa común a los diferentes miembros de la unidad productiva que estaría relacionada con los vínculos familiares. Mientras que el otro extremo se daría cuando la propiedad de los medios de producción está alejada de los productores directos y el porcentaje en el cual los capitalistas o dueños participan en el producto es muy elevado, que no representa la situación de los pescadores de la flota costera relevados.

Este sistema se plantea como similar al pago a destajo en cuanto a equivalencia funcional, sin embargo, se diferencia del mismo porque se premia el esfuerzo colectivo y no el individual. Por lo que, en vez de competencia entre trabajadores, ésta se da entre unidades productivas. Entre las ventajas del pago a la parte dentro de un contexto capitalista suelen mencionarse el hecho de que disminuye la necesidad de control sobre el trabajo; que aumenta en la intensidad de trabajo por parte de los trabajadores, que intensifica el esfuerzo; que sustenta una ideología de participación en la pesca como empresa común, típica de modos precapitalistas; que traslada a los pescadores el "riesgo" capitalista sobre la producción que, como veremos, es incierta. Al aumentar la motivación de los trabajadores, pero también reducir el riesgo del dueño, Breton (1981) la define como una forma híbrida del salario. También vemos como, en cierto sentido, el pago a la parte se asemeja a la forma llamada de "mediería"103 en la agricultura. Como en la mediería, el sistema a la parte en la pesca acarrea una serie de ventajas para el empleador, como eludir las obligaciones económicas de la contratación bajo dependencia, reducir costos y minimizar riesgos debido a que se comparten con el mediero y transformar los costos laborales en costos variables, trasladando hacia abajo las fluctuaciones de rentabilidad (Benencia, 1994).

La retribución percibida depende de las condiciones técnicas de la producción, de su volumen y de las funciones particulares realizadas en el proceso de trabajo. En primer instancia puede parecer una distribución justa basada en el esfuerzo colectivo y en la cualificación o rol de cada participante, pero Giasson (1981, en Rubio Ardanaz, 1994) llama la atención sobre el hecho de que este sistema cuando se incorpora en el sistema capitalista y los medios de producción están alejados de los productores, entonces se genera una

\footnotetext{
${ }^{103}$ Consiste en una forma de organización del trabajo agrario y modalidad de remuneración en la que una de las partes aporta el factor tierra (a veces herramientas) y la otra parte aporta el factor trabajo. El producto luego es dividido en partes iguales.
} 
reproducción parcial de los productores fetichizando su autonomía frente a los empresarios capitalistas, ya que el sistema a la parte no incluye el costo real de la fuerza de trabajo.

El correlato concreto de la forma de remuneración para los pescadores entrevistados implica cierta incertidumbre en relación con su remuneración, destacando una relativa fluctuación en los ingresos mensuales: "cobramos lo que pesca el barco... si hacemos una salida y no rindió" "lo mucho que ganaste un mes lo tenés que repartir en los dos meses que estuviste a pérdida". Sin embargo, las variaciones más grandes que son percibidas por los pescadores se refieren a momentos cuando la actividad "no rinde" y que corresponde con factores externos como la cotización del tipo de cambio o alguna situación crítica en relación con el recurso base o a situaciones meteorológicas adversas. A partir del Convenio Colectivo de Trabajo de 2001 se estipula un sueldo básico, que es considerado como muy bajo por los pescadores. En caso de que con la producción no se llegue a superar el propietario del barco se hace cargo de este estipendio.

La "aventura" de la pesca no consiste sólo en llenar la bodega del barco y, si la marea fue buena, traer también cajones en cubierta. Una vez que el barco amarra, hay que colocar el pescado rápidamente. La importancia de tener establecida la forma de comercializarlo también es parte de las destrezas del buen pescador-armador. En Puerto Quequén a inicios del período se comercializaba por intermedio de la Sociedad de Pescadores.

\footnotetext{
"Antes una pescadería necesitaba pescado y se lo pedía a la Sociedad. Entonces la Sociedad decía, bueno ¿cuántos barcos hay? Entonces la Sociedad decía, vos me tenés que traer 5 cajones de esta variedad, 10 cajones de esta, 15 de la otra y tantos de la otra. Y después lo demás era todo harina. Todo lo que no iba a la exportación iba todo a la harina. Y ahora la harina de pescado se hace con todos los restos. $Y$ entonces ¿quién cobraba? La Sociedad y la Sociedad cuando llegaba a fin de mes te pagaba a vos. Lo que te pagaban ya lo tenían vendido a tal precio, todo" (pescador-armador).
}

Este método de prorratear la captura en Mar del Plata se lo denomina "pesca a tarifa" y la demanda la hacían las conserveras (Mateo, 2003). Luego se formó el Mercado Concentrador Pesquero en Mar del Plata, que funcionó entre 1981 y 1991 y se extendió en todo el país. En Puerto Quequén funcionó una delegación, el mercado proveía los cajones y cobraba un porcentaje por la venta del pescado, que era rematado. En esa época, aunque quisieran venderlo a alguna pescadería en particular, no podían cobrarlo si no era a través del Mercado. 
Hacía fines del período los propietarios o armadores se ocupan directamente de la comercialización, generalmente vendiendo una parte en Necochea y otra enviada para Mar del Plata. Algunos armadores venden y facturan toda la carga a un establecimiento de procesado local, pero luego el pescado sigue por un circuito de reventas o pases en función de la demanda de las pescaderías o fábricas locales. Otros armadores deciden ellos a quién venderles en el momento con la expectativa de obtener mejor precio. La mayoría destaca la intención de dejar el pescado a las pescaderías o procesadoras locales y recién cuando sobra para cubrir la demanda local se ocupan de enviarlo a Mar del Plata. Antes de llegar al puerto el patrón de pesca le pasa la información por radio sobre la cantidad y variedad de la captura, para poder facilitar su ubicación ya que diferentes fabricantes locales adquieren distintas variedades de pescado.

Como decíamos a comienzos de la sección, entre los pescadores la recurrencia del uso de la metáfora de familia, para caracterizar el trabajo en el barco nos invita a pensar la misma como la condensación de un núcleo de significación pasible de ser interpretado o, al menos, problematizado. Al trabajar de pescador se deja la familia de tierra en tierra, para conformar la familia del barco. La unidad de producción se estructura en torno a la metáfora familiar. Nos preguntamos qué implícitos culturales respecto de la familia se ponen en juego.

En el trabajo pesquero, sobre todo a pequeña o mediana escala suele reconocerse un énfasis igualitario en las relaciones entre las partes involucradas. Acheson (1981) sostiene que las explicaciones sobre este énfasis igualitario pueden resumirse principalmente en dos grupos, uno relacionado con la necesidad de disponer de tripulaciones con un nivel similar de preparación para evitar que la falla en uno perjudique a todos; y otro vinculado al conjunto de riesgos que deben afrontar y que los hace parecer participantes de una misma aventura implicados a un mismo nivel tanto físico como psíquico.

La metáfora de familia podría estar relacionada con sustentar este énfasis. En una familia, todos deben (o deberían) tirar para el mismo lado. Sin embargo, hace ya un tiempo que la noción de familia ha sido desacralizada (Collier et al., 1997; Salles, 1991). También reconocemos el papel que puede tener la manipulación de lazos reales o ficticios de parentesco para acceder y controlar el trabajo (Meillasoux, 1977) en este caso por parte del "patrón" como pater104. Observamos como la voz padre y patrón comparten la raíz indoeuropea pater, y los sentidos dados a la circulación de poder y de cohesión que enarbola esta figura. Tengamos presente también que muchas veces quién oficia de patrón es a la vez

104 Jefe de familia, patrono, defensor o protector. 
propietario o familiar cercano del propietario del barco. La familia, plantea Meillasoux (1977) nos recuerda la paradoja de una asociación orgánica que juega entre las relaciones de reproducción y las de producción, que tiene muchas veces el sentido de movilizar gratuitamente trabajo y la explotación de los sentimientos afectivos que se dan en la relación padres-hijos. En este sentido, la organización del trabajo en el barco siguiendo un modelo familiar está connotando y reforzando un modelo de trabajo ajustado a las contingencias y del cual es pasible de exigir y conformarse en términos diferentes a los disputados en el plano público de lo laboral. Recuperamos recurrentemente en el discurso de los entrevistados que en el barco tienen que "tirar todos para el mismo lado", "tenés que convivir con las personas que están en el barco, tu familia son las personas que están trabajando en el barco" se puede marcar un tácito acuerdo de que las tensiones de poder deben ser puestas al costado para poder desarrollar la empresa pesquera. Un conflicto en altamar puede derivar en tragedia, y en caso de que se desate, el "buen accionar" del patrón refuerza la lógica de trabajo y convivencia. En las familias los lazos son adscriptos a los individuos; un individuo llega precedido de lazos familiares que son relativamente fijos en la historia de dicha persona. En la familia del barco se recuperan y reinscriben lazos familiares que traen su propia lógica de poder (padre patrón/ hijo marinero) con otras propias de la unidad productiva (propietario patrón/ marinero trabajador). De lo analizado, destacamos como una característica las variantes y la movilidad dentro de un universo relativamente acotado. En este marco el rédito económico, más que otras fuentes de autoridad, ofrece una dirección en la que orientar la legitimidad del poder. Tal y como dice Acheson (1981), en la pequeña empresa pesquera, el "énfasis igualitario" representa una ideología que sustenta el trabajo cotidiano. Así, el sentido recuperado de que "en el barco hay que bancarse" asume por un lado un factor de cohesión al tiempo que tiende a invisibilizar u opacar posibles puntos de disputa y reduce el marco de conflictividad. La prolongada convivencia en condiciones diferentes a la comodidad del hogar pero que comportan una cotidianeidad, un conocimiento del otro en lo bueno y en lo indeseable. Una vez en el barco, como en la familia, hay que poner el esfuerzo para salir adelante todos juntos. El sentido de familia aporta a la cohesión de la tripulación. A saberse partícipes de una empresa común y dependiente de otros para cumplir el objetivo, siguiendo roles que son aportados por las representaciones asociadas a la familia. Esta metáfora cobra sentido en el imaginario extendido en el sentido común de que la familia es un homogéneo que tiene una función. Desde la perspectiva antropológica podemos problematizar qué implica la familia y avanzar en la interpretación de qué uso tiene en este contexto. Grassi (1999) se pregunta ¿qué es la familia? para situarla como un dato incuestionable de la realidad; una entidad abstracta; un objeto de políticas públicas; un objeto polémico (u objeto de 
polémicas) y (o) un objeto de estudio. Frente a esta polisemia, reflexionamos sobre posibles vías de interpretación sobre qué representa la metáfora de la familia para los pescadores, para aquellos pescadores de las lanchas amarillas. Porque en los barcos de altura, la metáfora se vuelve laxa, ya no los representa "y en el barco grande también es como una familia, pero no es lo mismo, cada uno tiene un camarote, hay más distancia". En vistas de lo expuesto hasta aquí, destacamos dos puntos: por un lado, lo relevante es plantear el papel que juega entre los pescadores costeros relevados el continuum familia -núcleo reproductivo- unidad productiva y, por otra parte, reflexionar sobre el papel ideológico que representa esta metáfora para sostener el trabajo conjunto.

Resulta oportuno recordar que los primeros pescadores de Necochea y Quequén fueron migrantes italianos, mientras que para el período de interés la actividad es llevada adelante por algunos de sus descendientes, aunque no exclusivamente. Históricamente al ampliarse la demanda de pescado las familias italianas no pudieron sostener la provisión de mano de obra en los límites de su red étnico-familiar y se extendió a una red social más amplia (Mateo, 2003). Luego de algunos momentos excepcionales de acumulación de capital estas familias y sus descendientes se ubicaron en otro lugar de las relaciones de producción (afianzándose en la distribución y producción en tierra) mientras que otros la dejaron, pero la actividad pesquera costera conservó una fuerte impronta étnica. Por ello, podemos problematizar los valores simbólicos aportados al trabajo de este grupo social, que pueden haber contribuido a instaurar y sostener las representaciones sociales circulantes en la actividad en el barco.

Teniendo en cuenta estas consideraciones retomamos la polisemia que comporta la noción de "familia" para rescatar entre sus sentidos posibles el de entidad abstracta, meta-histórica en el marco de sistemas de creencias ideológicos o religiosos (Grassi, 1999); esto nos interesa para analizar el lugar que tiene la familia y el parentesco en los "valores" atribuidos a las comunidades mediterráneas, como la italiana. Sin ahondar en la controversia sobre la denominada antropología del mediterráneo (Boissevain, 1979; Gilmore, 1982; Herzfeld, 1984; Pina Cabral, 1989; Llovera, 1990), vale la pertinencia de recuperar los aportes de una amplia serie de estudios desarrollados en al área europea del mediterráneo que dan cuenta del lugar de la familia y el parentesco, del "honor" y la "vergüenza" en diversas localidades de esta área (Pitt-Rivers, 1963 y 1979; Peristiany, 1968; Davis, 1983). Entonces, teniendo en cuenta los lazos establecidos en su origen entre las poblaciones mediterráneas y los pescadores de la costa atlántica bonaerense, resulta sugestivo marcar el papel que pueda tener en esta imbricación de lazos familiares y de trabajo el uso de la metáfora de familia en los pescadores de Necochea y Quequén. A la luz de la antropología del mediterráneo se destacan los valores puestos de relieve en esta área, 
por ejemplo, el acentuado rol que desempeña el parentesco tanto en los ámbitos privados como públicos; sobresale también el papel instrumental de la amistad, con la consiguiente dificultad de distinguir entre amistad, parentesco y relaciones de tipo clientelar. Otro de los aspectos que nos interesa remarcar es el lugar que se da a expresiones simbólicas e institucionales de relaciones sociales que enfatizan los valores de jerarquía y segregación según clase, sexo y edad. Nos interesa señalar que estamos en el particular contexto de una diferente estructura nacional, en otro momento histórico, para una actividad laboral particular en una coyuntura político-económica y ecológica puntual, o sea en otro contexto e intersectado por otras variables. Sin embargo, esta perspectiva nos invita a seguir pensando el lugar que tienen los sistemas simbólicos (la cultura) en tanto que "son utilizados como instrumentos de ordenamiento de la conducta colectiva, esto es, en la medida en que son absorbidos y recreados en las prácticas sociales" (Durham, 1999). Defender la familia por encima de todo ha llevado a Schenider (1971) a afirmar que en el mediterráneo el honor como ideología contribuye a fortalecer la identidad de un grupo familiar y a confiar a él la lealtad de sus miembros, que sin ésta sería dudosa, por lo que el "honor" definiría los límites sociales del grupo. En este sentido, sostenemos como Durham (1999) la noción de familia como un modelo en el sentido de una representación pero que al mismo tiempo ofrece una pauta de acción, o sea un modelo para el comportamiento social. En nuestro caso consideramos que el modelo familia (como representación, como entidad abstracta) está siendo utilizada también como modelo de comportamiento para regular las relaciones de trabajo dentro de la embarcación. Al situar estos sistemas simbólicos como representaciones sociales interiorizadas a partir de una base material resulta interesante no sólo dar cuenta de ellos en sentido descriptivo sino establecer puentes para pensar su relación con la estructura del sistema. En este punto situamos la cultura como elaboración simbólica de la estructura material.

\subsection{Tiempo de mar}

Hacía el final del período la mayoría de los barcos de Puerto Quequén tienen salidas que duran 48 o 72 horas según sus características técnicas, con una posibilidad muy utilizada de una extensión de 12 horas más. Para los pescadores el trabajo es casi continuo cuando están embarcados, con ciclos de dos horas, a veces tres para tirar las redes, hacer maniobras o subir la red. En cubierta cuando sube el pescado es clasificado y puesto en bodega. El sueño es intermitente y está marcado por el ritmo de trabajo. 
A este tiempo de trabajo continuo en el mar hay que sumarle el tiempo de trabajo en tierra, los preparativos del barco para la salida y el tiempo de descarga, y el mantenimiento del barco.

Antes de salir al alistar los barcos, al volver y descargar, los días ventosos o feos la banquina cobra vida con las lanchas amarradas y los trabajadores subiendo y bajando de los barcos, reparando las redes en la banquina, socializando. Si el barco pasa unos días en tierra, los pescadores van a la banquina y al barco unas horas de mañana y otras de tarde, "si no salís siempre tenés que estar mirando el barco, más si son de madera, mirar que no pase nada, que no esté haciendo agua".

Las salidas están plenamente restringidas por las condiciones meteorológicas, por lo que los días trabajados por mes varían según las condiciones climáticas. Las posibilidades de salir embarcado en caso de mal tiempo también se relacionan con el tamaño de la embarcación. En general, el tiempo que pasan embarcados es de 15 y 25 días por mes "salvo que el tiempo no acompañe". Efectivamente, en 1999, 2000 y 2001, los barcos de la flota costera de Puerto Quequén operaron un promedio de 131, 130 y 135 días (Rispoli y Nogueira, 2007).

Esta particular organización del trabajo supone al mismo tiempo una particular organización del tiempo para los trabajadores-pescadores y sus familias. Como sostiene Elias (1989), el tiempo no es ni un dato objetivo, en el sentido de una entidad con una existencia real en el mundo exterior, pero tampoco un dato subjetivo, o sea, un producto exclusivo de la capacidad simbólica humana sin correlato en el mundo exterior. El tiempo constituye, ante todo, un dato social. Siendo el tiempo invisible (e inconmensurable por tanto en sentido "objetivo" lo que puede medirse es una norma social, una jornada de trabajo, un eclipse de luna (Elías, 1989).

Así como distinguimos un espacio de tierra de uno de mar, podemos pensar para los pescadores un tiempo de tierra, de familia, de rutinas y horarios orientados hacia la vida social, la escolarización de los hijos, la dinámica del hogar y la sociabilidad. Este tiempo se distingue del tiempo de mar, un tiempo en el que los relojes no tienen sentido. Durante el tiempo de mar, no es posible diferenciar en el trabajo entre el día y la noche, días de semana de fines de semana, feriados de días laborables. El trabajo es continuo. Como señalan los entrevistados, "en el barco no hay horarios", el tiempo de trabajo y de no-trabajo no está determinado por un horario fijo, sino que son condicionados por las actividades necesarias de desarrollarse según el momento del proceso productivo. Las salidas están restringidas por las condiciones meteorológicas y el trabajo en el barco, estipulado por la disponibilidad y movilidad del recurso y la posibilidad de las artes de pesca, esto configura una 
estructuración en función de la actividad, o sea, lo que Thompson (1979) ha denominado "orientación según el quehacer".

En este sentir objetivo-subjetivo del tiempo algo recurrente es la percepción del cambio de la duración de las salidas de pesca de las lanchas, la intensificación de la jornada de trabajo en el mar es ampliamente recuperada en las entrevistas. Al principio del período los pescadores de la pesca costera salían y volvían en el día. Con el tiempo cada vez se tardaba más en completar la bodega, en "hacer una marea rentable". Observamos una extensión del tiempo reglamentario en altamar, a la vez que los entrevistados reiteran el cambio que implicó de salir y volver en el día a hacer salidas de dos o tres días "estos son barcos chiquitos, no son como para estar tres días y medio como están ahora, sería como para estar día y medio como mucho, pero no da para eso, no dan los costos, no da nada. No rinde nada para lo que es el trabajo".

Más allá de que las salidas en la pesca costera tienen una mayor duración que antaño, los entrevistados que la elijen la siguen privilegiando en relación con los cambios en la temporalidad que representa la pesca de altura "es más lindo barcos grandes, pero son muchos días, la familia".

\subsection{Saber del trabajo en el mar}

Saber dónde pescar lleva años de experiencia, pericia y también picardía, “cada año se da en una posición el pescado, lo tenés anotado o te acordás y después lo buscas, hasta que lo encontrás, día a día vas buscando al pescado. Tenés muchas anotaciones". Estas anotaciones, cálculos son parte privilegiada que puede marcar la diferencia entre una empresa exitosa y otra que no. Hay mucho recelo con la información privilegiada de cada patrón y cada barco. Como se comunican frecuentemente por radio entre barcos "amigos" es una práctica muy común que pasen información falsa para despistar a otros pescadores. Mentir sobre el lugar donde la pesca fue buena es moneda corriente y la principal estrategia para marcar una diferencia entre los barcos. Llegar primero a la buena zona y hacer una buena marea rápido se vuelve el objetivo de todo patrón. Se privilegia el conocimiento en el manejo de las artes, y sobre todo en poder seguir al pez. Sin embargo, un lugar destacado merece la referencia a los cambios tecnológicos que impactaron en el período en el saber hacer de los pescadores "también la tecnología está muy avanzada. Antes cuando recién empecé no teníamos navegador, no teníamos computadora, no teníamos nada. Ahora estamos con computadora, radar, sonda. Vas grabando en la computadora y eso queda grabado. Año a año se va viendo". 
Ser un buen pescador es algo que se aprende en la práctica. En el período de interés se dio un proceso de formalización de la formación profesional que había sido exclusivamente familiar o personal hasta principios de los años 1970, momento en que comenzó a estar institucionalizada por el Estado. Sin embargo, puede sostenerse que no hay una escuela de "pescadores" sino que se accede a una acreditación formal para poder salir embarcado. A ello hay que sumar el aprender un oficio, el de pescador. En este aprendizaje del oficio, juegan un papel privilegiado las relaciones en el trabajo en sí con otros trabajadores. Muchas veces, estos coinciden con miembros de la familia como nos cuenta un patrón de pesca "a manejar las redes, maniobras, me enseño mi papá y la gente que había en el barco de mi papá. Después vas mirando, observando. Pasar por muchos barcos. Juntando todo hasta que después lo sabés hacer". En este sentido, la rotación de barcos también desempeña un papel formador, la posibilidad de conocer otras experiencias de manejo. Otro patrón nos dice "está en vos, es cómo el que juega a la pelota, vos vas mirando, querés hacer una jugadita y está en vos si te sale o no. Tenés que observar mucho, y estar, estar". Por su parte un marinero dice "salí con mis tíos, tuve esa suerte. Ellos ya eran grandes, eran las últimas salidas que hacían, pero me enseñaron mucho. Me decían, me explicaban como largar el equipo, cómo esto cómo lo otro". Vemos entonces como la observación, la familia y la rotación por barcos y grupos de trabajo aparecen como elementos privilegiados en la configuración de un "saber hacer", "aprendí de chiquito, prestar atención, observar. Hay gente que está toda la vida y no aprende nada", dice un pescador. Como en la labor de la artesanía la transmisión de los conocimientos y habilidades resulta un problema porque las aptitudes no son fácilmente explicables, corresponden a un conocimiento tácito (Sennet, 2009). La particularidad de la actividad y del tipo de medio en el que sea realiza, hace que en la pesca costera en Puerto Quequén -y a diferencia de los barcos de altura- la transmisión de los conocimientos para llevar adelante la actividad pesquera se desarrolle en el barco y la banquina durante los momentos de sociabilidad y en el proceso de trabajo.

Cada barco es una unidad productiva independiente, pero "salir a la pesca" implica una concepción simbólica compartida más amplia en el sentido de que se sale en "equipo" en grupo, "generalmente trabajamos dos o tres barcos juntos por si pasa algo. Somos dos o tres, un grupito que andamos siempre juntos". Otras lanchas hacen igual. Y entre ellos, todos en comunicación. Como muchos otros oficios, en la pesca, las habilidades y destrezas para el desarrollo de la actividad se transmiten de padres a hijos, por lo que se suele hablar de "familia de pescadores". El conocimiento técnico especializado constituye un capital social y cultural, en el sentido dado por Bourdieu (1997), por lo que trata de mantenerse dentro 
de la familia o dentro de grupos restringidos de confianza (por ejemplo, las cofradías ${ }^{105}$ de pescadores españolas). El papel que juega el "secreto" entre los pescadores es considerado de importancia para el éxito de la empresa, y tiene relación con la territorialidad y con la acumulación de recursos, entre otros factores. En Puerto Quequén funcionó hasta principio de la década de 1980 la Sociedad de Pescadores que luego se disolvió, y si bien tenía otras funciones, pudo actuar para establecer grupos de afinidades entre barcos. Hay patrones de pesca que siempre están en comunicación entre sí y que se organizan para salir juntos. Entre los diferentes grupitos "de confianza" no se quieren pasar los datos, hay pica dicen. La competencia, como la incertidumbre es parte del trabajo pesquero en las lanchas de la pesca costera. Los patrones y los marineros están atentos a cuánto "hicieron" los otros. Este también es un conocimiento necesario. Se fijan y preguntan “¿cuántos cajones habrán hecho?". Hay pica de saber si "las chiquitas" pueden traer más pescado que "las grandes". Entre lanchas "amigas" también hay competencias, salen y uno pesca de noche, pero no le avisa al otro. Se pasan información confusa por la radio. Hay un patrón conocido por estar siempre escuchando las conversaciones entre otros barcos. Estos "grupos de confianza" no sólo comparten información, sino que toman la decisión de salir o no en conjunto (sobre todo las más chicas), no es habitual que salga una lancha sola. En la actividad pesquera costera, el conocimiento sobre los recursos, el secreto y la circulación de información entre estos grupos, marcados por la afinidad, el parentesco y la confianza, también opera como una forma de regulación del acceso a los recursos, En este sentido, la delimitación entre espacio marítimo en un sentido físico y espacio social son difusos. El incremento del acceso a tecnologías cada vez más potentes y, más aún con el mayor desarrollo de la pesca de altura en detrimento de la actividad costera de menor escala, representan un impacto significativo en este aspecto.

Ser buen pescador implica manejarse en un medio que parece homogéneo pero que no lo es en absoluto. Para desenvolverse exitosamente en el medio marino hay que manejar muchas variables y articular conocimientos de diferentes tipos. El éxito suele ser explicado por diferentes razones, como por ejemplo el esfuerzo pesquero o las características personales o psicológicas de los capitanes. Mientras que las habilidades son importantes, es difícil obtener información de esas habilidades. Acheson (1981) plantea cuatro tipos diferentes de conocimientos necesarios, aparte del manejo específico de las artes de pesca. Primero, para encontrar las concentraciones de peces, los pescadores deben conocer los lugares aptos para que estén. Deben tener un buen conocimiento del océano en

105 Es una forma tradicional de asociacionismo que actúa aglutinando a los pescadores, principalmente costeros o artesanales, son un órgano de consulta y suelen estar involucradas en la comercialización (la subasta del pescado). 
sí mismo (como profundidad, corrientes, entre otros) lo que también es importante para evitar daños pérdidas de artes de pesca. Deben tener conocimiento sobre las especies que buscan (hábitos, ciclos de alimentación, enemigos, hábitat y pautas migratorias) aunque no necesariamente esto implica que sepan de taxonomía. Y, por último, tienen que saber lo que otros pescadores saben, cómo se comportarán.

En términos de Breton (1990), los saberes, conocimientos sobre el barco, las artes de pesca, entre otros, conforman una cultura técnica que mediatiza las relaciones de los pescadores con el medio que explotan, al mismo tiempo que mediatiza también sus conocimientos sobre este medio (biología marina, fondos, especies, etc.). Por lo que esta cultura técnica es una herramienta más, un medio de producción. En este momento histórico, con la incorporación y el uso de la tecnología, en el que la brújula fue reemplazada por el GPS, va cambiando la configuración de saberes.

Un buen pescador debe poder articular los conocimientos técnicos específicos del manejo de las artes de pesca, con el conocimiento del ecosistema marino y el uso y manejo de tecnologías de última generación. En Puerto Quequén toda la flota costera tiene radio y navegador satelital, mientras que el 93\% cuenta con sonda y radar (Nogueira, 2003). La actividad, y las habilidades necesarias para desarrollarla, se redefine en el contexto del uso de nuevas tecnologías. Por ejemplo, desde 2006 en la Provincia de Buenos Aires todos los barcos de la flota costera deben contar con sistema de monitoreo satelital106. El uso de instrumentos tecnológicos permite minimizar, aunque no erradicar, el riesgo de la actividad pesquera y acompañan en el seguimiento de los recursos.

\subsection{Salir y no volver}

"Al mar hay que respetarlo mucho. Hay que conocerlo.

Hay que estar atento todo el tiempo"

La edición del diario local del 7 de enero de 1975 publica una sentida nota del naufragio de una lancha pesquera en la zona de Bahía Blanca. Trabajar en altamar implica un riesgo implícito, el de salir a trabajar y no regresar. Lo fundamental del conocimiento del medio en el que se trabaja, el arte y la pericia en las maniobras, las decisiones acertadas en el momento justo se ponen en juego en cada marea. Dice un pescador "algo siempre puede

\footnotetext{
106 "Rescatan tripulantes de una lancha naufragada", Ecos Diarios, 7 de enero de 1975.
} 
pasar..." salir al mar comporta riesgos, los pescadores y sus familias siempre lo tienen presente.

Así y todo, a veces por negligencias o por imponderables, el horizonte de lo posible y nunca esperado ocurre. Para los pescadores de Puerto Quequén, los riesgos de salir al mar se enfrentan con conocimiento, sobre el medio, precauciones y cábalas. Usar siempre la misma gorra, una cinta roja, una imagen religiosa. No se silva porque llama al viento. Durante mucho tiempo las faldas (de las mujeres, y de los curas) sólo en días festivos podían subir al barco. En todos los barcos hay imágenes de vírgenes (y de chicas desnudas) y otros objetos que funcionan como amuleto. Cada propietario y cada patrón suma algo para la confianza en la aventura pesquera. Pero para un patrón su cábala es que del barco al que sube saca todas las fotos de chicas desnudas. Dicen los pescadores, que antes los gringos eran cabaleros con los gatos o ratas. Si aparecía una rata muerta no salían. Si se les caía sal, tampoco.

Cuando las tragedias ocurren, los casi invisibles trabajadores de la pesca se vuelven preocupación generalizada de la sociedad. "Cuando pasa un accidente en un barco, siempre en el mar si hay un accidente se ve mucho más". En el horizonte de expectativas de los pescadores está esa posibilidad, y que no implica sólo la muerte sino el vacío que representa la pérdida en el mar, muchas veces sin la materialidad del reencuentro con el cuerpo para los parientes. En la Tabla 9 se recopilan los casos de hundimientos de lanchas pesqueras en la zona de Puerto Quequén con fallecimiento de tripulantes.

Tabla 9. Lanchas pesqueras hundidas en la zona de Puerto Quequén. Elaboración propia en base a: Díaz Llanos (2011), Histamar'107 y Ecos Diarios.

\begin{tabular}{|l|l|l|}
\hline \multicolumn{1}{|c|}{ Barco } & \multicolumn{1}{c|}{ Año } & \multicolumn{1}{c|}{ Tripulantes } \\
\hline La Graciosa & 1945 & Hundido, todos los tripulantes desaparecidos \\
\hline Quo Vadis? & 29 de agosto de 1946 & Hundido, 5 tripulantes muertos \\
\hline San Marcos & 26 de abril de 1962 & Hundido, 5 tripulantes muertos \\
\hline Costa Mar & Diciembre de 1966 & Varado, un tripulante ahogado \\
\hline Nuevo Gaucho & 24 de noviembre de 1972 & Hundido, todos los tripulantes muertos \\
\hline Luisito Tirasso & 21 de marzo de 1974 & Desaparecido, tres tripulantes muertos \\
\hline Don Laureano & 2 de mayo de 1990 & Hundida, cuatro tripulantes muertos \\
\hline Altair108 & 2 de mayo de 1997 & Hundido, 9 tripulantes muertos \\
\hline
\end{tabular}

${ }^{108}$ Barco hundido al sur de Necochea, aunque tenía como puerto base a Mar del Plata.
} 
Desde la perspectiva social, aquellos barcos varados o hundidos han sido y son fuente de inspiración artística y algunos de ellos se han incorporado al imaginario y al paisaje de la ciudad. El libro Historias de Varaduras y Naufragios en el área de influencia del Puerto Quequén de Nicasio Díaz Llanos representa pictóricamente las efímeras postales de estos barcos. En este libro se presenta una recopilación de dibujos y pinturas realizas por el mencionado artista plástico, las cuales constituyen un registro de casi todos los barcos que han quedado varados, producto de las frecuentes tormentas, en las últimas décadas en los alrededores de Quequén (Díaz Llanos, 2011).

Algunas de las historias más emblemáticas de naufragios en la costa de Puerto Quequén son anteriores al período de estudio. En 1945, durante la fiebre del tiburón, la lancha amarilla La Graciosa, de $8 \mathrm{~m}$ de eslora se hundió con todos sus tripulantes cuando desapareció a 10 millas del puerto durante un fuerte temporal. Al año siguiente, el 29 de agosto de 1946, durante otro temporal que azotó la costa bonaerense sudeste se perdieron varias lanchas costeras de Mar del Plata y Necochea, que pescaban tiburones. Una de ellas fue la Quo Vadis?, que se dio vuelta cuando se hallaba cerca de Puerto Quequén, llevándose consigo a sus 5 tripulantes (Mateo 2006). Sólo se salvaron dos tripulantes, quienes llegaron a nado hasta la playa de Quequén ${ }^{109}$, uno de ellos llegó casi desnudo luego de nadar más de nueve horas, y se acercó -como pudo- a una casa de familia que lo socorrieron (Díaz Llanos, 2011).

El 26 de abril de 1962 desapareció la lancha pesquera San Marcos. Se trataba de un barco de reciente construcción que, al volver de una temporada de dos meses de pesca por la costa de Chubut, regresaba a Puerto Quequén. Viajaban cinco tripulantes junto con un pescador que aprovechaba el viaje para visitar a la familia. Sin embargo, cuando se encontraban cerca de este puerto, un fuerte viento y un oleaje embravecido provocan que la nave se voltee y quede destruida, falleciendo cinco marineros, sólo uno logró sobrevivir (Díaz Llanos, 2011).

En diciembre de 1966, debido a una densa niebla, la lancha Costa Mar se desorientó y quedó varado al norte de Quequén, falleciendo ahogado uno de los tripulantes. Otra tragedia ocurrió el 24 de noviembre de 1972, cuando la lancha pesquera Nuevo Gaucho se hallaba a 8 millas de la costa en un día calmo. Quizás debido a una sobrecarga producto de una buena cosecha de peces, la embarcación repentinamente se dio vuelta de campana y se hundió, falleciendo todos sus tripulantes. Poco después, el 21 de marzo de 1974, la lancha Luisito Tirasso de $14 \mathrm{~m}$ de eslora fue sorprendido por fuertes vientos y desapareció, cerca

109 "Naufragio", Ecos Diarios, 13 de junio de 1971. 
de donde lo había hecho la Nuevo Gaucho. Fallecieron sus tres tripulantes, entre ellos un padre y su hijo.

Más allá de las relativamente buenas características de Puerto Quequén, las condiciones para el ingreso de los grandes barcos -sobre todo cerealeros- son dificultosas por los bancos de arena que suele juntarse en el canal de acceso, razón por la que estos barcos deben operar con la asistencia de un práctico ${ }^{110}$. El dragado del puerto siempre ha sido un tema de preocupación portuario y, las varaduras y encalladuras de barcos en la zona de entrada, relativamente frecuentes. Se recuperan a continuación algunas de las situaciones más significativas por estar vinculadas al sector pesquero o por su impacto en la configuración del paisaje local. Durante el período de interés, el barco Alco Buenos Aires fue un pesquero de altura de $50 \mathrm{~m}$ de eslora que es el primer barco de este tipo que se hunde dentro del Puerto Quequén. Se hallaba amarrado en el muelle Vanoli, con problemas legales, cuando el 11 de junio de 1978 comenzó a hundirse a babor. Al tiempo se intentó reflotarlo sin lograrlo. Actualmente se halla en el lecho del río, dentro del puerto.

En febrero de 1980, el Camba Cuá -una embarcación deportiva de mediano tamaño- se hundió cerca de la escollera sur cuando dejaba paso a una draga, que en su desplazamiento provocó varias olas. Esto generó que impactara contra las rocas de la escollera sur, y que cuatro de los siete ocupantes fallecieran, a pesar del intento de ayuda de gran cantidad de pescadores que se encontraban en la escollera.

Durante la inundación de abril de 1980 varios barcos se vieron afectados. El Pesquera II, de media altura, que se encontraba atracado en el muelle de Puerto Quequén fue arrancado y llevado por la corriente hasta el antepuerto, donde quedó escorado y se hundió, sin tener tripulantes a bordo. Similar suerte sufrió el Pesquera III, barco pesquero de media altura de fabricación soviética. Al igual que el anterior fue arrancado del puerto y arrastrado hasta la playa de Bahía de los Vientos, donde encalló. Para la misma fecha también se hundió en el canal de acceso al puerto el pesquero Anna C. Una historia particular y única sacudió al Puerto Quequén el 28 de diciembre de 1978 cuando arribo el barco Caribea $^{111}$ sin que pudiera establecerse origen ni destino. Luego de la inundación de 1980 se soltó del amarre y termino encallando en la playa de Quequén frente a la zona conocida como Bahía de los Vientos.

\footnotetext{
${ }^{110}$ El práctico es la persona que cumple el rol de asistencia a los capitanes de barcos para llevar adelante las maniobras de entrada y salida a puerto.

${ }^{111}$ Existen varias historias sobre este barco, algunas refieren que trajo refugiados angoleños que escapaban de la guerra civil que asolaba dicho país, otros que lo vinculan con tráfico de drogas u otros ilícitos, incluso es recordado como un barco fantasma por la forma en que llegó a puerto y, también por la forma en que salió de él sin tripulantes a bordo.
} 
La lancha pesquera Don Laureano naufragó el 2 de mayo de 1990. Según el relato de uno de sus tripulantes que sobrevivió, poco antes del amanecer ocurrió la tragedia. Se trataba de una lancha nueva que mientras se dirigía, junto con otras lanchas, a la zona de pesca a 9 millas de la costa, se encontró con el Mar Bravo, un buque de gran porte de bandera argentina que transportaba químicos desde Bahía Blanca. Si bien los tripulantes lograron evitar el choque, quedaron a merced del oleaje que produce el otro barco al desplazarse, lo que provocó una vuelta de campana. Las lanchas que se encontraban, entre ellas la San Camilo, lograron rescatar a dos sobrevivientes. Sin embargo, escuchan golpes desde el interior del casco, aunque no pudieron hacer nada para salvar a sus compañeros que se encontraban adentro. Al rato, la Don Laureano se hunde, llevándose con ella al resto de sus tripulantes.

El Persuasa II era un pesquero congelador de altura, relativamente nuevo que, tras quedar inactivo en el puerto Quequén, se hunde hacia babor el día 10 de junio de 1996. En 1998 es reflotado y llevado hacia Punta Carballido, donde lo encallan deliberadamente.

El tema de los barcos abandonados en el Puerto Quequén debido a problemas legales ocurridos luego del cierre y clausura de empresas dedicadas a la pesca a comienzos de la década de 1990 fue muy grave, generando distintas consecuencias. Por ejemplo, el Knossos fue un barco pesquero de altura, y el mayor que opero en Puerto Quequén, aunque tuvo sólo salidas esporádicas y quedó finalmente sujeto a problemas legales. Finalmente, en el año 1997 fue trasladado a la zona denominada la Pileta, en el antepuerto de Quequén, donde con el paso del tiempo y la ayuda humana se va destruyendo. Mientras que el Ribera Gallega, un buque pesquero congelador, quedó varado -y luego se incendió- en el interior del puerto del lado de Quequén, casi pegado a los restos de pilotes del puente Ignacio Ezcurra. El Kabril, por su parte, era un buque congelador de altura que se encontraba en similar situación legal, quedando inactivo en Puerto Quequén en 1992. Sin embargo, en este caso, en el año 1999, se decidió llevarlo desmantelado frente a las playas de Necochea y hundirlo deliberadamente para crear un parque recreativo submarino.

El Tordillo, emblemático pesquero de madera de Necochea que fuera construido en el año 1884, naufragó en 1993. Reflotado, siguió trabajando hasta el final del período analizado en esta tesis. Posteriormente, fue desafectado y actualmente se encuentra en el paseo de la rotonda portuaria que vincula las avenidas 10 y 59, y donde se halla la entrada de Puerto Quequén en la margen Necochea (Figura 29). La popa redonda en lugar de la "cola de pato" que caracteriza a las lanchas amarillas desde la época del tiburón rememora a las primeras balandras italianas a vela que desarrollaron la pesca marítima argentina. 


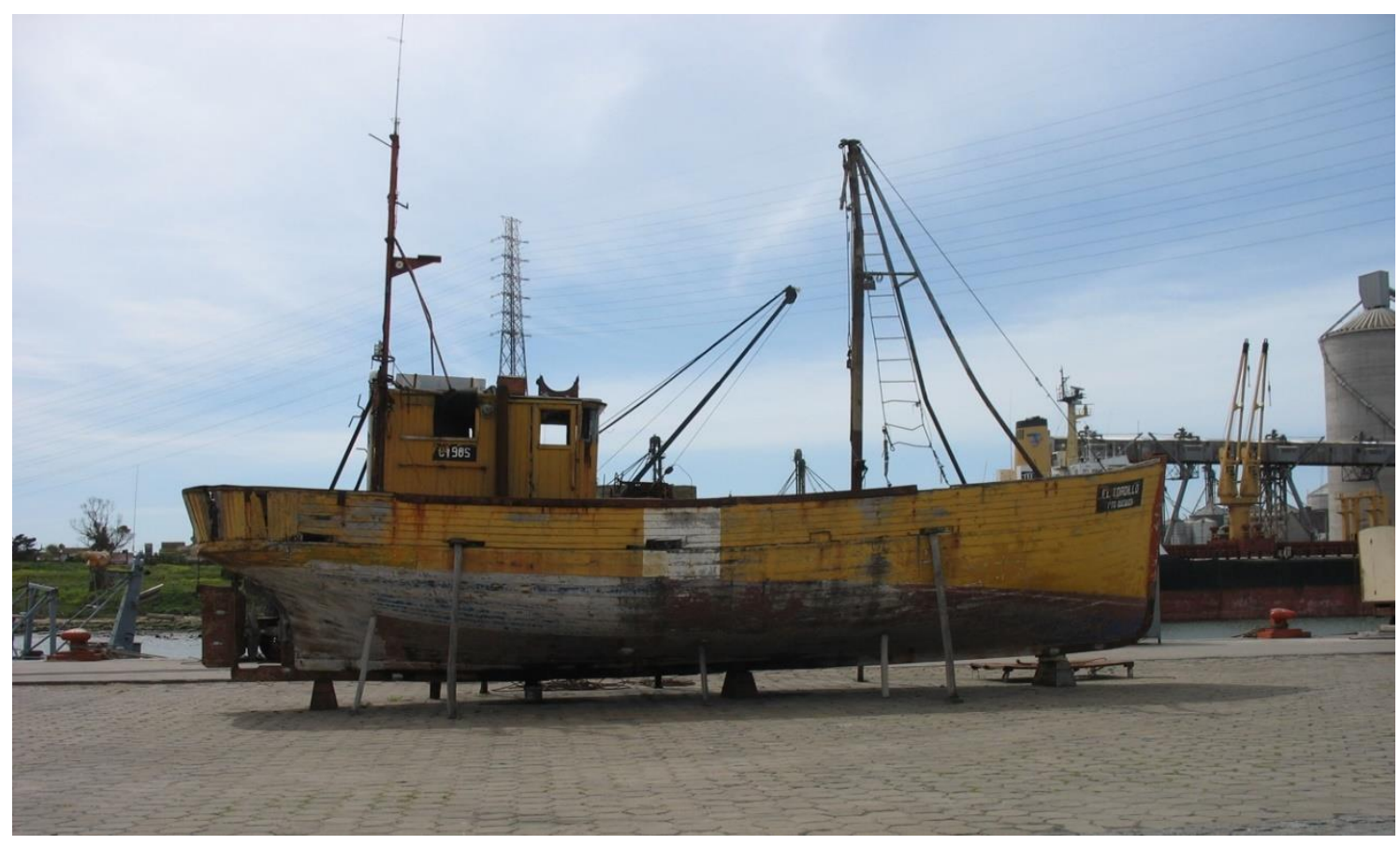

Figura 29. Vista de la lancha El Tordillo en el año 2006, ubicada sobre la banquina de pescadores.

\section{Palabras finales}

En este capítulo hemos ponderado aquellos aspectos en que los pescadores se parecen a sí mismos más que a la comunidad de la que forman parte (ingreso y permanencia en el oficio, sistemas de retribución, jerarquización a bordo y formas concretas y hasta metafísicas de afrontar la incertidumbre, etc.) con las características concretas de los pescadores de Necochea y Quequén (tipos de flota, especies capturadas, artes de pesca, autoridades marítimas). Entre una y otra característica se sintetiza al pescador en la intersección del ser y el hacerse pescador en esta configuración local. 


\section{Capitulo 5.}

\section{Entre el mar y la tierra: los pescadores costeros de Puerto Quequén}

\section{Introducción}

El título de este capítulo Entre el mar y la tierra: los pescadores costeros de Puerto Quequén alude al clásico libro de Pascual Fernández Entre el mar y la tierra: los pescadores artesanales canarios. Entre uno y otro de estos ámbitos los pescadores y sus familias viven, trabajan y constituyen su subjetividad. Tomando esto como punto de partida, el presente capítulo tiene por intención caracterizar a los pescadores locales en su ámbito histórico y geográfico dentro de la ciudad. En lo social, en cuánto a sus relaciones familiares, la organización de su vida y su inserción laboral. En lo subjetivo, en la relación simbólica con su trabajo como pescadores y como hombres. También quedan incluidos en este ámbito, aquel espacio más amplio donde las lanchas y el puerto son significados como paisaje.

\subsection{Los inicios del trabajo de los pescadores en Puerto Quequén}

Para poder brindar una caracterización de la historia de los pescadores de Necochea surge una dificultad, que es la escasez de referencias a dicha comunidad. La información que existe sobre la misma es fragmentaria y dispersa por diferentes fuentes de distinta índole. Sin embargo, y en general, podemos decir que los pescadores de Necochea han estado desde sus inicios estrechamente vinculados con la comunidad más numerosa, desarrollada y conocida de Mar del Plata (Mateo, 2003).

La primera referencia sobre la pesca en la zona de Necochea está en el artículo Notas sobre la industria de la pesca en la Provincia de Buenos Aires de Fernando Lahille, quien nos trae el relato de la excursión que realizó durante los meses de septiembre-octubre de 1895 por la costa bonaerense. De este artículo, que hace un estado de la situación pesquera en la región, podemos rescatar las primeras noticias sobre el desarrollo de la actividad pesquera en la desembocadura del Río Quequén. Nos cuenta el autor: 
"Catorce napolitanos reunidos en sociedad é instalados á inmediaciones de la Aduana son actualmente los únicos pescadores de la localidad. Los medios de que disponen son mediocres. Constituyen la mayor parte de su capital, cuatro pequeñas embarcaciones, pudiendo en caso necesario armarlas á balandras. Algunas líneas de fondo, algunos esparavelos ${ }^{112}$ y dos jabeques ${ }^{113}$ son los únicos aparatos de que se sirven. Tanto vale decir que la pesca no se practica en Necochea."

Describe que, por las características de la zona, en la desembocadura del río los peces costeros entran en cantidades bastante grandes. Como no pueden aclimatarse al agua dulce y remontar la corriente quedan atrapados y en esta circunstancia es que los pescadores los recogen. Cuando la marea sube y los peces vuelven al mar, los pescadores quedan ociosos incluso por semanas. La falta de insumos y conocimientos técnicos por estos pescadores, según el autor, impiden que se puedan desarrollar pesca mar adentro y un adecuado ejercicio de la actividad. Llama la atención sobre el hecho que le relatan los dos primeros pescadores napolitanos que se radicaron en la zona y que afirman haber pescado varias veces "espléndidos atunes", que Lahille está convencido de que se trataba no de atunes sino de germón ${ }^{114}$ (otra variedad más apreciada). La explotación de este pescado, muy estimado en Francia, permitiría desarrollar la incipiente actividad pesquera. Insta a los veleros y transportes marítimos que pasan por la zona en la recorrida Buenos Aires-Bahía Blanca, o hacia el sur, a que pesquen atún blanco o germón, y sostiene:

"les procurará no solamente agradables distracciones, pero también les permitirá variar la comida monótona de á bordo. Para el país, el conocimiento de esas riquezas marítimas favorecerá la colonización costera mucho más aun que las concesiones de tierras y los decretos del P. E., llenos de promesas, pero que aún no han producido beneficios por la forma en que han sido aplicados" (Lahille, 1895).

Este autor destaca las buenas condiciones del río Quequén, similares a las de Mar del Plata y, en otro trabajo posterior (Lahille, 1901), incluye a Necochea entre los posibles abrigos naturales en los que será factible la pesca marítima, como bahía San Clemente, Mar del Plata, Bahía San Blas, entre otras.

\footnotetext{
112 Un arte de pesca similar a una red o mediomundo.

113 Tipo de embarcación de pesca que cuenta con una vela triangular y que también podía ser usada para navegar a remo.

114 Se está refiriendo al bonito (Sarda sarda).
} 
Al finalizar la Primera Guerra Mundial llega una corriente migratoria que incluye a italianos y españoles, algunos de ellos se radicaron en Necochea y posiblemente pescaran, pero es recién después de la Segunda Guerra Mundial cuando se establecieron en la localidad los italianos del sur con sus lanchas y se consolidó el establecimiento de la actividad.

Durante las décadas de 1950 y 1960, la comunidad pescadora de Necochea se hallaba ya asentada, contando con gran cantidad de embarcaciones y 11 plantas en tierra dedicadas al procesamiento de pescado. Durante esta época comienza a celebrarse la Fiesta de los Pescadores (Nogueira, 2018b). Esta se celebraba en la zona del puerto, sobre la margen Necochea, y se caracteriza por contar con elementos típicos de la tradición y religiosidad italiana (Castro, 1996; Mateo, 2003). Se realizaban procesiones con la Virgen, a la que se le agradecía la suerte en el año, se le pedía protección ante los riesgos inherentes a la profesión, y se recordaba aquellos que habían fallecido ejerciendo su oficio.

Con el tiempo, y sobre todo luego del auge que representó la actividad pesquera, que en principio fue desarrollada por inmigrantes, especialmente italianos, que trajeron su oficio desde su país natal, fue incorporando nuevos agentes. En una entrevista, una hija y esposa de pescador nos cuenta:

"Mi papá era pescador, mi abuelo era pescador, toda la familia de mi papá era pescador, nosotros vinimos de Italia. Mi papá siempre fue pescador, pero acá en la Argentina tenía miedo porque el mar era muy, muy abierto. Acá se va mar adentro y en Italia no, pescaban de costa a costa".

Con la migración italiana se asentaron algunas de las familias de pescadores que tuvieron larga y fuerte presencia en la zona, algunos saliendo a la mar y otros diversificando sus actividades dentro del sector, prestando servicios, con pescaderías o fábricas de fileteado. Desde la actividad pesquera en mar proyectaron y desarrollaron la actividad en tierra.

Durante el período de estudio, se dieron significativos cambios en la forma que asumió la actividad pesquera marítimo comercial en nuestro país con el impacto que tuvieron dos hechos. Por un lado, el establecimiento y consolidación de la flota de altura, cuyos volúmenes de capturas rápidamente superaron a los de la flota costera. Y por otro, la perdida de la primacía de la zona bonaerense -encabezada por Mar del Plata- frente a la Patagonia. Es durante este periodo en el cual la primera deja de ser prácticamente la única y más productiva zona de pesca, y queda integrada a un nuevo esquema más amplio que incluye a los puertos del sur del país. En este escenario los pescadores de Puerto Quequén 
tuvieron que reubicar el modo y las condiciones en que se desarrollaba la actividad. En el plano local, esto conllevó también a tensiones dentro del grupo de pescadores. La forma en que se manifestaron las tensiones no tuvo que ver tanto con conflictos gremiales (como en Mar del Plata) sino que se manifestó de forma más difusa en los campos social y comercial, y en la reconfiguración de las relaciones entre los pescadores y la localidad.

Durante décadas, la instituida Fiesta de los Pescadores, que supo lucir en el verano turístico, ofrecía una oportunidad a turistas y locales de participar del mundo de los pescadores. La fiesta proponía un encuentro en la banquina, la oportunidad de comer productos de mar en puestos, espectáculos y la inefable elección de la Reina de los Pescadores. Aunque sin tener el objetivo de recaudar fondos, la Fiesta en muchas ocasiones dejaba un rédito que era utilizado para realizar alguna donación a fundaciones o escuelas, hacer un monumento, retribuir a diversos actores estatales o institucionales, vinculados con la actividad o que colaboraron económicamente para la fiesta con una cena. También era usual que, en caso de que hubiera algún pescador o algún barco con dificultades, parte de ese rédito sirviera para colaborar económicamente con el barco en dificultad. Sobre la percepción de la participación de las mujeres (familiares de pescadores) en la organización encontramos diferentes apreciaciones, mientras en algunos casos son valoradas y remiten a su participación en la organización del evento, otras percepciones marcan que desde la organización es subvalorada porque "la mujer no es pescadora", aunque pasara toda la fiesta cocinando y atendiendo los puestos de venta para celebrarla.

Hacia el final del período, las dificultades en relación con los tiempos para organizarla junto a las críticas recibidas por los organizadores, las dificultades de comunicación con la Secretaría de Turismo de la Municipalidad en un contexto en que la actividad no era pujante, con caída de la producción y pérdida de rentabilidad, llevaron a la desafiliación de algunos de los que usualmente participaban en su organización. Se percibe desmotivación que contrasta con los relatos de otras épocas en las que la actividad brillaba y la fiesta resultaba un momento familiar y de la comunidad pesquera y la comunidad local. Los cambios operados en el puerto también tuvieron implicancias en los sentidos y formas de experimentar la Fiesta de los Pescadores que pasó a celebrarse fuera de la banquina en un terreno municipal lindero a la zona del puerto. En palabras de una entrevistada, esposa de pescador "...antes era distinto, se iba se disfrutaba en la banquina, se subía a los barcos, ahora es otra cosa". Este es uno de los cambios, ya fuera del período de interés la fiesta cambiaría aún más ${ }^{115}$.

\footnotetext{
${ }^{115}$ Nogueira (2018a) analiza cómo luego de estar suspendida por cuatro años, se retoma la fiesta en 2012 pero con un cambio significativo en los organizadores y su significado.
} 
Así como sostenemos la fuerza que se establece en los lazos entre la tripulación de los barcos pesqueros costeros de Puerto Quequén, no encontramos la misma correspondencia en relación a la pertenencia a grupos y asociaciones que nuclean a los trabajadores pescadores en función de su lugar en el proceso productivo, como si ocurre para Mar del Plata (Mateo, 2003). A inicios del período de interés funcionaba la "Sociedad de Pescadores", que aglutinaba a los propietarios de barcos, pero hacia los años '80 dejó de tener actividad y se desintegró. Por su parte, más adelante se conformó una "Cámara de Armadores" que nuclea a los propietarios-armadores. Y los marineros agremiados al Sindicato de Obreros Marítimos Unidos (SOMU). A diferencia de Mar del Plata dónde la actividad sindical y de las asociaciones es fuerte (Mateo, 2006), en Puerto Quequén se destaca la poca adhesión a las formas asociativas. Más allá de que todos los entrevistados participaban en ellas, no era percibida como significativa. Consideramos que la pequeña escala de la actividad, y la existencia de lazos familiares que cruzan la pertenencia laboral son una explicación para la baja adherencia y actividad en formas asociativas. Reflexionando sobre la actividad de la Cámara un entrevistado sostiene:

\begin{abstract}
"Las reuniones son pocas o inexistentes porque cada vez somos menos, tres o cuatro somos o cinco, ponele y nos vemos todo el día en el puerto, o sea que para que vamos a reunirnos si lo conversamos ahí. No es como cuando tenés una asociación de 50 o 100 personas, que entonces sí tenés reuniones más periódicas" (pescador-armador).
\end{abstract}

La falta de regularidad en las reuniones no impide que se organicen cuando es necesario en pos de un interés común y haciéndose valer como actor social, por ejemplo, para solicitar permiso excepcional para pescar en zonas de veda. Aunque pescan en Mar del Plata, no pudimos registrar que participen de las asociaciones de la vecina localidad. La Cámara de Armadores, a diferencia de la Sociedad de Pescadores en su momento, no está implicada en la comercialización de pescado. Los conflictos laborales entre los diferentes actores involucrados en la actividad, no son percibidos como significativos, con la excepción de aquellos casos que son considerados como mala conducta a bordo por poner en riesgo la integridad de las personas o del barco.

Los lazos familiares y el sistema de retribución a la parte actúan como un freno para la emergencia de conflictos y refuerzan el sentimiento de empresa común (Acheson, 1981). Las formas de conflicto quedan en el ámbito de lo personal, resulta muy raro y no fue referido en ninguna de las entrevistas que escale en una forma de conflictividad capitaltrabajo dentro del barco. Como ya dijimos, debemos tener en consideración la escala de la actividad en Puerto Quequén y los estrechos lazos familiares y personales como atenuantes, 
o como expresa un pescador: "conflicto hay siempre en todas partes, pero en la pesca como es a la parte, más plata hace el barco más plata hace el marinero". El principal motivo de disputa o tensión que emerge entre los pescadores locales tiene que ver con las formas establecidas para la comercialización. En esta instancia observamos cómo el tejido social de la actividad se vuelve laxo o conflictivo, tal como ocurrió en la organización de la fiesta de los pescadores. El papel desempeñado por la antigua Sociedad de Pescadores, es bien recordado por algunos, pero en otros casos recordado como un espacio en el que algunos pescadores encargados de la comercialización sacaban "ventajas" en detrimento de aquellos que no participaban.

Acá antiguamente cuando estaba la Sociedad de Pescadores, se manejaba toda la plata de la venta de pescado. Todos acá como era muy poca la venta se manejaba por la Sociedad de Pescadores, que vendía todo el pescado junto. Pero como siempre después hubo gente que estaba ahí adentro y que se robaba la plata, que se quedaba con la plata de los pescadores y eso. Entonces se fue saliendo de esa sociedad (pescador).

\subsection{Origen local y extra local de los trabajadores-pescadores en Puerto Quequén}

El desarrollo de la actividad pesquera tuvo a nivel regional y nacional un desarrollo que llevó a que en ciertos momentos la actividad fuera preponderante en algunos lugares por ejemplo, en el sur del país- y que para su desarrollo hiciera falta más mano de obra que la disponible. Al depender de un recurso móvil, al haber diferentes grados de desarrollo de la industria pesquera asociada y, también en correlación a los ciclos establecidos, es posible encontrar trabajo de personas de diferentes localidades en los puertos que lo requieran. La migración temporal laboral ha sido un tema abordado para el ámbito rural (Benencia y Forni, 1986; Berger y Neiman, 2016; Alberti, 2015) pero no ha sido especialmente trabajado para el sector pesquero.

En las encuestas realizadas durante 2003 la mayoría de los pescadores relevados en esa oportunidad, y que se encontraban en ese momento trabajando en la pesca costera desde Puerto Quequén, tenían residencia en Necochea-Quequén. Sólo dos encuestados tenían residencia en Mar del Plata. No encontramos en esa ocasión pescadores trabajando en la pesca costera que residieran en otros lugares. 
A partir del procesamiento de la información de los libros de embarque de 1987 y $2001^{116}$ se construyó una base de datos desde la que analizamos la composición local y extra-local de los trabajadores para esos años. De los 906 movimientos efectuados en esos dos años, distinguimos aquellos que correspondieron a barcos pesqueros, incluyendo los de altura (650) ya que en los mismos libros también se asientan para otros barcos, como mercantes, de pasajeros o deportivos, y otros que se vinculan con las actividades específicas del puerto, entre ellos dragas, remolcadores, y otros (Tabla 10). Por el carácter de la fuente están representados los movimientos tanto de las lanchas amarillas como de los barcos de altura. Desde Puerto Quequén, en el año 1987 se registraron 272 movimientos de embarco de barcos pesqueros, y otros 63 movimientos corresponden a diferentes tipos de buque como dragas, remolcadores, lanchas de pesca deportiva. En el año 2001 los movimientos totales en los roles de embarco ascienden al número de 571, de los cuales 395 corresponden a barcos pesqueros. La información sobre la procedencia, junto con la información recabada en las trayectorias nos permiten establecer la fuerte movilidad de los trabajadorespescadores.

Tabla 10. Movimientos según tipos de embarcaciones en Puerto Quequén en los años 1987 y 2001. Elaboración propia a partir de los libros de embarque de la Prefectura Naval Argentina.

\begin{tabular}{|l|c|c|c|}
\hline \multicolumn{1}{|c|}{ Tipo de embarcación } & $\mathbf{1 9 8 7}$ & $\mathbf{2 0 0 1}$ & Total \\
\hline Pesqueros & 272 & 395 & $\mathbf{6 6 7}$ \\
\hline Mercantes y pasajeros & 0 & 35 & $\mathbf{3 5}$ \\
\hline Del puerto & 26 & 136 & $\mathbf{1 6 2}$ \\
\hline Sin datos & 37 & 5 & $\mathbf{4 2}$ \\
\hline Total & $\mathbf{3 3 5}$ & $\mathbf{5 7 1}$ & $\mathbf{9 0 6}$ \\
\hline
\end{tabular}

Para el año 1987, sobre el total de 272 registros de embarques en pesqueros se contabilizaron un total de 211 personas que se embarcaron en Puerto Quequén (Tabla 11). La mayoría residían en el conglomerado Necochea-Quequén, y de estas localidades, predominaban aquellos de la primera. En cuanto a los pescadores residentes en otros lugares, aquellos que provienen de Mar del Plata constituyen el grupo más importante, siendo aproximadamente el $20 \%$ del total. A estos le siguen, aunque con un porcentaje inferior al 7\% aquellos que provienen de distintas localidades del Gran Buenos Aires (como, por ejemplo, Hurlingham, Ramos Mejía, Carapachay, Florencio Varela o San Isidro), y otras localidades de la provincia de Buenos Aires, todos del sudeste bonaerense (Bahía Blanca,

116 Rispoli (2014). 
Punta Alta, Balcarce y Batán). Es de destacar 12 pescadores que residían en el noreste y noroeste del país, en su mayoría -salvo dos de Tucumán- provenían del litoral, mayormente de Concepción del Uruguay. En este sentido, el litoral del río Paraná ha sido una zona tradicional de pescadores, aunque en este caso, de río (Prol, 2008). Por último, muy pocos provenían de la Ciudad Autónoma de Buenos Aires o la Patagonia.

Tabla 11. Localidades de procedencia de los pescadores embarcados en Puerto Quequén en los años 1987 y 2001.

Elaboración propia a partir de los libros de embarque de la Prefectura Naval Argentina.

\begin{tabular}{|c|c|c|c|c|}
\hline \multirow{2}{*}{ Localidades } & \multicolumn{2}{|c|}{$\mathbf{1 9 8 7}$} & \multicolumn{2}{c|}{$\mathbf{2 0 0 1}$} \\
\cline { 2 - 5 } & Cantidad & $\%$ & Cantidad & $\%$ \\
\hline Necochea-Quequén & $\mathbf{1 0 3}$ & $\mathbf{4 8 , 8} \%$ & $\mathbf{1 5 5}$ & $\mathbf{6 0 , 1 \%}$ \\
\hline Necochea & 75 & $35,5 \%$ & 107 & $41,5 \%$ \\
\hline Quequén & 28 & $13,3 \%$ & 48 & $18,6 \%$ \\
\hline Otras localidades & $\mathbf{8 8}$ & $\mathbf{4 1 , 7 \%}$ & $\mathbf{7 6}$ & $\mathbf{2 9 , 8} \%$ \\
\hline Mar del Plata & 42 & $19,9 \%$ & 43 & $16,7 \%$ \\
\hline CABA & 8 & $3,8 \%$ & 5 & $1,9 \%$ \\
\hline Gran Buenos Aires & 15 & $7,1 \%$ & 3 & $1,2 \%$ \\
\hline Resto prov. Buenos Aires & 10 & $4,7 \%$ & 3 & $1,2 \%$ \\
\hline NEA-NOA & 12 & $5,7 \%$ & 7 & $2,7 \%$ \\
\hline Patagonia & 1 & $0,5 \%$ & 15 & $5,8 \%$ \\
\hline Colonia (Uruguay) & 0 & $0,0 \%$ & 1 & $0,4 \%$ \\
\hline Sin datos & $\mathbf{2 0}$ & $\mathbf{9 , 5} \%$ & $\mathbf{2 6}$ & $\mathbf{1 0 , 1 \%}$ \\
\hline Total & $\mathbf{2 1 1}$ & - & $\mathbf{2 5 8}$ & - \\
\hline
\end{tabular}

Por su parte, a partir de los libros de embarque del año 2001 se observan algunas diferencias. La cantidad de movimientos en Puerto Quequén aumento en 123, un 68\% más que en el año 1987, totalizando 395 registros (Tabla 10). A su vez, la cantidad de pescadores con residencia en Necochea-Quequén aumentó también en términos proporcionales, ya que dan cuenta del $60,1 \%$ del total de pescadores embarcados ${ }^{117}$; por lo que aquellos que provenían de otras localidades descienden de casi de poco más del 40\% en 1987, a poco menos del 30\% en el 2001. En relación a estos últimos, nuevamente la mayoría proviene de Mar del Plata. Le siguen en orden decreciente aquellos que proceden de localidades de la Patagonia (Sierra Grande, Puerto Madryn, Rawson y Ushuaia), lo que parece reflejar una

\footnotetext{
117 A título comparativo, en las encuestas realizadas durante 2003 a 18 pescadores de Puerto Quequén, el 89\% de aquellos que se encontraban en ese momento trabajando en la pesca costera tenían residencia en Necochea o Quequén. Sólo dos encuestados, que representan el 11\% restante, tenían residencia en Mar del Plata. No encontramos en esa ocasión pescadores trabajando en la pesca costera que residieran en otros lugares.
} 
consolidación de la misma en el mapa pesquero del país. De las localidades mencionada de procedencia, se destacan siete registros que tenían como lugar de residencia Sierra Grande, una localidad del interior de la provincia de Río Negro que atravesó durante la década de 1990 una profunda crisis por el cierre de la mina de hierro HIPASAM118. Por otro lado, disminuyen notoriamente los registros de zonas que en el año 1987 tenían porcentajes más altos, como Gran Buenos Aires, resto de la provincia de Buenos Aires y el NEA-NOA.

Tengamos presente que más movimientos en los libros de embarque no significa necesariamente un incremento en la producción, sino que implica que la conformación del grupo de trabajo ha variado o es menos estable. Problematizar los movimientos de los embarques y la procedencia de los lugares de residencia de los trabajadores nos invita a pensar los flujos de los trabajadores en función de la demanda, y, también de la existencia de redes de reclutamiento que pueden darse por intermedio de la acción gremial en la contratación de los pescadores, sobre todo para la situación de la pesca de altura. Las formas de reclutamiento también se dan en el marco de redes de parentesco y compañerismo. Si bien se observa que la mayoría de los trabajadores-pescadores de Puerto Quequén para ambos años tienen lugar de residencia en el aglomerado urbano Necochea-Quequén; no es menor la proporción de trabajadores de Mar del Plata, Ciudad Autónoma de Buenos Aires, diversas localidades del conurbano bonaerense, y de otras regiones más lejanas como el noreste argentino o la Patagonia. Así como se observan movimientos de trabajadores entre barcos en el puerto local, también ocurre en relación a otros barcos en otros puertos, por ejemplo, muchos de los pescadores radicados en Necochea y Quequén también embarcan desde otros puertos, generalmente de Mar del Plata, pero también del sur del país, lo que supone una relativa movilidad entre los tripulantes vinculada, también, a la oferta de trabajo.

A partir de estos datos problematizamos la constitución de la categoría 'pescadores de Puerto Quequén' que es la que tomamos para la indagación de este estudio. Entonces, podemos distinguir las siguientes categorías: por un lado, pescadores radicados en núcleo urbano Necochea-Quequén y que trabajan en Puerto Quequén; por otro lado, pescadores que residen en el núcleo urbano Necochea-Quequén pero que trabajan desde otros puertos; por último, aquellos pescadores que residen en otros lugares pero que embarcan desde Puerto Quequén. Tengamos en cuenta que entre el primer y el segundo grupo no hay una diferenciación definitiva, sino que esta distinción responde a un circuito temporalmente diferenciado en el ciclo laboral de muchos de los trabajadores-pescadores. En función del desarrollo de la actividad pesquera en nuestro país, es posible sostener que

118 HIPASAM (Hierro Patagónico Sociedad Anónima). 
Puerto Quequén provee de mano de obra a otros circuitos pesqueros. La existencia del puerto, de la posibilidad de formación como marineros por parte de Prefectura Naval Argentina, y de actividad pesquera -aunque sea de baja escala-, propicia la formación de mano de obra. Esta mano de obra queda disponible ya que no es absorbida en su totalidad en el medio local sobre todo al desarticularse el carácter de puerto pesquero de altura y la menor demanda de pescado por el cierre de las industrias vinculadas en tierra. En este sentido, podemos considerar que la masa crítica de trabajadores embarcados para la pesca con residencia en Necochea y Quequén abasteció la demanda laboral de la flota pesquera global que desarrolló su actividad en el Mar Argentino, no restringiéndose sólo a Puerto Quequén. Por su parte, la presencia de trabajadores pescadores extra local se incrementa, sobre todo, al considerar los barcos de altura. En menos casos, pescadores de otros puertos se embarcan en la flota costera local por largos períodos y cuando esto ocurre, mayormente corresponde a pescadores de Mar del Plata o de otras localidades pero que han compartido embarques con otros pescadores oriundos de Necochea y Quequén.

La pequeña y cada vez menor flota pesquera local aparece como un refugio y una opción sólo para una pequeña proporción de los trabajadores-pescadores neco-quequenenses, esto es, aquellos que tienen barco propio o familiar o, que tienen lazos familiares con los propietarios. Por lo que tienen una vinculación más fuerte con los medios de producción de la pesca, y probablemente una relación más estrecha con las formas tradicionales de captura del recurso.

\subsection{Patrón de asentamiento y características de las viviendas de los trabajadores-pescadores}

A partir de los datos recabados en los Libros de Embarque (1987 y 2001) ubicamos la dirección de las viviendas de los trabajadores pescadores en las ciudades de Necochea y Quequén. A diferencia de Mar del Plata, donde el barrio puerto constituye una verdadera comunidad portuaria (Mateo, 2004a), en Necochea Quequén no hay un claro patrón de asentamiento que vincule a los trabajadores de la pesca con el barrio puerto, aunque muchas de las familias de más de una generación de pescadores y propietarios de embarcaciones viven en este barrio o sus alrededores.

La localización de los trabajadores pescadores puede observarse para el año 1987 en la Figura 30 y para el año 2001 en la Figura 31.

De esta forma podemos observar que en los dos años se comprueba que los pescadores vivían en distintos barrios de las ciudades de Necochea-Quequén. No se registra una concentración particular en torno al puerto -como es esperable en el caso de Mar del 
Plata, como ya dijimos- sino que éstos radican en distintas zonas, con una mayor densidad de domicilios en el casco histórico.

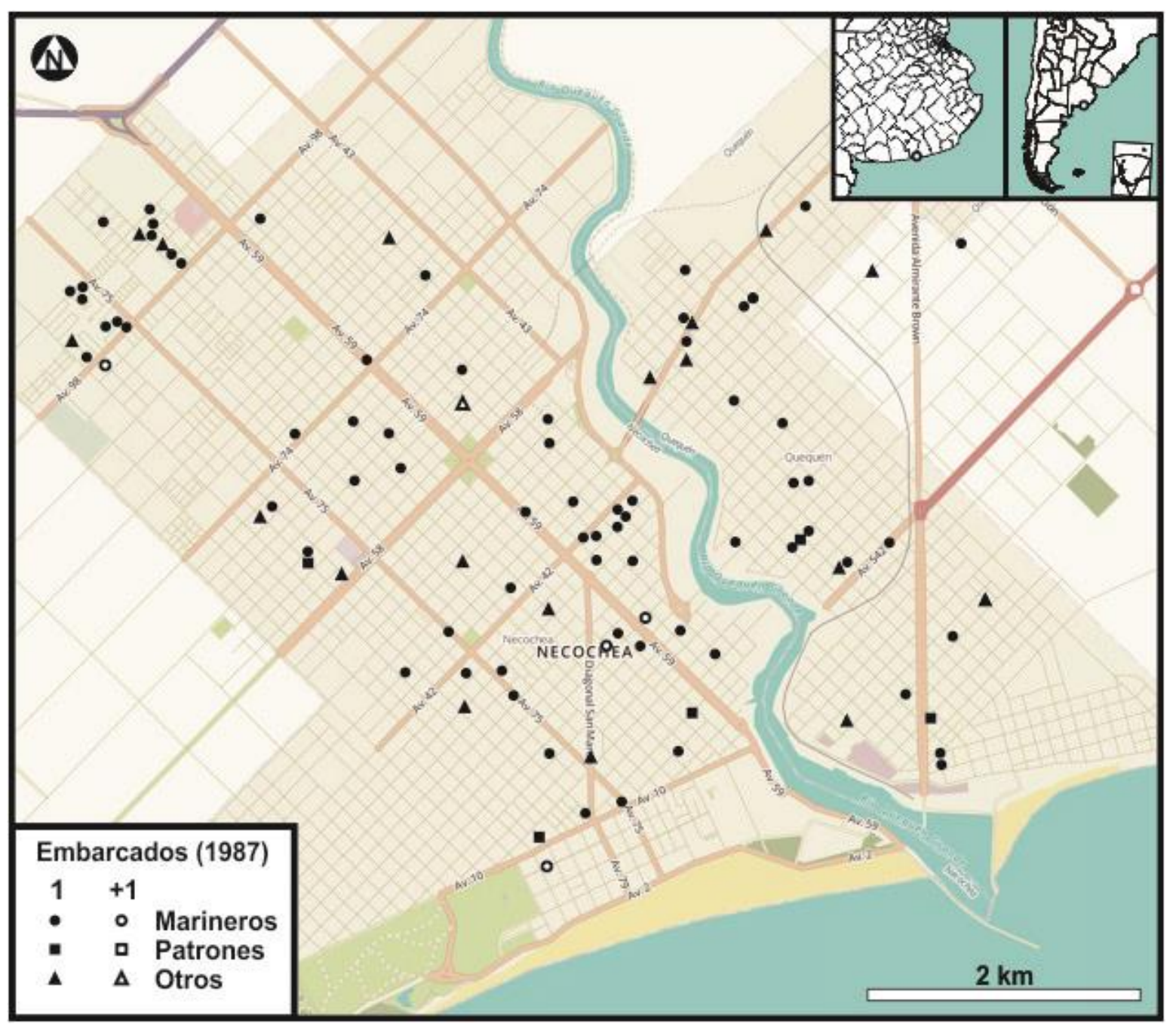

Figura 30. Localización de los trabajadores pescadores para el año 1987. Elaboración propia a partir de los libros de embarque de la Prefectura Naval Argentina y de OpenStreetMap ${ }^{119}$.

Con respecto a las condiciones de vivienda ${ }^{120}$, de los datos relevados de la encuesta realizada en el año 2003 se desprende que en todos los casos la vivienda es ocupada por la familia nuclear, excepto los dos casos de pescadores encuestados que viven solos. La mayoría de las viviendas cuentan con dos habitaciones, algunas con tres o cuatro. En función de la cantidad de ocupantes y las características de los inmuebles ocupados podemos sostener que se no hallan casos de hacinamiento ${ }^{121}$. Todas las viviendas cuentan

\footnotetext{
119 https://www.openstreetmap.org/

120 La información es consistente con la recabada para 1988 por Errazti et al. (1998).

121 Se considera como tal cuando habitan más de tres personas por cuarto (INDEC, 1984).
} 
con electricidad, agua, baño adentro con botón y arrastre. El desagüe, en la mayoría de los casos, es a red pública o cloaca. Solamente en el $26 \%$ de los casos el desagüe va a pozo ciego. En todos los casos la mampostería es el material predominante de las paredes de la vivienda, mientras que los pisos son de madera, mosaico, cerámica o baldosas plásticas. El material de los techos varía entre chapa, losa y teja. Exceptuando un caso, en que la vivienda es prestada por el padre del ocupante, el resto de los encuestados son propietarios del inmueble.

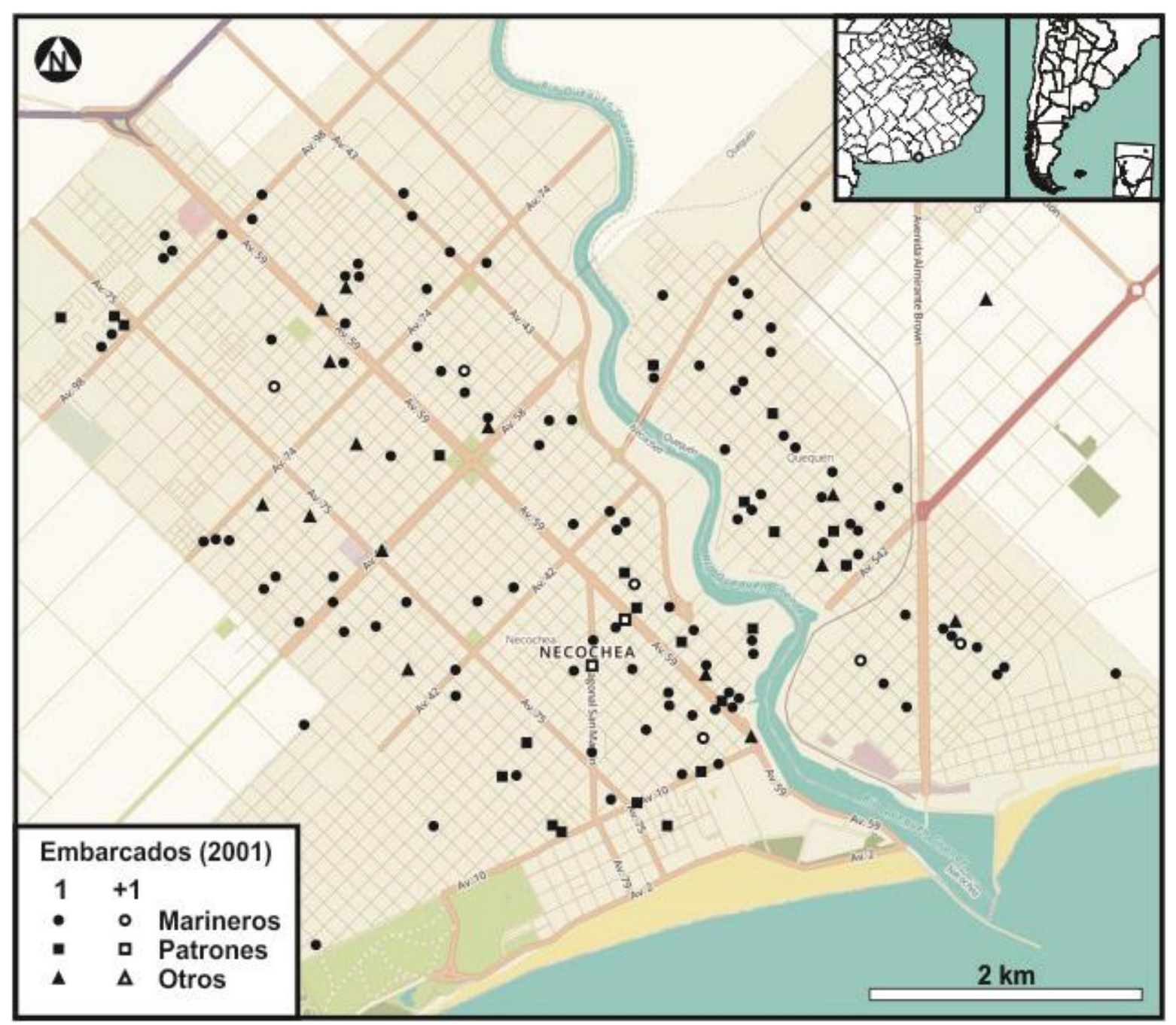

Figura 31 Localización de los trabajadores pescadores para el año 2001.

Elaboración propia a partir de los libros de embarque de la Prefectura Naval Argentina y de OpenStreetMap ${ }^{122}$.

Si evaluamos las características sociodemográficas de los encuestados y entrevistados encontramos que las familias consideradas no se encuentran en situación de tener Necesidades Básicas Insatisfechas. Los hogares con Necesidades Básicas Insatisfechas

122 https://www.openstreetmap.org/ 
$(\mathrm{NBI})^{123}$ son aquellos que presentan al menos uno de los siguientes indicadores de privación: a) en relación a la vivienda: hogares en una vivienda de tipo inconveniente (pieza de inquilinato, vivienda precaria u otro tipo, lo que excluye casa, departamento y rancho); b) En relación a las condiciones sanitarias: hogares que no tuvieran ningún tipo de retrete; c) hacinamiento: hogares que tuvieran más de tres personas por cuarto; d) en relación a la asistencia escolar: hogares que tuvieran algún niño en edad escolar ( 6 a 12 años) que no asistiera a la escuela y e) en relación a la capacidad de subsistencia: hogares que tuvieran cuatro o más personas por miembro ocupado y, además, cuyo jefe no haya completado tercer grado de escolaridad primaria.

Como ya se ha dicho, Mar del Plata puede ser reconocida como una "comunidad de pescadores" por el patrón de asentamiento compacto, con preponderancia económica y cultural de la pesca y actividades estrechamente vinculadas espacialmente en la zona del puerto (Mateo, 2003). En el caso de Necochea-Quequén, como observamos a partir de la información recabada sobre la ubicación de la vivienda de los pescadores de Puerto Quequén, no encontramos una asociación tan fuerte al respecto entre la actividad y el barrio donde se halla inserto. Esto puede deberse a dos razones no necesariamente excluyentes. Por un lado, la incorporación de trabajadores pescadores no vinculados a familias de tradición pesquera, en cuyo caso, ser pescador sería una opción para jóvenes provenientes de todos los barrios y no sólo para los descendientes de los migrantes italianos que se establecieron originalmente cerca de la zona portuaria. Por otra parte, al no hallarse establecida una fuerte red de sociabilidad entre los pescadores y en torno al barrio puerto, es más probable que no se sostenga una identificación barrial y la localización de la vivienda esté influida por otras variables.

\subsection{Características de las familias de los pescadores, organización doméstica y estrategias familiares}

Nos interesa comprender el trabajo los pescadores en el marco de sus familias ${ }^{124}$, por lo que retomamos la discusión sobre estrategias de sobrevivencia, existencia o familiares de vida, recordando que este fue uno de los puntos iniciales en el abordaje de la

\footnotetext{
123 INDEC (1984).

${ }^{124}$ Fortes (1958) distingue tres etapas del ciclo familiar (expansión, dispersión y reemplazo) según el lugar que ocupan en la estructura social. La mayoría de los entrevistados y encuestados podemos ubicarlos en la primera etapa caracterizada por el matrimonio y nacimiento de todos los hijos. Mientras que otros de los entrevistados se encontraban en la fase de dispersión.
} 
presente investigación ${ }^{125}$, si bien para la investigación no tomamos exclusivamente como referencia analítica la unidad doméstica y/o familia, sino que definimos al sujeto de estudio como los pescadores. Se nos hace imposible, desde nuestra perspectiva teóricometodológica caracterizar a los trabajadores-pescadores como sujetos aislados. Sostenemos que decisiones y representaciones sobre el propio trabajo se dan indisociablemente vinculadas con otras esferas supraindividual es de actuación en la que se reconoce lo familiar como un punto de mediación en la toma de decisiones que afectan a los sujetos. Del concepto de estrategia rescatamos su carácter de estructura de opciones, y no al de acciones racionales guiadas por normas y valores interiorizados (Przeworski, 1982). Esta estructura de opciones se presenta en función de la compleja relación que se da entre una dimensión 'familia-sociedad', que hace referencia las condiciones macrosociales que estructuran y otra dimensión 'familia-individuos' en la que se toman decisiones y forman acciones y que su despliegue también contribuye a reproducir o transformar la estructura social (Salvia, 1995) ${ }^{126 .}$

Cariola (1992) utiliza el concepto de estrategia de sobrevivencia que en su sentido más amplio involucra las redes familiares, vecinales y del paisanaje. De esta autora se toma como concepto guía el de organización doméstica entendida como "la distribución de las responsabilidades de producción de ingresos y de mantenimiento cotidiano entre los miembros de la unidad doméstica, la cual está ligada a valoraciones ideológicas acerca de los roles que deben ocupar el hombre, la mujer y los hijos en el hogar, y que asumen distintas modalidades de acuerdo con el ciclo de vida de cada grupo familiar".

Por su parte, Sáenz y Di Paula (1981) manejan el concepto de estrategias de existencia. Destacan que se deben privilegiar no sólo las redes de reciprocidad utilizadas en los casos de extrema necesidad, sino también tomar en cuenta en la subsistencia la participación del propio sector capitalista, el Estado y de instituciones privadas, tratando de ver el peso cuantitativo de cada uno de estos elementos en el conjunto de la estrategia. La unidad de análisis que definen estos autores es el agregado familiar, definido como aquel que afronta la acción de subsistencia como un conjunto. La estrategia de existencia implica una configuración de diferentes "instancias" que son actividades asumidas por el agregado familiar para satisfacer las necesidades relativas, maximizar los ingresos y minimizar los egresos. Rodríguez (1981) entiende las estrategias de supervivencia como los comportamientos o arreglos que se hacen en el ámbito de la familia (unidad de análisis)

\footnotetext{
125 Ver, por ejemplo, Rispoli (2003 y 2005).

126 Y que también nos permiten discutir y problematizar las complejas mediaciones que existen entre lo individual y lo estructural social Giddens (1995) y Bourdieu (1990).
} 
para enfrentar el problema de "existir" o vivir. No se trata de arreglos coyunturales que pueden hacer las familias para enfrentar momentos de crisis, sino aquellos de carácter más general ligados al, y condicionados por, el "estilo de desarrollo" vigente en una sociedad concreta. Cuando Torrado (1983) se refiere a estrategias familiares de vida o estrategias de supervivencia familiar, destaca que este concepto es susceptible de ser desarrollado dentro de un modelo referente a la sociedad global, que da cuenta de manera integrada y coherente de fenómenos (económicos, sociales, demográficos) que antes se estudiaban aisladamente y que permitió un cambio de la unidad de análisis, de la unidad-individuo, a la unidadfamilia. Con este concepto la autora se refiere a "aquellos comportamientos de los agentes sociales de una sociedad dada que se relacionan con la constitución y mantenimiento de unidades familiares en el seno de las cuales pueden asegurar su reproducción biológica, preservar la vida y desarrollar todas aquellas prácticas económicas y no económicas, indispensables para la optimización de las condiciones materiales y no materiales de existencia de la unidad y de cada uno de los miembros". Las estrategias familiares de vida de la unidad familiar están condicionadas, entonces, por la posición que estas últimas ocupan en el sistema de estratificación social.

Torrado sostiene que la definición del concepto de estrategias debe hacerse por enumeración exhaustiva de las dimensiones conductuales que, en cada caso, de acuerdo con el estado del conocimiento, puedan considerarse relacionadas con los tres elementos incluidos en la definición general: reproducción biológica, preservación de la vida y optimización de las condiciones de existencia. Es necesario rescatar la visión temporal de las estrategias como un proceso que se desarrolla a lo largo del ciclo de vida de la familia. En nuestro caso, preferimos el concepto de estrategias familiares de vida a otras posturas que caracterizan las estrategias como de supervivencia o existencia porque se ajusta más a la realidad de los sujetos y familias consideradas. Recordemos que en su surgimiento y en la mayoría de sus contextos de uso este concepto remite al análisis de aquellas familias en situación de pobreza o vulnerabilidad social. Sin embargo, lo consideramos un concepto muy interesante para analizar la dinámica social en la mediación entre individuo y estructura no restringiéndolo a una clase o situación social particular. Bourdieu (1988) se refiere a estrategias de reproducción social y las entiende como el "conjunto de prácticas fenomenalmente muy diferentes, por medio de las cuales los individuos y las familias tienden, de manera consciente o inconsciente, a conservar o aumentar su patrimonio, y correlativamente a mantener o mejorar su posición en la estructura de relaciones de clase".

De las dimensiones conductuales propuestas por Torrado (1981) que quedan incluidas en las estrategias de la vida de la familia obrera, retomamos sólo algunas, más pertinentes con los objetivos particulares del presente diseño de investigación. Incluimos 
como parte de las estrategias aspectos como la participación económica, la organización doméstica, migraciones laborales, la existencia de redes familiares o de allegados para la obtención del empleo, y para la circulación de bienes como alimentos, dinero, vestimenta. En este apartado nos centraremos especialmente desde esta perspectiva a la división familiar del trabajo y la cooperación extrafamiliar. La migración como estrategia la retomaremos en función de la categoría de trayectoria, esta que no es una migración de la familia sino en el marco de las características del trabajo pesquero y de las elecciones laborales.

Entendemos la división familiar del trabajo como aquellos comportamientos relativos a la asignación de la fuerza de trabajo disponible dentro de la unidad familiar sea actividades económicas que producen ingresos, o el trabajo doméstico que no produce ingresos. En el primer caso los aspectos a considerar son las pautas de participación por sexo en el mercado de trabajo, las características relativas a la ocupación principal, así como la estabilidad del empleo. En cuanto al trabajo doméstico nos interesamos en cómo se organiza en torno a la actividad principal de la pesca.

En relación con la conformación del hogar y a la organización doméstica, de lo relevado en la encuesta se desprende que el $88 \%$ de los encuestados está casado o vive en relación de concubinato. De las esposas el $50 \%$ no trabajan y sólo un $25 \%$ trabajan afuera de la casa. Aunque Wainerman 2003 observa la pérdida de popularidad de proveedor único (varón) y la expansión del modelo de dos proveedores para el AMBA de 1980 a 2000, podemos reflexionar las razones por la que una gran proporción de las cónyuges de los pescadores no trabajan fuera del hogar. Mientras el pescador está en actividad y la familia tiene hijos pequeños podemos pensar que representa una opción valorada reservar un miembro adulto del hogar con mayor presencia ya que la actividad pesquera no supone una rutina predecible para la organización del hogar. El rédito económico del trabajo pesquero -más allá de las fluctuaciones e imponderables- suele alcanzar para cubrir los gastos de reproducción de la familia en función de las expectativas de sus integrantes. La presencia de la mujer en la casa permite cierta predictibilidad en la organización de las funciones de reproducción social y, además, actúa como una reserva en caso de que el pescador deba interrumpir su trabajo, quedando disponible para ingresar ella en el mercado laboral. Entre los relevados, son mínimos los casos en los que la actividad de la mujer se vincula con el deseo y desarrollo de una carrera profesional independiente. Mientras que entre la mayoría de las esposas trabajadoras es considerada una necesidad para complementar el ingreso de la familia. De los casos considerados en que la mujer trabaja fuera de la casa, una sola es maestra y el resto se dedica al trabajo doméstico por hora. 
La cantidad de hijos promedio entre los encuestados fue de entre 2 y 3 por familia. No se detectó ningún caso de familia extensa, tampoco de hogares múltiples. Observamos que la situación relevada acompaña la tendencia social argentina relevada por Torrado (2007) en la que se instala el predominio de la familia nuclear, es decir donde solo están los parientes nucleares, aumenta en el conjunto de los hogares conyugales, en la medida que descienden las familias extensas, aquellas a las que se allegan parientes no nucleares. La totalidad de los encuestados en pareja declara que la mayoría del trabajo doméstico lo realiza la cónyuge, y en una proporción muy baja ayudadas por las hijas. No se registraron casos de trabajo doméstico pago. Solamente los dos casos de pescadores que viven solos (uno soltero y uno separado) declararon realizar ellos la mayor parte del trabajo doméstico. En los casos en que la cónyuge (e hijas) realizan la mayoría del trabajo doméstico todos -excepto uno- declaran colaborar en esas tareas, la mayoría (73\%) un rato y el resto toda la mañana o toda la tarde o ambas. Las tareas que habitualmente realizan por los que colaboran están, sobre todo, relacionadas con el cuidado de los hijos. En mayor proporción $(73 \%)$ declaran llevar los niños a la escuela, seguido por cuidarlos (60\%), alimentarlos (53\%) y bañarlos (40\%). La tarea más realizada en el hogar consiste en la reparación de instalaciones y artefactos (60\%). La misma proporción (60\%) declara cocinar habitualmente y en menor medida (47\%) realizar las compras. El 40\% colabora en hacer las camas y ordenar la habitación, y sólo el 33\% en lavar. Mientras que, para actividades como planchar y coser, la proporción es irrelevante. Casi la mitad de los encuestados (47\%) se ocupa de realizar trámites. Entre los entrevistados también la mayoría de las tareas son realizadas por las mujeres. En algunos casos, mientras están solas, son ayudadas por la madre, o por alguna persona de confianza. Todos los entrevistados colaboran en las tareas del hogar cuando están y/o cuando pueden. La responsabilidad que más asumen es en relación al cuidado de los hijos: llevarlos y participar en la escuela, educarlos y compartir momentos con ellos.

Entre los entrevistados con cónyuges la situación en relación con el trabajo de las parejas se mantiene en la misma proporción, sólo una cuarta parte de las parejas trabaja fuera de la casa y la mayoría no trabaja. Sin embargo, si tenemos en cuenta como mujeres trabajadoras a todas las que trabajan y/o trabajaron la proporción aumenta a dos tercios. Entre las que trabajaron y no trabajan la razón esgrimida es que abandonaron el trabajo para hacerse cargo de las y los hijos. Dentro del universo de las que trabajan y/o trabajaron fuera de la casa la mitad tienen un oficio o profesión (docentes, oftalmóloga, peluquera) y la otra mitad no, estando o habiendo estado ocupadas en el servicio doméstico. No se relevaron situaciones de cónyuges cuentapropistas. 
No obstante, lo analizado hasta aquí, resulta imprescindible dar cuenta de dos cuestiones. Hasta ahora estuvimos hablando del trabajo fuera de la casa, entendiendo a aquel trabajo por el que se recibe un salario u alguna retribución. Entonces, por un lado, debemos explicitar como trabajo el realizado exclusivamente por las esposas y/o hijas de pescadores dentro de la casa, aquel trabajo que se realiza en el ámbito doméstico y que constituye un requisito indispensable para la reproducción social, que no implica un salario, pero es la fuente que permite la organización de la familia y su reproducción (Durham, 1999). Por otra parte, tenemos que dar cuenta de otra forma que asume el trabajo de las mujeres en las familias vinculadas a la actividad pesquera. Del universo de las esposas que "aparentemente" no trabajan (y siendo la familia propietaria de embarcación) un tercio "colabora" en las tareas de administración del barco (pago de cuentas, liquidaciones para los trabajadores, pago de impuestos, entre otros). Este trabajo que podría ser tercerizado (algunas embarcaciones tienen agentes marítimos) y que tendría un costo implica una forma de subsumir e invisibilizar el trabajo femenino. No necesariamente porque no se identifique, sino que no es nombrado trabajo y no cuenta con un reconocimiento material. El papel de la "ayuda" y poder considerarla como trabajo susceptible de salario, sobre todo en las formas de trabajo familiar ha sido un problema ampliamente estudiado (Jelin, 1984, Attademo, 1999). Junto con el sistema a la parte, debemos reflexionar sobre la flexibilidad que aporta mantener estas estructuras basadas en la solidaridad ya sea familiar o laboral, en actividades capitalizadas pero susceptibles de grandes variaciones en la rentabilidad a lo largo del tiempo. Es interesante marcar el caso de las mujeres flamencas que también se mantuvieron cercanas a la industria de la pesca confeccionando y reparando redes para sus maridos, incluso estableciendo pequeños emprendimientos y que, a diferencia de las italianas esposas de pescadores, contaban con una mayor independencia (Masid, 2004).

Como sostienen Ariza y Oliveira (en Wainerman, 2003), gradualmente en las últimas décadas los sectores más progresistas de la sociedad han problematizado el carácter "natural" del ámbito de la reproducción sociobiológica, la transformación de la imagen de la mujer ha favorecido también la emergencia de nuevas masculinidades fundadas no sólo en el rol de proveedor económico y en la sexualidad sino también en el ejercicio de una paternidad más activa y cercana a los hijos. Sin embargo, para 2003 las autoras sostenían que en la mayoría de los sectores sociales la esposa sigue siendo la responsable del control y/o de la realización de las tareas domésticas situación que, como vemos, se sostiene en el universo relevado.

"Trabajó hasta el año pasado, pero acá la pesca mejoró y monetariamente no, digamos no necesita trabajar, más dedicarse a los 
hijos y no salir a trabajar..." (pescador).

"Y porque, eh una porque no hay mucho trabajo y otra que yo tengo dos hijos (...) ponele que uno va a la escuela, otro va al jardín, y si trabajaría eh, en el caso de mi familia yo no los puedo cuidar..." (pescador).

"Es decir para mí, la mujer del marino ideal es aquella persona, aquella mujer que tiene alguna actividad, es decir, no digamos que sea una profesional, pero digamos que tenga una actividad, no cual, un negocio, no sé, que venda ropa, no sé que tenga algo, ¿por qué? porque la mujer está muy sola, si yo conozco la esposa de muchos marinos que no hacen nada, no hacen nada, es decir, crían a su hijo, a sus hijos, y nada más..." (pescador con esposa profesional).

Los pescadores cuando realizan pesca costera no perciben diferencias importantes en la organización doméstica según si están o no presentes en el hogar. Sin embargo, varios destacan que si la mujer trabajara se complicaría porque ellos están afuera mucho tiempo. También destacan que las complicaciones y las diferencias son mayores cuando se va a la pesca de altura por la cantidad de días seguidos que están afuera. Es recurrente que sostengan que las esposas de los pescadores (sobre todo los de altura) tienen que hacer de padre y de madre. Remarcan las dificultades de llevar adelante la crianza solas, y los problemas que deben enfrentar. Por ejemplo, un pescador se emociona al contar sobre cómo su esposa tuvo que pasar dos pérdidas de embarazo sin que él la pudiera acompañar porque estaba en altamar. Compartimos algunos relatos que acompañan estas apreciaciones:

No, no mientras pueda estar acá, pueda sobrevivir acá me quedo acá. Pero en cambio el compañero que sigue en los barcos grandes, sí, se le complica, la mujer de, eh, de un marinero de un barco grande hace de padre y de madre, porque son casi dos meses que están afuera, un mes y medio, 50 días ya casi dos meses..." (pescador).

“yo tenía que hacer de mamá y de papá, de todo, la responsabilidad de los chicos si le pasa algo, si no le pasa algo, tomar una decisión, la decisión correcta, mucha responsabilidad, si les pasa algo a los chicos, yo crie a los dos chicos sola, ¿viste?, que te salgan bien, hacer todo yo acá en la casa y que te salgan bien..." (esposa de pescador).

Los entrevistados que se dedican a la pesca de altura perciben mayores diferencias en la organización doméstica vinculada con su presencia/ausencia en el hogar. Destacan 
que la casa cambia de ritmo y organización. Por ejemplo, cuando está el pescador, actividades que realiza habitualmente la madre pasan a ser realizadas por el padre, la mayoría en relación a la crianza y cuidado de los hijos. Algunas de las dificultades que perciben este tipo de matrimonios se refieren a la distribución de responsabilidades en la casa, la toma decisiones en conjunto, así como la integración al ritmo del hogar. Entre los pescadores de altura hay una apreciación de desarme de la dinámica familiar cuando ellos están presentes, "es increíble, vos llegas y es otra cosa, ya cambian los horarios, cambian las formas". Pero no sólo esto, sino que un punto conflictivo tiene que ver con la toma de decisiones en el hogar y la crianza. Es una prerrogativa (o un mandato) de los modelos patriarcales que la voz final en decisiones relevantes para la familia la tome el componente masculino del término. En los casos descriptos el tenor de las ausencias lleva a que los hombres deban ceder el espacio de decisión y las mujeres tomarlos. Entonces, la contrariedad se presenta cuando el pescador está en la casa y no encuentra su lugar en la toma de decisiones.

"La mujer con los chicos y sola es como que, eh vos tenés, la persona que navega, es como que clan en su casa, no sé si logro que me entiendas. La mujer es ella y los chicos, y vos llegás, estás una semana y es como que le descalabrás un poco el ritmo, después llegas, y a mí me pasa, eh. Me ha pasado, y eso que mi señora trabaja y cada uno tiene sus cosas, es increíble, vos llegas y es otra cosa, ya cambian los horarios, cambian las formas..." (pescador de altura).

"Inclusive es difícil reubicarse después, porque ella, mal que mal, aunque dice, bueno, no voy a asumir el rol del padre, pero cuando está en la casa sola la autoridad de la casa es ella, y va pasando el tiempo y los meses y los años y se va acostumbrando y se le vuelve parte de tomar decisiones, que sé yo y de golpe estoy yo, y de golpe tengo que tomar la decisión yo y por ahí la tomó ella porque está acostumbrada, porque le nace ya tomarla, y entonces a veces opinamos diferente también, porque no siempre se opina igual, sobre todo en la educación de los hijos, y realmente no, se discute bastante..." (pescador altura).

Cuando pensamos la categoría de estrategias familiares, hicimos explícita la necesidad de no restringir el análisis social a la noción de individuo que tendería a opacar los complejos vínculos que este tiene con otros sujetos en el entramado social. Nociones como las de familia -ya sea de origen o de procreación-, o unidad doméstica u hogar (entendido como el conjunto de personas que comparten la vivienda y la alimentación sin importar los lazos biológicos existentes) nos permiten poner al individuo en relación con esos otros más cercanos en función de los cuales el sujeto toma decisiones y se organiza la 
reproducción social. Sin embargo, también sería una reificación pensar la familia aislada; por ello es relevante considerar como una dimensión de las estrategias a la cooperación extrafamiliar, o sea, aquellos comportamientos relacionados con la formación de redes de cooperación más allá de los límites de la unidad tendientes a facilitar, en el caso particular de estudio, la obtención de trabajos, y la existencia de otras redes de ayuda. Estas redes pueden ser personales y/o estatales y la dependencia o independencia de la familia a ellas también implica un indicador del lugar de esta en la posición estructural de la sociedad. Desde esta perspectiva fue que nos interesó relevar y dar cuenta de la utilización de otros recursos no provenientes del trabajo.

Los resultados en relación con la existencia y utilización de redes de ayuda extrafamiliar nos indica que un 28\% de los encuestados expresó no haber ayudado él, ni nadie de su familia, durante el último año a personas que no vivan con ellos, en forma habitual o con alguna regularidad. Este grupo tampoco indicó haber recibido ayuda de otras personas ni instituciones. El 72\% restante sí brindó ayuda; y con respecto al tipo de colaboración brindada en primer lugar aparece la ayuda monetaria con casi 70\%, seguido por alimentos (54\%) y en orden decreciente por vestimenta, colaboración en la consecución de trabajo (30\%) y, en menor medida, la categoría 'otros'. En un solo caso colaboración en la construcción de vivienda. En cuanto quiénes son beneficiados con esta ayuda, en cada ítem la relación se mantiene constante. En primer término, se menciona a familiares que no conviven con el encuestado (alrededor de un 70\%), seguido por amigos, y en menor medida vecinos (aproximadamente 50\% y 30\% respectivamente). También aparecen ayudas dadas a instituciones (capillas, comedores, sociedades de fomento) y a desconocidos. Sin embargo, del subgrupo que brindó ayuda, la proporción que dice haber recibido ayuda es mucho menor (30\%) siendo ésta dada por familiares y en menor medida por amigos. De la indagación sobre la utilización de otros recursos, sean gubernamentales como no gubernamentales, se observa que ninguno de los encuestados percibe ingresos por pensión, seguro de desempleo, subsidio del gobierno, jubilación o cuota de alimentos. La mayoría declara no utilizar recursos gubernamentales. Solamente dos encuestados tienen hijos que son beneficiarios del Plan Vida ${ }^{127}$, y hacen una valoración favorable del mismo. El resto no sólo no es beneficiario, sino que, en varios casos, no hacen una buena valoración del plan estatal. Algo similar sucede con el plan Jefes y Jefas de Hogar ${ }^{128}$ del que ningún encuestado,

\footnotetext{
127 Plan puesto en ejecución por el gobierno de la provincia de Buenos en el año 1994 orientado a paliar el impacto de la pobreza en la población materno-infantil, en el cual se entregaba leche y un suplemento nutricional de alimentos secos y frescos a la población beneficiada. Actualmente continua, con algunos cambios, en el denominado Plan Más Vida (Albano 2014).

${ }^{128}$ En 2002 el Ministerio de Trabajo, Empleo y Seguridad Social creó el Programa Jefes de Hogar, destinado a jefes o jefas de hogar con hijos de hasta 18 años de edad, o discapacitados de cualquier
} 
ni otros miembros del hogar, son beneficiarios y declaran tampoco haber sido usuarios de planes anteriores. Todos los hijos en edad escolar están escolarizados y ninguno de ellos es usuario del comedor escolar. El 22\% de los hogares tienen huertas, siendo consideradas como complemento o como actividad de distracción y no constituyen una base para el aprovisionamiento. Un solo encuestado (que también tiene huerta) tiene gallinas para huevos y consumo.

Las redes personales son las más fuertes y más utilizadas y valoradas por los pescadores y sus familias que las redes estatales. En momentos cruciales como el embarazo se recurre a la familia extensa para acompañar a la esposa. De las entrevistas también se recupera la ayuda familiar entre padres e hijos, para conseguir trabajo e insertarse en la actividad, con préstamos económicos o "ayudas" económicas intrafamiliares sobre todo al momento de constituir el hogar y el nacimiento de los hijos.

Los pescadores de Puerto Quequén no se definen y autoreconocen explícitamente como religiosos, pero la mayoría de las familias observan las prácticas del catolicismo, cumpliendo con los ritos de casamiento, bautismo y comunión de los hijos. Algunas esposas de pescadores participan más activamente de la comunidad de la parroquia de la Medalla Milagrosa. En las casas de los pescadores son frecuentes las imágenes, en la entrada, en los patios y en estatuas o altares a vírgenes, muchas de estas imágenes fueron dadas y bendecidas por el Padre Jesús Domaica.

\subsection{Los pescadores como trabajadores, una distinción analítica}

La mayoría de las veces que nos referimos los pescadores los englobamos en un homogéneo, aunque no lo sean. En algunos momentos específicos los llamamos trabajadores-pescadores y esta distinción analítica es la que queremos problematizar a continuación. Con trabajadores-pescadores nos referimos a trabajadores que se caracterizan por vender su fuerza de trabajo en el mercado laboral, y que en algún momento de su trayectoria laboral lo hicieron en el ámbito de la pesca de altura o en la flota costera. Las clases u estratos sociales no son un dato de la realidad objetiva de la sociedad. En este sentido, el recorte dado a la categoría "pescadores" no queda ajeno a esta consideración. Entre los pescadores reales que tomamos como referencia a partir de los archivos, las encuestas, las entrevistas y las observaciones en términos económicos hay diferencias en sus posicionamientos y lugares en torno a la propiedad de los medios y a la remuneración

edad, o a hogares donde la jefa de hogar o la cónyuge, concubina o cohabitante del jefe de hogar se hallare en estado de gravidez, todos ellos desocupados y que residan en forma permanente en el país. 
percibida. Aquellos que realizan pesca de altura y, sobre todo si tienen como rol capitán, pueden tener una diferencia de ingreso muy marcada en relación a un marinero. En las lanchas la mayor diferencia se da en la conjunción entre aquellos que son propietarios de la embarcación y además salen como patrón de pesca.

Para Marx (1980) el reconocimiento de distintas clases sociales puede encontrarse en la relación con los medios de producción y su propiedad. En este sentido, en el universo relevado distinguimos dos clases, aquellos que son los propietarios de alguna embarcación y aquellos que trabajan. Sin embargo, también podemos pensar cómo las clases sociales se distinguen no sólo al momento de la producción sino al momento del consumo (Bourdieu, 1988), este es el espacio en el que, cada vez más en nuestras sociedades contemporáneas, opera ideológicamente la distinción de clases, constituyendo un espacio de apropiación desigual de bienes económicos y simbólicos (García Canclini, 1984). A su vez, Weber (1969) al pensar la conformación de las clases sociales no está restringiéndolas a lo económico, sino que reserva un lugar para el prestigio social y el poder político. Si tomamos en cuenta esta instancia, no hay tanta distancia social entre sí entre los trabajadores-pescadores y los pescadores considerados para el recorte analítico de esta investigación. En la sociedad la estratificación social se corresponde con distancias económicas y estructurales que afectan las condiciones de las personas y las familias. Esta posición más objetivista si se quiere, puede ser complementada por la percepción subjetiva de los sujetos en relación con su posición social. Si de modo general consideramos las prácticas sociales de los pescadores, incluso considerando las diferencias salariales y económicas entre ellos según su posición en relación a los medios de producción o al ingreso monetario, podemos englobarlos en una misma clase o segmento. En término analíticos la clase no existe como un en sí, Thompson (1989) nos recuerda que "la clase no existe por fuera de la experiencia vivida por los sujetos y sólo es construida como categoría colectiva histórica o analíticamente".

\subsection{Trayectorias laborales}

Cuando presentamos las estrategias familiares de vida nos referimos a una dimensión configurada por las trayectorias laborales. Consideramos las trayectorias laborales en relación con los comportamientos laborales y desplazamientos geográficos tendientes a posibilitar, facilitar o mejorar las formas de inserción en el mercado de trabajo y que implican decisiones que toma el individuo, pero muchas veces en relación a los vínculos o posicionamientos familiares. En las encuestas y entrevistas nos interesó relevar especialmente la trayectoria en relación con la actividad pesquera, pero también aquellos 
trabajos no vinculados al sector pesquero. Además, intentamos evaluar cómo inciden las diferentes trayectorias en la organización doméstica de la unidad familiar involucrada.

Abordamos las trayectorias centradas en lo laboral ${ }^{129}$, pero reconociendo que no son un absoluto. Aunque con cierta independencia, tienen relación con otros dominios de la existencia de vida de los sujetos. Al recuperar desde un enfoque biográfico (Bertaux, 1993) la trayectoria laboral reconocemos que en la historia de vida hay una superposición de trayectos en esferas diferenciables (laborales, educativas, residenciales, familiares, de salud, entre otras). Podemos pensar que en diferentes momentos de la vida de las personas algunas de esas esferas o trayectorias serán más destacadas por ejemplo las educativas en la infancia y/o juventud según la clase social. Según la etapa del ciclo de vida la relevancia de una u otra variará. Además, esta perspectiva permite reconocer elementos personales, subjetivos y, a la vez, ponerlos en relación con otros estructurales (de las condiciones de la actividad, por ejemplo). Como sostiene Bourdieu (1988 y 1997) las trayectorias particulares están siempre insertas en trayectorias de clase y están inscriptas en contextos espacio-temporales específicos, que implican condicionamientos estructural e históricamente variables. Desde nuestra perspectiva, analizar las trayectorias laborales, también nos permitió interiorizarnos sobre el modo en que la subjetividad de los trabajadores pescadores procesa las transformaciones estructurales. Para recuperar la dimensión diacrónica referenciamos los casos a la noción de trayectoria, entendida como espacios de tomas de decisiones, en este caso con énfasis en lo laboral, pero que no puede entenderse desvinculada de otros ámbitos de la vida. Pensar desde la noción de trayectoria permite ampliar el marco temporal en el que la "elección" es tomada, sin olvidar que la misma está vinculada con la conformación de una estrategia que excede al individuo y cuyo referente más amplio es la familia; y que también se articula con la estructura de oportunidades.

Del análisis de las entrevistas se desprende que casi todos los entrevistados en algún momento de su trayectoria laboral realizaron pesca de altura. Algunos lo hicieron saliendo desde Necochea, cuando desde allí salían barcos pesqueros de altura. Pero en gran medida salieron de puertos del sur como Puerto Deseado, Rawson, Puerto Madryn y Comodoro Rivadavia, decreciendo la cantidad respectivamente. La mayoría también salió alguna vez del puerto de Mar del Plata. Uno de los pescadores entrevistados no salió nunca de otro puerto que no sea el local ni realizó pesca de altura, alegando que no le interesó, por la familia y porque le alcanzaba con lo que ganaba "claro, 30, 40, 50 días, 60, no, o 10, pero

\footnotetext{
${ }^{129}$ En trabajos anteriores me focalicé en reconstruir trayectorias familiares y laborales (Rispoli, 2005 y 2009a).
} 
no, no me interesó y que se yo, me alcanzaba con lo que ganaba y listo. Más por la familia que por lo que ganaba".

Entre los pescadores que realizaron pesca de altura pero que al momento de ser entrevistados estaban trabajando en la pesca costera la tendencia en la explicación es que de casados prefieren trabajar en las lanchas para estar más cerca de la familia porque en los barcos grandes se pasa mucho tiempo afuera.

"Y sí cuando yo me iba en barcos grandes, ahí a ella se le complicaba, desde ya que cuando yo estaba en barcos grandes ellos estaban en el jardín, y el otro era chiquito. Yo hace acá que estoy, y va a hacer 4 años, pero en enero ya va a hacer 4 años que me quede acá, en las lanchas (...) No, no mientras pueda estar acá, pueda sobrevivir acá me quedo acá (...) Es mucho tiempo, por necesidad a veces lo tenés que hacer, a mí me gusta la pesca, pero me gusta más esto, lo que pasa que la vida de soltero es otra cosa, la vida de soltero... pero estar en otros puertos en otros lados yo la tuve y sé lo que es. Tenés tus viejos y algunos hermanos, pero no tenés otras obligaciones, otros, otras obligaciones, en cambio el que tiene que estar, el que tiene que ir obligado a trabajar en barco grande porque no tiene trabajo acá, acá son pocas lanchas..." (pescador que hizo pesca de altura).

"Perdí muchas, muchas cosas digamos, en ese tiempo se ganaba mucha plata, muchísima, para que te des una idea, yo me casé en el '86 me casé. Con una marea de 60 días, pagué la fiesta de casamiento y me fui de luna de miel, compré muebles y estuve seis meses sin trabajar, ¡mirá si ganaba plata! ¿pero qué hice? cambié plata por algo muy importante, que es por ejemplo con mi primera hija cuando yo quise acordar llegué un día y estaba con el guardapolvo puesto y ¿ cómo va a primer grado? Me perdí de verla caminar, las monerías, digamos cosas que son esenciales en la vida de una persona calculo, sino para qué te casas, si te casas para decir estoy acompañado y llegar a tu casa y encontrar a alguien, no, no, yo por lo menos no lo veo así, y entonces dije bueno y ahora la segunda si la aproveché totalmente pero cambiamos, cambiamos la parte económica, vos vas ahora al sur y se gana mucho..." (pescador que hizo pesca de altura).

En algunos casos toda la trayectoria laboral del individuo se refiere a la actividad pesquera (o marina). En otros casos la trayectoria incluye actividades no ligadas al mar o "trabajos de tierra". Presentamos a continuación algunos modelos de trayectorias laborales:

- G. hizo pesca de altura hasta diez años antes de ser entrevistado en 2003, mientras era soltero. Dejó de trabajar en el sector cuando se casó para trabajar 
en un correo privado durante 7 años. Dejó este trabajo porque no le redituaba y decidió volver al sector pesquero para tener mayores ingresos monetarios en un momento en que la situación en la pesca parecía mejorar.

- R. durante tres años no se embarcó porque no le redituaba. En ese tiempo trabajó en un taller naval.

- P., antes de trabajar como marinero, trabajó en Chile en aserraderos y luego en Argentina en las cosechas, en calderas y en el asfalto, pero desde que se embarcó no volvió a hacer trabajos en tierra. Teniendo edad para jubilarse le cuesta desembarcarse.

- F. prefiere trabajar en Puerto Quequén, hizo pesca de altura en otros puertos en el sur cuando las cosas 'no andaban bien' e intentó hacer trabajos en tierra (en comercios), no le redituaron lo esperado. La actividad que más le gustó es la pesca y espera poder seguir embarcado.

- D. se desempeñó primero como marinero, luego como motorista naval y como patrón y, ahora sigue vinculado al sector como dueño de barco. Dice no extrañar el trabajo en el barco, por las durezas del mismo.

- N. tiene una antigüedad en la actividad de 23 años al momento de ser entrevistado. Realizó pesca de altura, pero en los últimos cinco años también es electricista debido a la crisis. Había dejado la pesca por unos años y volvió un año antes porque el sector mejoró.

- A. Empezó a salir a pescar con el papá y el hermano. Trabajó como patrón de pesca. Luego se empezó a dedicar a la parte mecánica, preparación de barcos. Es propietario y armador. Dejó de salir embarcado.

- L. Tuvo trabajos previos en tierra en una zapatería, panadería. Empezó en la pesca por su familia y luego fue a estudiar a Mar del Plata como patrón.

- A. Empezó de joven a trabajar como pescador, pero no le gustó el trabajo en el mar, tuvo la oportunidad de pasar a ser representante gremial y no extraña salir embarcado.

- M. Sus primeros trabajos fueron como filetero y en la década del '90 por su suegro empezó a salir embarcado. Al momento de la entrevista es patrón de pesca.

- C. sacó la libreta de grande para mejorar su situación laboral (antes era carpintero) ahora oficia de patrón de pesca y no bajaría del barco. No tiene familiares en la pesca pero introdujo a su yerno en la actividad.

- B. Tiene la libreta desde mediados de la década del '70 pero antes también salía. Tuvo actividades en tierra, pero no se afianzó en ellas. Pasó por pesca costera y 
de altura hasta ser capitán. Intentó comprar un barco en sociedad, pero no pudo concretarlo. Invirtió en otros proyectos comerciales.

Las trayectorias desplegadas por aquellos pescadores que realizan pesca de altura difieren en ciertos aspectos de los casos anteriores. En aquellos que no son marineros sino capitanes o conductor naval se destaca el cambio que implicó estudiar para tener un mejor puesto en el barco. Entre los que son marineros la ventaja económica es la preponderante para elegir la actividad. En el caso del capitán se destaca que trabajó embarcado no sólo en la pesca, sino que comenzó en la Marina de Guerra (desde el año 67 al 74), pasó por la Marina Mercante hasta el año 82 en el que comenzó y se afianzo en la pesca de altura.

Mientras que en los marineros el desarrollo de otras actividades (electricidad, albañilería, "changas" y cuentapropismo) se vincula generalmente a los momentos de contracción. Pero casi todas, sino todas las trayectorias redundan en una alternancia de la pesca costera con la de altura y el paso por otras actividades. De los casos analizados, no se desprenden largos períodos de inactividad (exceptuando los casos en los que estuvieron capacitándose en la Escuela Nacional de Pesca, en Mar del Plata).

Aunque se evidencian períodos de inactividad (de hasta cuatro meses), los entrevistados en ningún caso se refirieron a sí mismos como desocupados, sino que estos períodos son interpretados -en sus propios términos- en función de las nociones de "inestabilidad" y "libertad" de la actividad, como veremos más adelante.

Una de las dificultades más grandes que perciben los pescadores pasa por unificar sus propios intereses y los de la familia. Más que preocuparse por la propia incomodidad o riesgo en el trabajo, llama la atención que se remarca la pérdida de compartir momentos familiares, el crecimiento de los hijos y la necesidad del apoyo familiar para poder realizar el trabajo.

Los singulares caminos que se habilitaron en estas trayectorias toman como presupuestos necesarios la confluencia de dos hechos. Por un lado, que existe una demanda social de producción de pescado y la organización de la actividad que requiere de cuerpos que lleven adelante el trabajo pesquero en el mar. Por otra parte, una elección, decisión, mandato o condición de oportunidad en situaciones (más o menos) conscientes y (más o menos) libres de algunos individuos (pero que muchas veces son tomadas en el marco de la familia) de trabajar de pescador. Dice Bourdieu (2011) que las estrategias de reproducción se encuentran interrelacionadas, que actúan como sistema y, en este sentido, las estrategias que despliega un grupo deben ser entendidas en su conjunto.

Podemos reconocer que, en las trayectorias de aquellos con un vínculo fuerte con la actividad por razones familiares, pero que el trabajo en el mar les resultaba difícil, 
impracticable, fueron desarrollando estrategias para seguir vinculados con la actividad, pero desde otros lugares. Por ejemplo, pasando al mantenimiento mecánico y la preparación de los barcos en un caso, para luego también ser propietario en sociedad. En otro caso, pasando a trabajar como referente gremial. En otra familia con fuertes vínculos en la familia extensa en la pesca, ninguno de los hijos continuó con la tradición. La madre definiéndose enfáticamente como no-italiana (y marcando como era llamada "la argentina" por la familia de su esposo) discutía enfáticamente con la familia para que los hijos no siguieran en la actividad "la lancha era del hermano de él [por su esposo] y de un tío. Él quería que siguiera la tradición, que manejara la lancha, yo discutía a muerte". Al jubilarse el padre, venden el barco ${ }^{130}$ y los hijos se insertan como empleados de comercio y realizando oficios.

Queremos destacar la observación de que algunos propietarios que no tienen en el universo doméstico ayuda para realizar la administración del barco implican una decisión importante decidir si desembarcarse y tomar otro patrón para dedicarse a la administración y mantenimiento o tener que contratar a otra persona para esto. El resultado de la decisión marca un cambio en la trayectoria laboral. En aquellos que disfrutan del trabajo en altamar es difícil que resignen las salidas en el barco. En el mismo sentido, en las familias en las que varios miembros trabajan en la pesca, usan diferentes estrategias para proyectar, por ejemplo, en la jubilación y pensar en el retiro. Una de ellas, por ejemplo, si son propietariosarmadores es auto-emplearse para el mantenimiento del barco.

\section{7. ¿Quiénes pueden pescar? ¿quiénes pescan?}

Al pensar el trabajo de los pescadores debemos considerar de forma independiente, pero en relación tres aspectos: las formas de reclutamiento, la posesión de la libreta de embarque, y la posesión de saberes respecto al ser pescador. La libreta de embarque es el instrumento legal expedido por la Prefectura Naval Argentina que habilita al pescador para conseguir trabajo, aunque no marca la forma en que este lo obtendrá, o sea, el sólo hecho de tener la habilitación formal no implica que ese marinero podrá ser un pescador. Los conocimientos específicos para ser pescador no se ponen en juego en la obtención de la libreta de embarque, que no implica ninguna capacitación profesional y práctica sobre la pesca como oficio, sino que está focalizada en cuestiones teóricas generales y otras más pragmáticas en torno a la seguridad en el mar.

\footnotetext{
${ }^{130}$ El barco es vendido para transferir el valorado permiso de pesca a otra embarcación que operará desde el sur.
} 
Del análisis de los libros de embarque del año 1987, tomando los movimientos de embarques tanto de los barcos de la flota costera como de altura, en función de la categoría consignada para el trabajador es significativa la proporción de marineros que embarcaron como "aprendiz de marinero" (45) y también con la figura "operario de planta" (25). Por su parte son 43 los que embarcan como marineros (o marineros de segunda) y sólo tres como patrones de pesca. Otros roles representados son conductor naval y auxiliar de máquinas. Para el año 2001, en relación con la dispersión de roles son 206 los ingresos de embarco como marinero, 36 como patrones y 25 que englobamos en la categoría "otros" (como maestranzas, motoristas navales, auxiliares o jefes de máquinas navales) también un conductor y un piloto de pesca.

En 1987, gran parte del reembarco de un trabajador durante el año corresponden al mismo barco, lo que puede interpretarse como una baja temporaria por enfermedad, vacaciones o razones particulares o porque alternó con la pesca de altura desde otro puerto. En muchos otros casos, un mismo trabajador pescador, se embarca por poco tiempo en distintos barcos durante el transcurso del año. En esta situación se entiende que el pescador está posiblemente cubriendo la falta de otro pescador, o no se consolidó con el grupo de trabajo del barco, y denota menor estabilidad en el trabajo. En 2001 pudo detectarse que un trabajador embarcado como marinero se embarcó en el mismo año en otro barco como patrón de pesca. A su vez, alguien de su familia también trabaja como patrón en otro barco. En los casos de familias de pescadores (igual apellido y/o dirección) puede verse que trabajan en el mismo o en distintos barcos cumpliendo diferentes roles. Otro trabajador pescador, está embarcado como marinero en un barco para, a mediados de año, embarcar en otro como patrón y dos meses después cambiar, también como patrón a un tercer barco. Al menos en un caso un trabajador pasó de estar embarcado como patrón a marinero en el mismo barco. Son sólo seis los pescadores que aparecen en los dos años y en diferentes barcos. Un trabajador pescador que en 1987 salió embarcado como marinero y como segundo patrón, en 2001 embarca como patrón. La mayoría mantiene la dirección, y en un caso que cambió de domicilio, la dirección de 1987 la registramos ocupada por un familiar pescador.

La figura de "aprendiz de marinero" muy representada en 1987 ya no se encuentra presente en 2001, teniendo en cuenta también que cambiaron normativas y reglamentaciones para el embarco. Los pescadores que eran aprendices en 1987 y los encontramos en 2001 ya detentan la calidad de marinero o patrón. La estratificación en los roles de trabajo se presenta como una división técnica, sin embargo, corresponde también a una división económica y social en la que las relaciones familiares y los lazos sociales juegan un rol importante. 
En las encuestas y entrevistas realizadas es más difícil distinguir en las primeras preguntas el rol ejercido en el barco. Al ser preguntados por la ocupación, la mayoría declara ser marinero mientras que otros dicen "salir" como patrón. Sin embargo, algunos declaran que su ocupación es "marinero" y el trabajo que hacen es de patrón, o que en el próximo viaje o en el anterior salieron como patrones. En general la primer auto-adscripción es como marinero o pescador, sin distinguir el rol en los casos en que fueran patrón. Lo que nos lleva a considerar la diferencia entre un posicionamiento etic (categoría construida desde el analista) como el que nos aporta el trabajo desde el archivo y uno emic (que incluya la propia consideración y clasificación de los entrevistados).

Con respecto al reclutamiento, la mayoría de los encuestados (casi el 59\%) declaró haberse iniciado en la actividad pesquera por su propia cuenta, estudiando para sacar la libreta, sólo algunos comenzaron antes de sacar la libreta. El 23\% comenzó incentivado por algún amigo o conocido y el 18\% restante por familiares directos. Sin embargo, es interesante marcar que, en las entrevistas, al recuperar las pautas de reclutamiento, en todos los casos es posible reconocer un intermediario familiar o basado en afinidad que influyó en la elección de la actividad.

Con respecto a cómo consiguieron el trabajo, la motivación principal en la elección es por una combinación de lo que se ganaba, con la inserción por parte de familiares en el sector, o por la iniciativa de algún amigo que trabajaba en el mismo. La mitad de los entrevistados le consiguió trabajo en el sector a alguien más (por lo menos a una persona, pero a veces a más de uno), siendo en todos los casos familiares. Solamente en dos de diez casos no hay otros pescadores en la familia. Esta información más la consignada en la entrevista nos muestra la fuerte presencia de lazos (familiares, sobre todo) en la conformación del universo relevado. En virtud de lo observado y analizado podemos remitir a la existencia de dos modelos de origen de la vinculación de los trabajadores pescadores con la actividad pesquera. Por un lado, en virtud de la actividad familiar previa al trabajador en el sector $y$, por otra parte, la posesión de la libreta de embarque como puerta de entrada al mercado laboral.

Para dar cuenta de la particularidad de Puerto Quequén podemos remarcar el hecho de que al observar a quienes tienen a Puerto Quequén y la pesca costera como fuente de trabajo son en su mayoría pescadores vinculados con familias de pescadores. Son mínimos los casos de no tener alguna forma de relación familiar o intergeneracional con pescadores. Además, como dijimos la mayoría en algún momento salió embarcado desde otro puerto $\mathrm{y}$, agregamos ahora, muchos de ellos tienen relaciones familiares contemporáneas (hermanos, cuñados, hijos) llevando adelante la actividad en otros puertos, sea el caso de Mar del Plata y de la Patagonia. En este sentido la pequeña -y cada 
vez menor durante el período- actividad pesquera local ofrece un refugio para aquellos pescadores relacionados por medios productivos y/o lazos familiares con la actividad y que quieren seguir trabajando desde el puerto local, aunque resignen rentabilidad económica. Sin embargo, observamos cada vez más hacia el final del período el establecimiento en o la migración hacia otros puertos. Además, se insertan en el trabajo de la flota local, como lo expresa un pescador "muchos muchachitos nuevos, que sacaron la libreta porque no tienen otra forma de vivir de trabajar. Es una forma de sobrevivir tener la libreta de embarque a la falta de tanto trabajo". Según un pescador en tierra, "muchos de ellos si consiguen un trabajo estable en tierra, ya no salen más a pescar". Esta apreciación también es compartida por el representante gremial y por el personal de prefectura, que apreciaron el crecimiento exponencial en la cantidad de jóvenes que sacan la libreta para salir embarcados en otros puertos. Tal es el caso de un trabajador entrevistado cuentapropista, que tiene un comercio, pero realizó pesca en las lanchas amarrillas durante poco tiempo, luego hizo "dos mareas" y como no se adaptó se quedó trabajando en tierra.

La libreta de embarque, repetimos, es un documento emitido por Prefectura Naval Argentina que implica para quién la obtiene la habilitación para poder navegar y trabajar embarcado. Para obtenerla hay que realizar un breve curso teórico y uno práctico. Son dictados por las Escuelas de Formación y Capacitación para el Personal Embarcado de la Marina Mercante, y es posible obtenerla en la delegación Puerto Quequén. Para ser patrón de pesca costera o capitán de pesca de altura es necesario hacerlo fuera del núcleo urbano de Necochea-Quequén, generalmente para aquellos que son patrones de pesca el lugar elegido fue la Escuela Nacional de Pesca de Mar del Plata. Cabe remarcar que con anterioridad a nuestro período de estudio las formas de acreditación para las condiciones de trabajo en el mar eran más laxas. Durante el período analizado se fueron sistematizando, y se fue regulando cada vez más el trabajo en el mar. No es difícil encontrar anécdotas de que a poco de partir para el trabajo en el mar si faltaba alguno de los marineros registrados (en el libro de embarque) salía algún otro marinero que estuviera disponible en banquina sin necesariamente asentar el cambio. Era una práctica común que el patrón de pesca retuviera las libretas y embarcara a una persona que no tuviera libreta con la libreta de otro pescador. La mayoría de nuestros entrevistados hizo sus primeras salidas sin libreta. Al momento en que obtuvieron la libreta nuestros entrevistados y encuestados el requisito excluyente además del certificado de salud era de educación primaria.

En este sentido, la pesca de embarcado constituyó una opción laboral certera no sólo para aquellos vinculados por lazos familiares con la actividad sino también como una opción de mejorar el ingreso económico con poca capacitación. En las entrevistas, al momento de indagar sobre las motivaciones para la elección de la actividad juega un factor 
importante el "dinero" y muchas veces es presentado en relación con otras opciones frente a la rentabilidad del trabajo en tierra. Entonces, en las diversas trayectorias podemos observar como la posesión de los saberes y la habilitación para poder trabajar embarcado con la "libreta de embarque" constituyó una herramienta laboral alternativa a otras formas de obtener ingreso, utilizada de acuerdo a las estrategias reproductivas de los agentes sociales.

Al ser una actividad volcada al mercado y que representa la fuente de ingreso principal en las familias cuyos integrantes están vinculados a la misma, para considerar las condiciones de reproducción de la actividad debemos tener en cuenta que la misma se sustenta en la posibilidad de que esta continúe siendo rentable para los agentes que la desempeñan. Por supuesto, y como ya explicitamos, las elecciones no son necesariamente racionales, pero en una actividad orientada al mercado tampoco queda del todo excluida la relación con cierta racionalidad, tal y como queda representado en los discursos de los entrevistados.

Entre algunas de las familias de pescadores la pesca es una pequeña actividad empresarial. Ser pescador o incluso ser patrón, no es lo mismo que ser propietario de barco y organizar la actividad productiva. Como vimos en una gran proporción de los barcos la organización de la producción implica la existencia de lazos familiares. Por ejemplo, el propietario sale de patrón y también forma parte de la tripulación algún pariente sanguíneo o político. La esposa y/o hija del propietario se ocupa de la administración. Este es un esquema recurrente en la organización del trabajo. Cuando lo pensamos en clave temporal y de reproducción de la actividad encontramos tres casos en los que el propietario de la embarcación ya no trabaja embarcado (pero lo hicieron), en dos casos hijas mujeres se encargan de la administración y los esposos de ellas son patrón/o marinero del barco. En otro de los casos, es un hijo quién sale como patrón. En un grupo significativo de situaciones observamos entonces cómo la reproducción de la vida y de la actividad están íntimamente relacionadas. La imbricación entre las decisiones tomadas por y para el ámbito de la vida y del trabajo tienen límites difusos.

Otras familias de pescadores organizan de modo diferente la reproducción en la actividad. Por ejemplo, un reconocido comerciante del sector, hijo de una de las familias fundantes de la actividad pesquera local dice públicamente en relación con su actividad ${ }^{131}$ que está vinculada con el sector pesquero, pero en tierra: “yo estoy acá, porque mi papá siempre quiso que yo estuviera acá en tierra y no en el mar. El mar es muy ingrato, te agarran muchos temporales que no sabés si volvés".

131 Propietario de pescadería y procesadora de pescado. 
Las estrategias de capitalización que relevamos entre los pescadores entrevistados incluyen variantes que ponen en relación los ciclos de alta rentabilidad de la actividad pesquera por un lado o, por otra parte, el mayor rédito de trabajo por un largo período en la pesca de altura, con la oportunidad que esto implicó poder derivar dividendos a los ámbitos domésticos o a otros ámbitos productivos (por ejemplo, para acceder a una embarcación propia). Los ciclos buenos en la pesca son aprovechados para capitalizarse en bienes, la casa propia como objetivo principal y luego autos y otras inversiones diversificadas en el pequeño comercio, sobre todo. Otra de las formas de acceder a la propiedad del barco es estableciendo sociedad con parientes y, en menor caso con amigos. Por lo que recuperamos, el crédito no es una opción valorada y ha resultado difícil el acceso a él, y en caso de acceder resulta muy difícil poder pagarlos, una embarcación no es una garantía sólida. Aquellos que tienen más oportunidades de pensar y definir como capitalizarse son los pescadores de altura jerarquizados, quienes invirtieron en otros negocios, como locutorios o un geriátrico. Y los propietarios de las embarcaciones tienen la posibilidad de disponer del capital que representa el barco o, más aun, los permisos de pesca del barco ${ }^{132}$, para la salida de la actividad. Entre los dueños de barcos otra forma que asume la planificación del retiro, tiene que ver con la apuesta a la formación del marinero en patrón para poder consolidar el ingreso diferencial y sostener la actividad. Con respecto a las hijas mujeres, en algunos casos se incentiva su formación para el desarrollo de una actividad autónoma (maestras). Sin embargo, en el período de estudio no apareció en los entrevistados como central la formación educativa de las y los hijos más allá del secundario y/o algún oficio y los nombrados casos de estudio de magisterio.

Tenemos que considerar dos esferas diferenciables, pero íntimamente relacionadas. Por una parte, el desarrollo de la actividad pesquera en sí misma en donde podemos observar momentos de expansión y/o de retracción de la actividad, acompañado también de cambios en las características en la que ésta se desarrolla. En este marco podemos pensar cómo los agentes se incorporan y propician estos desarrollos, impulsando la actividad, por ejemplo, la llegada de inmigrantes italianos y el desarrollo de la pesca costera; con otra oleada migratoria el desarrollo de la pesca de altura, el impulso que tuvo la demanda de tiburón durante la segunda guerra mundial, el impacto de la presencia de buques factorías congeladores. Por otro lado, reflexionar sobre las condiciones en que se da la incorporación de los agentes en la actividad, considerando para ello sus expectativas, su posición estructural al inicio de su trayectoria, la forma en que fue reclutado, el momento

\footnotetext{
132 Los permisos de pesca, principalmente los de tipo nacional tienen gran valor, sobre todo luego de la crisis del sector. Los permisos son transferibles siempre y cuando el barco sea de las mismas características.
} 
del ciclo de vida familiar. Tengamos en cuenta que en el universo relevado las decisiones laborales y familiares se toman mayormente en simultáneo. Entre los encuestados, la edad varía en un rango de 24 a 62 años con una media de 40,2 años, la antigüedad promedio en la profesión es de 18,3 años, mientras que la edad promedio de inicio en la actividad es de 21,2 años. La mayoría de los inicios laborales son tempranos en la trayectoria laboral, son muy poco frecuentes los inicios posteriores a los 30 años. El establecimiento laboral y la consolidación familiar suelen darse en simultáneo. Es posible interpretar ciertas decisiones tomadas por los individuos en su trayectoria laboral, siempre y cuando se tenga en cuenta que las estrategias constituyen un proceso que se desarrolla a lo largo del ciclo de vida propia y de la familia (Torrado, 1983). De este modo, puede verse cómo ciertas decisiones en relación a cuestiones como a qué tipo de pesca dedicarse se vinculan a momentos específicos del ciclo familiar. Por ejemplo, de soltero, mientras los niños del hogar son pequeños o en otros casos en momentos en que la familia necesita afrontar un gasto "extraordinario" como favorecer el ahorro para la capitalización:

Soy de acá, nacido acá. Siempre trabajé alrededor de la pesca y del mar. En un momento estuve en un barco de pasajeros, en el año 78, como ayudante de cocina y máquinas, después como cocinero. Ahí anduve casi dos años dando la vuelta al mundo, para conocer y ahorrar. Cuando volví acá me puse para comprar un barco, me salió como un negocio redondo y bueno... (pescador-armador).

\subsection{Las representaciones sobre el trabajo en el mar}

La tradición occidental se sustenta en una distinción naturaleza/cultura que puede retrotraerse a la escisión cartesiana y que toma como supuesto la necesidad de diferenciar categóricamente estos conceptos. El problema de definir y delimitar qué es lo "natural" y qué es lo "cultural" ha resultado en la historia de conocimiento una fuente de diversas interpretaciones. Siguiendo el planteo marxista, la naturaleza representa la fuente de todos los objetos que utilizan los seres humanos para organizarse para la vida social. Los seres humanos representamos un nivel emergente en la organización de la vida, pero la base de sustentación de ésta (por más complejos que sean los rodeos) siempre está en relación con la potencialidad de la naturaleza, al conocimiento que las sociedades tienen de ella, al desarrollo y organización para dominarla. Esta organización social de los seres humanos para sustentar la vida a partir de lo que la naturaleza "ofrece" constituye una de las formas de interpretar el pasaje de "lo natural" a "lo social" o específicamente humano. Nos estamos 
refiriendo al proceso de trabajo ${ }^{133}$. Si con Marx (1980) sostenemos que el trabajo es transformación de la naturaleza en manos del ser humano, la pesca como actividad extractiva en el mar, pero integrada a la lógica capitalista imperante, nos acerca a esa visión utópica de contacto entre hombre y naturaleza. Pero el trabajo, también transforma a los humanos. Por eso analizamos la amplitud de estos procesos que impactan en la subjetividad de los trabajadores, dando cuenta de la tensión que se plantea entre el trabajo entendido como empleo, y el trabajo como eje central en la vida de los sujetos, en el que se despliega su subjetividad y que actúa como constructor de identidad (Presta, 2006; Wallace, 1999).

En un sentido antropológico, el trabajo define al hombre, es el que instituye su humanidad. Para las concepciones ligadas al materialismo histórico, el proceso de trabajo no es solamente una actividad económica, sino que es el medio por el cual el hombre se crea a sí mismo, en tanto ser humano, en su relación con la naturaleza (Marx, 1980). Por esa razón nos interesa situar el trabajo en la doble tensión y articulación de constituir una actividad económica, por un lado, y por otra parte entenderlo como generador de representaciones, subjetividades e identificaciones. Comenzamos preguntándonos ¿qué se entiende en términos generales por trabajo? El diccionario de la Real Academia Española recopila entre las acepciones de "trabajar" (del lat. *tripaliāre, de tripalium) que se refiere a tener una ocupación remunerada; ocuparse de cualquier actividad física o intelectual; ejercer determinada profesión u oficio; elaborar o dar forma a una materia; aplicarse o dedicarse con esfuerzo a la realización de algo. El "trabajo" es la ocupación retribuida, el esfuerzo humano aplicado a la producción de riqueza en contraposición al "capital"134 -que también constituye un factor de producción-, trabajo también puede ser el lugar donde se efectúa la labor, la obra resultante de la actividad humana, además son trabajo la penalidad, la molestia, el tormento o un suceso infeliz. Vatin (2004) bien recuerda que el sentido moderno de pena apareció a partir del verbo (tripaliere: hacer sufrir en el tripalium) y no por medio del sustantivo, que hace referencia al trabajo productivo en el tripalium. Aunque no acordamos enteramente con el planteo de Vatin sobre el lugar de las palabras en la construcción del mundo, tampoco consideramos que, como sostiene Hanna Arendt, debamos "reservar la palabra trabajo sólo para el registro de lo penoso" (Vatin, 2004).

\footnotetext{
133 Otra de las formas de caracterizar y delimitar esa línea demarcatoria de humanidad es la interpretación de Levi Strauss a partir de la regla, con su análisis sobre la prohibición del incesto (Levi-Strauss 1970).

${ }^{134}$ Aunque en algunos estudios se tiende a considerar a los tres factores de producción -tierra, capital y trabajo- como formas de capital, mantener la distinción permite captar, entre otras cosas, que a cada factor le corresponde un tipo de remuneración y el conflicto consustancial que ello implica.
} 
Además, tengamos en cuenta que las últimas décadas, el concepto de trabajo sufrió cambios significativos a partir de la reestructuración capitalista de la década de 1970, y los procesos de globalización en los '90. La reestructuración implicó la inserción en el ámbito del trabajo formal de nuevas formas de organización del proceso productivo seguida de nuevas tecnologías, y de un aumento del mercado de empleo informal, subcontratación, flexibilización laboral y terciarización (Presta, 2006). En el marco de los cambios en el trabajo como consecuencia de la crisis del modelo de acumulación tylorista-fordista, se centra la discusión sobre los cambios en la significación del trabajo, pudiendo tomarse como referencia la ya clásica obra de Castel (1997) La metamorfosis de la cuestión social que plantea la caída de la sociedad salarial, con la consiguiente pérdida del rol del trabajo como "integrador social". En términos de Wallace estas transformaciones contribuyen al desarrollo de un "proceso de profundos cambios en la situación objetiva, peso social, valoración y prestigio del trabajo que implicarían la posible desestructuración de las viejas identidades laborales y la configuración de nuevas estructuras de sentimiento que están en la base de culturas laborales diferentes (¿nuevas?) y que quizás involucren una transformación de las identidades colectivas de distintos oficios y tareas" (Wallace, 1999). Tomamos esta inquietud como punto de partida, y en este sentido, consideramos que los estudios sobre las representaciones y las trayectorias de los individuos pueden llegar a constituir una base para comenzar a interiorizarnos sobre el modo en que su subjetividad procesa las transformaciones estructurales en los trabajadores. En ese sentido retomamos una vía para la interpretación de los discursos sobre su trabajo ${ }^{135}$.

Realmente estoy trabajando en lo que me gusta. Me gusta estar en el mar y gracias a Dios estoy haciendo lo que me gusta que muchos no pueden. $Y$ te tiene que gustar para estar en el mar. Es sacrificado porque son muchos días que estás afuera de tu familia. Allá si se pone viento estás todo el día en movimiento. Mojados.... En los barquitos que estamos nosotros no tenés la comodidad de un barco grande, que vos te mojás te podes duchar (pescador).

"es tranquilo" en el sentido con la ciudad. Cero problema, tenés problema de que tenés que estar pescando. Y me gusta la aventura de ver lance a lance el pescado que agarrás. Al que no le gusta se le pone muy pesado (pescador).

135 Una primera problematización de este tema se presentó en Rispoli (2009b, 2012). 
Si nos quedáramos con lo primeramente enunciado por los sujetos, diríamos con ellos que la principal motivación para trabajar en el mar es por "lo que se gana", diríamos también que el de pescador, es un trabajo "duro" (cuestiones por tanto más que ciertas). Sin embargo, no estaríamos siendo justos con la riqueza de explicaciones y motivaciones presentes en los discursos que los pescadores tienen sobre su actividad, y que no siempre aparecen inmediatamente seguidos a la pregunta ¿por qué usted trabaja en el mar? Entonces, rescatando todas las referencias al trabajo y la motivación de su elección laboral, intentaremos construir un cuadro más complejo, y esperamos más cercano a la realidad subjetiva de los pescadores. Para ello tendremos en cuenta la utilidad del concepto de representaciones sociales para el estudio de las formas interiorizadas de la cultura (Giménez, 2005). Este tipo de abordaje, que prioriza analizar los discursos de los entrevistados nos permite retomar, siguiendo a Arfuch (2002) la dimensión narrativa simbólica de la identidad, el hecho de que ésta se construye en el discurso y no por fuera de él. La noción de identidad narrativa "permite analizar ajustadamente ese vaivén incesante entre el tiempo de la narración el tiempo de la vida, pensar la compatibilidad de una lógica de las acciones con el trazado de un espacio moral". En este sentido, ser pescador aparece como algo que se "lleva en la sangre", referencia arraigada sobre todo en quienes son de familia pescadora. Pero están aquellos que son primera generación de hombres de mar, a quienes el mar los eligió, que no pueden dejarlo, aunque quieran. Para ellos el mar representa un "imán". Resaltamos aquí dos casos: el de un capitán que no es de familia de pescadores, pero desde su infancia y por una cuestión de proximidad ya que su padre tenía un kiosco en la banquina se sintió atraído por el mar, comenzó en la actividad de joven y se mantuvo en ella en contra del mandato paterno; intentó complacer a su padre, pero "tuvo" que seguir dedicándose a lo que se "reveló" como su profesión. Por otra parte, nos dirá uno de los entrevistados "el que se moja el culo con agua...", la frase aparece cortada, pero el silencio siguiente es más que significativo: no "necesita" terminar la frase.

Coincidimos con lo planteado por Jahoda en considerar que "el trabajo es una noción que abarca, pero no equivale al empleo (trabajo realizado bajo condiciones contractuales, pero y por el cual se recibe una remuneración material)" (Jahoda, 1994). El trabajo tiende a provocar una representación positiva en la que el sujeto puede volcar su personalidad en lo que hace y obtener satisfacción. En contraposición, el trabajo-empleo se percibe en general negativamente con relación a otros tipos de trabajo (Presta 2006). Esta consideración nos permite entender mejor la articulación de valoraciones, positivas y negativas, que se dan en torno al trabajo. Para los entrevistados, trabajar en el mar los hace "libres", pero ¿de qué libertad están hablando? Retomando los discursos ésta parece ligarse a, o mejor dicho "desligarse" de, "los problemas de tierra", "la falta de dinero", "el ritmo de vida de allá abajo". 
Los "problemas de tierra" o "la falta de dinero" pueden estar vinculados con la propia actividad en el mar, si es que "no se gana lo suficiente" (en términos de lo esperado por su propio esfuerzo) como es tantas veces repetido. Sin embargo, el barco y el mar aparecen como lugares de evasión. Reforzando esta idea, se reafirma la dicotomía tierra/mar: los problemas son de tierra, no deben "subir" al barco. Esto no aparece solamente en lo discursivo enunciado, sino que subyace en varias de las explicaciones de los "problemas" que pueden darse durante el trabajo en el mar, que abarcan desde la falta de integración a la sociabilidad del barco hasta los mareos y descomposturas. Esta también fue la explicación esgrimida en referencia al caso de un joven pescador que tuvo una seria descompensación en el mar: "y éste porque se trajo los problemas de abajo". Pareciera que el mar "en sí mismo" no generara problemas.

"Quería un trabajo libre de ir y venir", la idea de "libertad" también aparece vinculada a la posibilidad de alternar de barco, si no se está cómodo con las condiciones de trabajo, porque se gana más, porque lo convocó un amigo o pariente, en virtud de lo cual se actualizan las redes sociales con que cuenta el individuo. Es una práctica habitual la circulación de marineros y patrones por diferentes barcos en el puerto local, alternando en algunos casos también con las salidas desde otros puertos, ya sea Mar del Plata, del sur o estacionalmente el de Ensenada, etc. En su valoración positiva la actividad en el mar aparece asociada a diversión, deporte, libertad. Pero esto tampoco tiene que considerarse como un absoluto en la significación. Es en su articulación con el mundo "del abajo", de la tierra que choca el "mundo del barco" para encontrar su significación negativa, que va, no sólo de la dureza, rudeza ${ }^{136}$ del trabajo, sino de cómo se integra el trabajo con el trabajo-empleo. Por un lado, tenemos que los sujetos definen la pesca como un trabajo de suma "inestabilidad" y esto lo vinculan al desarrollo mismo de la actividad productiva, en referencia a los altibajos, donde se culpabiliza al Estado y los empresarios del sector por no generar un modelo más sustentable.

Para caracterizar la actividad, se crea una articulación en términos simbólicos entre las nociones de "libertad", "inestabilidad” y "expectativas". La inestabilidad laboral, está dada por lo que en la literatura sobre antropología marítima se denomina la "incertidumbre" en referencia a la falta de control sobre los factores climáticos, ecológicos, etc., pero que los pescadores también ligan a las de condiciones venta, las fluctuaciones históricas de los precios, o los riesgos e imprevistos al salir a pescar "la pesca es fluctuante, eso es lo que tiene" califican la inestabilidad en un sentido negativo, vinculada a la falta de

\footnotetext{
136 "Rudo", "fuerte", "sacrificado" pero sobre todo "duro" son los adjetivos que aparecen ligados al trabajo en el mar en un sentido que tomamos como negativo.
} 
estabilidad en los ingresos, la falta de vacaciones pagas, licencias por enfermedad, al hecho que sus ganancias no sean consideradas válidas para un crédito. La contracara en la valoración de esta "incertidumbre" está en la esperanza de que ese mismo azar "juegue" a favor: "podés salir y encontrar el pescado ahí nomás y volvés rápido lleno", "acá podés estar dos meses mal, pero después viene una buena y te salvás, va... no te salvás pero te cubrís" es un discurso que se mantiene y que forma parte de la auto-representación sobre "ser pescador".

Entonces, esa inestabilidad de los ingresos que continuamente aparece en los discursos en referencia a que, por condiciones climáticas, o del barco pueden estar más de un mes sin hacer salidas, o salir y volver sin nada "yendo a pérdida" no puede verse independientemente del otro término que le termina de dar sentido: si se gana poco o nada, también se puede ganar mucho, o se espera ganar mucho en algún momento ${ }^{137}$. Este ideal, se expresa hacia el pasado, como recuerdo gratificante "y en esa época con dos mareas pagué la fiesta [de casamiento], amoblé la casa"; y hacia el futuro como expectativa, esperanza de "salvarse". Las "buena rachas" parece que "no deben" ser justificadas más que por las propias destrezas del grupo de trabajo " $y$, veníamos siguiendo el pescado... y esa fue una buena", ya que no se encuentran ligadas en los discursos a referencias situacionales de un nivel mayor. La fusión del horizonte de cielo y mar, mientras para algunos representa una tranquilidad y algo para disfrutar para otros representa la opresión “ ¿a quién puede gustarle trabajar en altamar? Vos sabés que ahí tenés agua y cielo, no tenés otra cosa".

\subsection{Hombres de mar}

En los primeros trabajos que realicé sobre pescadores ${ }^{138}$ referí los términos de uno de mis entrevistados. En ese momento, esas palabras marcaron una huella -profundaplausible de problematizar. El pescador, en tono firme, y con la exigencia de la inexperta entrevistadora que trataba de captar el ethos de ser pescador, frente a la pregunta sobre que significaba ser pescador, expresó convencido "hay tres clases de hombres: los solteros, los casados y los marinos, porque son realmente una clase especial de gente". Retomo ahora esa temprana revelación para desentrañar -entre los discursos de los entrevistados y la interpretación analítica- qué implica ser pescador, hombre de mar.

Hay un hecho ineludible del que partimos: la totalidad del universo de referencia de los pescadores analizados para este trabajo son varones. Por supuesto que esto no es una

\footnotetext{
137 En otro trabajo analizamos el papel del azar en la representación que los horticultores tienen sobre su trabajo, ver Waisman et al. (2008).

${ }^{138}$ Rispoli (2003 y 2005).
} 
casualidad ni un sesgo en la selección de la muestra. Esto representa un dato importante para no naturalizar. Todos los movimientos en los Libros de Embarque de Puerto Quequén, tanto en 1987 como en 2001, corresponden a trabajadores pescadores varones. Tradicionalmente en la actividad pesquera, la captura, actividad que transcurre en el mar, se caracteriza por ser un ámbito masculino y suele diferenciarse explícita o implícitamente de otras formas de relación social o productiva que se desarrollan en "tierra" (Pascual Fernández, 1991a). Aunque desde hace unos años es posible para las mujeres tener libreta de embarque y trabajar en la pesca, todavía no es una situación presente en Puerto Quequén, siendo de a poco, más frecuente en los barcos de la flota de altura.

La pesca desarrollada en Puerto Quequén, y en general la pesca comercial marítima argentina se desarrolló a partir de la pesca europea que trajeron los inmigrantes transoceánicos. En ese sentido, también trajeron consigo no sólo los rudimentos de las técnicas de pesca que servirán de base para el desarrollo de la actividad local, sino también la forma de organización de esta y la carga simbólica asociada a la misma. Entre las gentes de mar es común sostener que "en el mar las faldas traen mala suerte" haciendo referencia a la presencia de mujeres o curas en los barcos, cuya presencia sólo estaba "permitida" en ocasiones festivas. En nuestras entrevistas a pescadores encontramos referencias que no se asocian a la mala suerte, pero remiten a la exclusión o a la rareza de imaginar a la mujer realizando el trabajo de ellos (o con ellos), "que va a hacer una mujer en el agua", "no, no... la pesca no es para mujeres, no sé ahora, pero no creo, no en estos barquitos no", "y la mujer en la casa, el barco no es para mujeres", "ni siquiera hay baño acá". Al preguntar a esposas de pescadores (algunas de ellas incluso hijas de pescadores) sobre la posibilidad de haberse embarcado, tampoco apareció como una situación plausible, sino que se presentó la extrañeza como reacción. En la concepción es "natural" que la pesca que es un trabajo de hombres.

En nuestro referente empírico, el universo simbólico de la pesca es masculino durante la mayor parte del período de estudio ${ }^{139}$, y con una historicidad que se retrotrae incluso a antes del desarrollo local de la actividad. Como en muchos otros lugares, la pesca es una actividad eminentemente masculina porque fue desarrollada durante generaciones exclusivamente por seres humanos adscriptos al sexo/género masculino. Esto comporta un irrefutable carácter descriptivo. Sin embargo, nos interesa también explorar el marco interpretativo de este hecho. La pesca es masculina, porque es no-masculino excluyente.

139 Recordemos que hacia el final del período es posible en términos legales para las mujeres embarcarse. Sin embargo, esto no es corriente en la práctica de la pesca en los barcos de poco porte como los de la flota analizada. En 2009, un pescador joven me pregunta en banquina si estoy para embarcarme. 
Desde lo simbólico podemos llamar la atención sobre el valor que tiene excluir aquello que no se identifica como hombre en el sentido masculino sexual del término: mujeres, curas. Mientras que la homosexualidad masculina aparece como algo lejano, una referencia a las bromas. Tal como plantea y problematiza Connell (1997), en el registro cultural de nuestra sociedad occidental el ser hombre se asocia al ser violento, dominante, activo. Por su parte, aquellos no-masculinos se caracterizarían por ser pacíficos, conciliatorios, pasivos. Estos campos no-masculinos excluidos -mujeres y curas- a la vez legitiman y articulan el campo de la masculinidad pescadora. Las mujeres se vinculan con en el trabajo en tierra, ya sea asociado a la actividad pesquera (manejo de dinero, reparación de redes, conserva) y en sostener la organización doméstica que permita el desempeño de los hombres en el barco. Los curas y/o religiosos en "ofrecer" la protección necesaria para sostener. 0 sea, es una organización que se sostiene por la presencia y la participación "regulada" de aquellos que excluye. Nos interesa remarcar también que recuperamos el papel central que desempeña lo doméstico en la definición de lo masculino, y no sólo aquellos rasgos atribuidos al orden de lo público (Fuller, 2008).

Y es duro, sí. Es decir, en este tipo de rubro es importante que, cuando uno tiene familia, que la familia, tanto la esposa como los hijos te acompañen (...). La parte familiar es un punto muy vulnerable para la persona, y para el que trabaja y para la señora y por eso tienen que ser personas, no especiales, pero más que nada fieles..." (pescador).

Así que realmente si vas a hacer este tipo de vida tu señora tiene que saber que te tiene que acompañar, porque si no pasan cosas graves, graves (pescador altura).

Entre las características que los pescadores se autoperciben como masculinas recuperamos la posibilidad de sostener económicamente a la esposa y a la familia, poder dar educación y lo necesario para vivir "sin tener que pedir nada a nadie”, símbolos de poder económico como poder hacer la fiesta de casamiento, tener la casa propia y auto. Resulta significativo el lugar dado a poder construir cierta estabilidad económica, "yo la tengo bien a mi señora, a mis hijos, que no les falte nada, si no hay lujos no importa, pero yo quiero tenerla bien". Entonces marcamos el sostén económico hacia la esposa, los hijos como una de las formas que asume el mandato de masculinidad para los pescadores. Tengamos presente que la mayoría de los encuestados y entrevistados estaban casados y tenían hijos ${ }^{140}$.

\footnotetext{
140 En 1988 la mayoría de los pescadores de Puerto Quequén están casados, y el porcentaje es más alto que en otros puertos de la costa bonaerense (Errazti et al., 1998).
} 
En cuanto a las mujeres, los rasgos y cualidades que ellas mismas se adjudicaron o que sus esposos refirieron sobre ellas las posicionan en el lugar de "femenino" con los hijos y la familia como centro de la definición de esa femineidad.

"Durante todos los años que trabajó de pescador yo me levantaba y le tenía listo el mate, tomábamos mate todas las mañanas (...) a la noche llegaba tarde, tarde y cansado, yo viste eh, tenía la comida para calentar y a los chicos listos. Que ya comidos, que estuvieran acostados para que pudiera descansar un poco. Pero se lo perdió todo, de grande los disfrutó. Pero ya eran grandes los chicos, cuando se jubiló recién" (esposa de pescador).

La referencia a la buena mujer es central. Porque si el hombre de mar es un tipo especial de hombre, la mujer del marino también lo es. Se recuperan muchas anécdotas, de situaciones en que un marinero regresa a su casa, habiendo salido para embarcar por unos días, porque el barco se averió o alguna otra circunstancia y, al entrar, se encuentra a la esposa con otro hombre en la casa, o en la cama. Mucho se habla y se tiene en el imaginario de sentido común la noción de un marinero con una novia en cada puerto. Pero estos pescadores, que salen a pescar desde el puerto local, que se ausentan periódicamente de sus casas ponen un énfasis muy fuerte en la elección de una "buena esposa", como dice un pescador “... yo pienso que una mujer decente siempre es una mujer decente, pero una mujer que es una porquería siempre va a ser una porquería...". Son muy comunes los chistes "pesados" entre pescadores sobre lo que están haciendo o con quiénes están las esposas y es parte de la sociabilidad jocosa que comparten en la banquina y el barco. Mateo y Correa (2008) para las familias de los pescadores en Mar del Plata sostienen que el temor al engaño por las ausencias durante el trabajo, el acceso al dinero ganado por el varón y el rol preponderante de la mujer en la administración de los bienes familiares, la escasa capacidad de control y de participación en la vida hogareña por parte del varón constituyen aspectos que plantean con fuerza el carácter simbólico de la dominación masculina. Como las "brujas" esposas y parejas de los petroleros de Comodoro Rivadavia (Palermo, 2017) que son vistas como "encantadoras" para sacarles sus propios salarios, los pescadores de Puerto Quequén tienen reparos con las mujeres que se acercan por el dinero. Un entrevistado nos cuenta de otro pescador joven que cuando empezó no sabía qué hacer con el dinero, que "salía con una chica, con otra, todas le querían sacar algo y nosotros que le decíamos buscá una buena y cásate, guardá para la casa, y el loco este compró un auto y lo chocó". Las referencias a "buena mujer" y "hombre de mar" pueden ser vinculadas a valores como las de "honor" y "vergüenza", ampliamente estudiados y discutidos por la antropología del mediterráneo. El honor de cada familia es considerado como vulnerable y debe ser protegido, por ello la 
sexualidad de las mujeres resultaría fundamental para el honor y la vergüenza de la comunidad misma. Mientras que para las mujeres hay discrepancia en cuanto al grado de recato sexual según el cual se conserva el honor, tanto Davis (1983) como Scheneider (1971) acuerdan en que el honor masculino se deriva tanto del trabajo y de la actividad económica como de una vida sexual activa. Para Davis (1983) el honor está relacionado primordialmente con la riqueza: alimentar a la familia, cuidar a las mujeres, mantener al grupo puede ser hecho más fácilmente cuando la familia no es pobre. En este sentido y para este autor el honor es la capacidad de cumplir el rol que la jerarquía social compartida por la comunidad atribuye. La noción de honor marcada por esta tradición académica sugiere estar relacionada con las valoraciones establecidas entre los géneros, pero también, como veremos a continuación, con las identificaciones en torno al "aguante" en la masculinidad. Consideramos que el honor, o las formas que pueden asumir los honores, no sólo se negocian dentro de una comunidad, sino que pueden modificarse en el contacto entre diversos entornos. Más allá de las diferencias de contextos culturales, resulta interesante recuperar la concepción de "poética del yo" que propone Herzfeld (1985) ligada a la de la representación del género. El exitoso desempeño de la personalidad masculina en diversos contextos internos y frente al exterior depende de la capacidad de identificar al "yo" con categorías de identidad más amplias, que contribuyen a dar cuenta de cómo son negociadas e interpretadas por los sujetos las nociones de masculinidad. En este sentido, también nos parece interesante situar el lugar que cabe para las esposas de pescadores en relación con la valoración y efectivo aporte de trabajo afectivo necesario para sostener al esposo y la familia que se amalgama con el trabajo sexual y reproductivo (Falquet, 2017). Dar cuenta de este aporte necesario para el desarrollo y sostén del pescador nos permite ubicar su aporte en las funciones domésticas de reproducción social (Federici, 2010) y continuar en la línea de cuestionar la pertinencia de la separación analítica entre trabajo productivo y reproductivo (Durham, 1999).

Por otra parte, en el trabajo, una de las formas en que se expresa de manera implícita entre los pescadores la masculinidad tiene que ver con la noción de "aguante", de resistencia frente al trabajo, a sus condiciones, al dolor por el esfuerzo, el cansancio. El de pescador es autopercibido como un trabajo extremadamente duro por aquellos que lo desempeñan, "que no es para cualquiera" se refuerza. Esto se expresa con la ambivalencia de enorgullecerse de poder realizarlo. Resulta interesante pensar esto no sólo en clave de género sino de clase social. En este sentido, en la conformación de ideologías la atribución de mayor capacidad de aguante, fuerza y fortaleza en las clases subalternas, trabajadoras, constituye un elemento de diferenciación y un recurso en los procesos de socialización interiorizados que permite que se sostengan relaciones de dominación inscribiendo en el 
cuerpo marcas que permiten la adscripción a una clase social (Otegui Pascual, 2009). Representaciones como las de resistencia y aguantes, atribuidas como valor positivo en función de la pertenencia de género y de clase resulta fundamental los trabajadores.

Desde una perspectiva constructivista (Badinter, 1993) y relacional (Connel, 1997) sobre los géneros la masculinidad no constituye una esencia, sino que implica una ideología que apunta a justificar la dominación masculina. Con gran desarrollo a partir de la teoría feminista se develó el modo en que esta ideología articula la sociedad al tiempo en que esa articulación oprime a un segmento de la misma tanto en nuestra sociedad como en otras sociedades no occidentales (Bourdieu 2000). En este sentido, la masculinidad no es un hecho "en sí" sino que se aprende. Las implicancias teóricas y prácticas llevan a sostener que se pueden cambiar, pueden existir nuevas formas de aprender y ejercer la masculinidad. Esto lleva a identificar en la actualidad una crisis de la masculinidad hegemónica (Badinter, 1993). La masculinidad hegemónica no sólo se estructura en oposición a la identidad femenina, sino también aglutinando en torno de sí, de modo subalterno a otras masculinidades (Connell, 1997). Dentro de este posicionamiento de cómo entender la(s) masculinidad(es), nos interesa retomar los casos estudiados sobre pescadores en Puerto Quequén. Tomamos como punto de partida que la masculinidad opera como una ideología que se incorpora en los sujetos con particularidades específicas en las múltiples etapas de los ciclos de socialización (Berger y Luckman, 1994). Retomando a Badinter (1993) el niño a lo largo de toda su vida tiene que convencerse y convencer a los demás que no es una mujer; que no es un bebé y que no es homosexual. En este sentido la interiorización de la masculinidad requiere monopolizar la actividad y suprimir toda expresión de pasividad y feminidad. Veamos particularmente cómo se da esta incorporación de los mandatos de masculinidad durante la socialización en los procesos de trabajo:

"Y la primera vez que salís en el barco es difícil, todavía no sabés si te mareas, que se yo, es todo nuevo, yo viste mucho no me maree ese día pero lo pasé fulero ehh si te mareas no te joden porque ya es jodido eso. P- qué pasó? cómo te joden?

Ehhh no, no sé, que si... que si, que si te tiran una raya, que si te tienen de acá para allá o a tirar red sin que haga falta, qué se yo viste" (patrón).

En el barco, en el tiempo juntos en precarias condiciones de comodidad, de estrecho contacto social, pero también físico y emocional, siempre está latente el horizonte de la "relación homosexual" estigmatizada en ese ámbito. En este sentido podemos 
recuperar desde los discursos trabajados que hay no necesariamente consciente, pero sí explicita intención de marcar los hitos de la heterosexualidad entre los entrevistados en profundidad. La primera novia, el casamiento y la conformación de la familia, el valor de los hijos, tensionan con los discursos sobre los compañeros en el trabajo donde se marca una imbricación en el proceso laboral pero una distancia en lo personal-afectivo. El barco y las relaciones en el barco "son como una familia". Esta frase que es la más recuperada, y que se analizó anteriormente para pensar el proceso de trabajo, también la recuperamos ahora para pensar la forma en que se establecen los vínculos congéneres, en una familia sólo de hombres. Las referencias al otro cercano compañero laboral están marcadas por el chiste, la pelea, el desmerecimiento jocoso, donde en algunos casos es evidente la confianza, el cariño y el respeto, pero expresados con la suficiente distancia para que no queden lugar a dudas de que no es una relación "más cercana”, lo que podría resultar problemático. En simultáneo encontramos que los chistes, los relatos de las experiencias en el barco recurrentemente están "jugando" con la homosexualidad; el uso de homosexualidad como fantasma o límite para reafirmar y constituir la masculinidad ha sido muchas veces referenciado entre grupos de pares, en diferentes ámbitos de socialización ya sean deportivos o de trabajo (Archetti, 2003; Garriga Zucal, 2013; Palermo, 2017; Branz, 2015). En la transmisión de la masculinidad y de la conformación de la heterosexualidad es reconocible una "pedagogía homosexual" que se configura entre los grupos de pares y entre mayores y menores. Es extensa la literatura sobre la necesidad de identificación del niño con sus pares masculinos, los ritos masculinos de pasaje tienen la función de dividir y sostener la separación de los hombres del mundo femenino, que se identifiquen plenamente como hombres y con el modelo de masculinidad hegemónico.

Reconocemos que el trabajo en el barco, en el ser pescador, hombre de mar instituye uno de los grupos de pares donde estos sujetos, trabajadores pescadores, articulan la afirmación de su masculinidad. Si volvemos a la cita inicial, podemos interpretar que la mitad género masculina de la sociedad puede dividirse en tres. En primer lugar, los solteros, aquellos no casados, que aún no demostraron social y definitivamente su heterosexualidad, aun no comprometidos, signo de juventud y de las libertades que otorga el imaginario de "una novia en cada puerto" o plausibles de no ejercer la masculinidad. Los casados: representando la adhesión social con la (hetero)norma, el trabajo, el compromiso con la familia y la reproducción social esperada como una etapa en la trayectoria y el sentido de la vida. Los hombres de mar: una distinción en torno al compromiso con una masculinidad diferente. Una arista de esta distinción la interpreto en función del espacio. Mientras hay un espacio de tierra, y ese espacio tiene lugar para diferentes géneros y situaciones; el mar se constituye como un espacio de constitución subjetiva de la masculinidad excluyente de 
otros géneros. A su vez, el ser de mar el poder ser de mar, en el sentido de "bancarse", "aguantar", "soportar" es una garantía de masculinidad. Es ser hombres y más hombres.

Al considerar las identidades desde una perspectiva relacional, resulta imprescindible identificar aquellos elementos que son recuperados por los grupos o los colectivos para marcar y sostener la distinción que marca el límite de pertenencia (Barth, 1976; Tamagno, 1988). Los varones, aquellos sujetos con atributos fenotípicos caracterizados como masculinos también deben probar a los otros (tanto a los diferentes hombres no masculinos como mujeres) su masculinidad. Para probarla, esta masculinidad que no corresponde a una esencia, debe ser puesta en acto en los diferentes ámbitos de la vida social. El ejercicio y el "aguante" frente a la violencia simbólica, pero sobre todo física es uno de los elementos en torno a los cuales los hombres se constituyen como tales (Connel, 1997; Garriga Zucal, 2013; Palermo, 2017).

La violencia es parte de la constitución y de los circuitos del patriarcado que se establece y reproduce en dos ejes, el de los pares, ya sean aliados o competidores y el de los desiguales frente a quienes se legitima el status dominante de quién ejerce la violencia (Segato, 2010). En el trabajo de los pescadores el momento de iniciación laboral, las primeras salidas en el barco pueden entenderse como un ritual de pasaje de ser hombre a hombre de mar. Aguantar los mareos y pasar las bromas pesadas de los compañeros. Los primeros viajes comportan un carácter de liminalidad (Turner, 1988), y pasar esa "prueba" permite diferenciar entre aquellos que nunca entraron, y cuando lo pasan ayuda a la cohesión y la constitución de cierta homogeneidad interna dentro del grupo. Ser parte en el sufrimiento contribuye a construir una subjetividad más estable. En este modelo el lugar del "sufrimiento" y consiguientemente soportarlo, es fundante. La violencia, el sufrimiento y el "aguante" del sufrimiento aparecen en los relatos como constitutivos de la identidad. Al observar los tipos de violencia que aparecen entre los pescadores, recordamos la ventaja que suponen los modelos ritualizados, donde el ejercicio de la violencia está "limitado", se ejerce entre los pares un ejercicio y un control de la situación de violencia. Lo diferenciamos de otras formas en que la masculinidad ejerce la violencia entre pares o entre desiguales, pero sin una limitación (Segato, 2010; Garriga Zucal, 2018).

En los grupos de pares masculinos los ritos de iniciación suponen una ruptura simbólica con las madres, con las mujeres, un pasaje a un estado en el que se permite actuar la masculinidad. Pero en el barco, en el mar, el rito de iniciación, mediado por la propia particularidad y dificultad del medio inhóspito al que se suman las bromas pesadas a los no iniciados, se da al mismo tiempo que una legitimidad sobre la masculinidad una ruptura simbólica más sobre aquellos hombres no iniciados. El fin de este rito de pasaje no se da en la primera salida al mar, sino que según las características de cada marinero puede 
extenderse hasta cuando "soporte", “aguante", "reprima” y oculte el sufrimiento que puede comportarle el trabajo en el mar. Los vómitos, mareos, desvanecimientos, el acostumbrarse a un ritmo de trabajo marcado por la vigilia, el frío y la humedad constante, las bromas pesadas. La necesidad de un reconocimiento por parte de los pares da fuerzas, insta a seguir. Sin embargo, algunos no lo pasan. No se convierten en hombres de mar, o como dicen ellos "el mar no es para todos".

\subsection{De tierra y de mar...}

Como ya comentamos en el apartado sobre estrategias, en las familias de pescadores es plausible diferenciar los espacios domésticos y laborales según género. Sin embargo, nos interesa hacer más detenidamente una caracterización de estos espacios, sus límites materiales y simbólicos y los espacios de contacto, los flujos de continuidad entre ellos. Desde la perspectiva de las representaciones sociales interpretamos la forma en que se configuran simbólicamente estos espacios. Los análisis sobre el sector pesquero y las comunidades de pescadores han generado un corpus de conocimiento entre los que destacamos, en primer lugar, la dicotomía entre el mar como espacio masculino de "a bordo" y, la tierra como espacio femenino y de otras relaciones sociales no productivas (Pascual Fernández, 1991a).

Dentro de cada una de las esferas mencionadas pueden identificarse ciertas características distintivas; por ejemplo, en el espacio de mar, la organización del trabajo dentro del barco, el sistema de retribución "a la parte“, las jerarquías dentro de la flota, la estratificación social, el sistema de reclutamiento de la mano de obra, entre otras. Estas, a su vez, se entrecruzan con factores propios de la actividad como el riesgo de la producción y la incertidumbre del recurso, la territorialidad, la discusión sobre la propiedad de los recursos, los usos de diferentes tecnologías y estrategias productivas teniendo en cuenta sus cambios e intensificación. Especialmente rescatamos que existen diferencias en la configuración de las tripulaciones, en los procesos de trabajo y en las relaciones que se establecen entre "pesca costera" y "de altura" (Pascual Fernández, 1991a). Ambos contextos difieren notablemente y plantean problemáticas dispares en cuanto al aprendizaje de los saberes, las habilidades de la profesión, los procesos de comunicación en el barco y las formas de autoridad, y también en su papel en la unidad doméstica (Pascual Fernández, 1991a, Rispoli, 2005). En el espacio de tierra, la organización doméstica y la configuración de las estrategias familiares de vida, están influidas por el ritmo del trabajo pesquero (Rispoli, 2005), por lo que el hogar es delegado, aunque no concedido, a las mujeres (Pascual Fernández, 1991a). 
A partir de lo indagado en función de la actividad pesquera proponemos para Puerto Quequén distinguir tres espacios material y simbólicamente diferenciables, el mar, la tierra y la banquina. Los pescadores, sus esposas y familias circulan de diferente forma a por ellos. Como esos campos que propone Barnes (1954) para Bremmes, cada uno está configurado por características distintivas y la puesta en acción de un tipo particular de lazos.

- El mar: materialmente representado por el barco, es un espacio masculino y de trabajo, de identificación personal, de "sacrificio" en el que hay que "aguantar" pero donde también es plausible disfrutar y alejarse de los problemas de tierra. Comporta una distancia material y simbólica con el espacio de tierra. La inmensidad, los peligros, la soledad, la posibilidad de no volver, esa estricta negociación diaria con la posibilidad de la muerte en mar. Los lazos con la tripulación, la cohesión familiar en el trabajo. Una distintiva temporalidad orientada según el quehacer. Aunque en tierra, el trabajo del barco, su mantenimiento y administración es entendido por los pescadores de Puerto Quequén como un trabajo de mar.

- La tierra: el espacio de la casa, el hogar, familia nuclear y extensa, amistades, es un espacio genéricamente mixto. En el hogar la responsabilidad doméstica es primordialmente femenina pero el varón no se desentiende y mantiene la legitimidad de su rol como proveedor de ingresos económico. Cuando los pescadores aluden a tierra, se refieren al hogar, pero también a los trabajos en tierra, aquellos que no están vinculados con la actividad pesquera, o aquellos vinculados con la actividad, pero no embarcados. Así, la comercialización y el procesamiento del pescado son considerados una actividad de tierra. También quedan incluidos en este ámbito, aquel espacio más amplio donde las lanchas y el puerto son significados como paisaje.

- La banquina: un espacio masculino, de trabajo y sociabilidad. En la proximidad río, mar y tierra, es un límite, un borde, un lugar de encuentro. Se da la estiba, se arregla el barco y las redes, se comparte con los tripulantes de diferentes barcos, se consigue trabajo. Es un borde, un espacio de circulación de personas, productos y relaciones sociales. Se comparte con otros trabajadores no pescadores: estibadores, personal de Prefectura, visitantes. No es excluyente de las mujeres, aunque no es habitual que las esposas de los pescadores circulen por este ella salvo en contadas ocasiones, por ejemplo, para la fiesta de los pescadores. En el fin del período y por las normativas post 11 de septiembre de 2001, se cerró el puerto. Pero durante décadas, además de la sociabilidad específica de los trabajadores portuarios, la banquina fue un espacio abierto de flujo de personas, ya sean turistas que venían a sacarse fotos en las típicas lanchas amarillas, pescadores 
deportivos, pequeños comerciantes, donde los pescadores convivían con otros usos del espacio y reconocidos en su quehacer.

Queremos marcar una distinción entre aquellos pescadores que trabajan como marineros y que no tienen otro vínculo con la actividad, de aquellos que son de familia de pescadores y/o propietarias de embarcaciones. Entre los primeros, el rol de las mujeres es excluido y/o indiferente respecto de la actividad pesquera. Lo doméstico y lo laboral pesquero resultan campos diferenciados y excluyentes, y así son representados los espacios de mar y tierra por hombres y mujeres. Pero hacemos una observación respecto de aquellas familias que son propietarias de lanchas pesqueras, dónde en algunos casos, además se conjuga con no ser de primera generación de pescadores (hijas de pescadores). En este subgrupo destacamos el papel de estas mujeres, en el trabajo pesquero, fuera del barco, pero encargadas de la administración, con un rol activo en la "empresa pesquera" familiar. En estos casos el mar es distante en lo material pero simbólicamente cercano para estas mujeres que se ocupan de la administración, de las cuentas, del pago de los marineros, de la compra para el abastecimiento de la salida. En este sentido, podemos reflexionar sobre cómo se configura la estrategia de vida y la división del trabajo en las familias de pescadores.

Hacia el final del período, obtener la libreta de embarque y la posibilidad de trabajar embarcada es una posible realidad para las mujeres, aunque no concretada en Puerto Quequén. La incorporación de la mujer en la pesca supondrá una reestructuración del sistema simbólico tradicional. Cómo sostiene Scott (2008) los cambios en la organización de las relaciones sociales siempre corresponden a cambios en las representaciones del poder, pero la dirección del cambio no es única. La salida de la mujer a trabajar y a disputar en el campo público por sus derechos implica necesariamente la constitución de nuevas masculinidades y la reconfiguración de los espacios simbólicos, véase por caso la experiencia de las mujeres en la pesca del camarón (Alcalá Moya, 2003).

\section{Palabras finales}

En mar, en tierra y en la banquina los pescadores costeros de Puerto Quequén viven, trabajan y constituyen su subjetividad. Decisiones y sentires de un ámbito tienen correlato en otro de ellos. El apropiarse material y simbólicamente del medio marino para obtener recursos en un marco económico y social más amplio, configura una serie de potencialidades y restricciones que impactan en las decisiones que toman los pescadores y sus familias para para organizar y garantizar sus vidas. La estructuración de las relaciones familiares lleva la huella del trabajo en el mar. La inserción laboral lleva las huellas de la familia. Las redes de los pescadores no son solamente las utilizadas para calar sino también 
las redes sociales para conseguir y permanecer en el trabajo, las que conforman y cohesionan al grupo de trabajo al interior del barco. Las de redes entre barcos para salir y acompañarse solidariamente en el mar. Las redes en tierra, los lazos familiares en el grupo doméstico. 


\section{Conclusiones}

\section{Conclusiones generales}

Si bien los pescadores de Puerto Quequén están presentes desde los inicios del puerto, llevan adelante su actividad en un puerto en el cual la actividad pesquera no es la central, dado que este se ha orientado desde sus inicios hacia la salida de la producción agropecuaria de su zona de influencia. Toda la infraestructura portuaria y el trazado de comunicación de las ciudades adyacentes de Necochea y Quequén y de la zona están en función de garantizar la salida de los productos agropecuarios del campo, y gran parte de la actividad económica del núcleo urbano se vincula con la actividad portuaria. En este sentido, los pescadores y la actividad pesquera en este puerto representan una alteridad. Esto se ve especialmente resaltado por su particular localización, central entre dos localidades que están separadas -y al mismo tiempo unidas- por el río Quequén, que divide a dichos núcleos urbanos y al puerto en sus márgenes. La integración entre estas localidades ha variado en el tiempo, producto de la construcción o la rotura de puentes. El proceso de consorciación del puerto en la década de 1990 -que significó virtualmente una privatización- y los cambios en las medidas de seguridad, llevaron al cierre del puerto y a una mayor aislación respecto de ambas márgenes portuarias y de los núcleos urbanos. Estos cambios influyeron en el modo en que los visitantes transitan por la banquina portuaria y comparten el espacio con los trabajadores.

Sin embargo, y a pesar de los avatares que influyeron en este puerto -que es principalmente cerealero, pero también de los pescadores y las tradicionales lanchas amarillas- constituye parte del imaginario de la ciudad en virtud de ser un espacio con diferentes connotaciones, como espacio de laboral, de paseo, de transgresión social o de delito. En este sentido, se integra claramente con otro aspecto de las ciudades donde se inserta, ya que forma parte de los atractivos turísticos locales, e incluso una fuente de inspiración para representaciones artísticas. En el puerto o en la línea de costa, la materialidad de los barcos pesqueros hundidos o encallados, más allá de su atractivo visual, para los pescadores remiten al riesgo de la actividad es resignificada en clave artística, haciéndolos presentes en otros ámbitos. De esta forma, los pescadores son parte de las 
ciudades donde se halla el puerto, donde están los barcos -sus medios de producción- o su lugar de trabajo en tierra -la banquina- sino que se encuentran representados en distintos lugares. Su presencia se materializa también en los monumentos conmemorativos a su actividad. El espacio significado, en el palimpsesto de los objetos acumulados y transformados, se vuelve paisaje en el puerto y su barrio. Sin embargo, es interesante destacar que en el caso de Necochea-Quequén, los pescadores no tienden a hallarse aglutinadas en el sector portuario, sino que se encuentran dispersos en la ciudad.

Como hemos visto en esta tesis, a lo largo del periodo considerado han ocurrido una serie de cambios en la legislación internacional y nacional sobre el mar y los permisos de pesca, en consonancia con factores económicos nacionales e internacionales y con el propio desarrollo global del mercado de pescado, que han llevado a transformaciones estructurales en el desarrollo de la actividad pesquera en nuestro país. Todo esto ha impactado en los pescadores objeto de análisis en función del modo en que la Argentina se integró al mercado internacional de pescado, y el rol que ha tenido dentro del país la pesca en Puerto Quequén. El desarrollo del modelo pesquero argentino durante el período tomó la forma de un modelo extractivo - principalmente durante la década de 1990- de una mercancía cuya valorización está dada por la demanda externa, esto llevó a la crisis de uno de los recursos base en los que se asienta el modelo.

Mientras las capturas de pescado a nivel nacional se incrementaron y la participación de la flota costera se mantiene relativamente constante desde hace décadas; en el caso de la flota de Puerto Quequén su participación sobre el total nacional se halla en retroceso, tanto en volumen de capturas como en cantidad de embarcaciones. En la Argentina, en las últimas décadas, las capturas pasan a estar concentradas cada vez más en la flota de congeladores y en pocas empresas. Esto llevó además a una presión extrema sobre el recurso, produciéndose una sobrepesca de varias especies, como durante el período crítico de "la merluza". Ante esta situación, los pescadores de Puerto Quequén desarrollan discursos conservacionistas que se contradicen con las prácticas que ellos relatan sobre cómo llevan adelante la actividad de pesca y el descarte pesquero. Además, entre ellos es posible reconocer una serie de apreciaciones sobre la causalidad de la crisis que es situada en el plano político regulatorio nacional, en la acción de las grandes empresas y en el accionar de las empresas extranjeras. Otra consecuencia de las crisis pesqueras de la década de 1990 es la disminución de la industria de pescado en tierra con la consiguiente baja en demanda local de pescado que esto implica. Los factores locales y de escala nacional tienen consecuencias en el circuito laboral de los trabajadores-pescadores de Necochea y Quequén. Cada vez resulta más difícil conseguir trabajo en la flota local. En este contexto las trayectorias laborales y familiares de los pescadores están marcadas por la decisión de 
trabajar en la pesca costera en la localidad, trabajar en la pesca en otros puertos o desempeñarse en otros trabajos en tierra.

A su vez, la presencia de trabajadores pescadores extra locales se incrementa, sobre todo, al considerar los barcos de altura. En menos casos, pescadores de otros puertos se embarcan en la flota costera local por largos períodos y cuando esto ocurre, mayormente corresponde a pescadores de Mar del Plata o de otras localidades, pero que han compartido embarques con otros pescadores oriundos de Necochea y Quequén. La pequeña y cada vez menor flota pesquera local aparece como un refugio y una opción sólo para una pequeña proporción de los trabajadores-pescadores neco-quequenenses, esto es, aquellos que tienen barco propio o familiar o, que tienen lazos familiares con los propietarios. Por lo que tienen una vinculación más fuerte con los medios de producción de la pesca, y probablemente una relación más estrecha con las formas tradicionales de captura del recurso. Es mayor el número de pescadores-trabajadores con residencia local que los que efectivamente trabajan en Puerto Quequén, está reflejando que, si bien no trabajan el este puerto, continúan ligados a las actividades marinas al abastecer la demanda laboral de la flota pesquera global que desarrolla su actividad en el Mar Argentino.

En cuanto a la actividad pesquera propiamente dicha, consideramos que la pesca es una actividad sumamente incierta, entre otras cosas por las características de movilidad e imprevisibilidad que tienen los recursos marinos. Otra peculiaridad radica en que la propiedad del recurso no es de libre acceso, lo que conlleva particularidades en la forma en que se accede al mismo. Los pescadores de la flota costera de Puerto Quequén realizan su actividad orientada a la venta comercial de lo producido, por lo que ubicamos su actividad en relación con la conformación de un mercado primero interno, y luego internacional que incidió en las condiciones en las que participaron. La evolución nacional de la actividad, con sus ciclos de expansión y crisis, constituyó el marco en el que los pescadores costeros anclan sus percepciones e interpretaciones sobre su propio trabajo. Estas representaciones conjugan, articulan y tensionan nociones como las de dureza, riesgo, libertad, juego y aventura. En las concepciones de los pescadores sobre su trabajo se conjuga la ambigüedad que comporta el trabajo humano, por un lado, como empleo y por otra parte como identidad, en la que los sujetos pueden volcar y constituir su subjetividad.

Para apropiarse del medio marino y obtener del mar sus recursos los pescadores lo hacen en embarcaciones, que constituyen la unidad productiva en la que trabajan. Los barcos de la flota costera cambiaron durante el período de interés la autonomía de trabajo en altamar de un día a tres días y medio, en parte por la mejor tecnología disponible, pero también, por la mayor dificultad de completar la carga de la embarcación y, por lo tanto, para que la salida de pesca resulte rentable. El tipo de recurso que extrae este tipo de flota 
incluye una amplia variedad de especies (anchoíta, bonito, besugo, caballa, cornalito, corvina, gatuzo, camarón, langostino, lenguados, mero, pargo, pescadilla, pez ángel, pez palo, rayas y salmón de mar, entre otros) y se lo denomina variado costero. Las salidas están condicionadas por la situación meteorológica y, en el barco, el tiempo de trabajo es continuo, constituyendo lo que denominamos un tempo de mar que se organiza según el quehacer y se distingue de la rutina del tiempo en "tierra". El trabajo en el mar también implica una serie de conocimientos específicos que son aprendidas de forma tácita por los miembros de la tripulación, la destreza y la habilidad son transmitidas entre familiares y compañeros de la tripulación y los pescadores destacan el lugar que tiene la observación para el aprendizaje. Este conocimiento sobre el pescar lo distinguimos la posesión de la "libreta de embarque" que es la habilitación formal para poder embarcar. El conocimiento del mar es importante no sólo para la localización de los caladeros sino también para desempeñarse en un medio inhóspito como es el mar. La perspectiva del naufragio es un riesgo siempre presente en el horizonte de los trabajadores y sus familias. Las cábalas y amuletos son parte de los mecanismos desplegados para afrontar la tarea del trabajo en el mar.

La forma de organización del trabajo en el barco comporta una estratificación marcada en la que los participantes tienen una estrecha cohesión sustentada en el efectivo trabajo conjunto y en preceptos ideológicos que favorecen esa cohesión. La noción de familia aparece así representada en la materialidad de los vínculos familiares que se dan entre algunos de los miembros de la tripulación, pero también en la metáfora con la que explican su trabajo. En la familia del barco se recuperan y reinscriben lazos familiares que traen su propia lógica de poder (padre patrón/ hijo marinero) con otras propias de la unidad productiva (propietario patrón/ marinero trabajador). Otra de las características distintivas tiene que ver con el sistema de retribución "a la parte". Esta forma implica que los trabajadores obtienen el equivalente a una porción de las capturas una vez realizada la venta, lo que incrementa la motivación y reduce el riesgo de los armadores en una actividad incierta. El correlato concreto de esta forma de remuneración para los pescadores entrevistados implica cierta incertidumbre en relación con su remuneración, destacando una relativa fluctuación en los ingresos mensuales.

Del análisis de las entrevistas se desprende que casi todos los entrevistados en algún momento de su trayectoria laboral realizaron pesca de altura. Algunos pasaron por actividades en tierra. La mayoría de los pescadores relevados estaban casados y tenían hijos. A su vez, la mayoría de las esposas no trabajaba. En algunos casos las mujeres trabajaban en tareas relativas a la embarcación barco, pero sin un rol delineado sino considerado como ayuda. La tensión en la trayectoria laboral entre realizar pesca costera, 
de altura u otras actividades laborales es resuelta respecto de la organización doméstica y la configuración de las estrategias familiares. En la mayoría de los hogares la participación monetaria es aportada por el varón pescador y, según lo relevado los hogares y las viviendas de los pescadores, no comportan necesidades básicas insatisfechas.

La actividad pesquera en Puerto Quequén es eminentemente masculina. Las mujeres se vinculan con en el trabajo en tierra, ya sea en algunos casos asociado a la actividad pesquera y sobre todo en sostener la organización doméstica que permita el desempeño de los hombres en el barco. Consideramos que es una organización que se sostiene por la presencia y la participación "regulada" de aquellos que excluye, mujeres y curas (participando en la bendición de los barcos y de imágenes). La recurrente caracterización distintiva como marinos o "hombres de mar" es algo que se logra en la legitimación con los pares, navegando y soportando las condiciones del mar. Pero también en lo doméstico, en este ámbito en su ubicación como soportes económicos y la complementariedad con una "buena" mujer en tierra.

Los vínculos familiares y de amistad resultaron altamente significativos para conseguir trabajo entre los pescadores. Las motivaciones principales para la elección del trabajo resultan de una combinación de la rentabilidad con la inserción previa de algún familiar o amigo. Vemos así, como las redes de los pescadores no son solamente las utilizadas para calar sino también las redes sociales para conseguir y permanecer en el trabajo, las que conforman y cohesionan al grupo de trabajo al interior del barco. Las redes entre barcos para salir y acompañarse solidariamente en el mar; las redes en tierra, sobre todo los lazos familiares, en el grupo doméstico.

Finalmente, proponemos distinguir tres espacios, material y simbólicamente diferenciados, configurados, cada uno de ellos, por características distintivas, y la puesta en acción de tipos particulares de lazos sociales. El mar, representado por el barco, es un espacio masculino y de trabajo, de identificación personal, de "sacrificio" en el que hay que "aguantar" pero donde también es plausible disfrutar. Comporta una distancia material y simbólica con el espacio de tierra. La inmensidad, los peligros, la soledad, la posibilidad de no volver. Los lazos con la tripulación, la cohesión familiar en el trabajo. Aunque en tierra, el trabajo del barco, su mantenimiento y administración es entendido por los pescadores de Puerto Quequén como un trabajo de mar. La tierra: el espacio de la casa, el hogar, familia nuclear y extensa, amistades, es un espacio genéricamente mixto. En el hogar, la responsabilidad doméstica es primordialmente femenina pero el varón no se desentiende y mantiene la legitimidad de su rol como proveedor de ingresos económico. Cuando los pescadores aluden a tierra, se refieren al hogar, pero también a los trabajos en tierra, aquellos que no están vinculados con la actividad pesquera, o aquellos vinculados con la 
actividad, pero no embarcados. Así, la comercialización y el procesamiento del pescado son considerados una actividad de tierra. La banquina: un espacio masculino, de trabajo y sociabilidad. En la proximidad del río, mar y tierra, es un límite, un borde, un lugar de encuentro. Se da la estiba, se arregla el barco y las redes, se comparte con los tripulantes de diferentes barcos, se consigue trabajo. Es un borde, un espacio de trabajo y sociabilidad. Se comparte con otros trabajadores no pescadores: estibadores, personal de Prefectura, visitantes. No es excluyente de las mujeres, aunque no es habitual que las esposas de los pescadores circulen por este ella salvo en contadas ocasiones, por ejemplo, para la fiesta de los pescadores.

Hemos intentado en estas páginas sintetizar nuestro análisis sobre las particularidades de la apropiación material y simbólica del medio marino por parte de los pescadores costeros de Puerto Quequén.

\section{Reflexiones finales}

Construir el lugar de la analista en ciencias sociales siempre es un desafío que se resuelve en la práctica misma de la investigación y en la posterior elaboración de los resultados. Ponderar el lugar de ser mujer al entrevistar a hombres adultos, implica problematizar o intuir qué elementos se abrieron y cuáles se cerraron como temas a tratar. Las mujeres fueron entrevistadas en el ámbito doméstico, y esto pareciera ser menos susceptible de necesitar ser problematizado.

Otra cuestión que queremos resaltar es el haber realizado entrevistas desde un enfoque biográfico (Bertaux, 1993), ya que esta perspectiva nos permitió acceder a las trayectorias laborales y de vida para el período temporal definido y obtener discursos para adentrarnos en el análisis de las representaciones sociales. Pero, además, contribuyó a que cada entrevista tuviera su propio tono. La particularidad que cobró cada entrevista consideramos estuvo influenciada, también, por al ámbito de su realización. Una entrevista en el hogar con niños presentes, en banquina, en la embarcación, en un bar, implicaron diferentes posibilidades de apertura. En varios de los encuentros se generó una confianza traducible en desahogo, en ser escuchadas y escuchados en algo nunca preguntado, pocas veces reflexionado (con otra, con una "extraña"). En algunas situaciones la entrevista dio la oportunidad y condujo a el/la entrevistada a realizar un balance de vida y la charla se tornó emotiva. 


\section{Posibles nuevas vías de indagación}

La actividad pesquera costera es, para el período estudiado, un espacio materialmente masculino en el barco y mayormente en la banquina. Profundos cambios sociales indican que cada vez más la mujer comparte y compartirá los espacios de trabajo históricamente considerados como exclusivamente masculinos. En ese sentido, la incorporación de la mujer en el espacio marítimo pesquero supondrá una reestructuración del sistema simbólico tradicional que abre nuevas vías de indagación sobre cómo se reelaborará el sistema simbólico que contrapone tierra/doméstico/femenino y mar/laboral/masculino.

En los años subsiguientes al período estudiado se intensificó la concentración de las capturas en los barcos de altura en detrimento de la pesca costera y se intensificó el desmantelamiento de la flota costera de Puerto Quequén. En este contexto resultaría relevante continuar con el análisis de las trayectorias de los pescadores en cuanto a si se insertaron en la pesca de altura desde otro puerto o se establecieron en actividades en tierra.

Posteriormente a la salida de la convertibilidad, la pesca se volvió una actividad redituable en virtud de su cotización en el mercado internacional. Esto generó que se establecieran nuevos agentes que trabajan obteniendo recursos del mar como alternativa laboral. Para ello salen embarcados al mar desde la línea de costa usando una flota denominada "artesanal" que consiste en gomones o embarcaciones semirrígidas habilitadas para la pesca deportiva. Se abre así la posible indagación de establecer el desarrollo de esta actividad en relación con la pesca costera y de altura; el acompañamiento en el desarrollo de legislación y formas de control, la posible emergencia de conflictos con los pescadores costeros y el análisis de quiénes son y qué características sociodemográficas tienen los agentes que se incorporan a desempeñar esta actividad. 


\section{Referencias bibliográficas}

Acheson, J. (1981). Anthropology of fishing. Annual Review of Anthropology, 10: 275-316.

Adomilli, G. L. D’Ambrosio, G. Carreño \& F. de Souza Miller (coords.). (2012). Povos e coletivos pesqueros. Estudos etnográficos e perspectivas socioantropologicas sobre o viver e o trabalhar. Rio Grande: Editora FURG.

Aguirre Munizaga, C. A. \& M. O. Moya. (2014). La vida en un lance: el trabajo de pescador industrial en el norte de Chile. Interciencia, 39 (7): 483-489.

Aguirre Munizaga, C., A. Díaz Araya \& C. Mondaca Rojas. (2014). De pescador artesanal a tripulante pesquero. Pesca industrial y transformaciones sociales en Tarapacá. Norte de Chile (1950-1990). Intersecciones en Antropología, 15: 177-185.

Albano, D. (coord.). (2014). Estudio acerca del impacto de la aplicación del programa Más Vida. Informe final. Consejo Federal de Inversiones, Provincia de Buenos Aires. http://biblioteca.cfi.org.ar/wp-content/uploads/sites/2/2015/03/50173.pdf (consultado 17 noviembre 2018).

Alberti, A. V. (2015). Migraciones temporarias, ciclos laborales y estrategias de reproducción social: El caso de las unidades domésticas del área rural de Bernardo de Irigoyen (Misiones, Argentina). Mundo Agrario, 16 (33).

Alcalá Moya, G. (1985). Los pescadores de Tecolutla. El tiempo cotidiano y el espacio doméstico en una villa de pescadores. Serie Los Pescadores de México, vol. 10. México: Centro de Investigaciones y Estudios Superiores en Antropología Social.

Alcalá Moya, G. (2003). La pesca: ¿actividad de hombres y de mujeres?. Estudios del Hombre, 17: $163-184$.

Alcalá Moya, G. (ed.). (2011). Pescadores en América Latina y el Caribe: Espacio, Población, Producción y Política. Vol. I. México: Facultad de Ciencias de la Universidad Nacional Autónoma de México.

Alegret, J. L. (1987). Els armalladers de Palamós: una aproximació a la flota artesana des de l'antropologia marítima. Girona: Diputació de Girona.

Alegret, J. L. (1989). La antropología marítima como campo de investigación de la antropología social. Agricultura y Sociedad, 52: 119-142. 
Allega, L. (2012). Cambios recientes en la pesca costera con red de cerco en el puerto de Mar del Plata. Tesina de Licenciatura en Geografía, Facultad de Humanidades, Universidad Nacional de Mar del Plata.

Allen, A. (1999). Sustentabilidad productiva: ajuste político-económico estructural y efectos ambientales. El caso de la industria pesquera marplatense. En: Territorio, sociedad y desarrollo sustentable. Estudios de sustentabilidad ambiental urbana (pp. 117-131). Buenos Aires: Editorial Espacio.

Alonso, L. E. (1998). La mirada cualitativa en Sociología. Madrid: Editorial Fundamentos.

Alonso, L. N. (2015). La crisis pesquera de la flota de lanchas amarillas del puerto de Mar del Plata: una mirada hacia las instituciones. Cuadernos de Antropología, 13: 46-64.

Amato Uriburu, B. A. (2014). Conflictos socioambientales. Una experiencia de gestión comunitaria de recursos naturales. Cuadernos de Antropología, 11: 57-68.

Andersen, R. \& C. Wadel (eds.). 1972. North Atlantic Fishermen. Anthropological Essays on Modem Fishing. St. John's: Institute of Social and Economic Research, Memorial University.

Araya Umaña, S. (2002). Las Representaciones sociales: Ejes teóricos para su discusión. Costa Rica: FLACSO.

Archeti, E. (2003). Masculinidades. Fútbol, tango y polo en la Argentina. Buenos Aires: Editorial Antropofagia.

Arfuch, L. (2002). Problemáticas de la identidad. En: L. Arfuch (comp.). Identidad, sujeto y subjetividades (pp. 21-44). Buenos Aires: Prometeo.

Ariño, M. (2007) Familias tradicionales, nuevas familias. En: Población y Bienestar en la Argentina del primero al segundo Centenario. S. Torrado (comp.). Buenos Aires: Editorial Edhasa.

Attademo, S. (1999). El trabajo hortícola y la situación de la mujer en el Gran La Plata. En Sautu, R., Di Virgilio, M. M., \& Ojeda, G. (comps.). Mujer, trabajo y pobreza en la Argentina (pp. 163-170). Editorial de la Universidad Nacional de La Plata

Azcarate, L. (2009). Restructuración productiva y estrategias empresariales en el sector pesquero argentino, a fines del siglo XX. En: XII Jornadas Interescuelas/Departamentos de Historia. Departamento de Historia, Facultad de Humanidades y Centro Regional Universitario Bariloche. Universidad Nacional del Comahue, San Carlos de Bariloche.

Badinter, E. (1993). XY, la identidad masculina. Bogotá: Grupo Editorial Norma.

Balandier, G. (1975). Antropo-lógicas. Madrid: Editorial Península. 
Balbi, F. A. (1990). Desarrollo y reproducción de una forma de producción no empresarial: el caso de los pescadores del área del Paraná entrerriano. Cuadernos de Antropología Social, 2: 66-94.

Balbi, F. A. (1995). Las paradojas de la regularidad. Algunas consideraciones en torno al papel de los intermediarios en el proceso productivo pesquero del área del Delta entrerriano. En: Hugo Trinchero (ed.), Producción doméstica y capital. Estudios desde la antropología económica (pp. 139-170). Buenos Aires: Biblos.

Balbi, F. A. (2000). Interdependencia, memoria institucional y valores morales: fundamentos sociales de la moralidad en una cooperativa de pescadores entrerrianos". Avá. Revista de Antropología Social, 2: 95-111.

Balbi, F. A. (2007a). Usos de nociones ambientalistas en las vísperas de un proceso de sobrepesca: el caso de los pescadores comerciales del Delta del río Paraná (Entre Ríos, Argentina) en la segunda mitad de la década de 1980. Revista Estudios Sociales Comparativos, 1: 89-114.

Balbi, F. A. (2007b). Entre el futuro del recurso y el futuro de los hijos. Usos de términos y expresiones ambientalistas entre los pescadores del Delta del río Paraná. Cuadernos de Antropología Social, 26: 87-105.

Banton, M. (comp.). (1980). Antropología social de las sociedades complejas. Madrid: Alianza.

Barnes, J. (1954). Class and committees in a Norwegian Islan Parish. Human Relations, 7 (1): 39-58. (traducción de J. Mateo).

Barth, F. (1966). Models of social organization. London: Royal Anthropological Institute of Great Britain and Ireland.

Barth, F. (1976). Introducción. En: Barth, F. (comp.). Los grupos étnicos y sus fronteras. La organización social de las diferencias culturales (pp. 9-49). México: Fondo de Cultura Económica.

Basualdo, E., \& E. Arceo. (2006). Neoliberalismo y sectores dominantes. Tendencias globales y experiencias nacionales. Buenos Aires: CLACSO.

Benencia, R. (1994). La horticultura bonaerense: lógicas productivas y cambios en el mercado de trabajo. Desarrollo Económico, 34 (133): 53-73.

Benencia, R. \& F. Forni. (1986). Los procesos de transformación de las migraciones temporarias en el contexto de una provincia productora de mano de obra. Santiago del Estero, Argentina. En: Se Fue a Volver, C. Reboratti (comp.) (pp. 421-457). México: PISPAL-CENEP.

Benencia, R. \& F. Forni. (1988). El proceso de diferenciación económica en comunidades de pesca artesanal en el área del Paraná Medio. Cuadernos de Antropología Social, Dossier Antropología Rural, 1: 67-78. 
Berger, P. \& Luckman, T. (1994). La construcción social de la realidad. Buenos Aires: Amorrortu.

Berger, E. M. \& G. S. Neiman. (2016). Migrar para trabajar. Condicionantes de la inserción laboral de los trabajadores agrícolas temporarios en la Provincia de Mendoza, Argentina. Revista Latinoamericana de Estudios del Trabajo, 20(33): 161-186.

Bertaux, D. (1993). La perspectiva biográfica: validez metodológica y potencialidades. En: J. M. Marinas \& C. Santamarina (eds.). La historia oral: métodos y experiencias (pp. 149172). Madrid: Debate.

Bertolotti, M. I. (2001). Algunas consideraciones preliminares sobre el estado del sector pesquero. Informe Técnico $\mathrm{N}^{\circ} 71$. Buenos Aires: INIDEP.

Bertolotti, M. I. \& J. F. Gil Muro. (1991). La provincia de Buenos Aires y su participación en el sector pesquero argentino. Frente Marítimo, 8 (B): 119-125.

Bertolotti, M. I., E. Errazti, P. Gualdoni \& A. Pagani. (2008). Principios de política y economía pesquera. Buenos Aires: Dunken

Bertolotti, M. I., G. A. Verazay \& R. Akselman. (2001). El mar Argentino y sus recursos pesqueros. Tomo III. Flota pesquera argentina. Evolución durante el período 19601998. Mar del Plata, Instituto Nacional de Desarrollo Pesquero.

Bertolotti, M. I., G. A. Verazay, E. Errazti, A. N. Pagani \& J. J. Buono. (2001). Flota pesquera argentina. Evolución durante el periodo 1960-1998, con una actualización al 2000. En: El Mar Argentino y sus recursos pesqueros. Tomo 3. Evolución de la flota pesquera argentina, artes de pesca y dispositivos selectivos, M. I. Bertolotti, G. A. Verazay \& A. Akselman (eds.). Mar del Plata: Instituto Nacional de Investigación y Desarrollo Pesquero (INIDEP).

Bertolotti, M. I., W. M. D’Atri, A. Pagani \& M. Casanelli. (2017). Evolución de la flota pesquera argentina 1960-2015). Primera parte. Informe de Investigación. N 96. INIDEP.

Bidaseca, K. (2002). Nómades sin tierra. De hombres y mujeres poblando León Rougés en tiempos de zafra y migraciones. Tesis de Maestría, Facultad de Ciencias Sociales, Universidad de Buenos Aires.

Bird, J. H. (1963). The major seaports of the United Kingdom. Londres: Hutchinson \& CO.

Blehr, 0. (1963). Action groups in a society with bilateral kinship: a case study from the Faroe Islands. Ethnology 2: 269-275.

Boas, F. (1910). Kwakiutl Tales. New York: Columbia University Press.

Boas, F. (1964). The central Eskimo. Lincoln: University of Nebraska Press.

Boissevain, J., J. B. Aceves, J. Beckett, S. Brandes, T. Crump, J. Davis, D. D. Gilmore, C. C. M. Griffin, V. Padiglione, J. Pitt-Rivers, D. Schönegger \& R. Wade. (1979). Towards a 
social anthropology of the Mediterranean (and Comments and Reply). Current Anthropology, 20(1): 81-93 y 405-410.

Bourdieu, P. (1988). La distinción. Buenos Aires: Taurus.

Bourdieu, P. (1990). Espacio social y génesis de las clases. En: P. Bourdieu (ed.). Sociología y cultura (pp. 281-310). México: Grijalbo.

Bourdieu, P. (1997). Razones prácticas, sobre la teoría de la acción. Barcelona: Editorial Anagrama.

Bourdieu, P. (2000). La dominación masculina. Barcelona, Editorial Anagrama.

Bourdieu, P. (2011). Las estrategias de Reproducción Social. Buenos Aires: Siglo XXI.

Bourdieu, P. \& L. Wacquant. (2008) [1992]. Una invitación a la sociología reflexiva. Buenos Aires: Siglo XXI.

Branz, J. (2015). Deporte y masculinidades entre sectores dominantes de la ciudad de La Plata. Estudio sobre identidades, género y clase. Tesis para Doctor en Comunicación, Universidad Nacional de La Plata, Facultad de Periodismo y Comunicación Social, La Plata.

Branz, J. (2017). Masculinidades y Ciencias Sociales: una relación (todavía) distante. Descentrada, 1(1): e006.

Breton, Y. D. (1981). L'Anthropologie sociale et les societés de pécheurs: reflexions sur le naissance d'un sous-champ disciplinaire. Anthropologie et Societés, 5 (1): 7-27.

Breton, F. (1990). El aprendizaje del oficio de pescador: saber y transmisión del saber entre los Pescadores de arrastre. Eres (Antropología), 2: 143-159.

Broeze, F. (2002). Containerization, the ultimate internalization of linner shipping. St. John's, Newfoundland, Canada: International Maritime Economic History Association.

Cañete, M. V. (2011). Instituciones y políticas públicas en la expansión pesquera de la Argentina, 1946-1976. Anuario del Centro de Estudios Económicos de la Empresa y el Desarrollo, 3: 207-252.

Cañete, V., F. Rispoli, L. Ruocco \& G. Yurkievich. (eds.) (2011). Los Puertos y su gente: pasado, presente y porvenir. La problemática portuaria desde las ciencias sociales. Mar del Plata: GESMar UNMdP - CONICET.

Cariola, C. (1992). La reproducción de los sectores populares urbanos: una propuesta metodológica. En: Cariola, C. (coord.). Sobrevivir en la pobreza: el fin de una ilusión. Caracas, Editorial Nueva Sociedad.

Carman, M. \& V. González Carman. (2016). La fragilidad de las especies: tensiones entre biólogos y pescadores artesanales en torno a la conservación marina. Etnográfica, 20 (2): 411-438. 
Casteel, R. W. \& G. J. Quimby (comps.). (1975). Maritime adaptations of the Pacific. Chicado: La Haya, Mouton-Aldine.

Castel, R. (1997). Las metamorfosis de la cuestión social. Una crónica del salariado. Buenos Aires: Editorial Paidós.

Castro, M. O. (1996). La Iglesia católica y la religiosidad popular de los italianos del "Mezzogiorno" en el Puerto de Mar del Plata entre las décadas de 1920 y 1940. Estudios Migratorios Latinoamericanos, 11 (34): 569-592.

Cóccaro, J. M. \& R. O. Agüero. (1998). El espacio geográfico: un marco de análisis. Reflexiones Geográficas. Revista de la Agrupación de Docentes Interuniversitarios de Geografía, 8: 79-86.

Cóccaro, J. M., J. le Bail, A. Boetto \& O. Gómez. (2002). La minería pesquera argentina. En: Reflexiones Geográficas. Revista de la Agrupación de Docentes Interuniversitarios de Geografía. Río Cuarto: Agrupación de Docentes Interuniversitarios de Geografía.

Collier, J., M. Z. Rosaldo \& S. Yanagisako. (1997). ¿Is There a Family? New Anthropological Views. En: Lancaster, R. N. \& M. di Leonardo (comps.). The Gender Sexuality Reader (pp. 71-81). Londres: Routledge.

Colombo, G. J. (2011a). De clasistas a burócratas: el devenir de una traición. Acerca de la construcción moral del enemigo político en un sindicato de la industria del pescado (Mar del Plata - Argentina, 1997-2007). Revista Colombiana de Antropología, 47 (1): 43-68.

Colombo, G. J. (2011b). Los vaivenes de una "revolución productiva". Los orígenes de la política pesquera de la administración Menem (1989-1991). En: Los puertos y su gente: Pasado, presente y porvenir. La problemática portuaria desde las ciencias sociales (pp. 33-42). V. Cañete, F. Rispoli, L. Ruocco \& G. Yurkievich (comps.). Mar del Plata: Ediciones GESMar, UNMdP, CONICET.

Colombo, G. J. (2014). De la revolución productiva a la crisis de la merluza: El conflicto social en la industria pesquera marplatense. Años 1989-2001. Tesis Doctoral, Facultad de Humanidades y Ciencias de la Educación, Universidad Nacional de La Plata.

Colombo, G. \& A. Nieto. (2006). Bases sociales y económicas de la protesta. La industria de la pesca en Mar del Plata. De la convertibilidad a la devaluación (1991-2002). En: Actas de las XX Jornadas de la Asociación de Historia Económica. Mar del Plata: Asociación de Historia Económica.

Comaroff, J. \& J. Comaroff. (1992). Ethnography and the Historical Imagination. Boulder: Westview Press. 
Connel, R. W. (1997). La organización social de la masculinidad. En: T. Vadés \& J. Olavarría (eds.). Masculinidad/es: poder y crisis (pp. 31-48). Santiago de Chile: Isis Internacional, FLACSO.

Contreras, G. N. (2008). En río revuelto ganancia de Pescador. El gremio marítimo y el peronismo: un estudio de la huelga de 1950. Revista de Estudios Marítimos y Sociales, $1(1): 45-56$.

Cordini, J. M. (1960). La pesca en el Mar Argentino. Primera parte - Pesca costera. Buenos Aires: Dirección General de Pesca y Conservación de la Fauna.

Costa, A. M., S. S. Brieva \& L. Iriarte. (2006). Nueva institucionalidad en el sistema portuario argentino: vinculación público/privada en la organización y gestión del puerto Quequén. Economía, Sociedad y Territorio, V (20): 753-779.

Cova, R. O. (1966). Pedro Luro un pionero de la Pampa. Notas para un estudio histórico sobre la vida de Pedro Luro y la evolución de Mar del Plata. Mar del Plata: Municipalidad de General Pueyrredón.

Cruz Neto, O. (2004). El trabajo de campo como descubrimiento y creación. En: de Souza Minayo, M. C. (org.). Investigación Social. Teoría, método y creatividad (pp. 41-52). Buenos Aires: Editorial Lugar.

Cutuli, R. (2010). Trabajadores/as de la industria pesquera procesadora: conserva y fileteado en el puerto de Mar del Plata. En: L. A. Aguirre, A. Andreoni, R. M. Armendariz \& M. Arocena (eds.). Concurso bicentenario de la patria. El estado de la clase trabajadora en la provincia de Buenos Aires. La Plata: Ministerio de Trabajo de la Provincia de Buenos Aires.

D’Ambrosio, L., V. Lembo, B. Amato Uriburu y D. Thompson. (2010). El mundo sumergido: una investigación antropológica sobre la pesquería del mejillón en Piriapolis y Punta del Este. Montevideo: Facultad de Humanidades y Ciencias de la Educación. Departamento de Publicaciones.

Davis, J. (1983). Antropología de las sociedades mediterráneas. Anagrama: Barcelona.

Defensor del Pueblo de la Nación. (2011). Implicancias ecológicas, sociales y económicas de la pesca no sustentable en el Mar Argentino: El caso de la Merluza. https://farn.org.ar/wp-content/uploads/2012/07/informe merluza ago2011.pdf

Deslandes, S. F. (2004). Capitulo II. La construcción del proyecto de investigación. En: de Souza Minayo, M. C. (org.). Investigación Social. Teoría, método y creatividad (pp. 2539). Buenos Aires: Editorial Lugar.

de Souza Minayo, M. C. (2004a). Ciencia, técnica y arte: el desafío de la investigación social. En: de Souza Minayo, M. C. (org.). Investigación Social. Teoría, método y creatividad. Buenos Aires: Editorial Lugar. 
de Souza Minayo, M. C. (2004b). El desafío del conocimiento. Investigación cualitativa en Salud. Buenos Aires: Editorial Lugar.

Díaz Llanos, N. (2011). Historias de Varaduras y Naufragios en el área de influencia del Puerto Quequén. Mar del Plata: Gráfica Altamirano.

Dirección Provincial de Estadística. (2004). Medición de la economía provincial Provincia de Buenos Aires y sus municipios (1993-2004). http://www.estadistica.ec.gba.gov.ar/dpe/images/headers/pdfs/informetotalpbg. pdf

Domínguez Roca, L. J. (2006). Contenedores y Turistas: reflexiones sobre la relación entre ciudad y puerto a inicios del Siglo XXI. Revista Geografía, Espacio y Sociedad, 1 (1).

Donato Laborde, M. G. (2009). Representaciones del Puerto de Quequén a partir de su privatización y sus principales transformaciones territoriales. Geograficando, 5(5): 83-102.

Durham, E. R. (1998). Familia y reproducción humana. En: M. R. Neufeld, M. A. Grimberg, S. Tiscornia \& S. Wallace. Antropología social y política. Hegemonía y poder: El mundo en movimiento (59-84). Buenos Aires: Eudeba.

Elías, N. (1989). Sobre el tiempo. Buenos Aires: Fondo de Cultura Económica.

Espíndola, A. (2002). Diccionario del Lunfardo. Buenos Aires: Editorial Planeta.

Eraso M. M. (2009). Puerto y Territorio: análisis de lo global y debate de lo local. Revista de Estudios Marítimos y Sociales, 2 (2): 125-134.

Errazti. E. \& M. I. Bertolotti. (1998). Flota costera: descripción de las principales características en la región bonaerense. Frente Marítimo, 17 (B): 63-70.

Errazti, E., M. I. Bertolotti \& A. Pagani. (1998). Indicadores para el análisis socioeconómico de la actividad pesquera: un estudio socioeconómico del pescador costero de la región bonaerense. Frente Marítimo, 17 (B): 71-80.

Falquet, J. (2017). La combinatoria straight: Raza, clase, sexo y economía política: análisis feministas materialistas y decoloniales. Descentrada. Revista Interdisciplinaria de Feminismos y Género, 1 (1).

FAO. (1976). El estado mundial de la agricultura y la alimentación 1975. Análisis Mundial Análisis Mundial Segundo Decenio de las Naciones Unidas para el Desarrollo: Análisis a plazo medio y evaluación. Colección FAO: Agricultura № 1. Roma: Organización de las Naciones Unidas para la Agricultura y la Alimentación. http://www.fao.org/3/h3100s/h3100s.pdf

FAO. (1979). El estado mundial de la agricultura y la alimentación 1978. Análisis Mundial Problemas y Estrategias en las Regiones en Desarrollo. Colección FAO: Agricultura № 
9. Roma: Organización de las Naciones Unidas para la Agricultura y la Alimentación. http://www.fao.org/3/ap658s/ap658s.pdf

FAO. (1990). Definición y clasificación de las diversas categorías de artes de pesca. FAO Documento Técnico de Pesca N²22. Roma: Organización de las Naciones Unidas para la Agricultura y la Alimentación. http://www.fao.org/3/a-t0367t.pdf

FAO. (1999). Taller sobre comercialización de los productos pesqueros en América Latina. FAO Informe de Pesca $\mathrm{N}^{\circ}$ 603. Santiago de Chile: Organización de las Naciones Unidas para la Agricultura y la Alimentación. http://www.fao.org/tempref/docrep/fao/007/ae324s/ae324s00.pdf

FAO. (1993). El estado mundial de la agricultura y la alimentación 1993 . Las políticas de recursos hídricos y la agricultura. Colección FAO: Agricultura № 26. Roma: Organización de las Naciones Unidas para la Agricultura y la Alimentación. http://www.fao.org/3/a-t0800s.pdf

FAO. (2018). El estado mundial de la pesca y la acuicultura 2018. Cumplir los objetivos de desarrollo sostenible. Roma: Organización de las Naciones Unidas para la Agricultura y la Alimentación. http://www.fao.org/3/I9540ES/i9540es.pdf

FAO. (2019). Capture fisheries production measures the volume of fish catches landed by a country for all commercial, industrial, recreational and subsistence purposes. https://datos.bancomundial.org/indicador/ER.FSH.CAPT.MT.

Faris, J. (1977). Primitive accumulation in small scale fishing communities. En: Smith, M. E. (comp.). Those who Live from the Sea: a study in Maritime Anthropology (pp. 235251). Saint Paul: West Pub. Co.

Federici, S. (2010). Calibán y la bruja. Mujeres, cuerpo y acumulación originaria. Madrid: Traficantes de sueños.

Fermepin, R. R. (2000). Glosario de términos y abreviaturas de pesca marítima. Análisis de la Ley № 24.922 Régimen Federal de Pesca y su reglamentación. Buenos Aires: Servicio de Hidrografía Naval de la Armada Argentina.

Fermepin, R. R. \& J. P. Villemur. (2004). 155 años de la pesca en el mar argentino (1921-1975). Buenos Aires: Instituto de Publicaciones Navales.

Fernández de Rota Monter, J. A. (1987). Gallegos ante un espejo. Imaginación antropológica en la Historia. La Coruña: Ediciós do Castro. La Coruña

Ferreiro, L. A. (2018). Determinación de la Inversión Inicial Máxima para la Reconstrucción del Puente Ezcurra. Tesis de Grado para la Licenciatura en Logística Integral, Sede Quequén, Universidad Nacional del Centro de la Provincia de Buenos Aires. https://www.ridaa.unicen.edu.ar/xmlui/handle/123456789/1851 
Ferrero, B. G. \& N. G. Arizpe Ramos. (2015). Pescadores artesanales del bajo Paraná argentino: entre la complejidad y la tragedia de los comunes. Avá. Revista de Antropología Social, 15 (1): 177-185.

Firth, R. (1975). Malay Fishermen: their peasant economy. Nueva York: New York Norton.

Fortes, M. (1958). Introduction. En: Goody, J. (ed.). The development Cycle in Domestic Groups (pp. 1-114). Cambridge: The Syndics of the Cambridge University Press.

Fuller, N. (2008). No uno sino muchos rostros. Identidad masculina en el Perú urbano. En: M. Viveros Vigoya, J. Olavarria \& N. Fuller. Hombres e identidades de género. Investigaciones desde América Latina (pp. 267-370). Bogotá: CES. Universidad Nacional de Colombia.

Gambina, J. (2007). La economía argentina entre 1996-2006. Periferias. Revista de Ciencias Sociales, 14(1) 11-34.

García, M. C. \& M. C. Piccolo. (2006). Las precipitaciones en el sudeste bonaerense (comportamiento temporal y espacial en los dos últimos decenios. En: VIo Jornadas Nacionales de Geografía Física. Río Gallegos, pp. 154-164.

García Canclini, N. (1984). Ideología y Cultura. Buenos Aires: Facultad de Filosofía y Letras, Universidad de Buenos Aires.

Garriga Zucal, J. (2013). Géneros en acción. Prácticas y representaciones de la masculinidad y la femineidad entre policías bonaerenses. Intersecciones en Antropología, 14(1)

Garriga Zucal, J. (2018). Masculinidades, pruebas y violencias. En: Panel Masculinidades. Universidad Nacional de San Martín, San Martín.

Geertz, C. (1973). La interpretación de las culturas. Barcelona: Editorial Gedisa.

Ghasarian, C. (2008). De la antropología a la antropología reflexiva. Nuevos campos, nuevas prácticas, nuevas apuestas. Buenos Aires: Ediciones del Sol.

Giardino, G., M. Mandiola, R. Bastida \& D. Rodríguez. (2009). Movimientos estivales de machos de Otaria flavescens entre Puerto Quequén (Argentina), Uruguay y Patagonia. En Proceedings of the workshop Estado de situación del lobo marino común en su área de distribución. p. 35.

Giddens. A. (1995). La Constitución de la sociedad. Bases para la teoría de la estructuración. Buenos Aires: Editorial Amorrortu.

Gilmore D. D. (1982). Anthropology of the Mediterranean Area. Annual Review of Anthropology, 11: 175-205.

Giménez, G. (2005). La concepción simbólica de la cultura. En: Teoría y análisis de la cultura. Tomo 1. México: CONACULTA- ICONOCULT.

Gómez Lende, S. (2015). La pesca marítima en Argentina (1989-2013): un caso de (neo)extractivismo y acumulación por desposesión. Revista Geográfica, 156: 53-96. 
Gómez Otero, J. (1996). Primera noticia sobre el hallazgo de un anzuelo de madera en Patagonia: sus implicancias en el contexto de la arqueología regional. En J. Gómez Otero (ed.). Arqueología: sólo Patagonia (pp. 59-68). Puerto Madryn: Centro Nacional Patagónico.

González de Bonaveri, M. I. 2005. Arqueología de alfareros, cazadores y pescadores pampeanos. Buenos Aires. Sociedad Argentina de Antropología, Buenos Aires.

González, S. S. (2013). Los puertos sobre playas de arenas móviles. El caso de los puertos de Mar del Plata y Quequén en los inicios del s. XX. En: Temas de patrimonio cultural No 30: Argentina de puertos: III Jornadas Red de Estudios Portuarios (pp. 341-359). M. Weissel (comp.). Buenos Aires: Comisión para la Preservación del Patrimonio Histórico-Cultural, Ministerio de Cultura, Gobierno de la Ciudad Autónoma de Buenos Aires

Goode, J. W. \& P. K. Hatt. (1990). Métodos de investigación social. México, Editorial Trillas.

Grassi, E. (1999). La familia: un objeto polémico. Cambios en la dinámica de la vida familiar y cambios de orden social. En: M. R. Neufeld, M. A. Grimberg, S. Tiscornia \& S. Wallace. Antropología social y política. Hegemonía y poder: El mundo en movimiento (pp. 95-119). Buenos Aires: Eudeba.

Gravano, A., A. Silva \& S. Boggi. (2016). Introducción. En: Ciudades vividas: sistemas e imaginarios de ciudades medias bonaerenses (pp. 15-21). Buenos Aires: Editorial Café de las ciudades.

Guber, R. (2004). El salvaje metropolitano. Buenos Aires: Editorial Paidos.

Gutmann, M. C. (1999). Traficando con hombres: la antropología de la masculinidad. Horizontes Antropológicos, 5 (10): 245-286.

Halperín Donghi, T. (1963). La expansión Ganadera en la campaña de Buenos Aires (18101852). Desarrollo Económico, 3(1-2), 57-110.

Haraway, D. (2004). Situated Knowledge's: The Science Question in Feminism and the Privilege of Partial Perspective. En: S. Harding (org.). The Feminist Standpoint Theory Reader: Intellectual and Political Controversies (pp. 103-127). London: Routledge.

Hardin, G. (1968). The Tragedy of the Commons. Science, 162 (3859): 1243-1248.

Harding, S. (2004). Introduction: Standpoint Theory as a Site of Political, Philosophic, and Scientific Debate. En: S. Harding (org.). The Feminist Standpoint Theory Reader: Intellectual and Political Controversies (pp. 1-16). London: Routledge.

Harding, S. (2008). Sciences from Below: Feminisms, Postcolonialities, and Modernities. Durham: Duke University Press. 
Herzfeld, M. (1984). The Horns of the Mediterraneanist Dilemma. American Ethnologist, 11(3): 439-454.Herzfeld M. (1985). The poetics of manhood. Princeton: Princeton University Press.

Holm, P. (1998). The Global Fish Market, 1850-1995. En: G. Harlaftis \& D. J. Starkey (Eds.), Global markets: the internationalisation of the sea transport industries since 1850 (pp. 239-258). Madrid: Fundación Fomento de la Historia Económica.

INDEC. (1984). La pobreza en la Argentina. Serie Estudios INDEC, № 1, Buenos Aires.

INDEC. (2019). Definiciones distribución espacial y urbanización. http://www.estadistica.ec.gba.gov.ar/dpe/index.php/poblacion/distribucionespacial-y-urbanizacion/180-definiciones-distribucion-espacial-yurbanizacion/233-definiciones-distribucion-espacial-y-urbanizacion

Isla, F., G. Bértola, A. Merlotto, A. Ferrante \& L. Cortizo. (2009). Requerimientos y disponibilidad de arenas para la defensa de las playas de Necochea y Lobería. Revista de la Asociación Geológica Argentina, 65 (3):446-456.

Jahoda, M. (1994). Empleo y desempleo: un análisis socio-psicológico. Buenos Aires: Editorial Morata.

Jelin, E. (1984). Familia y unidad doméstica: mundo público y vida privada. Buenos Aires Estudios del CEDES.

Kelleher, K. (2008). Descartes en la pesca de captura marina mundial Una actualización. FAO Documento Técnico de Pesca $\mathrm{N}^{\circ}$ 470. Roma: FAO. http://www.fao.org/3/y5936s/y5936s00.htm

Kroeber, A. L. \& S. A. Barret. (1960). Fishing among the indians of northwestern California. Berkeley: University of California Press.

Krotz, E. (1994). Alteridad y pregunta antropológica. Alteridades, 4 (8): 5-11.

Lagos, A. N. (2001). Características de la pesca artesanal en el Partido de la Costa (Cabo San Antonio) y perfil socioeconómico de la actividad. Tesis de Grado para la Licenciatura en Ciencias Biológicas, Facultad de Ciencias Exactas y Naturales, Universidad Nacional de Mar del Plata.

Lahille, F. (1895). Notas sobre la industria de la pesca en la Provincia de Buenos Aires (excursión de septiembre octubre 1895). Revista del Museo de La Plata, VII: 2-13.

Lahille, F. (1901). Estudio sistemático de los peces. Buenos Aires: Compañía Sudamericana.

Lasta, C. A., C. O. Ruarte y C. R. Carozza. (2001). Flota costera argentina: antecedentes y situación actual (pp. 89-106). En: El Mar Argentino y sus recursos pesqueros. Tomo 3. Evolución de la flota pesquera argentina, artes de pesca y dispositivos selectivos, M. I. Bertolotti, G. A. Verazay y A. Akselman (eds.). Mar del Plata: Instituto Nacional de Investigación y Desarrollo Pesquero (INIDEP). 
Laubé, S. (2014). Les grues de l'arsenal en tant que marqueurs de l'évolution scientifique et technologique du port arsenal de Brest. En: J. L. Kerouanton \& S. Laubé (eds.). Le port: nouveaux problèmes pour l'histoire des sciences et techniques. Paris: Hermann.

Lázzaro, S. B. (1992). Estado, capital extranjero y sistema portuario argentino 1 (1880-1914). Buenos Aires: Centro editor de América Latina S.A.

Levi-Strauss, C. (1970). Las estructuras elementales del parentesco. Buenos Aires: Editorial Paidós.

Lindón, A. (2012). La concurrencia de lo espacial y lo social. En: E. Garza \& G. Leyva (Eds.). Tratado de metodología de las ciencias sociales: perspectivas actuales (pp. 588-622). México: FCE,UAM - Iztapalapa.

Llovera J. R. (1990). El mediterráneo ¿área cultural o espejismo antropológico? En: J. R. Llobera (ed.), La identidad de la Antropología (pp. 77-108). Barcelona: Anagrama.

Longino, H. (1990). Science as social knowledge: Values and Objectivity in Scientific Inquiry. Princeton: Princeton University Press.

Madaria, E. (1999). El sector pesquero argentino. Informe General (Preliminar II). Programa de Investigación Geográfico Político Patagónico. Escuela de Ciencias Políticas. Universidad Católica Argentina.

Malinowski, B. M. (1948). Los argonautas del pacífico occidental. Tomos I y II. Buenos Aires: Planeta Agostini.

Malleville, S. (2018). Mujeres de la industria pesquera. El trabajo en Engrau-coop, una fábrica recuperada por sus trabajadoras y trabajadores en Quequén, Buenos Aires, Argentina. Revista Latinoamericana de Antropología del Trabajo, 4 (2): 1-10.

Martínez Martín, C. (1994). Las reducciones de los pampas (1740-53): aportaciones etnogeográficas al sur de Buenos Aires. Complutum, 20: 145-167.

Marx, K. (1980). Contribución a la crítica de la economía política. México: Siglo XXI.

Masid, M. (2003). Los pescadores flamencos de Mar del Plata, la persistencia de antiguas redes en un nuevo asentamiento. Revista Nexos, 10 (17): 16-22.

Masid, M. (2004). Redes flamencas en Mar del Plata: una aventura que comienza en Nieuwpoort (1950-1960). Estudios Migratorios Latinoamericanos, 18 (54): 303-338.

Masid, M. (2005). La expansión del sector pesquero: el proceso de integración en el mercado exportador (1960-1980). En: X Jornadas Interescuelas/Departamentos de Historia. Rosario: Escuela de Historia de la Facultad de Humanidades y Artes, Universidad Nacional del Rosario y Departamento de Historia de la Facultad de Ciencias de la Educación, Universidad Nacional del Litoral.

Masid, M. \& J. A. Mateo (2008). De la sustitución a la exportación. El sector pesquero argentino entre 1930 y 1965. Revista de Estudios Marítimos y Sociales, 1(1): 71-81. 
Mateo, J. A. (2003). De espaldas al mar: la pesca en el Atlántico sur (siglos XIX y XX). Universitat Pompeu Fabra, tesis doctoral (mimeo), Barcelona.

Mateo, J. A. (2004a). Gente que vive del mar: La génesis y el desarrollo de una sociedad marítima y una comunidad pescadora. Prohistoria, 8, 59-86.

Mateo, J. A. (2004b). Cosechando el mar en lanchas amarillas. La expansión de la pesca costera marplatense (1939-1963). Anuario del Instituto de Estudios HistóricoSociales, 19: 305-335.

Mateo, J. A. (2004c). Separados por el mar, unidos por el mercado. En: XIX Jornadas de Historia Económica. San Martín de los Andes: Asociación Argentina de Historia Económica.

Mateo, J. A. (2005a). El periodo heroico de la pesca costera en Argentina (1940-1975). Cuadernos de Trabajo del Centro de Investigaciones Históricas, Serie Investigaciones, 9: 4-102.

Mateo, J. A. (2005b). El arte de vivir con fe. Pesca, religión y religiosidad en el Puerto de Mar del Plata (1920-1950). En: N. Álvarez, C. Rustoyburu \& G. Zuppa (eds.). Pasado y presente de la Mar del Plata social (171-183), Mar del Plata: EUDEM.

Mateo, J. A. (2006). Sembrando anzuelos para tiburones. Las demandas vitamínicas de la II Guerra Mundial y el desarrollo de la pesca comercial marítima en Argentina (19431952). Boletín del Instituto de Historia Argentina y Americana Dr. Emilio Ravignani, 29: 119-150.

Mateo, J. A. (2010). Un mar y tres fronteras para el desarrollo de la pesca en Argentina (1940-1975). En: Mateo, J. A. \& A. Nieto (eds.), Hablemos de puertos. La problemática portuaria desde las ciencias sociales (pp. 79-92). Mar del Plata: GESMar - Universidad Nacional de Mar del Plata.

Mateo, J. A. (2011a). Unidos por el mar, separados por el mercado. En: Pescadores en América Latina y el Caribe: situación y perspectivas. G. Alcalá \& A. Camargo (pp. 251316). México: Editorial de la UMDI de la Facultad de Ciencias de la Universidad Nacional Autónoma de México.

Mateo, J. A. (2011b). Un mar y tres fronteras para el desarrollo de la pesca en Argentina (1940-1975). En: Los puertos y su gente: Pasado, presente y porvenir. La problemática portuaria desde las ciencias sociales (pp. 79-91). V. Cañete, F. Rispoli, L. Ruocco \& G. Yurkievich (comps.). Mar del Plata: Ediciones GESMar, UNMdP, CONICET.

Mateo, J. A. (2011c). La comercialización primaria de la pesca costera marplatense (18801980. En: Temas de patrimonio cultural № 30: Argentina de puertos: III Jornadas Red de Estudios Portuarios (pp. 371-394). M. Weissel (comp.). Buenos Aires: Comisión 
para la Preservación del Patrimonio Histórico-Cultural, Ministerio de Cultura, Gobierno de la Ciudad Autónoma de Buenos Aires

Mateo, J. A. (2014a). El impacto de un nuevo puerto: la construcción de su hinterland y de su foreland. Puerto Quequén, provincia de Buenos Aires entre 1921 y 1932. Mundo Agrario, 15(29): 1-28.

Mateo, J. A. (2014b). Entre la crisis y un puerto nuevo: las exportaciones agrícolas de la región de Puerto Quequén durante la Gran Depresión (1929-1939). HiSTOReLo. Revista de Historia Regional y Local, 6 (11): 220-250.

Mateo, J. A. (2017). El granero ¿de dónde y de qué? De los granos de trigo al poroto de soja en Puerto Quequén (1970-2010). Revista Iberoamericana de Viticultura, Agroindustria y Ruralidad, 4 (12), 69-91.

Mateo, J., A. \& A. Correa. (2008). Hábitos sexuados en la ciudad puerto de Mar del Plata: mujeres y pescadores en los inicios del milenio. Historia Unisinos, 12(1), 34-48.

Mateo, J. A. \& A. Nieto (eds.). (2010). Hablemos de puertos. La problemática portuaria desde las ciencias sociales. Mar del Plata: GESMar-Universidad Nacional de Mar del Plata.

Mateo, J. A.; Nieto, A. y Colombo, G. (2010). Capítulo 10: Precarización y fraude laboral en la industria pesquera marplatense. El caso de las cooperativas de fileteado de pescado. Estado actual de la situación y evolución humana de la rama 1989-2010. En: L. A. Aguirre, A. Andreoni, R. M. Armendariz \& M. Arocena (eds.). Concurso Bicentenario de la Patria, Premio Juan Bialett Massé (págs. 177-203). Buenos Aires: Ministerio de Trabajo de la Provincia de Buenos Aires.

Mateo, J. A. \& M. F. Rispoli. (2015). Mil intentos y un puerto. De José Cardiel a Ángel Gardella: la boca del Quequén en las vísperas de su terminal portuaria. En: M. A. De Marco (comp.), M. B. Girardi \& J. P. Robledo (eds.), Acta de las 6tas. Jornadas Internacionales e Interdisciplinarias de Estudios Portuarios (pp. 79-94), Rosario: Nodo Instituto de Historia - Instituto de Estudios Históricos, Económicos, Sociales e Internacionales.

Meillassoux, C. (1977). Mujeres, graneros y capitales: economía doméstica y capitalismo. Madrid: Siglo Veintiuno.

Menéndez, E. L. (2010). La parte negada de la cultura. Relativismo, diferencias y racismos. Rosario: Prohistoria.

Merlotto, A. \& M. C. Piccolo. (2009). Tendencia climática de Necochea-Quequén (19562006), Argentina. Investigaciones Geográficas, 50: 143-167.

Merlotto, A.; M. C. Piccolo \& G. R. Bertola. (2012). Crecimiento urbano y cambios del uso/cobertura del suelo en las ciudades de Necochea y Quequén, Buenos Aires, Argentina. Revista de Geografía, Norte Grande; 53; 159-176. 
Montes del Castillo, A. (1999). Antropología de la pesca: Debates en el Mediterráneo. Murcia: Universidad de Murcia.

Moreno, I. (1991). Identidades y Rituales. En: J. Prat i Carós, I. Moreno Navarro, U. Martínez Veiga, J. Contreras (comp.), Antropología de los pueblos de España (pp. 601-636), Madrid: Editorial Taurus.

Narotzky, S. (2004). Antropología económica. Barcelona: Nuevas Tendencias.

Natali, J. (2014). Turismo Cultural: Puesta en valor del Ex Hotel Quequén y las Casonas aledañas. Tesina de Licenciatura en Turismo, Departamento de Geografía y Turismo, Universidad Nacional Del Sur, Bahía Blanca. http://repotur.yvera.gob.ar/handle/123456789/14310

Neufeld, S. \& M. R. Wallace. (1999). Antropología y Ciencias Sociales. De elaboraciones históricas, herencias no queridas y propuestas abiertas. En: M. R. Neufeld, M. A. Grimberg, S. Tiscornia \& S. Wallace. Antropología social y política. Hegemonía y poder: El mundo en movimiento (pp. 37-58). Buenos Aires: Eudeba.

Nieto, A. (2018). Entre anarquistas y peronistas. Historias obreras a ras del suelo. Buenos Aires: Imago Mundi y Ediciones CEHTI.

Noceti, M. B. (2014). Lecturas antropológicas en torno a la problemática ambiental en el humedal de Villa del Mar. En: XI Congreso Argentino de Antropología Social “Edgardo Garbulsky". Perspectivas críticas en Antropología Social Construcciones teóricas y prácticas desde América Latina. Escuela de Antropología y el Departamento de Antropología Sociocultural de la Facultad de Humanidades y Artes, Universidad Nacional de Rosario, Rosario.

Noceti, M. B. (2017). ¿Reserva, puerto o ría? Conflicto socio ambiental en el estuario de Bahía Blanca, Argentina. Etnografías Contemporáneas, 3 (4): 64-91.

Nogueira, J. L. (2003). Características de la flota pesquera de Puerto Quequén en el año 2002. Informe interno. Estación Hidrobiológica de Puerto Quequén.

Nogueira, M. L. (2018a). La(s) Fiesta(s) de los Pescadores en Necochea - Quequén. Convergencias y disonancias entre pasado y presente (Argentina, 1950-2015). Travesía, 20 (1): 57-77.

Nogueira, M. L. (2018b). Mar del Plata y Necochea: cara y ceca de la industria pesquera argentina tras la reestructuración capitalista (1970-2013). Revista de Estudios Marítimos y Sociales, 11(12): 127-159.

Nogueira, M. L. (2019a). Entre la precarización y la autogestión: estrategias laborales y subjetividades inherentes a las y los trabajadores de la industria pesquera de Mar del Plata y Necochea-Quequén, 1997-2012. Tesis Doctoral. La Plata, Facultad de Ciencias 
de Humanidades y Ciencias de la Educación, Universidad Nacional de La Plata. http://sedici.unlp.edu.ar/handle/10915/73749

Nogueira, M. L. (2019b). Entre la precariedad y la autogestión: reconfiguraciones en las subjetividades inherentes a los trabajadores de las empresas pesqueras recuperadas de Necochea y Quequén (Argentina). Trabajo y Sociedad, 32: 551-568.

Nogueira, M. L. (2019c). Lo que el viento se llevó: cambios en la actividad pesquera comercial marítima de Puerto Quequén tras la reestructuración capitalista (Argentina, 1970-2012). Coordenadas. Revista de Historia Regional, VI (1): 64-91.

Nuñez Sanchez, C. (2013). Relaciones puerto-ciudad y conflictos ambientales asociados, en el sistema urbano Necochea-Quequén. En: $1^{\circ}$ Jornada de Investigación en Formación (pp 199-205). Buenos Aires: FADU.

Oliver Sánchez-Fernández, J. (1992). Ecología y estrategias sociales de los pescadores de Cudillero. Madrid: Siglo XXI.

Ortiz, A. S. (2006). Río liberado. Emergentes culturales en el sistema ambiental Paraná Medio. Tesis de licenciatura en Antropología. Buenos Aires, Facultad de Filosofía y Letras, Universidad de Buenos Aires. http://repositorio.filo.uba.ar/handle/filodigital/1013

Otegui Pascual, R. (2009). El sufrimiento: la forma sociocultural del dolor. En: M. Grimberg (ed.). Experiencias y narrativas de padecimientos cotidianos: miradas antropológicas sobre la salud, la enfermedad y el dolor crónico (pp. 147-166). Buenos Aires: Aires: Editorial Antropofagia.

Palermo, H. M. (2016). Machos y brujas en la Patagonia. Trabajo, masculinidad y espacio de la reproducción. Antípodas Revista de Antropología y Arqueología, 25: 99-119.

Palermo, H. M. (2017). La producción de la masculinidad en el trabajo petrolero. Buenos Aires: Editorial Biblos.

Pascual Fernández, J. (1991a). Antropología marítima: historia, ecología, organización social y cambio económico entre los pescadores. Madrid: Ministerio de Agricultura, Pesca y Alimentación. Secretaría General Técnica.

Pascual Fernández, J. (1991b). Entre el mary la tierra: los pescadores artesanales de canarios. Madrid: Dirección General de Cooperación Cultural, Ministerio de Cultura Santa Cruz de Tenerife.

Pastoriza, E. (2008). El turismo social en la Argentina durante el primer peronismo. Mar del Plata, la conquista de las vacaciones y los nuevos rituales obreros, 1943-1955. Nuevo Mundo Mundos Nuevos, CERMA. Centre d'études et de recherches sur les mondes américains. Paris. 
Pérez Comesaña, J. E. \& J. L. Nogueira. (2013). Evolución de la pesca costera de arrastre de fondo en Puerto Quequén, provincia de Buenos Aires, Argentina: Periodo 19992010. Revista del Museo Argentino de Ciencias Naturales, Nueva Serie, 15 (2): 183190.

Peristiany, J. G. (ed.). (1968). El concepto del honor en la sociedad mediterránea. Madrid: Editorial Labor.

Perrot, D. \& R. Preiswerk. (1982). Etnocentrismo e Historia. América indígena, África y Asia en la visión distorsionada de la cultura occidental. México: Nueva Imagen.

Perrota, B. G. (2008). Procesos empresariales del sector pesquero argentino orientado a la explotación de la merluza común (Merluccius hubbsi). Expansión productiva y crisis de un recurso de propiedad común (1985-2001). Revista de Estudios Marítimos y Sociales, 1 (1): 137-139.

Perrota, B. G., C. Ruarte \& C. Carozza. (2007). La pesca costera en la Argentina. Ciencia Hoy, 17 (97): 167-177.

Peyrelongue, C. M. (1999). El puerto y la vinculación entre lo local y lo global. Revista Eure, XXV (75): 103-120.

Pili, N., E. Schinder, R. Rafagheli, L. Ricci, M. Vachino, C. Spillman, A. Petersen y S. Vergaral. (1993). Estudio epidemiológico del perfil de salud de pescadores de Mar del Plata, Argentina. Tabaquismo y alcoholismo. CM Publicación Médica, 7 (1): 2-10.

Pina Cabral, J. (1989). The Mediterranean as a Category of Regional Comparison: A Critical View. Current Anthropology, 30(3); 399-406.

Pitt-Rivers, J. (ed.). (1963). Mediterranean Countrymen: Essays in the Social Anthropology of the Mediterranean. Paris: Mouton \& Co.

Pitt Rivers, J. (1979). Antropología del honor o política de los sexos. Barcelona. Editorial Crítica.

Pradas, E. M. (2006). Un acercamiento a la problemática pesquera marplatense. Mar del Plata: Ediciones El Mensajero.

Presta, S. (2006). Transformaciones en el concepto de trabajo. En: A. Balazote, M. Ramos \& S. Valverde (eds.). La antropología y el estudio de la cultura (pp. 103-112). Fundamentos y antecedentes. Buenos Aires: Biblos.

Prol, L. (2008). El sector pesquero en la provincia de Santa Fe: resultados preliminares de investigación. En: IX Congreso Argentino de Antropología Social. Facultad de Humanidades y Ciencias Sociales - Universidad Nacional de Misiones, Posadas.

Prol, L. \& A. Ortíz. (2009). Nuevos mercados, regulaciones estatales y conflictos ambientales: la actividad pesquera en la región del Paraná Medio e Inferior. En: VIII Reunión de Antropología del Mercosur (RAM). Diversidad y poder en América Latina, Instituto de 
Altos Estudios Sociales (IDAES) y la Escuela de Humanidades de la Universidad Nacional de San Martín (UNSAM), Buenos Aires.

Prunier, D. (2011). Los impactos de la migración internacional en el campo nicaragüense. Las transformaciones de la organización productiva familiar. Trace (60), 54-68.

Przeworski, A. (1982). Teoría sociológica y el estudio de la población: reflexiones sobre el trabajo de la comisión de población y desarrollo de CLACSO. En: Reflexiones teórico metodológicas sobre las investigaciones en población. México: CLACSO-EI Colegio de México.

Quiroz Londoño, O. M., S. Grondona, H. Massone, M. Farenga, G. Martínez \& D. Martínez. (2013). Modelo de anegamiento y estrategia de predicción-prevención del riesgo de inundación en áreas de llanura: el sudeste de la provincia de Buenos Aires como caso de estudio. GeoFocus, 13(1): 76-98.

Rapoport, M. (2007). Historia económica, política y social de la Argentina (1880-2003). Buenos Aires: Emecé.

Rial, C. \& M. Godio (orgs.). (2006). Pesca e Turismo: Etnografias da Globalização no Litoral do Atlântico Sul. Florianópolis: NUPPE/CFH/UFSC.

Rispoli, M. (2003). Estrategias familiares de vida en hogares con jefes dedicados a la pesca. Una experiencia en Puerto Quequén. III Jornadas de Sociología de la UNLP. La Argentina de la crisis: Desigualdad social, movimientos sociales, política $e$ instituciones. Departamento de Sociología, Facultad de Humanidades y Ciencias de la Educación, Universidad Nacional de La Plata. http://www.memoria.fahce.unlp.edu.ar/trab eventos/ev.6984/ev.6984.pdf

Rispoli, M. F. (2005). Estrategias familiares de vida en hogares con jefes dedicados a la pesca. Una experiencia en Puerto Quequén. En: A. Cetti, A. Re, D. Rindel \& P. Valeri (coords.), Entre pasados y presentes. Trabajos de las VI Jornadas de Jóvenes Investigadores en Ciencias Antropológicas. Buenos Aires: Instituto Nacional de Antropología y Pensamiento Latinoamericano. CD-Rom.

Rispoli, M. F. (2006a). Los pescadores de Puerto Quequén durante la crisis del caladero del sur atlántico (1999/2001). XXJornadas de Historia Económica, Asociación Argentina de Historia Económica, Mar del Plata.

Rispoli, M. F. (2006b). Trabajar de pescador. Aportes desde la antropología marítima. En: 8vo Congreso Argentino de Antropología Social, Universidad Nacional de Salta, Salta. http://www.fcnym.unlp.edu.ar/catedras/mtiantropologica/Trabajar\%20de\%20p escador.pdf

Rispoli, M. F. (2009a). Elegir el mar. Experiencias de trabajadores de la pesca en Puerto Quequén. En: VIII Reunión de Antropología del Mercosur (RAM). Diversidad y poder 
en América Latina, Instituto de Altos Estudios Sociales (IDAES) y la Escuela de Humanidades de la Universidad Nacional de San Martín (UNSAM), Buenos Aires.

Rispoli, M. F. (2009b). Representaciones en torno al trabajo en el mar. En: Mateo, J. A. \& A. Nieto (eds.), Hablemos de puertos. La problemática portuaria desde las ciencias sociales (pp. 201-206). Mar del Plata: GESMar - Universidad Nacional de Mar del Plata.

Rispoli, M. F. (2011). Relaciones salariales no típicas en tiempos del ¿fin? del trabajo. El caso de los pescadores costeros y los horticultores. En: V. Cañete, M. F. Rispoli \& G. Yurkievich (eds.). Los puertos y su gente: pasado, presente y porvenir. La problemática portuaria desde las ciencias sociales (pp. 129-135). Mar del Plata: GESMar Universidad Nacional de Mar del Plata.

Rispoli, M. F. (2012). Elegir el mar. Representaciones en torno al trabajo en pescadores. En: Adomilli, G. L. D’Ambrosio, G. Carreño \& F. de Souza Miller (coords.). Povos e coletivos pesqueros. Estudos etnográficos e perspectivas socioantropologicas sobre o viver e o trabalhar (pp. 47-65). Rio Grande: Editora FURG.

Rispoli, M. F. (2014). Donde hay patrón, no manda marinero. Análisis de la tripulación de trabajadores pescadores de la flota de Puerto Quequén (1987-2001). En: XI Congreso Argentino de Antropología Social "Edgardo Garbulsky". Perspectivas críticas en Antropología Social Construcciones teóricas y prácticas desde América Latina, Escuela de Antropología y el Departamento de Antropología Sociocultural de la Facultad de Humanidades y Artes, Universidad Nacional de Rosario, Rosario.

Rispoli, M. F. \& L. Nogueira. (2007). Puerto Quequén: operación de la flota costera, caracterización del trabajo y estrategias familiares de los Pescadores. Zainak, 29: 6579.

Rodríguez, D. (1981). Discusiones en torno al concepto de estrategias de supervivencia. Relatoría del taller sobre estrategias de supervivencia. Demografía y Economía, XV (2): 238-250.

Rosaldo, R. (2000). Cultura y Verdad. La reconstrucción del análisis social. Quito: Abya Ayala. Rosato, A. (1988). Ganadería, pesca y caza en el Delta Bonaerense. Desarrollo Económico, 108: 607-626.

Rubio Ardanaz, J. A. (1994). La antropología marítima subdisciplina de la antropología sociocultural. Teoría y métodos para una aproximación a la comunidad pescadora de Santurtzi (Bizkaia). Bilbao: Universidad de Deusto.

Rubio Ardanaz, J. A. (2006). Lemanes, Sardineras y Pescadores. Realidades marítimas en perspectiva antropológica. Barcelona: Editorial Grafema. 
Ruiz Olabuénaga, J. I. (1999). Metodología de la Investigación Cualitativa. Bilbao: Universidad de Deusto.

Ruocco, L. (2008). De las obreras de la conserva a las fileteras. Cambios y continuidades del trabajo femenino en la industria del pescado. Mar del Plata 1942-1975. Revista de Estudios Marítimos y Sociales, 1 (1): 129-130.

Sábato, H. (1989). Capitalismo y ganadería en Buenos Aires: la fiebre del lanar, 1850-1890. Buenos Aires: Editorial Sudamericana.

Sáenz, A. \& J. Di Paula. (1981). Precisiones teórico-metodológicas sobre la noción de estrategias de existencia. Demografía y Economía, XV (2): 149-163.

Salles, V. (1991). Cuando hablamos de familia, ¿de qué familia estamos hablando?. Nueva Antropología, XI (39): 53-87.

Salvia. A. (1995). La familia y los desafíos de su objetivización: enfoques y conceptos. Estudios Sociológicos, XIII (37): 143-162.

Sánchez Fernández, J. O. (1992). Ecología y estrategias sociales de los pescadores de Cudillero. Madrid: Editorial Siglo XXI

Sánchez, R. P., G. Navarro \& V. Rozycki. (2012). Estadísticas de la pesca marina en la Argentina: evolución de los desembarques 1898-2010. Buenos Aires: Ministerio de Agricultura, Ganadería y Pesca.

Santos, M. (1994). O Retorno do Território. En: Santos, M., M. A. de Souza \& M. L. Silveira. Território, Globalização e Fragmentação (pp. 15-20). San Pablo: Hucitec-ANPUR.

Santos, M. (2000). La naturaleza del espacio. Técnica y tiempo. Razón y emoción. Barcelona: Editorial Ariel.

Sassen, S. (1998). Ciudades en la economía global: enfoques teóricos y metodológicos. Revista Eure, XXIV (71): 5-25.

Schávelzon, D. (2008). El Área Fundacional de Puerto Deseado. Buenos Aires: Deloscuatrovientos Ediciones.

Schulze, M. S. (2013). Trayectorias de clase e identidades obreras. Los trabajadores/as en tierra del puerto de Mar del Plata (2007-2012). Tesis de licenciatura en Sociología, Facultad de Humanidades, Universidad Nacional de Mar del Plata.

Schneider, J. I 971. Of vigilance and virgins. Ethnology, 9: 1-24.

Scott, J. W. (2008). Genero e Historia. México: Fondo de cultura económica.

Segato R. (2010). Las estructuras elementales de la violencia. Buenos Aires: Prometeo Ediciones.

SENASA. (2019). Marea roja, consultado el 22/2/2019. http://www.senasa.gob.ar/cadenaanimal/animales-acuaticos/produccion-primaria/marea-roja

Sennet, R. (2009). El artesano. Barcelona: Anagrama. 
Silva, H. A. (1978) La economía pesquera en el virreinato del Río de la Plata. Buenos Aires: Fundación para la Educación, la Ciencia y la Cultura.

Silveira, M. L. (2008). Globalización y territorio usado: imperativos y solidaridades. Cuadernos del Cendes, 69: 1-19.

Smith, M. E. (comp.). (1977). Those who Live from the Sea: a study in Maritime Anthropology. Saint Paul: West Pub. Co.

Solimeno, D. A. (2015). Cambios en la pesca marítima argentina en el último medio siglo: la reducción de la tradicional flota menor, "lanchitas amarillas". Argentina como Geografía, 1: 85-100.

Spoehr, A. (ed.). (1980). Maritime adaptations: essays on contemporary fishing communities. Pittsburgh: University of Pittsburgh Press.

Tamagno, L. (1988). La construcción social de la identidad étnica. Cuadernos de Antropología, 2: 48-60.

Teruggi, L. B., Martínz, G.A., Billi, P. \& E. Preciso. (2005). Geomorphic units and sediment transport in a very low relief basin: Río Quequén Grande, Argentina. En: Geomophologic processes and human impacts in river basins. Proceedings International Conference, IAHS Publication 299: 154-160.

Testa, J. (2017). Políticas turísticas, escalas y lugar en el municipio de Necochea, Buenos Aires, Argentina desde 2005 hasta la actualidad. Tesis de maestría, Facultad de Filosofía y Letras, Universidad de Buenos Aires.

Thompson, E. P. (1979). Tiempo, disciplina de trabajo y capitalismo industrial. En: Thompson, E. P (ed.). Tradición, revuelta y consciencia de clase. Estudios sobre la crisis de la sociedad preindustrial (pp. 239-293). Barcelona: Editorial Crítica.

Thompson, E. P. (1989). La formación de la clase obrera en Inglaterra. Barcelona: Crítica.

Tobío, O. (2012). Territorios de la incertidumbre. Apuntes para una geografía social. General San Martín: Universidad Nacional San Martín.

Torrado, S. (1981). Estrategias familiares de vida en América Latina: la familia como unidad de investigación censal. Buenos Aires: Centro de Estudios Urbanos y Regionales.

Torrado, S. (1983). El enfoque de las estrategias familiares de vida en América Latina. Orientaciones teórico-metodológicas. Cuadernos del Centro de Estudios Urbanos y Regionales, 2: 1-25.

Torrado, S. (2007). Transición de la familia: tamaño y morfología. En: S. Torrado (comp.) Población y Bienestar en la Argentina del primero al segundo Centenario. Una historia social del siglo XX, Tomo II (pp. 207-253). Buenos Aires: Ensayo Edhasa.

Turner, V. W. (1988). El proceso ritual: estructura y antiestructura. Madrid: Taurus. 
Trpin, V. (2007). Identidades en movimiento. Familias chilenas en la fruticultura del Alto Valle de Río Negro, Argentina. Cuadernos Pagu, (29), 227-255.

Valette, L. (1921). Apuntes sobre la industria pesquera nacional. Someras consideraciones. Boletín del Ministerio de Agricultura de la Nación, XXVI (3): 320-373.

Valles, M. (1997). Técnicas cualitativas de Intervención Social: Reflexión, metodología y práctica profesional. Madrid: Editorial Síntesis.

Vatin, F. (2004). Trabajo, ciencias y sociedad. Ensayos de sociología y epistemología del trabajo. Buenos Aires: Lumen Editorial / Humanitas.

Vazquez, M. \& A. F. Zangrando. (2017). Estructuras de pesca en el canal Beagle. Magallania, 45(1): 101-122.

Wainerman, C. (comp.). (2003). Familia, trabajo y género. Un mundo de nuevas relaciones. Buenos Aires: Fondo de Cultura Económica.

Waisman, A., F. Rispoli \& S. Attademo. (2008). Expectativas, opciones y proyectos: la dimensión subjetiva en la elección laboral de horticultores platenses. En: Actas del IX Congreso Argentino de Antropología Social. Misiones: Universidad Nacional de Misiones.

Wallace, S. (1999). Trabajo y subjetividad. Las transformaciones en la significación del trabajo. En: S. Wallace (comp.). Antropología social y política, Hegemonía y Poder: el mundo en movimiento (pp. 251-260). Buenos Aires: EUDEBA.

Weber, M. (1969). La Ética protestante y el espíritu del capitalismo. Barcelona: Ediciones Península.

Williamson, J. (2004). The Washington Consensus as Policy Prescription for Development. En: Practitioners of Development (pp. 1-22). Washington: Institute for International Economics.

Wissler, C. (1940). Indians of the United States. Four centuries of their history and culture. Nueva York: Doubleday, Doran and Company, Inc.

Yurkievich, G. (2009). Actualidad de los puertos argentinos en el marco de los nuevos paradigmas portuarios de la globalización. En: Gejo, O. H. y A. M. Liberali. (comps.), La Argentina como geografía: Procesos productivos e impacto social, 1990-2008 (pp. 161-201). Mar del Plata: Universidad Nacional del Mar del Plata.

Yurkievich, G. \& A. Nieto. (2014). Organización y lucha obrera en la Argentina contemporánea: La experiencia del Sindicato Marítimo de Pescadores (2000-2012). Trabajo y Sociedad, 23: 179-204.

Zuidwijk, A. J. (2001). Contenedores, buques y puertos: partes de un sistema de transporte. Buenos Aires: Actualidad Producciones. 
- 234 - 


\section{Anexo}

\section{Universidad Nacional de La Plata}

Cuestionarios confidenciales

Fecha:

Nombre informante:

Edad:

\section{Componentes del hogar}

Nombre, edad, relación de parentesco y ocupación:

3- ¿Qué tareas realiza personalmente en esa actividad?

1 -

2-

4- ¿Cómo se llama la ocupación?

3-

4-

5- ¿Cuánto hace que tiene esa ocupación?

5 -

6-

6- ¿Cómo consiguió este trabajo?

7-

Lugar de residencia habitual de la unidad familiar

7- Tiene en su trabajo ...

a) aportes jubilatorios?

b) obra social?

c) salario familiar?

\section{Trabajo}

d) vacaciones?

1-¿Cuántas ocupaciones tiene?

e) aguinaldo?

Una sola ocupación

f) seguro de trabajo?

Dos ocupaciones

g) otros beneficios? (especificar)

2- ¿Cuántas días trabajó en total en el mes en la ocupación principal? ¿Y cuántas horas por día?

8- Es un trabajo ...

estable?

por un plazo determinado? 
inestable?

9- ¿En ese trabajo le pagan...

Para todos

sueldo básico?

Horas extra?

1- ¿Busca otra ocupación?

Salario familiar?

Comisiones por venta producción?

2- ¿Por qué?

Tickets, bonos?

Otro? Especificar

3- ¿ Recibió en el último tiempo ingresos por ...

10- ¿Cuánto recibe por mes en su trabajo?

a) pensión?

b) seguro de desempleo?

Para los que tienen dos ocupaciones:

c) subsidio del gobierno?

d) jubilación?

1- ¿Cuántas horas trabajó en total en la

e) cuota de alimentos?

semana en la ocupación secundaria?

otro? (especificar)

Menos de 5 horas

De 6 a 10 horas

De 11 a 15 horas

De 16 a 34 horas

35 horas y más

ns/nc

\section{Organización y trabajo doméstico}

1- ¿Quién hace la mayor parte de las tareas del hogar?

Jefe de familia

Cónyuge

Hijos

2- ¿Qué tareas realiza personalmente en

Hijas

esa actividad?

Otro (especificar)

3- ¿Cómo se llama la ocupación?

2- ¿Ud. colabora con las tareas del hogar? $\mathrm{Si}$

4- ¿Cuánto hace que tiene esa ocupación?

No

5- ¿Cómo consiguió este trabajo?

3- La semana pasada ¿cuánto le dedicó por día a estas tareas?

6- ¿Es un trabajo... Todo el día

estable?

Toda la mañana

por un plazo determinado?

Toda la tarde

inestable?

Un rato

9- ¿Cuánto gana en ese trabajo? 
4- ¿Realiza habitualmente alguna de las siguientes tareas:

a) Lavar la ropa?

b) Planchar la ropa?

c) Arreglar la ropa (costura)?

d) Hacer las camas?

e) Ordenar la habitación?

f) Hacer las compras?

g) Cocinar?

h) Cuidar a los niños de la casa?

i) Dar de comer a los niños?

j) Bañar a los niños?

k) Llevar los niños a la escuela?

l) Reparar artefactos o instalaciones de la casa?

m) Atiende a los animales?

n) Realiza trámites?

o) Otras tareas? (especificar)

\section{Redes}

1- ¿En el último año usted o alguien de su familia ha ayudado (en forma voluntaria) a personas que no vivan con usted, en forma habitual o con alguna regularidad... enviando dinero dando alimentos?

dando vestimenta?

ayudando en la construcción de vivienda? consiguiendo trabajo?

de otro modo?

A quiénes?

familiares que no viven con usted? vecinos?

amigos?

otros? (especificar)
2- ¿En el último año usted o alguien de su familia estuvo recibiendo ayuda (en forma voluntaria) en forma habitual o con alguna regularidad? Por ej. recibiendo dinero, alimentos, vestimenta, o en la construcción de vivienda? ¿De quién/es?

3- ¿Ha recibido ayuda de alguna iglesia, centro vecinal o de fomento, partido político u otro? Especificar en qué consistió.

\section{Recursos gubernamentales}

1- ¿Algunas de las personas de su hogar son beneficiarais del Plan Vida?

SI ¿Cuántos? ¿Que les parece? ¿Por qué? NO ¿Por qué?

2- ¿Alguno de los chicos va al comedor escolar?

SI

¿Cuántos? ¿Qué les parece? ¿Por qué? NO

¿Por qué?

3- ¿Alguna de las personas de su hogar participa del Programa Jefes y Jefas de Hogar?

SI

¿Quiénes? ¿Qué les parece? ¿Por qué?

NO

¿Por qué?

\section{Otros recursos del hogar}


1- ¿Tienen huerta para el consumo del hogar?

2- ¿Tienen animales para el consumo del hogar?

\section{Vivienda}

1- ¿Cuántas habitaciones usan en su casa para dormir?

2- $i$ Tiene agua...

por cañería dentro de la vivienda?

dentro del terreno?

fuera del terreno?

3- ¿Tiene instalación de baño...

Adentro de la vivienda?

Afuera de la vivienda?

Con inodoro con botón o cadena y arrastre de agua? Con inodoro sin botón o cadena y arrastre de agua?

Letrina sin arrastre de agua? ¿El desagüe va a...

Red pública o cloaca?

Cámara séptica y pozo ciego?

Sólo a pozo ciego?

4- ¿Tiene electricidad?

5- ¿Es usted... propietario de la vivienda?

Inquilino?

Ocupante con relación de dependencia?

Ocupante gratuito?

Otros? Especificar

6- ¿Cuál es el material predominante de las paredes de su vivienda?

Mampostería (ladrillo, bloques, paneles)

Madera

Chapas de metal o fibrocemento

Otros (especificar)

7- ¿Cuál es el material predominante en los pisos?

Madera, mosaico, cerámica, baldosas plásticas

Cemento o ladrillo fijo

Ladrillo suelto o tierra

Otro

8- ¿Cuál es el material predominante en el techo?

Losa

Chapa

Cartón alquitranado

Otro 